UNIVERSIDAD NACIONAL DE LA PLATA

FACULTAD DE HUMANIDADES Y CIENCIAS DE LA EDUCACIÓN SECRETARÍA DE POSGRADO

\title{
Concepciones en torno a la
}

\section{normatividad en la didáctica.}

Un análisis interdisciplinario de obras teóricas didácticas y curriculares en la Argentina, entre 1960 y 1990.

Sofía Picco

Tesis para optar por el grado de Doctor en Ciencias de la Educación

Director Dr. Juan Ignacio Piovani - UNLP - UNIBO

La Plata, 21 de Febrero de 2014 


\section{RESUMEN}

Las concepciones en torno a la normatividad en la didáctica constituyen el problema de investigación central de esta tesis y cobran relevancia al postular que la didáctica es una teoría acerca de la enseñanza con posibilidades de influir en el mejoramiento de las prácticas.

Se propone indagar, desde una perspectiva histórica, cómo se ha ido resolviendo la cuestión de la normatividad, o más específicamente, cómo aparece planteada la normatividad en la producción teórica de la didáctica entre los años 1960 y 1990 en la Argentina.

Asimismo, se incluyen las relaciones entre la didáctica y el curriculum. Se parte de dos supuestos principales: el primero de ellos se refiere a que la didáctica ha incorporado en su estructura disciplinar la teoría curricular ocasionando que desde ella se definan los temas, problemas y orientaciones de la producción curricular, y que -en parte por esto- el curriculum no posee un desarrollo autónomo en nuestro país, al menos en el período aquí estudiado. El segundo supuesto se refiere a un comportamiento disímil que cada una de estas disciplinas evidencia en torno a la normatividad.

Por otra parte, esta forma de entender la didáctica conduce a introducirse en teorías epistemológicas y metodológicas con una doble intención: en primer lugar, para indagar en problemas y esquemas interpretativos que con respecto a la normatividad aparecen en la reflexión epistemológica y metodológica en las ciencias sociales, para luego con ellos enriquecer el análisis en la disciplina de base. En segundo lugar, porque parece evidente que una investigación como la que se realiza no es posible sin contar con categorías que habiliten un análisis metateórico.

A su vez, la didáctica ha ido atravesando por diferentes momentos históricos en su constitución y los mismos pueden analizarse desde una particular configuración integrada por conocimiento, normas, valores y 
prácticas. Construcción histórica que se enriquece en su comparación con el recorrido realizado por teorías epistemológicas y metodológicas.

La construcción de conocimientos que se propone para esta tesis se realiza en el diálogo entre el marco conceptual-referencial antes delineado y el análisis de un corpus empírico integrado por diez (10) obras de didáctica y de curriculum seleccionadas en base a cuatro criterios centrales.

El primer criterio permite seleccionar obras de Imídeo Nérici y Hans Aebli para dar cuenta de las características de la didáctica general que se conoció en Argentina en las décadas del '50 y del '60. El segundo criterio se refiere a considerar obras de la teoría curricular norteamericana y que se difundieron en nuestro país desde principios de los '70, específicamente se analizan trabajos de Ralph Tyler, Hilda Taba y Clifton Chadwick. El tercer criterio permite considerar textos de Susana Avolio, Susana Barco, Gloria Edelstein y Azucena Rodríguez, ya que dan cuenta de las características del pensamiento local en el área de didáctica general en los años '70. Por último, el cuarto criterio se refiere a obras de curriculum de Joseph Schwab y Lawrence Stenhouse que se conocieron en la Argentina en la década del '80 y que impactaron en la didáctica.

Palabras clave: didáctica, curriculum, concepciones acerca de la normatividad, reflexión epistemológica, reflexión metodológica. 


\section{ABSTRACT}

The core problem of this investigation is related to the conceptions that exist about normativeness in didactics and become relevant when asserting that didactics is a theory about education with the possibility of having influence in the improvement of practices.

From a historic perspective this work will try to investigate how the matter of normativeness has been solved or, more specifically, in what ways normativeness appears in the theoretical production of the theory of didactics from 1960 to 1990 in Argentina.

Also, the present work includes relations between didactics and curriculum. Two theoretical assumptions appear: the first one postulates that didactics has incorporated curricular theory in its disciplinary structure. From that point, all topics, issues and orientations of the curricular production are being defined from that theory, which in part is related to the lack of autonomy that curriculum has in our country, at least in the time period under study. The second assumption has to do with the dissimilar behavior that each discipline presents around the topic of normativeness.

In addition, this way of understanding didactics leads to introducing to epistemological and methodological theories with a hidden purpose: in the first place, to investigate interpretative problems and models that appear in the epistemological and methodological consideration in the social sciences to enrich the analysis of the main discipline. On the second place, it seems evident that an investigation of the kind carried in this work would not be possible without categories that allow a meta theoretical analysis.

At the same time, didactics has gone through different historic moments in its formation. Those moments can be analyzed from a particular viewpoint made of knowledge, rules, values and practices. That historical construction has 
been enriched in comparison with the development of epistemological and methodological theories.

The knowledge construction proposed in this thesis is built from the discussion about the conceptual-referential setting outlined above and the analysis of an empiric corpus of ten (10) works about didactics and curriculum that were selected according to four central criteria.

The first criterion selects works by Imídeo Nérici and Hans Aebli in order to provide with the characteristics of the general didactics that were known in Argentina in the '50s and '60s. The second criterion considers works from the American curricular theory that were spread in our country in the earliest '70s - specifically, the works of Ralph Tyler, Hilda Taba and Clifton Chadwick are analyzed. The third criterion considers the writings of Susana Avolio, Susana Barco, Gloria Edelstein and Azucena Rodríguez since they consider the characteristics of the local thought in the area of general didactics in the '70s. Finally, the fourth criterion refers to works about curriculum from Joseph Schwab and Lawrence Stenhouse, works that were known in Argentina in the '80s and had an impact on didactics.

Keywords: didactics, curriculum, conceptions about normativeness, epistemological perspectives, methodological perspectives. 


\section{AGRADECIMIENTOS}

Deseo agradecer a quienes de diferente manera hicieron posible que esta tesis salga hoy a la luz:

A la Facultad de Humanidades y Ciencias de la Educación de la Universidad Nacional de La Plata (FaHCE, UNLP) porque desde el año 1996 me permite formarme en su interior, con sus docentes y estudiantes, algunos hoy colegas.

Al Instituto de Investigaciones en Humanidades y Ciencias Sociales de la mencionada Casa de Altos Estudios (IdIHCS, FaHCE, UNLP-CONICET) por permitirme encontrar un lugar de trabajo en el que asentar mi investigación.

Al Centro Interdisciplinario de Metodología de las Ciencias Sociales (CIMeCS, FaHCE, UNLP), a su directora, Amalia Eguía, a sus investigadores y becarios, por el espacio brindado y el apoyo permanente para realizar esta investigación.

A CONICET por haber depositado su confianza y apoyo para la investigación en las problemáticas aquí expuestas a partir del otorgamiento de las becas doctoral tipo I y tipo II.

Al Doctorado en Ciencias de la Educación (FaHCE, UNLP), especialmente a su directora, Myriam Southwell, por su atención y preocupación permanente por los cursantes de la carrera y por saber escucharme desde el punto de vista humano y profesional.

A Juan Ignacio Piovani, por su confianza, su paciencia, su atenta lectura de mi trabajo y su respeto, valores que no son fáciles de encontrar en un director y en los tiempos que corren. Juan mantuvo humildemente un diálogo permanente conmigo y sus orientaciones fueron fundamentales para que esta tesis alcance sus objetivos. 
A María Raquel Coscarelli, quien fue la co-directora de la tesis de maestría y quien también me acompañó con sus lecturas, comentarios y enseñanzas en el desarrollo de esta tesis doctoral. Kelly, como todos la conocemos, siempre me ha acompañado en mis decisiones personales $y$ profesionales, orientándome y respetándome con la mirada de "mi segunda mamá".

A Estela Beatriz Cols que partió de nuestro lado el 27 de marzo de 2010. Ella me ayudó con su sabiduría y su paciencia infinita a conceptualizar por primera vez, allá a mediados de 2006, las líneas centrales del problema de la normatividad en la didáctica, líneas que constituyeron el eje del proyecto de tesis de maestría, del proyecto de tesis doctoral y de las presentaciones a las becas CONICET.

A ambas nos interesaban estas cuestiones y yo siento que me ha acompañado en cada línea escrita en esta tesis. Cuando la alegría de cada avance me inundaba, cuando me emocionaba por una idea nueva que lograba formular, cuando me cansaba y no quería seguir, yo sé y ella sabe que silenciosamente le hablaba.

A Julia Silber, quien también tristemente nos ha dejado el 30 de noviembre de 2011, por su defensa sólida de una pedagogía que se constituye en la teorización y en la intervención. Recuerdo especialmente sus clases, sus brillantes explicaciones que hacían todo fácil y entendible, y algunas correcciones a mis trabajos como estudiante que espero aparezcan en esta tesis para rendirle homenaje.

Creo que con las enseñanzas de Kelly, Julia y Estela es posible construir ese continuum pedagógico-didáctico que postulaban, tan necesario para mejorar la educación argentina y latinoamericana hoy.

A quienes fueron consultados en su carácter de expertos o informantes clave y colaboraron desinteresadamente con esta tesis, respondiendo el cuestionario y también haciendo valiosos comentarios como sujetos profesionales reconocidos por sus aportes a la didáctica y al curriculum. Muchos 
de ellos, la mayoría, sin conocerme, me mandaron rápidamente sus respuestas permitiéndome avanzar en mi trabajo como explicaré oportunamente. En este sentido, expreso mi profundo agradecimiento (por orden alfabético) a: Stella Maris Abate; María Teresa Alcalá; Sonia Alzamora; Rebeca Anijovich; Susana Avolio de Cols; Marina Barcia; María Laura Basabe; Liliana Campagno; Graciela Cappelletti; Raquel Cavalli; María Raquel Coscarelli; Silvina Feeney; Daniel Feldman; Diana Mazza; Mariano Palamidessi; Silvia Paley; Jorge Steiman.

A Susana Avolio de Cols, Ana Dumrauf y Miguel Ángel Rossi, quienes integraron el jurado que evaluó mi tesis de maestría, porque sus cálidos y sabios comentarios se convirtieron en valiosos e indispensables aportes para avanzar en esta tesis doctoral.

Susana, a su vez, realizó una lectura de un borrador de la presente tesis, acercándome comentarios sustanciales y experienciales -de ésos que no aparecen en los libros- sobre todo al capítulo VII.

A María del Carmen Cosentino y Leandro Stagno que también leyeron un borrador de esta tesis y realizaron señalamientos que me resultaron fundamentales para consolidar mi trabajo. Ambos me indicaron la necesidad de fortalecer la información sobre los procesos históricos para contextualizar el análisis del corpus empírico de la segunda parte.

María, especialmente, me estimuló para ubicarme como escritora con ideas propias y capacidad para contarlas. Recuerdo que siempre en sus clases decía que hay que poner el libro delante de los ojos, para leerlo y discutir con el autor, y no arriba de la cabeza para acatar sus mandamientos.

A María Estela de Souza, quien leyó a una velocidad asombrosa y con una rigurosidad impecable el último borrador de esta tesis, haciendo minuciosas correcciones de redacción para que mis ideas, por momentos confusas, adquieran mayor claridad expositiva. Su paciencia y acompañamiento 
permanente como "tía postiza" exceden lo que pueda decir en estas líneas.

A una nueva amiga, Mariana Iacobucci, porque sus conocimientos como traductora de inglés me ayudaron a completar las formalidades que la presentación de esta tesis me exige.

A mis compañeras de cátedra: Silvana Cerasa, Viviana Moroni, Silvia Navarro y Noelia Orienti. Ellas me tuvieron infinita paciencia a lo largo de este proceso y espero ahora poder retribuirles tiempo y energía.

A Andrea Guzmán, una compañera y amiga especial, que leyó un primer desordenado borrador de esta tesis y me ayudó con sus comentarios a organizar mis ideas.

A quienes fueron mis alumnos durante todos estos años en los que he tenido la suerte de ser docente. Ellos, posiblemente sin saberlo, me ayudaron a madurar algunas de las problemáticas centrales y de las explicaciones que aparecen en esta tesis. Ellos, seguramente sin saberlo, me obligaron a estudiar mucho para cada clase. Ellos, tal vez sin sentirlo así, me regalaron la posibilidad de volverme a mi casa, después de cada encuentro, con nuevas preguntas, con nuevos hallazgos, con nuevos caminos para seguir explorando.

A mi familia, especialmente a mi marido, a nuestros hijos Valentino, Ohanna y al bebé en camino, les tengo que dedicar esta tesis. Su paciencia, su apoyo incondicional, los momentos compartidos aun cuando yo no pudiera explicarles lo que estaba pensando "sobre la normatividad en la didáctica y el curriculum", me ayudaron y sostuvieron en los momentos más críticos de esta tesis. Jugar con mis hijos es un regalo de la vida que pasa a un segundo plano el resto del mundo.

A todos ellos, mi más profundo agradecimiento. 
“[...] Necesito comprender lo que nos está pasando. Confrontar mis análisis, compartir mis inquietudes, poner a prueba mis preguntas. Sin duda, tengo la suerte de poder hacerlo regularmente con padres, educadores, docentes, estudiantes universitarios o colegiales. Estos encuentros, estas conferencias, estos cursos son valiosísimos, pero la escritura, a mi entender, exige algo más.

Escribir es exponerse, arriesgarse a dejar una huella que sobrevive a la enunciación, un signo que no se puede modificar después conforme a las reacciones del destinatario. Escribir implica estar lo más cerca posible de lo más certero. Escribir no es sólo exponer un pensamiento; es intervenir e invitar al otro a compartir tu perspectiva. Es proponer al lector, «mi semejante, mi hermano», que desbrocemos juntos el camino [...]" (Meirieu, 2010, p.10). 


\section{PRIMERA PARTE: MARCO CONCEPTUAL-REFERENCIAL Y}

METODOLÓGICO

CAPÍTULO I: SENTIDOS DEL TÉRMINO “NORMATIVIDAD”............ 28

I - 1 - Algunos sentidos del término "normatividad" en los diccionarios............................................................................................. 29

I - 1 - a - Diccionarios de consulta general....................................................... 29

I - 1 - b - Diccionario de filosofía..................................................................... 30

I - 1 - c - Diccionario de sociología ............................................................... 32

I - 1 - d - Diccionario de ciencias de la educación................................................. 34

I - 2 - La normatividad en las ciencias de la educación.................................... 36

I - 3 - La normatividad en la didáctica y el curriculum.................................. 42

CAPÍTULO II: DIDÁCTICA Y CURRICULUM EN LA ARGENTINA..... 57

II - 1 - El desarrollo de la didáctica en la Argentina....................................... 57

II - 2 - Didáctica y curriculum entre 1960 y 1976: la irrupción de la teoría curricular.

II - 3 - Didáctica y curriculum: sus relaciones durante la última dictadura militar (1976-1983)................................................................. 88

II - 4 - Didáctica y curriculum: la comprensión didáctica y la diversificación del pensamiento curricular a partir de 1983 ....................... 101 II - 5 - Didáctica y curriculum: algunas notas actuales para concluir........ 118 
CAPÍTULO III: CONSTRUYENDO CRUCES ENTRE LAS

DISCIPLINAS: APORTES PARA ENRIQUECER EL DEBATE EN

TORNO A LA NORMATIVIDAD .................................................. 125

III - 1 - Carácter de la norma en una teoría normativa............................. 126

III - 2 - Aspectos que constituyen la norma........................................... 134

III - 3 - Relaciones entre aspectos normativo/prescriptivos y

descriptivo/interpretativos en la conformación de una teoría

normativa.

III - 4 - Disponibilidad de saberes interdisciplinarios para realizar una reflexión de segundo orden.................................................................. 153

III - 5 - Teorías de alcance intermedio o teorías cercanas a la práctica..... 160

CAPÍTULO IV: METODOLOGÍA

IV - 1 - Construcción del objeto de estudio y caracterización general de la perspectiva de abordaje.

IV - 2 - El juicio de los expertos en la conformación del corpus

empírico

IV - 2 - a - Descripción del instrumento y modalidad de administración. 168

IV - 2 - b-Análisis de los resultados y conformación del corpus de obras de didáctica y de curriculum. 172

IV - 3 - Caracterización del corpus empírico. 180

SEGUNDA PARTE: ANÁLISIS DEL CORPUS EMPÍRICO. 186

\section{CAPÍTULO V: OBRAS DE DIDÁCTICA PREVIAS AL IMPACTO DE}

LA TEORÍA CURRICULAR EN LA ARGENTINA.

V - 1 - Caracterización de las obras.

V - 2 - Análisis de las obras: la aparición de algunos emergentes que

permiten caracterizar una didáctica normativa.. 
$V-2-b-$ Aspectos que constituyen la norma.............................................. 202

$V-2-c-$ Predominio de aspectos normativos................................................. 206

$V-2-d$-Disponibilidad de saberes interdisciplinarios para la constitución de

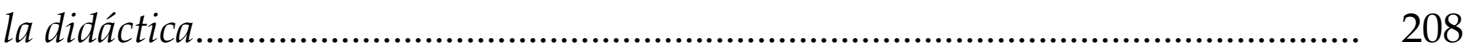

$V-2$ - e-Teorías de alcance intermedio o teorías cercanas a la práctica.............. 209

\section{CAPÍTULO VI: LA TEORÍA CURRICULAR NORTEAMERICANA}

QUE LLEGA A LA ARGENTINA...................................................... 211

VI - 1 - Caracterización de las obras.......................................................... 212

VI - 2 - Análisis de las obras: la aparición de algunos emergentes que

permiten caracterizar la prescripción curricular.

VI - 2 - a - Carácter de la norma en una teoría normativa y en una teoría

prescriptiva.

VI - 2 - b-Aspectos que constituyen la norma............................................... 237

VI - 2 - c - Predominio de aspectos prescriptivos............................................. 239

$V I-2-d$-Disponibilidad de saberes interdisciplinarios para la constitución de la teoría y del diseño del curriculum.

VI - 2 - e-Teorías de alcance intermedio o teorías cercanas a la práctica

\section{CAPÍTULO VII: DESARROLLOS LOCALES DE DIDÁCTICA Y}

CURRICULUM

VII - 1 - Caracterización de las obras.

VII - 2 - Análisis de las obras: la aparición de algunos emergentes que

permiten caracterizar el desarrollo local de la didáctica y el

curriculum

VII - 2 - a - Carácter de la norma en una teoría normativa.

VII - 2 - b-Aspectos que constituyen la norma.

VII - 2 - c-Presencia de aspectos normativos e interpretativos.

VII - $2-d$-Disponibilidad de saberes interdisciplinarios para la conformación de una teoría didáctica.

VII - 2 - e-Teorías de alcance intermedio o teorías cercanas a la práctica. 


\section{CAPÍTULO VIII: LA EMERGENCIA DE LA PERSPECTIVA}

PRÁCTICA EN EL CURRICULUM Y SU IMPACTO EN LA

DIDÁCTICA

VIII - 1 - Caracterización de las obras

VIII - 2 - Análisis de las obras: la aparición de algunos emergentes que permiten caracterizar la perspectiva práctica en el curriculum y su impacto en la didáctica.

VIII - 2 - a - Carácter de la norma en una teoría normativa.

VIII - $2-b-$ Aspectos que constituyen la norma 296

VIII - 2 - c - Presencia de aspectos normativos e interpretativos.

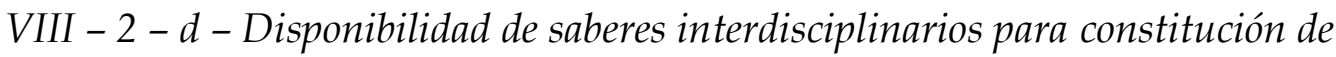
la teoría y del desarrollo del curriculum. 


\section{INTRODUCCIÓN}

Las concepciones en torno a la normatividad en la didáctica constituyen el problema de investigación central de esta tesis y cobran relevancia cada vez que postulamos que la didáctica es una teoría acerca de la enseñanza y que nos preguntamos acerca de su posibilidad de influir en el mejoramiento de la práctica.

Si bien en los capítulos que siguen profundizamos en las distintas concepciones que se generan en torno a la didáctica y sus características teóricas y epistemológicas, como punto de partida basta aquí plantear que la didáctica apunta a construir un marco conceptual-referencial, desde un determinado posicionamiento ético-político, que le posibilite explicar y comprender la enseñanza, así como elaborar normas u orientaciones para que se lleven a cabo "buenas prácticas" hacia la concreción de un proyecto político-social.

En este sentido entendemos que la didáctica es una teoría normativa acerca de la enseñanza. Esta afirmación no es unánimemente aceptada y, a su vez, aparecen diferentes matices entre quienes acuerdan total o parcialmente con ella.

Así conceptualizada, nos proponemos indagar, desde una perspectiva histórica, cómo se ha ido resolviendo la cuestión de la normatividad, o más específicamente, cómo aparece planteada en la producción teórica de la didáctica entre 1960 y 1990 en la Argentina.

Focalizamos la atención en la didáctica denominada "general" y no conforman nuestras preocupaciones actuales las relaciones que la misma mantiene con las didácticas especializadas en áreas de conocimiento o en niveles del sistema educativo. 
En el estudio de la didáctica entre 1960 y 1990 en la Argentina incluimos sus relaciones con el curriculum ${ }^{1}$ a partir de la llegada de las teorías curriculares norteamericanas desde finales de los años '60.

Cabe aclarar que las relaciones entre la didáctica y el curriculum no son fáciles de resolver. La respuesta se va configurando en función del posicionamiento de cada autor y de la perspectiva desde la que se entienda cada teoría y sus referencias a las prácticas educativas.

Diferentes autores ${ }^{2}$ coinciden en que tradicionalmente el curriculum se ha ocupado de manera prioritaria por el qué enseñar, mientras que la didáctica ha estado más inclinada a pensar las cuestiones de método, es decir, el cómo enseñar. No obstante, las preocupaciones de la didáctica siempre fueron más amplias que el método y abarcaron otras dimensiones, como por ejemplo, las intenciones educativas -objetivos, fines, propósitos-, el contenido, la organización de la clase, los recursos, la evaluación de los aprendizajes y de la enseñanza, la formación docente, etc. (Cols et al, 2002; Amantea et al, 2004; Camilloni, 2007b).

Podemos afirmar que el curriculum se concreta en la enseñanza y que la enseñanza se realiza en un contexto curricular (Barbosa Moreira, 1999; Bolívar Botia, 2008). Esta compleja articulación nos lleva a coincidir con Camilloni (1996) cuando plantea que existen ciertas controversias acerca de si la didáctica es una teoría de la enseñanza, como lo indica la tradición europea; si se confunde con la psicología educacional más propia de la tradición

\footnotetext{
1 “...la ortografía del término curriculum plantea algunos problemas ante los cuales es necesario tomar posición. (...) La palabra curriculum está tomada del latín; es una expresión formulada en singular, no lleva tilde, su plural es curricula y tampoco lleva tilde. Las expresiones correctas son en principio "el curriculum" y "los curricula". Si se quiere castellanizar el término, entonces hablamos de "el currículo" y "Ios currículos", con acento ortográfico" (Terigi, 1999, p.28. El subrayado figura en cursiva en la edición consultada).

Cabe agregar que la misma autora, más adelante en el texto en el que se localiza la cita tomada, da cuenta de la aceptación de la expresión "currículum vítae" (acentuada) por parte de la Real Academia Española.

Nosotros optamos por las expresiones en latín -curriculum y curricula- motivo por el cual las escribimos con letra cursiva, como otras expresiones que utilicemos en otros idiomas. No obstante, al momento de realizar citas textuales, respetaremos las formas de escritura elegidas por el autor con el que estamos trabajando.

${ }^{2}$ Entre ellos podemos citar: Barbosa Moreira (1999), Álvarez Méndez (2001) y Bolívar Botia (2008).
} 
norteamericana; o si debe ser reemplazada por alguno de sus objetos de estudio, entre ellos el curriculum.

Hay que mencionar también el origen geopolítico de surgimiento de cada disciplina. El curriculum prosperó en países anglosajones, con un sistema educativo básicamente descentralizado en su forma de gestión, mientras que la didáctica se desarrolló más en Europa continental, en países que sustentaban una estructura centralizada en la organización de sus sistemas educativos.

A pesar de lo anterior, analizamos las relaciones entre la didáctica y el curriculum desde una perspectiva histórica y contextualizada en nuestro país y partimos de dos supuestos principales: el primero se refiere a que la didáctica ha incorporado en su estructura disciplinar la teoría curricular, y que -en parte por esto- el curriculum no posee un desarrollo autónomo en Argentina, al menos en el período aquí estudiado.

El segundo supuesto se refiere a un comportamiento disímil que cada una de estas disciplinas evidencia en torno a la normatividad. Por las características disciplinarias y los vaivenes que ha ido atravesando históricamente la didáctica, podemos decir que la normatividad no siempre ocupó el centro de su producción teórica. Por el contrario, consideramos que esto no fue posible en el curriculum, en tanto objeto que se formula para buscar su concreción en la práctica y en tanto teoría que problematiza en muchos casos las relaciones entre el curriculum prescripto y el curriculum real.

A los fines de esta introducción conviene reconocer la polisemia del término "teoría". Piovani sistematiza algunos sentidos y usos del concepto frecuentes en el lenguaje científico, asumiendo la diversidad que los mismos evidencian. En el desarrollo de esta tesis, utilizamos el término en el sentido de disciplina, subdisciplina o campo de estudio, poniendo el énfasis en el objeto al que se refiere (Marradi, 19893; citado en Piovani, 2014). Por lo tanto, decimos que la didáctica es la disciplina que se ocupa de estudiar la enseñanza.

\footnotetext{
${ }^{3}$ Marradi, Alberto. (1989). "Teoría: una tipología de sus significados". En: Papers. Revista de Sociología, n. 31: 77-98.
} 
Asimismo, es también pertinente aquella acepción del término "teoría" que la liga a un marco conceptual o a un sistema de conceptos interrelacionados lógicamente. Siguiendo a Archenti (2007)4, Piovani expone que el énfasis de este sentido del término está puesto en la interconexión entre los componentes que integran la teoría y puede, a su vez, presentar un alto grado de generalización (“teoría general”), o tener una vinculación más cercana con los fenómenos a los que se refiere ("teoría de alcance medio”). Desde esta perspectiva, pensamos la didáctica como una teoría acerca de la enseñanza que tiene, a su vez, pretensiones normativas sobre ella y puede ser concebida como una teoría cercana a la práctica.

Nuestra propuesta de indagación, y teniendo en cuenta la forma en que se ha conceptualizado la didáctica, nos ha llevado a introducirnos en teorías epistemológicas y metodológicas, así como en perspectivas de la sociología de la ciencia y del conocimiento, para conocer, en primer lugar, problemas y esquemas interpretativos que con respecto a la normatividad aparecen en esos campos, para luego enriquecer con ellos el análisis en nuestra disciplina de base.

Reconocemos que existen diferentes teorías epistemológicas y metodológicas que han reflexionado en torno a la constitución de la normatividad y que evidencian, con diferentes niveles de articulación, aspectos descriptivo/interpretativos -que informan acerca de qué y cómo son sus respectivos objetos de análisis- y otros normativo/prescriptivos -que dicen cómo los mismos deberían ser.

Realizamos un recorrido por algunos de estos planteos teóricos que nos aportan categorías para pensar las cuestiones de la normatividad en la didáctica. Construimos a su vez una serie de cruces entendidos como puentes que tienen el propósito de utilizar problemas y esquemas interpretativos surgidos en los planos epistemológico y metodológico en torno a la

\footnotetext{
${ }^{4}$ Archenti, Nélida. (2007). "El papel de la teoría en la investigación social (capítulo 4)”. En: Marradi, Alberto, Archenti, Nélida y Piovani, Juan Ignacio. Metodología de las ciencia sociales (pp.61-69). Buenos Aires: Emecé.
} 
normatividad para analizar las concepciones que acerca del mismo aspecto aparecen en la didáctica.

En segundo lugar, sabemos que la didáctica ha ido atravesando por diferentes momentos históricos en su constitución y que los mismos pueden analizarse desde una particular configuración integrada por conocimiento, normas, valores y prácticas. Y el estudio de esta construcción histórica también puede enriquecerse a partir de la comparación con el recorrido realizado por teorías epistemológicas y metodológicas.

Desde una perspectiva histórica habría ciertos puntos afines en la configuración de los momentos que atravesó la reflexión en todos estos campos. En este sentido, visualizamos un primer momento en el que estas disciplinas tienden a resaltar su aspecto normativo/prescriptivo, fijando de manera abstracta las pautas de lo que debe entenderse por buena ciencia y por buenas prácticas de enseñanza, respectivamente. Pero el desarrollo de la perspectiva sociológica de la ciencia, especialmente a partir de la década del '60, llama la atención sobre el hecho de que las prácticas que la epistemología y la metodología buscan regular y prescribir son parte de un conjunto de cuestiones que pueden -y tal vez deben- ser investigadas empíricamente. Se propone incluso que se debería partir de este análisis empírico para luego enunciar los cursos de acción a seguir que mejor posibiliten el alcance de determinados fines. Se abre paso así a una perspectiva más descriptiva, tendiente a dar cuenta de aquello que los científicos entienden por ciencia (y aquello que hacen y dicen hacer), en vez de decidir de manera genérica y a priori qué es ella y qué deberían hacer los científicos para practicarla.

En tercer lugar, nos aproximamos a las teorías epistemológicas y metodológicas porque sostenemos que el abordaje de la normatividad en la didáctica demanda categorías teóricas e instrumentales que habiliten un trabajo metateórico o de segundo orden. Preguntarnos acerca de si la didáctica es una teoría normativa, si le corresponde o no orientar el rumbo de la enseñanza, qué características debe poseer una orientación didáctica, etc., son preguntas que demandan categorías didácticas pero, además, un posicionamiento 
epistemológico para dar cuenta de la construcción de la teoría didáctica, de sus alcances y posibilidades.

En el marco de esta tesis y para alcanzar nuestros objetivos, vamos a entender la epistemología como "una teoría del conocimiento científico o como una reflexión sobre la ciencia" (Díaz, 1997, p.21). La epistemología se ocupa de estudiar las condiciones de producción y validación del conocimiento científico, realizando de esta manera un trabajo crítico sobre la ciencia (Klimovsky, 1994, p.28), en nuestro caso, las ciencias sociales. Así es que nos proponemos un trabajo de reflexión epistemológica sobre la constitución de la normatividad en la didáctica.

En otros términos, entendemos la reflexión epistemológica en un sentido amplio y la utilizamos para hacer referencia a aquélla que se produce en un nivel metateórico o en un segundo orden, tomando como su objeto el conocimiento científico. Se incluyen en el estudio enfoques epistemológicos pero también otros propios de la sociología de la ciencia, la filosofía de la ciencia, la sociología del conocimiento, etc., según la inscripción disciplinaria de los autores consultados.

Como su etimología lo indica, "epistemología" deriva del griego;

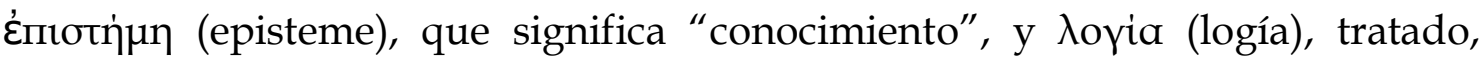
estudio $^{5}$. En este sentido, cuando aludimos a "perspectivas epistemológicas" queremos recuperar aquellas miradas que ponen el acento en los orígenes y en las posibilidades de construcción del conocimiento (Ardoino, 2005).

Por su parte, también entendemos que se produce un trabajo de segundo orden en la reflexión metodológica. En este caso, se refiere a la metodología como el análisis de los supuestos y métodos que se utilizan en una investigación. Las raíces griegas del término metodología nos llevan a entenderla como el estudio o reflexión sobre el método en tanto camino que se recorre para alcanzar un fin, en este caso, la producción de conocimiento científico.

\footnotetext{
5 Diccionario de la Lengua Española de la Real Academia Española, disponible en http://lema.rae.es/drae/?val=epistemolog\%C3\%ADa y http://lema.rae.es/drae/?val=log\%C3\%ADa consultado 11/04/2013.
} 
En coincidencia con lo planteado por Klimovsky (1994) y Piovani et al (2008) sostenemos que esta forma de entender la metodología conlleva un posicionamiento epistemológico. En este sentido, incluimos trabajos de autores que, posicionados desde diversas perspectivas teórico-epistemológicas, analizan los cambios ocurridos en torno a la normatividad en la metodología.

Por otro lado, consideramos pertinente mencionar algunos planteos teóricos y metodológicos que aparecen en esta investigación. En primer lugar, abordamos nuestro objeto de estudio desde una perspectiva multirreferencial. La misma "[...] consiste en implementar ópticas de lectura plurales y contradictorias para entender mejor [...] un objeto de investigación [...]" (Ardoino, 2005, p.22). Se refiere a un enfoque que busca sopesar las potencialidades y los límites de las distintas corrientes en vistas a una comprensión más profunda de la normatividad en la didáctica, como es nuestro caso.

Por otra parte, analizamos nuestro objeto de estudio en perspectiva histórica, concentrándonos en el período aproximado entre los años 1960 y 1990. Consideramos que se trata de un recorte que entraña riqueza analítica ya que las teorías involucradas evidencian en estos años cambios en torno a la constitución de la normatividad, un pasaje o giro desde un momento más prescriptivo a otro más descriptivo, la aparición de posturas que desde distintos ángulos cuestionan la elaboración de prescripciones a priori, etc.

Específicamente para el caso de la didáctica podemos decir que atraviesa un primer momento normativo caracterizado por la articulación de explicaciones, valores, normas y prácticas. En nuestro país, esta articulación se quiebra hacia finales de los años '60, evidenciando una expansión de su costado más tecnicista y en consonancia con la entrada de las teorías curriculares norteamericanas. Posteriormente, se configura un momento interpretativo, de ampliación de su caudal comprensivo, perdiendo aquel componente normativo que se encuentra en su misma definición como disciplina.

La elaboración de este recorrido histórico por la didáctica encuentra su principal antecedente en la tesis de maestría titulada La normatividad en discusión: el caso de la didáctica a partir de debates epistemológicos y metodológicos 
contemporáneos ${ }^{6}$. En la presente investigación nos proponemos ampliar el alcance y la profundidad de este trabajo previo incorporando: 1- las complejas relaciones entre la didáctica y el curriculum; 2- las diversas concepciones que se presentan en ambas teorías en torno a la normatividad; 3- los problemas y esquemas interpretativos en torno a la normatividad que aparecen en la reflexión epistemológica y metodológica, para comparar con lo que sucede en la didáctica y el curriculum; 4- las categorías que favorecen y potencian una reflexión epistemológica en la didáctica; 5- la manifestación de las concepciones en torno a la normatividad en obras de didáctica y de curriculum publicadas en nuestro país, o extranjeras pero con reconocido impacto en la producción local, entre los años 1960 y 1990; 6- las continuidades y rupturas que puedan presentarse entre los momentos del desarrollo histórico de la didáctica y las obras que conforman el corpus empírico.

Con respecto a este último punto, cabe mencionar que arribamos a su constitución a partir de la administración y análisis de una encuesta a informantes clave. Consideramos que la consulta a expertos y la selección de obras para analizar, a partir de su opinión, requiere reconocer, desde la teoría de la recepción, que el proceso de selección del corpus empírico se realiza a partir de la mediación que pone en juego cada encuestado con su bagaje cultural y sus experiencias de vida.

No realizamos un estudio biográfico de los autores ni de la totalidad de sus obras, aunque sí incluimos una referencia al contexto de producción de las aquellas que nos interesan. Tampoco nos concentramos en el bagaje cultural ni en los procesos que cada informante clave pone en juego en la selección de las obras de didáctica y de curriculum que considera relevantes para estudiar diferentes concepciones en torno a la normatividad.

A pesar de estas aclaraciones, reconocemos la importancia que posee la teoría de la recepción y los estudios emparentados con ella, que se preocupan por la forma en la que el lector recepciona la obra, más que por lo que la obra

\footnotetext{
${ }^{6}$ Tesis para optar por el grado de Magister en Ciencias Sociales, Facultad de Humanidades y Ciencias de la Educación, Universidad Nacional de La Plata. Director: Dr. Juan Ignacio Piovani; co-directora: Mg. María Raquel Coscarelli. Defendida y aprobada con calificación 10 (diez) puntos el 26/10/2010.
} 
dice en sí misma (Sánchez Vázquez, 2005). No descartamos para futuras investigaciones estudiar la manera en la que los referentes locales de la didáctica y el curriculum entran en diálogo con las obras que aquí analizamos.

Antes de finalizar esta introducción, cabe una breve descripción de los capítulos que componen esta tesis. En líneas generales, la misma está integrada por dos partes. La primera abarca los capítulos I, II, III y IV, dedicados prioritariamente al desarrollo del marco conceptual-referencial y metodológico; y la segunda parte comprende los capítulos V, VI, VII y VIII, abocados al tratamiento de las obras de didáctica y de curriculum. Por último, el capítulo IX está destinado a la presentación de las conclusiones.

En el capítulo I revisamos algunas concepciones acerca del término "normatividad" que aparecen en diferentes fuentes, avanzando desde el sentido común y diccionarios de consulta cotidiana hasta sentidos más filosóficos, epistemológicos y académicos vinculados al ámbito de las ciencias de la educación, la didáctica y el curriculum.

En el capítulo II, con estos aportes previos, trazamos un recorrido por las complejas relaciones entre didáctica y curriculum en nuestro país en el período 1960-1990. Partimos de una consideración sobre la constitución histórica de la didáctica y las distintas concepciones que han aparecido en torno a la normatividad, y las resignificamos en el marco de distintos momentos construidos con la bibliografía disponible sobre la temática que da cuenta de distintas modalidades de relación entre la didáctica y el curriculum.

Se le da prioridad a la forma en que la didáctica recibe el discurso de la teoría curricular a partir de los años '60. Pero, sin corrernos del eje que estructura nuestro trabajo, en todo momento se van enfocando los posicionamientos que se van generando en torno a la normatividad.

En el capítulo III abordamos los complejos cruces entre las teorías didácticas, curriculares, epistemológicas y metodológicas contemporáneas. Asimismo, estos cruces permiten la apertura de dimensiones y la presentación de algunas categorías que se recuperan luego en la segunda parte de la tesis, es decir en el análisis del corpus empírico de obras didácticas y curriculares. 
Por último, en el capítulo IV desarrollamos la estrategia metodológica que orientó la investigación.

La segunda parte de la tesis la reservamos para el análisis de las diez (10) obras que conforman el corpus empírico. En el capítulo V estudiamos Una didáctica fundada en la psicología de Jean Piaget de Aebli y Hacia una didáctica general dinámica de Nérici, por considerarlas representativas del área de la didáctica denominada "general" y con influencia en nuestro país con anterioridad al impacto de la teoría curricular.

En el capítulo VI nos dedicamos a estudiar las obras Principios básicos del curriculum de Tyler, Elaboración del curriculum de Taba y Tecnología educacional para el docente de Chadwick, por ser estos autores exponentes del pensamiento curricular norteamericano.

Luego, en el capítulo VII estudiamos los trabajos La tarea docente de Avolio, “Antididáctica o una nueva didáctica?” de Barco y “El método: factor definitorio y unificador de la instrumentación didáctica" de Edelstein y Rodríguez, para dar cuenta de la producción local de la didáctica denominada general con posterioridad al impacto de la teoría curricular norteamericana.

Al final de esta segunda parte dedicamos el capítulo VIII al estudio de las obras Un enfoque práctico para la planificación del currículo de Schwab e Investigación y desarrollo del curriculum de Stenhouse, en tanto autores representativos de lo que se denomina corriente práctica del curriculum con influencia en la didáctica.

Terminamos nuestro trabajo con las conclusiones expuestas en el capítulo IX en el que sistematizamos los hallazgos y dejamos abiertas algunas líneas para habilitar futuras indagaciones sobre la temática. 
PRIMERA PARTE:

\section{MARCO CONCEPTUAL-REFERENCIAL Y METODOLÓGICO}

Como mencionamos en la introducción, esta primera parte de la tesis está integrada por los capítulos I, II, III y IV. En términos generales en ellos se desarrolla el marco conceptual-referencial y el diseño metodológico que se pone en diálogo en la segunda parte con las obras de didáctica y de curriculum que integran el corpus empírico.

Recordamos que consideramos a la didáctica es una teoría normativa acerca de la enseñanza. Por este motivo, sostenemos que debe ocuparse de la descripción y comprensión de la enseñanza como práctica social y, a su vez, de la elaboración de orientaciones tendientes a la resolución de los problemas que presenta dicha práctica educativa.

Acordamos en este sentido con Camilloni cuando dice:

“[...] la didáctica es una disciplina teórica que se ocupa de estudiar la acción pedagógica, es decir, las prácticas de la enseñanza, y que tiene como misión describirlas, explicarlas y fundamentar y enunciar normas para la mejor resolución de los problemas que estas prácticas plantean a los profesores [...]" (2007b, p.22).

De una manera general asumimos que el conocimiento científico se ocupa de describir y explicar el objeto de estudio al que se refiere (Díaz, 1997). En este sentido, en primer lugar sostenemos que la didáctica describe la enseñanza -su objeto de estudio- cuando da cuenta de sus partes constitutivas y de sus cualidades. La respuesta genérica a la pregunta “¿qué se entiende por enseñanza?", recuperando la conceptualización de Fenstermacher (1989), es un ejemplo de esto. Cuando el autor dice que la enseñanza involucra al menos tres (3) elementos: un sujeto que posee cierto saber, otro que carece de él y un contenido que se intenta transmitir/compartir, está brindando una definición claramente descriptiva, como él mismo la entiende, de la enseñanza como práctica social. 
Pero como también hemos hecho referencia a la explicación y comprensión, en segundo lugar corresponde una aclaración de dichos términos. Como plantea von Wright (1979), el primero es heredero de la tradición galileana y el segundo de la aristotélica, enmarcándose así con particulares sentidos en distintas tradiciones filosóficas ${ }^{7}$. Como diferencias a tener en cuenta, reconocemos que al hablar de "compresión" se evidencia mayor afinidad a considerar el bagaje psicológico, los sentidos y las intenciones que mueven las acciones de los sujetos, que al utilizar la expresión "explicación". No obstante, como el mismo autor reconoce, prácticamente cualquier explicación nos brinda una comprensión de los hechos.

En el mismo sentido, tomando los aportes de Klimovsky e Hidalgo (1998), podemos decir que en este trabajo nos proponemos formular explicaciones comprensivistas, ya que sostenemos que las mismas son las que mejor permiten expresar las finalidades de la didáctica en tanto teoría de la enseñanza. Estas explicaciones apuntan a dar cuenta de la multiplicidad de dimensiones que intervienen en la situación a la que esperan darle inteligibilidad, además de los sentidos que los sujetos sociales como tales les asignan a sus acciones.

Asimismo, acordamos con Pardo cuando defiende una relación dialéctica entre la explicación y la comprensión en las ciencias sociales:

“[...] la comprensión envuelve a la explicación. Pues el momento de la pertenencia del intérprete a un horizonte previo de significados siempre la precede, la acompaña y la clausura. [...] Pero en compensación, también debería decirse que la explicación desarrolla analíticamente a la comprensión. Y este desarrollo es necesario a la luz de los requisitos de fundamentación y de criticidad que incumben a la ciencia [...]" (1997, p.94. La cursiva figura en la edición consultada).

\footnotetext{
${ }^{7}$ Consideramos que la profundización en estas dos tradiciones no forma parte del objeto de estudio de la presente tesis. Baste recordar que la tradición galileana ha sido identificada con la investigación en las ciencias naturales y la forma más común de dar cuenta de los objetos de estudio se refiere a explicaciones causales. La tradición aristotélica, por su parte, involucra las investigaciones en ciencias humanas y sociales, partiendo del reconocimiento de que son diferentes ontológica y metodológicamente con las ciencias naturales y que demandan, por tanto, una forma particular de aproximarse a su objeto y de dar cuenta de él (von Wright, 1979).
} 
En tercer lugar, consideramos pertinente introducir una definición general del concepto de "norma" con el que acordamos y que mantenemos en esta tesis a pesar de las especificaciones que pretendemos lograr en el desarrollo de los próximos capítulos. Precedentemente dijimos que la didáctica se propone elaborar normas que tiendan a la solución de los problemas que se presentan en las prácticas de enseñanza y enfatizamos desde la introducción que entendemos a la didáctica como una teoría normativa acerca de la enseñanza.

Von Wright reconoce en primera instancia la heterogeneidad de significados que porta el término "norma". En líneas generales explica que las normas son aquéllas que se ocupan de lo que debe y puede hacerse y de lo que no tiene que hacerse (1970, p.32). Establece una distinción, que retomamos, entre norma y prescripción, siendo ésta última un tipo particular de aquélla (junto con las reglas y las directrices o normas técnicas). Las prescripciones son emitidas por un sujeto que se erige como autoridad normativa, están orientadas a un sujeto normado 8 para que este último adecue a ellas su comportamiento. En consecuencia, las prescripciones son "órdenes" o "permisos" dirigidos a regular la conducta de los sujetos normados.

Si bien dedicamos los capítulos I y II a discriminar mejor el sentido de norma $\mathrm{y}$, más específicamente, de norma didáctica, baste aquí plantear que cuando asignamos a la didáctica una finalidad normativa con respecto a la enseñanza aludimos a que esta teoría se ocupa también de lo que debe y puede hacerse $y$ de lo que no tiene que hacerse en la enseñanza para que sea considerada una buena práctica. En este sentido es que decimos que la norma didáctica brinda orientaciones para la acción así como también motivos para fundamentarla.

\footnotetext{
${ }^{8}$ Cabe aclarar que la expresión "sujetos normados" nos pertenece ya que en la edición consultada del libro de von Wright se los denomina "sujetos normativos". Según entendemos, los "sujetos normativos" son más bien aquéllos que emiten o fijan las prescripciones y no quienes son regidos por ellas.
} 


\section{CAPÍTULO I: SENTIDOS DEL TÉRMINO “NORMATIVIDAD”}

Iniciamos este capítulo con algunas búsquedas generales en torno a la normatividad $\mathrm{y}$, progresivamente, nos acercamos a la concepción de normatividad en la didáctica y el curriculum que sustentamos en esta investigación.

Los interrogantes centrales a los que volvemos en diferentes momentos, intentando responderlos con un gradual nivel de profundización, son: ¿qué se entiende por norma?; ¿qué relaciones se configuran entre normas, conocimientos, valores y prácticas en la didáctica y el curriculum?

Para lograr nuestro cometido, iniciamos el primer apartado de este capítulo recuperando los sentidos que la "normatividad" y lo "normativo" adquieren en el lenguaje corriente. Para ello, partimos de la tesis de Marradi (2007b) según la cual existe una continuidad -más que una ruptura- entre este lenguaje y el científico. El autor coincide en este sentido con Schutz ${ }^{9}$, quien sostiene que el lenguaje que utiliza el científico social debe basarse en el lenguaje corriente $\mathrm{o}$, al menos, resultar comprensible para los sujetos sociales que constituyen su objeto de estudio. Teniendo en cuenta estas cuestiones, resulta oportuno realizar una indagación de distintas definiciones de "normatividad" en algunos diccionarios de consulta general. Asimismo, revisamos sentidos del término en otros diccionarios de consulta más específica, a saber, uno de filosofía y otro de sociología.

Luego exploramos algunas concepciones sobre lo normativo en las ciencias de la educación y especialmente en la pedagogía. Consideramos pertinentes estas menciones para visualizar similitudes entre la didáctica y las ciencias de la educación -en tanto marco disciplinar de referencia más amplio-

\footnotetext{
${ }^{9}$ SCHUTZ, Alfred. (1953). “Common Sense and Scientific Interpretation of Human Action”. Philosophy an Phenomenological Research, XIV, (1, September), 1-37.
} 
importantes para discutir su componente normativo. Reservamos para el último apartado la presentación específica de los sentidos de la "normatividad" en la didáctica y el curriculum.

\section{I - 1 - Algunos sentidos del término "normatividad" en los diccionarios.}

I- $1-a-$ Diccionario de consulta general.

Según el Diccionario de la Real Academia Española (2001), el término "norma" deriva del latín norma, escuadra; y un primer sentido se refiere a las reglas $^{10}$ a las que debe ajustarse el comportamiento de los sujetos ${ }^{11}$. Moliner (2007) en su Diccionario amplía esta información al decir que un sentido del término "norma" las liga a aquellas reglas que expresan la forma en la que deben hacerse las cosas o la manera en la que se ha convenido que se lleven a cabo determinadas acciones.

Aparecen aquí, al menos, dos vinculaciones importantes para esta tesis: una entre la norma y el deber ser, y otra entre el deber ser y las acciones humanas. Para el primer caso, la norma representa lo que es considerado correcto. Para la segunda relación, la norma estaría marcando una orientación o intentando influir en las acciones humanas para que se lleven a cabo de un modo particular, adecuándose a lo que ella indica que es correcto.

Por otra parte, en el Diccionario de la Real Academia Española encontramos que "prescribir", del latín praescribĕre, significa preceptuar, determinar $\mathrm{u}$ ordenar algo. Esta definición resulta pertinente para nuestro trabajo cuando analizamos las diferencias entre una didáctica normativa y otra preceptiva a partir de los estudios de Camilloni (2007d). Para esta autora hay

\footnotetext{
${ }^{10}$ Para von Wright (1970), las reglas constituyen un tipo particular de normas. Además, discrimina las "reglas ideales" definidas como normas que están más relacionadas con el ser que con el hacer, son reglas relativas a la bondad y las virtudes. Así, un buen docente puede defirnirse a partir de algunas reglas ideales como por ejemplo la paciencia, la firmeza y el compromiso

${ }^{11}$ Cabe aclarar que en este apartado, como en los siguientes, presentamos sólo las acepciones que nos posibilitan problematizar nuestro objeto de estudio, no todas las que aparecen en los diccionarios consultados.
} 
muchas semejanzas entre normas y preceptos, no obstante en el uso las primeras aparecen con un carácter más general mientras que los segundos presentan un sentido más analítico y específico.

$$
\text { I- } 1-b-\text { Diccionario de filosofía. }
$$

Ferrater Mora (1994), en su Diccionario de Filosofía, sostiene que ciertas disciplinas filosóficas como la lógica, la ética y la estética, han sido consideradas -aunque no en buena parte del siglo XX-como disciplinas normativas. Esta consideración implica que son disciplinas que estipulan cómo hay que pensar o razonar, cómo hay que actuar, o cómo hay que hacer una obra de arte o juzgarla, según los casos.

Esta perspectiva, que suele denominarse normativismo, fue dejada de lado y luego recobró interés en tiempos más actuales al plantearse como problema las relaciones entre disciplinas que incluyen enunciados normativos dirigidos a sus respectivos objetos de estudio y teorías relativas a las normas y su carácter.

Más allá de las críticas al normativismo filosófico, de la definición de "norma" aportada por Ferrater Mora resta recuperar dos cuestiones de interés: una se vincula con la diversidad de sentidos que el término ha adquirido; la otra se refiere a la justificación racional ${ }^{12}$ que requieren las sentencias normativas en comparación con los valores ${ }^{13}$.

Retomamos estas afirmaciones más adelante, sobre todo la que se refiere a la vinculación entre normas y valores, pero baste aquí decir que la norma adquiere un sentido que la liga a lo que es correcto. Al igual que en el

\footnotetext{
${ }^{12}$ Esta justificación racional puede ser entendida como lo hacen Tardif y Gauthier (2008) quienes aluden al docente como un ser racional en tanto posee la capacidad de exponer públicamente las razones y motivos que justifican sus opiniones, decisiones y acciones en la enseñanza. Así planteado, lo racional se vincula directamente con la posibilidad de esgrimir aquellas razones que sustentan las acciones de los sujetos.

Olivé (1995) también expone un sentido de razón que se relaciona con la asignación de un fundamento que justifica la aceptación de una creencia, un fin o valor, o la elección de determinado curso de acción. Consideramos que estos sentidos son pertinentes para comprender en qué medida una norma brinda una justificación racional, tal como es planteado en este trabajo.

${ }^{13}$ Aquí el autor retoma a Hierro, José S. P., “Normas y valoraciones” en Teoría y sociedad, 1970.
} 
diccionario de consulta general, lo normativo, visto desde la filosofía, también representa aquello que es correcto, adecuado o que debe ser realizado de una determinada manera.

Por su parte, von Wright (1970) realiza un análisis filosófico de las normas que es igualmente relevante comentar aquí. Para el autor, todos los tipos de normas poseen un "núcleo normativo" compuesto por tres componentes, a saber, el carácter, el contenido y la condición de aplicación. Este núcleo es objeto de estudio de la teoría formal de las normas o de la lógica deóntica.

El carácter de las normas se vincula, por un lado, con el deber, con la obligación de hacer algo, y por el otro con el poder hacer una cosa. Así, el autor habla de normas de obligación para el primer caso y normas permisivas para el segundo. El contenido de una norma se refiere a aquello que se debe hacer, que se puede hacer o que tiene que hacerse o no hacerse, es decir, apunta a las acciones que se permite o se prohíbe realizar. Por último, la condición de aplicación se refiere a la condición, o a las condiciones que deben darse para que se pueda realizar el contenido de la norma. Este componente permite diferenciar entre normas categóricas -que son aquéllas en las que la condición de aplicación aparece formulada en el contenido o aparece presupuesta en el contenido- y normas hipotéticas -cuando la condición de aplicación requiere ser aclarada o explicitada más allá de la formulación del contenido de la norma.

Según von Wright las prescripciones, como un tipo particular de norma, además de los tres ingredientes mencionados precedentemente poseen otros tres en su "núcleo normativo", a saber, autoridad, sujeto o sujetos y ocasión. La “autoridad" de la prescripción se refiere al agente la emite, quien prohíbe o permite hacer determinada cosa a otros sujetos.

“Al llamar a la autoridad de una prescripción agente, indicamos que las prescripciones se producen como resultado de una acción. Para el modo peculiar de la acción, que tiene como resultado la existencia de prescripciones, acuñamos el nombre de acción normativa" (von Wright, 1970, pp.91-92. La cursiva figura en la edición consultada). 
El agente que emite la prescripción puede tener un carácter personal o impersonal, aludiendo en este último caso a la autoridad que le confiere la ocupación de un cargo en el Estado o en cualquier otra institución.

Por su parte, los "sujetos" son todos aquéllos a los que van dirigidas las prescripciones. Por último, la "ocasión" se refiere a una especificación espacial o temporal para la realización del contenido de la prescripción.

Sostenemos que el análisis precedente relativo al "núcleo normativo" de las normas en general y de las prescripciones en particular es pertinente para reflexionar en torno a las normas y a las prescripciones en la didáctica. Como dijimos, la didáctica elabora una serie de normas que pretenden orientar las acciones de enseñanza y, principalmente, del docente como responsable de llevarlas a cabo. Estas normas pueden tener un carácter permisivo o prohibitivo dependiendo de las acciones que se consideren necesarias para lograr buenas prácticas de enseñanza.

I - 1 - c-Diccionario de sociología.

Consideramos pertinente aludir a algunos sentidos de "norma social". Si bien los mismos no se refieren directamente al núcleo de esta tesis, recuperamos aquéllos que nos ayudan a pensar la "norma didáctica".

Gallino (1995) expresa que en la literatura sociológica prevalece un sentido de norma social que la vincula a aquella proposición que prescribe el comportamiento o la conducta que se estima correcta para un sujeto en un marco social y cultural particular, en un momento histórico determinado. La mayor parte de las normas sociales, en este sentido, utilizan de manera explícita o implícita expresiones como "se debe", "es correcto que", " no se puede"14, etc.

Otro sentido de norma que es utilizado con frecuencia la vincula con aquello que hace la mayoría de la población. Esta definición de norma

\footnotetext{
${ }^{14}$ Gallino aclara que las normas son prescriptivas cuando indican cuál es la acción correcta a desarrollar y proscriptivas cuando prohíben determinadas acciones.
} 
estadística ha tenido y tiene implicancias en diversos ámbitos y temáticas sociales y particularmente educativas.

Gallino dice que este sentido de norma, entendida como comportamiento más frecuente, y aquel primero que la liga a la prescripción, coinciden toda vez que la mayor parte de los sujetos de una sociedad adecuan su comportamiento a lo que prescribe una determinada norma, o cuando los investigadores enuncian la norma como prescripción a partir del estudio del comportamiento de la mayoría de los sujetos. En el marco de esta tesis, retomamos esta última coincidencia más adelante, al analizar cómo se construye la norma didáctica con los aportes de la investigación empírica.

Además, Gallino plantea que las normas enunciadas de una manera general suelen confundirse con los valores porque los expresan más o menos implícitamente. Por ejemplo, en didáctica suele sostenerse que "una buena enseñanza debe recuperar y ampliar el universo cultural con el que los estudiantes llegan a la escuela", lo que está prescribiendo una acción moral vinculada al respeto por los sujetos. Pero de aquí se desprenden otras normas más específicas que tienen relación más directa con el tipo de acciones docentes particulares que se requiere llevar a la práctica para concretar aquellos valores.

Podemos adelantar aquí que esta vinculación con los valores es muy clara cuando nos referimos a las normas en la didáctica pero no necesariamente aparece cuando hablamos de prescripciones en la didáctica. En parte en esto radica la diferencia entre normas y prescripciones que manejamos en esta tesis.

Por último, las normas sociales como las normas didácticas, a pesar de las diferencias vinculadas a su contexto de origen, expresan los intereses de diferentes sujetos que lograron imponerlos, pero también aparecen los de aquéllos que resisten dicha imposición y que también deben ser considerados cuando se habla de normas sociales y didácticas ${ }^{15}$.

\footnotetext{
15 A modo de ejemplo, recordamos la definición de curriculum que aporta De Alba (1995), en la que claramente se expresa esta puja de intereses y relaciones de fuerza entre diferentes sujetos en la constitución del curriculum. Si bien la autora no lo desarrolla en estos términos, consideramos que podemos reflexionar en torno a conceptualizar el curriculum como norma desde una perspectiva crítica aun cuando no lo hagamos en el marco de esta tesis.
} 
I-1 - d-Diccionario de ciencias de la educación.

Encontramos algunas definiciones de "norma" en el Diccionario de las Ciencias de la Educación de la Editorial Santillana (1995) que aportan otros elementos a los ya expuestos y, a su vez, acercan el análisis al campo de la educación.

Hay distintos significados derivados de su acepción latina (norma $=$ regla, modelo, medida, mandato, principio rector).

“[...] 2) En sentido técnico-pragmático, patrón o modelo, fijado convencionalmente, que posibilita la clasificación de objetos.

3) Idea, que contiene el máximo de perfección pensable con respecto a una determinada propiedad y que servirá de canon para juzgar acerca de objetos o acciones en qué medida se aproximan a ella (idea regulativa). [...] 5) Regla que dirige la conducta, y que se halla presente dondequiera que el pensamiento, el lenguaje o el obrar humanos se ordenan legalmente..." (Diccionario de Ciencias de la Educación, 1995, p.1009. La cursiva figura en la edición consultada).

Estos sentidos de "norma" son abordados de diferentes maneras en esta tesis. Las acepciones (2) y (3) aparecen contenidas en la misma definición de enseñanza cuando Fenstermacher (1989) postula que una concepción genérica de este proceso es aquélla de carácter descriptivo que se refiere a los rasgos básicos que posee este tipo de actividad humana. No obstante, el autor sostiene que esta definición, así planteada, posibilita distinguir si una práctica tiene o no las características necesarias para ser considerada de enseñanza, por lo que podemos pensar que también permite clasificar si una actividad es o no enseñanza. Para el mismo autor, una definición normativa es aquella de carácter elaborado que informa si una determinada acción de enseñanza es una buena o mala práctica desde un determinado marco conceptual-referencial particular y desde un posicionamiento político-ideológico ${ }^{16}$.

En el mismo sentido, podemos pensar que la definición genérica de enseñanza puede convertirse en una idea regulativa ya que, sin representar el

${ }^{16}$ Para profundizar el sentido de norma vinculado a un modelo ideal que sirve de patrón de comparación, es interesante el trabajo de Mancovsky (2000). La autora focaliza su objeto de estudio en las interacciones que se producen entre docentes y alumnos en la clase escolar y analiza los juicios de valor que construye el docente en dicha interacción. Retomamos este trabajo en el capítulo II. 
"máximo de perfección" como lo indica la definición del Diccionario, permite hablar de una mayor o menor aproximación de determinadas prácticas a ella.

Por último, el sentido de "norma" como regla (acepción 5) que dirige la conducta y que figura en la cita del Diccionario de Ciencias de la Educación antes expuesta, se refiere a que las normas tienden a que a ellas se subordine la acción, el pensamiento o la construcción del lenguaje, trascendiendo "arbitrariedades subjetivas". Ésta es una acepción que aparece reiteradamente en las indagaciones que realizamos en las teorías didácticas, curriculares, epistemológicas y metodológicas.

Igual relevancia cobran para nuestro trabajo las normas técnicas y prácticas señaladas -entre otros tipos- en este Diccionario. Las primeras brindan indicaciones para el dominio de la naturaleza y la sociedad, se hallan fundadas pragmáticamente y son aplicables en situaciones de carencia. Las segundas, por su parte, son principios que se vinculan al alcance de determinados fines, pero en situaciones de conflicto en las cuales no hay acuerdo sobre los mismos; "contienen una dimensión canónica, que se especifica como expresiva de un fin último [y que] constituye la fuente de la obligatoriedad con que pretenden dirigir la conducta" (Diccionario de Ciencias de la Educación, 1995, p.1012). Retomaremos estos sentidos al aludir a las perspectivas técnica y práctica en la didáctica y el curriculum.

Consideramos que en relación a lo anterior, se hallan las distinciones ya clásicas realizadas por Aristóteles entre pensamiento productivo, práctico y teórico, recuperadas y resignificadas por diferentes autores ${ }^{17}$.

Por otro lado, según se informa en el Diccionario, actualmente cuando se habla de "norma", se hace referencia a "saberes prácticos", que pretenden influir en las acciones humanas, y se definen como "disciplinas prácticas" aquellas que se ocupan de estudiar estas cuestiones.

Como síntesis de lo expuesto, decimos que la "norma" se expresa en un lenguaje prescriptivo, siendo una regla que busca influir en el obrar humano,

\footnotetext{
${ }^{17}$ A los fines de este trabajo, podemos mencionar: Habermas, 1982, 1992; Bernstein, 1982; Carr y Kemmis, 1988; Popkewitz, 1988; Grundy, 1994.
} 
pero conlleva, a su vez, un segundo elemento, un canon, en tanto la dirección hacia la que pretende guiar la acción se fundamenta en un modelo ${ }^{18}$. Si bien reconocemos que no es una postura unánimemente aceptada, sostenemos que una definición general de "norma" involucra la idea de que hay razones a favor de una determinada forma de comportamiento ${ }^{19}$.

\section{I - 2 - La normatividad en las ciencias de la educación.}

Pretendemos en este apartado realizar un recorrido por algunos de los sentidos que adquiere la normatividad en las ciencias de la educación y, específicamente, en la pedagogía. A los fines de esta tesis consideramos el área en un sentido genérico, aun cuando sabemos de las diferencias que, precisamente en torno a la normatividad, se generan entre "ciencias de la educación" y "pedagogía"20.

Sostenemos que la didáctica es una teoría afín a la pedagogía porque comparte preocupaciones teóricas y epistemológicas relativas a la intervención

\footnotetext{
${ }^{18}$ En relación con estas cuestiones, recuperamos lo que expresa Gimeno Sacristán a partir de los diferentes grados de directividad en la acción que postula O'Neill, quien “...considera que un comportamiento puede ser meramente conativo, lo que quiere decir que tiene un propósito implícito no consciente, una dirección que hace que las acciones tengan un orden y no sean arbitrarias; otras actuaciones son volitivas, con un propósito consciente y querido, lo que supone un compromiso adquirido con las mismas; un tercer grado de implicación lo representan las acciones normativas, que están dirigidas, implícita o explícitamente, por aquello que se considera bueno y deseable, lo que significa un acomodo buscado entre la acción querida y un sistema de valores objetivado" (O'Neill, W. (1981), Educational Ideologies. Santa Mónica. Goodyear Publishing Company; citado en Gimeno Sacristán, 1998, p.46. El subrayado figura en cursiva en la edición consultada).

${ }^{19}$ Como vimos, Ferrater Mora (1994) también asigna a las normas la característica de poseer una justificación racional.

${ }^{20}$ En el capítulo II aludimos al cambio de denominación que se produjo en algunas carreras universitarias entre los años '60 y '70 en Argentina, pasando de "pedagogía" a "ciencias de la educación". Reconocemos también que este pasaje estuvo influenciado por el enfrentamiento que se llevó a cabo previamente en Francia entre ambas disciplinas por los ámbitos de desarrollo y por las incumbencias profesionales: las "ciencias de la educación" pretendían una orientación hacia la investigación en las universidades diferenciándose de la "pedagogía" más preocupada por las prácticas de formación.

Por otro lado, hay diversos trabajos que analizan las diferencias entre "ciencias de la educación" y "pedagogía" desde una perspectiva epistemológica. Entre ellos, se puede profundizar en los textos de Silber que citamos en la bibliografía, así como también en Escolano (1978) y Olmedo (2006).
} 
en las prácticas educativas ${ }^{21}$. Esta afirmación puede sustentarse en las siguientes cuestiones: la didáctica tal vez sólo difiera de la pedagogía por su mayor "acercamiento" a la enseñanza; tiene como objetivo la intervención pedagógica, como plantea Camilloni (1996); sus componentes epistemológicos a saber, la explicación, la norma y la utopía (Davini, 1996) ${ }^{22}$ - la ligan a la pedagogía; su estudio de la enseñanza o del aula de clases (algunos de sus objetos de estudio según diferentes autores) la lleva a considerar su articulación con un proyecto educativo global para la formación de los sujetos.

Silber (2000) propone la conformación de un "continuum pedagógicodidáctico" en el que se compartan temáticas y problemáticas de conocimiento e intervención entre ambas disciplinas. Asimismo, defiende para el caso de la pedagogía las funciones prioritarias de teorización e intervención. Con rasgos similares a las propuestas que realiza Camilloni (1993; 1996; 2007b) para el caso de la didáctica, Silber postula una pedagogía que exceda sus capacidades contemplativas y que se comprometa con el mejoramiento de la formación, considerada su objeto de estudio.

Como sostienen Carr y Kemmis (1988), en tanto la educación es un problema práctico, las teorías e investigaciones educativas no pueden limitarse al descubrimiento de un nuevo saber, sino que también deben buscar confeccionar cursos de acción posibles que dirijan las prácticas en determinados sentidos.

Complementando los rasgos mencionados previamente, debemos reconocer que la educación, en un sentido general e involucrando la enseñanza, se constituye articulando aspectos descriptivos y normativos. En este sentido, Gimeno Sacristán $(1998 ; 2012)$ incluye estos aspectos en la conceptualización que elabora de la educación. Sostiene que se encuentra entre las inquietudes de las personas -cualesquiera, tanto especialistas como legos- el buscar

\footnotetext{
${ }^{21}$ Sustentamos esta afirmación en los trabajos de Camilloni; Davini; y Silber citados en este apartado. Asimismo, una concepción similar sustentan Garrido Pimenta (1998); y Martínez Bonafé (2004). Otros autores como Contreras Domingo (1990) y Araujo (2006) comparten la afirmación de que la didáctica forma parte de las ciencias de la educación. Quedan pendientes, entonces, otras investigaciones para estudiar las diferentes posturas que sobre este tema se evidencian en nuestro país.

${ }^{22}$ Estos componentes epistemológicos originalmente fueron trabajados por Gimeno Sacristán (1978) para estudiar las ciencias de la educación y Davini (1996) los traslada para analizar la didáctica.
} 
explicaciones acerca de cómo y qué produce los fenómenos, es decir, explicaciones acerca del por qué suceden, y cómo y qué podemos hacer para que los mismos se muevan en la dirección que nos interesa.

Para el caso de la educación, esta articulación entre lo que ella es y lo que se desea que sea, se corresponde con aquellas concepciones que la visualizan como un proceso de cambio o de "progreso". Desde la cultura clásica se ha visualizado la educación como un camino de mejora y perfección del hombre. La formalización del conocimiento sobre la educación, como parte del quehacer disciplinante, no ha podido quedar al margen de estas características, según plantea Gimeno Sacristán, cargando, por un lado, con explicaciones de los hechos y procesos y, por el otro, con guías para la acción educativa. Agrega que en la civilización moderna se ha profundizado la idea de que las prácticas humanas pueden guiarse según una determinada racionalidad.

El autor considera que estas dimensiones acerca de cómo la educación es y de cómo debemos hacer para que las prácticas se asemejen a la imagen guía que poseemos, se entrelazan con las relaciones entre la teoría y la práctica. Las mismas se presentan como un problema epistemológico ante aquellos sujetos que se cuestionan la distancia entre la realidad y la posibilidad, entre lo que es y lo que debería ser conforme a sus aspiraciones.

Planteado en estos términos, este binomio problemático entra en esta tesis aunque su tratamiento sea colateral. Al preguntarnos por la normatividad en la didáctica, por cómo se piensa y construye el componente normativo en la producción teórica didáctica, aparecen asociados planteos en torno a la relación teoría-práctica, o a cómo halla concreción una norma en la práctica educativa; cuestión central también para el curriculum si reconocemos que el mismo se formula para ser llevado a la práctica ${ }^{23}$. No obstante, no lo abordamos profusamente en esta oportunidad por no ajustarse estrictamente a los objetivos que nos hemos planteado.

\footnotetext{
23 “...El desajuste entre sistemas de pensamiento y acción práctica o realidad institucionalizada aparece como provocación y reto en el propio discurrir de la práctica de pensar y de la investigación, como conciencia de una identidad epistémica que se sabe débil a la hora de proponer normas para la práctica" (Gimeno Sacristán, 1998, p.28).
} 
Por otra parte, a partir de la bibliografía consultada podemos decir que la pedagogía está constituida por dos enfoques y que posee dos objetivos diferentes con respecto a su objeto de estudio, la educación. Esta configuración permite hablar de una pedagogía descriptiva y otra normativa ${ }^{24}$.

Para Nassif $(1958 ; 1980)$ la pedagogía normativa es aquélla que se ocupa de comprender el objeto y destacar sus rasgos característicos, suponiendo los fines de la educación. Es la que traza normas para la actividad educativa (Nassif, 1958) y es a su vez la que desenvuelve los fines de la educación, partiendo del supuesto que los fines de la educación constituyen el problema mayor de la pedagogía (Nassif, 1980) ${ }^{25}$.

En este esquema, Nassif (1958) reordena una clasificación previa de la pedagogía realizada por Luzuriaga, al incluir en la pedagogía normativa aquella parte teleológica que da cuenta de los fines e ideales de la educación -la pedagogía que Luzuriaga denomina propiamente normativa-, y aquella otra tecnológica que incorpora los métodos pedagógicos, la estructura de la educación, la organización educativa y las instituciones escolares. En este sentido, Luzuriaga dice:

“La pedagogía normativa trata [...] no de lo que es la educación, sino de lo que debe ser, no de su realidad, sino de su finalidad. Señala los objetivos o propósitos de la actividad educativa y muestra cómo se estructura ésta conforme a ellos. Determina las normas o leyes de la educación en un

\footnotetext{
${ }^{24}$ No consideramos en esta tesis a la pedagogía normalizadora, como sí lo hicimos en un trabajo previo (Picco, 2010), porque el sentido que en ella encierra la norma no se ajusta a nuestros intereses actuales de investigación.

Para ampliar sobre las características de la pedagogía normalizadora y su influencia en la conformación del sistema educativo argentino, se puede consultar Puiggrós (1990); Dussel (2004).

Es interesante también el sentido de "normalización" que despliega Foucault en sus escritos y que Puiggrós recupera para definir la pedagogía normalizadora; al respecto se puede consultar Castro (2004).

En otro trabajo (Picco, 2007) analizamos la pedagogía normalizadora como cuna en la que se formó Víctor Mercante quien tanta influencia ejerció en la formación de profesores en la Sección Pedagógica y en la Facultad de Ciencias de la Educación en la Universidad Nacional de La Plata a principios del siglo XX. También resaltamos aquí una diferencia entre "normativo" y "prescriptivo" que aparece en los escritos del autor. Resumidamente podemos decir que lo normativo engarzaba con aquel sustrato normalista y con elementos propios de la pedagogía de la época, buscando la clasificación y ordenación de las grandes masas de población; mientras que lo prescriptivo acentuaba la pauta a la que debía ajustarse el accionar del profesor para que su desempeño fuera eficaz y el proceso racional.

${ }^{25}$ Nassif utiliza las expresiones "pedagogía normativa" y "pedagogía prescriptiva", no estableciendo hasta donde hemos podido indagar- diferencias entre ambos términos como sí lo hacen otros autores a los que aludimos oportunamente.
} 
sentido general humano y reserva su aplicación y realización para la pedagogía práctica o tecnológica" (1958, p.103).

Del sentido que este autor le asigna a la pedagogía normativa, resulta relevante resaltar dos ideas: una de ellas se vincula con la convivencia en la pedagogía de aspectos normativos y descriptivos; la otra tiene que ver con la asociación entre las normas y las finalidades, entre lo normativo y lo utópico como también plantean Gimeno Sacristán (1978), Davini (1996) o Silber (1997), entre otros autores. Más aún, para Luzuriaga la pedagogía normativa incluye los ideales de la educación, como aquello no realizado que se configura en el contexto -espacial y temporal- de cada sociedad en particular.

Es interesante recuperar el planteo de Bruner (1969; 1988) porque también diferencia entre aspectos descriptivos, normativos y prescriptivos. La teoría de la instrucción que el autor propone es prescriptiva y normativa a la vez. Es prescriptiva porque brinda reglas acerca de la manera más eficaz de lograr ciertas finalidades $y$, a su vez, un canon para evaluar el desenvolvimiento de determinadas prácticas de enseñanza. Además, una teoría de la instrucción es normativa porque aporta criterios con distintos márgenes de generalidad y condiciones para satisfacerlos.

Feldman (2010b) sostiene que la distinción entre los aspectos descriptivos y prescriptivos es válida a los fines analíticos, pero no es neta teniendo en cuenta que un sentido de lo normativo está incluido en el carácter construido y constructor de todo conocimiento ${ }^{26}$.

Por otro lado, encontramos en la bibliografía otro grupo de trabajos afines al campo pedagógico que se concentran en analizar las características que debe tener el componente normativo. En este sentido, Silber (1997) plantea que la normatividad prescriptiva aisladamente tiene relación con lo consuetudinariamente aceptado y, por tanto, tiende hacia la reproducción social. La normatividad y la utopía -juntas- son las que permiten construir caminos alternativos, habilitando a los hombres a expandir sus posibilidades a

\footnotetext{
${ }^{26}$ En otro lugar del mismo trabajo, interpretamos que el autor diferencia entre "normativa didáctica" en la que existe una discontinuidad entre el caudal descriptivo y la elaboración de normas- y el "efecto normativo" que posee este carácter constructor de todo conocimiento.
} 
partir de la crítica y la creatividad.

En la misma línea, Gimeno Sacristán plantea que la normatividad construida desde, o deducida del conocimiento científico que se posee en un determinado momento histórico tiene un carácter reproductor de la realidad, válido siempre que se tome lo dado como modelo a propagar. No obstante, el autor propone una perspectiva superadora de la realidad educativa tal como es descripta por el componente explicativo que demanda la asociación con el componente utópico. Este último se convierte en el intermediario entre la explicación y la normatividad, diferenciando aquellos aspectos "válidos" de los "no válidos". La utopía permite visualizar lo dado y lo que se está dando en el proceso educativo, también en coherencia con la inconclusión propia que, para el autor, posee la educación en tanto se van evidenciando sus cualidades en el mismo desarrollo de la práctica. Se trata de un objeto abierto del que “[...] iremos captando su esencia a medida que lo vamos persiguiendo con la práctica educativa, lo vamos interpretando al tiempo que se va condensando en el transcurso de una experiencia [...]" (1978, p.159).

En otros términos, este posicionamiento es compartido por Contreras Domingo (1990), para quien la didáctica sólo puede analizarse en relación con los valores que se propone para la enseñanza y en qué medida su conocimiento científico y su vinculación con la práctica, se alejan o se acercan de la concreción de dichos valores. Esta referencialidad a los valores y a la elaboración de propuestas de enseñanza consecuentes con ellos se opone a una normatividad tecnológica derivada exclusivamente del aspecto explicativo de la disciplina.

Desde un punto de vista didáctico, Feldman también critica la elaboración de propuestas de enseñanza a partir de los datos obtenidos en la investigación de manera exclusiva. Esta forma de derivar cursos de acción desde el corpus de conocimientos didácticos o pedagógicos, es lo que el autor denomina "deslizamiento normativo" (2010b, p.103), y estaría desconociendo la importancia de los valores educativos sobre los que descansan las propuestas normativas. 


\section{I - 3 - La normatividad en la didáctica y el curriculum.}

Como adelantamos, antes de focalizar específicamente el problema de la normatividad, nos proponemos en este apartado presentar la definición de los términos "didáctica" y "curriculum" que utilizamos en esta tesis. Pretendemos abordarlos aquí desde el propio campo pedagógico, reservando para el capítulo III una revisión epistemológica al respecto.

Como mencionamos, sostenemos que la didáctica es una teoría que se ocupa de la enseñanza27, entendiéndola de manera genérica (Fenstermacher, 1989) como aquel proceso que involucra al menos a dos personas, con disímiles niveles de conocimientos y donde hay una explícita intencionalidad de parte de quien posee el conocimiento de hacer algo para que el mismo pase a estar en posesión de los dos al final del proceso (Feldman, 2010a). A pesar de esto, es necesario reconocer la polisemia del término en tanto asume diferentes sentidos en relación con la variedad de situaciones en las que se emplea (Basabe y Cols, 2007).

En la conceptualización genérica de enseñanza, la relación que se da entre estos dos sujetos es particular, en tanto hay una explícita intencionalidad de transmitir, compartir, enseñar, dar a conocer ese saber al alumno. La

\footnotetext{
${ }^{27}$ En líneas generales coinciden con esta afirmación diferentes autores, entre ellos: Contreras Domingo (1990); Davini (1995; 1996; 2008); Camilloni (1996; 2007a); Garrido Pimenta (1998); Feldman (2008). No desconocemos otras posturas que defienden otros objetos de estudio para la didáctica, como puede ser el proceso de enseñanza-aprendizaje, el acto pedagógico o el salón de clases. Becker Soares (1985) y Barco (1989), por ejemplo, plantean que la didáctica debe ocuparse del salón de clases. No obstante, cabe aclarar que de ambas autoras tomamos trabajos que datan de la década del '80, por su pertinencia para el período de estudio de esta tesis, años de fuertes cuestionamientos al tecnicismo y a las propuestas autoritarias en educación que lo implementaron y, a su vez, de emergencia de perspectivas etnográficas e interpretativas, en términos generales, en la investigación educativa. Resta indagar el posicionamiento de las autoras en trabajos más actuales.

Por su parte, Souto (1996) sostiene que el acto pedagógico es el objeto formal de la didáctica mientras que las situaciones de enseñanza son su objeto concreto. El acto pedagógico se lleva a cabo habitualmente en situaciones de clase escolar, pero muchas otras se presenta en ámbitos no formales 0 incluso informales, también en el espacio virtual, cuestiones que no permiten hablar de la clase escolar como el único objeto de estudio de la didáctica pero sí uno relevante. En otro trabajo (Souto y Mazza, 2001) la autora plantea que la didáctica es una teoría o un conjunto de teorías acerca de la enseñanza, pero aclara que este proceso no puede ser estudiado al margen de las situaciones en las que surge. Para comprender y analizar su objeto de estudio, la didáctica, desde el planteo de Souto, debe construir un enfoque multirreferenciado, teniendo en cuenta la complejidad del objeto, articulando perspectivas teóricas diversas y preservando su autonomía. A su vez, lo grupal se conforma en el nivel y ámbito de estudio de la clase escolar porque es el que articula diferentes dimensiones, a saber, individual, institucional, social, etc.
} 
asimetría es consustancial a esta práctica ya que el docente es quien posee mayor cantidad y calidad de esos conocimientos transformados en contenidos a enseñar y es quien se encuentra legitimado y autorizado por la sociedad para ejercer el rol de guía, orientador o promotor de la formación del niño ${ }^{28}$. Este esquematismo es tal a los solos efectos de la presentación porque acordamos con la existencia de una asimetría dinámica que por momentos puede llevar a la rotación de los roles de docente y alumno.

Lo dicho hasta el momento nos permite visualizar que la tríada didáctica o el triángulo didáctico ${ }^{29}$, configurado con la presencia del docente, el alumno y el contenido en sus polos, es una de las ideas que subyace a esta definición genérica de enseñanza. A su vez, emerge la diversidad de disciplinas que se ocupan de estudiarla -de manera total o parcial- así como también las potenciales relaciones interdisciplinarias que despierta. El docente y el alumno son sujetos que deben ser comprendidos en su integridad como sujetos biológicos, sociales, afectivos, epistémicos, etc. El contenido de la enseñanza es un saber cultural y por tanto requiere estudios específicos, desde las disciplinas científicas involucradas, la epistemología, la filosofía, etc. El triángulo didáctico en su conjunto está situado y -al mismo tiempo- es expresión de un triángulo aún mayor que da cuenta de las relaciones entre Estado, sociedad y educación, por lo que en su análisis intervienen perspectivas sociológicas, políticas, antropológicas, institucionales, etc. ${ }^{30}$.

Como ya mencionamos, la enseñanza es una práctica social y compleja. Entonces, si las pretensiones de la didáctica giran en torno a su explicación, establecimiento de valores-fines hacia los cuales tender y disponibilidad de normas que orienten acerca de cómo alcanzarlos, requiere de elementos

\footnotetext{
${ }^{28}$ Cabe aclarar que no estamos introduciendo definiciones acerca del docente o de lo que significa su accionar. Por el momento, sólo utilizamos estas conceptualizaciones de manera genérica, intentando aproximarnos a la caracterización de la relación que se produce entre docente y alumno intermediados por el contenido.

${ }^{29}$ Es interesante el análisis expuesto por Camilloni (2013) a propósito de la metáfora del "triángulo didáctico" como constructora pero, a la vez, limitante de determinados pensamientos sobre la enseñanza.

${ }^{30}$ Poggi (1997) utiliza estas ideas discutiendo con usos esquemáticos de la metáfora "el triángulo pedagógico o el triángulo didáctico". No obstante considera que es una expresión útil para mirar las múltiples relaciones que cruzan los procesos de enseñanza y de aprendizaje.
} 
conceptuales provenientes de otros campos disciplinarios que aporten inteligibilidad sobre dimensiones que escapan a su dominio exclusivo. Además, no podemos desconocer que la enseñanza en particular y la educación en general, por ser fenómenos sociales, son estudiadas con diversos grados de profundidad por otros especialistas provenientes de las ciencias sociales en su conjunto.

En vinculación con estas cuestiones, aparece otra característica que reconocemos central de la didáctica y que mencionamos someramente en el apartado anterior al exponer las similitudes con la pedagogía, a saber, las relaciones con otras disciplinas. El corpus de conocimientos de la didáctica, como dice Camilloni (1996), debe reconocerse deudor de aportes provenientes de otras disciplinas. En su devenir ha ido incorporando miradas disciplinarias y conocimientos que han contribuido en diversos grados a su constitución. Así, principalmente la psicología, pero también la antropología, la sociología, la política, etc., han aportado categorías conceptuales $\mathrm{y}$, en algunos casos, lineamientos prescriptivos asociados a las mismas.

En el contexto actual de las ciencias sociales, más que buscar una delimitación de sus incumbencias a partir de marcar las diferencias, la autora propone "[...] establecer vínculos armoniosos en la familia [...]" (Camilloni, 1996, p.26), teniendo en cuenta que la didáctica es una ciencia social y que nos encontramos en una época en la que las relaciones interdisciplinarias y la configuración de nuevos campos con distintos niveles de especificidad en torno a su objeto, son cuestiones epistemológicas definitorias.

En este sentido, la didáctica recibe aportes de otras teorías que directa o indirectamente enfocan la enseñanza. Algunas de ellas sólo buscan describir las prácticas, caracterizarlas, y no tienen pretensiones "didácticas" sobre la enseñanza. No obstante, sus aportes enriquecen a la didáctica que sí busca satisfacer sus pretensiones de guía sobre la enseñanza. En otros términos, hay investigaciones que persiguen explícitamente propósitos didácticos, que se generan en el campo de la didáctica y que buscan intencionalmente la construcción de normas o principios de intervención que digan -en términos 
generales o específicos- cómo deben ser las acciones en y de la enseñanza o qué rumbos deben éstas seguir ${ }^{31}$. Pero también hay investigaciones que se producen en otros marcos teóricos -como puede ser la sociología, la psicología, la lingüística o en las mismas ciencias de la educación- que persiguen propósitos explicativos o comprensivos y que brindan insumos en la construcción de explicaciones y/o normas para la enseñanza.

En síntesis, la didáctica construye un corpus teórico propio, recibiendo a su vez el aporte de muchas otras disciplinas, con la intención de explicar la enseñanza y de elaborar normas acerca de cómo debe comportarse dicha práctica.

Por otra parte, sostenemos que la didáctica es una teoría normativa en tanto adopta una responsabilidad directa por el curso de las prácticas de enseñanza. Basabe (2007) y Feldman (2008) aluden a estas responsabilidades de la didáctica como un criterio que delimita posiciones en el campo.

En este sentido, encontramos diversos trabajos que van a bregar por la constitución y el sostenimiento de la didáctica como una teoría normativa. Aun con sus matices, estos trabajos van a defender una responsabilidad directa de la didáctica por el rumbo de las prácticas de enseñanza toda vez que sostengan que la didáctica debe brindar a los docentes orientaciones o principios de acción para resolver los problemas cotidianos a los que los expone la práctica y para fundamentar sólida y racionalmente sus decisiones.

No obstante, reconocemos la existencia de otro tipo de trabajos que proponen una relación más indirecta entre la didáctica y la enseñanza. Son posturas más a favor de aumentar el caudal comprensivo de la disciplina, que no buscan influir en el rumbo de la enseñanza o que limitan su injerencia a brindarle a los docentes esas explicaciones para que ellos procedan en sus prácticas de la manera que lo estimen más conveniente.

\footnotetext{
${ }^{31}$ Profundizamos esta conceptualización a lo largo de este trabajo teniendo en cuenta, principalmente, los siguientes autores: los principios de selección de actividades expuestos por Raths (1971; citado en Stenhouse, 1991); los principios de selección de actividades que comentamos de Tyler (1973); los criterios aportados por Taba (1974); los principios de procedimientos desarrollados por Bruner (1988) y Stenhouse (1991) en el marco de un diseño curricular alternativo a lo que sería el modelo imperante en los '70 de planificación por objetivos; los principios para la selección de contenidos de Bourdieu y Gros (1997).
} 
Es pertinente aquí el análisis que realiza Davini (2008) a propósito de la base normativa de la didáctica. Para la autora, se incluyen en la base normativa los valores, como brújula que guía las prácticas de enseñanza; el acervo de conocimientos disponibles propios de la didáctica o provenientes de otros dominios, como mencionamos previamente; y la sistematización de experiencias concretas, que sean significativas y que resulten valiosas para su propagación.

Para la autora, es una necesidad contar con criterios básicos de acción didáctica que "[...] orienten las prácticas de enseñanza y permitan elegir entre alternativas, adecuándolas al contexto y a los sujetos, y contribuir a la transformación de las prácticas en los ámbitos educativos [...]" (2008, p.57).

Davini plantea que renegar contra la elaboración de normas didácticas es como decretar el fin de la disciplina. Muchas veces esto se ha hecho en un intento de oposición a una didáctica tecnicista. No obstante, dicha negación conlleva la identificación de una práctica educativa intuitiva o de carácter artístico, en la que los profesionales mejor formados o más reflexivos obtendrían mejores resultados.

“[...] La cuestión parece bastante riesgosa para la educación, especialmente si se consideran los efectos sociales y políticos de la enseñanza en las escuelas. La enseñanza y la acción docente en las instituciones educativas no pertenecen al mundo de las decisiones privadas sino a una acción pública con consecuencias sociales significativas" (Davini, 2008, p.57).

En las consideraciones sobre la cuestión normativa en la didáctica se debe también reconocer que esta disciplina se ocupa de estudiar una práctica conformada por sujetos sociales o ya intervenida por distintos sujetos ${ }^{32}$. Sostenemos que el aporte de Vasilachis (2008) sobre la Epistemología del Sujeto Conocido es pertinente para entender al docente como interlocutor privilegiado en la construcción del saber didáctico. La autora postula el reconocimiento de la identidad esencial -no existencial- entre el sujeto cognoscente y el conocido, lo que posibilita pensar la investigación social en general y la didáctica en

\footnotetext{
${ }^{32}$ Para un profuso tratamiento de las acciones humanas y de las prácticas sociales y culturales en educación, puede consultarse el trabajo de Gimeno Sacristán (1998).
} 
particular como un espacio de interacción cognitiva que permite la construcción cooperativa del conocimiento. De esta manera, en la investigación cualitativa, el centro se traslada al sujeto conocido en un intento de saber de él desde sus particulares formas de conocer el mundo.

Asimismo, podemos afirmar que todas las ciencias sociales tienen la complejidad de que el sujeto que conoce coincide con el sujeto que es conocido, aumentando así para Gimeno Sacristán (1998) la necesidad de un análisis epistemológico. En este trabajo más reciente, el autor alude a la importancia de la reflexividad como instancia de análisis crítico y toma de conciencia de la confluencia y mutua influencia entre el sujeto que investiga y el sujeto que es investigado ${ }^{33}$.

Por otro lado, acordamos con Basabe (2007) cuando especifica dos planos de dificultades a los que debe enfrentarse la didáctica y que coinciden con dos aspectos disciplinarios centrales para esta investigación. En primer lugar, debemos considerar la complejidad del objeto de la didáctica $\mathrm{y}$, por tanto, de la teoría didáctica, a la que referimos previamente. En un segundo plano de dificultades, hay que localizar un abanico de resoluciones de carácter ético que involucran la responsabilidad que le cabe a la didáctica con respecto a su objeto de estudio. Basabe defiende que la didáctica debe intervenir en la enseñanza y sostiene que esta disciplina, junto con la ética y la política, debe enfrentar los problemas de informar la acción y los riesgos que esto conlleva ${ }^{34}$.

\footnotetext{
${ }^{33}$ La reflexividad es una categoría muy trabajada por autores que realizan y defienden la investigación cualitativa para las ciencias sociales. Entre ellos: Hammersley y Atkinson (1994). Para el caso específicamente educativo, encontramos los trabajos ya citados de Achilli (1996; 2000: s/f); Batallán y García (1992); y Batallán (2007); que retoman esta categoría.

${ }^{34}$ Otros autores comparten esta afirmación. Por ejemplo: “...las disciplinas que terminan en -ica (como la ética, la política o la técnica) son aquellas que tienen que ver con la poiesis o con la praxis, pues son disciplinas de aplicación o de acción..." (Camilloni, 1996, pp.27-28. El subrayado figura en cursiva en la edición consultada).

"...Se dice que la ética es normativa en tanto y en cuanto estudia y propone las normas por las que se rige la acción humana, es decir, no se contenta con decir cómo son las acciones humanas, sino cómo deben ser" (Diccionario de las Ciencias de la Educación, 1995, p.1015).

"[...] Como toda disciplina cuyo nombre termina en ica (política, ética, estética), la Didáctica tiene que ver con lo que los griegos llamaban praxis y con la poiesis.

Recuperando la significación aristotélica de praxis y poiesis, podemos afirmar que la Didáctica es un discurso sobre un hacer que se compromete con la acción informada y prudente sometido a una "vigilancia" crítica y revitalizado por el compromiso con los valores educativos y sociales. Intenta orientar
} 
El tratamiento de la normatividad en la didáctica problematiza, según sostenemos, la relación entre la didáctica y sus posibilidades y condiciones de intervención en las prácticas de enseñanza. Consideramos que de manera no siempre explícita, la intervención se presenta como problemática cuando la didáctica se pregunta acerca de su responsabilidad por el rumbo que debe adoptar el objeto del que se ocupa.

Acordamos con Camilloni (2007d) cuando define a la didáctica normativa como aquella que está asentada en un proyecto político-educativo y pretende la concreción de valores. Los enunciados de este tipo de disciplina y su vinculación con la práctica se pautan de la siguiente manera: "la enseñanza debe buscar alcanzar determinadas finalidades; debe lograr tipos específicos de aprendizaje en los alumnos; debe transmitir ciertos contenidos; etc." 35.

Así entendida la didáctica, según plantea Camilloni, se convierte en una disciplina que se propone ayudar al docente en su trabajo cotidiano en el aula. Las normas que elabora respetan ciertos márgenes de autonomía, orientando pero no decidiendo por el docente. En todos los casos, éste es un profesional capacitado para la adecuación o resignificación de dicha normatividad a las particulares condiciones del grupo de alumnos, de la institución en la que se inscriben, así como del contexto social y cultural más amplio.

Al referirse específicamente al "sujeto destinatario del discurso didáctico" -el docente-, Camilloni concluye que debe ser conceptualizado como un sujeto individual y empírico y con la capacidad para realizar la necesaria traducción a la práctica que la teoría didáctica demanda para alcanzar sus intencionalidades. Este esfuerzo de acomodación de la teoría didáctica se lleva a cabo en el marco de las condiciones áulicas, institucionales y sociales que configuran el escenario en el que se concreta la enseñanza. " [...] Ninguna teoría permitirá pasar al caso individual sin una mediación, fruto de la reflexión crítica y de la

la determinación de fines y medios para la acción pedagógica, (la enseñanza), que se genera en una situación socio-cultural y política dada [...]" (Schwartz, 2000).

${ }^{35}$ Cabe destacar que Camilloni alude a la presencia de elementos prescriptivos también en una didáctica no tecnológica. La autora no excluye lo prescriptivo que responde a la necesidad de eficacia y basado en el conocimiento científico pero señala la necesidad de lo normativo en tanto normas no sólo sustentadas en una legalidad científica sino en un deber ser. 
decisión creativa. Éste es el aporte, su alcance y su límite, que la teoría didáctica puede hacer a la práctica pedagógica" (2007e, p.69).

Como dice Barco, "[...] entre las urgencias de lo cotidiano y las lógicas demoras de la construcción teórica, está ese actor social que es el docente" (1989, p.19). Quien en definitiva es el que porta con la responsabilidad social de desenvolver a diario las intencionalidades inherentes a la enseñanza.

Asimismo no debemos olvidar en estas consideraciones la complejidad de los sujetos y las prácticas de enseñanza y sociales. La didáctica persigue conocer e intervenir en la enseñanza, que en tanto práctica social se encuentra conformada por sujetos sociales que tienen sus propios modos de conocer y actuar en el mundo. La didáctica y las ciencias sociales en su conjunto buscan a partir de la investigación interpretativa acceder a esos sentidos que mediatizan las relaciones que los sujetos mantienen con sus contextos particulares de existencia.

De acuerdo a esta definición, acordamos con Frigerio cuando expresa que una norma debe poseer una "textura abierta" (1991, p.27) ${ }^{36}$. Así, la norma didáctica podría representarse como una red en cuyos intersticios emergen la libertad y creatividad del docente, necesarias para su resignificación y para la apertura de aquellos espacios indeterminados de la práctica. Parafraseando a la autora, no hay normativa que pueda clausurar todos los significados que le pueden adjudicar los sujetos.

Por otra parte, cabe mencionar que sostenemos en este trabajo una diferenciación entre lo normativo y lo prescriptivo en el marco de la didáctica. Vimos a partir del recorrido por los diccionarios de uso frecuente y aquéllos disciplinarios más específicos que lo normativo, a diferencia de lo prescriptivo, guarda una vinculación explícita con los valores. Asimismo, en el ámbito didáctico, Camilloni (2007d) les asigna a los preceptos un carácter más específico que a las normas y lo prescriptivo está más cercano a la concreción más eficiente de los fines propuestos.

\footnotetext{
${ }^{36}$ Este sentido de lo normativo y su vinculación con el curriculum y el protocurriculum se encuentra desarrollado en Coscarelli y Picco (2009).
} 
La didáctica preceptiva postula enunciados prácticos del tipo "si usted quiere alcanzar tal objetivo, realice tal acción”. Son reglas prácticas orientadas al logro eficaz de los objetivos. No obstante, este planteo didáctico no está comprometido con determinados fines, valores ni con un proyecto políticoeducativo en particular. Desde esta perspectiva, éstas son cuestiones a resolver por la filosofía de la educación, no por la didáctica.

Incorporando a la discriminación conceptual algunos elementos históricos que profundizamos en el capítulo II, lo prescriptivo ha quedado más asociado a la expansión de un proyecto tecnológico. En este sentido, Davini (1996) plantea que la armonía entre la explicación, la normatividad y la utopía, tan propia de la didáctica desde sus orígenes, comienza a romperse en la década del '60 bajo la hegemonía del tecnicismo.

Por su parte, Camilloni (1997; citado en Cols, 2003a) ${ }^{37}$ dice que el carácter prescriptivo es propio de un enfoque tecnológico y se interesa por el logro eficiente de los resultados; en cambio, una postura normativa, más característica del enfoque europeo, se ancla fuerte y explícitamente en un conjunto de valores y establece así qué es lo que se debe enseñar.

A partir del recorrido precedente, reafirmamos que la didáctica es una teoría normativa acerca de la enseñanza. Cabe ahora profundizar en una problemática que atraviesa las indagaciones de esta tesis así como también el análisis del corpus empírico que realizamos en la segunda parte, a saber: ¿cómo se construye la norma didáctica?

A partir del estudio realizado ${ }^{38}$, podemos decir que la didáctica contempla, en primera instancia, para la conformación de su componente normativo, las conclusiones a las que arriban las investigaciones empíricas acerca de las prácticas de enseñanza. Hablamos de investigaciones empíricas en un sentido amplio abarcando a todas aquellas indagaciones que se proponen

\footnotetext{
37 Camilloni, Alicia (1997). "Sobre los aportes de la psicología del aprendizaje a la didáctica". Revista Novedades Educativas, 84, 4-7.

En una línea similar, Barco (1989) también discrimina los términos prescriptivo y normativo, reservando para éste último la vinculación con los fines de la educación, con un proyecto educativo global y con los fundamentos de las acciones.

${ }^{38}$ Sustentamos este planteo principalmente en los textos de Camilloni citados en la bibliografía de la presente tesis doctoral; en Davini (1996; 2008); y en las indagaciones realizadas en Picco (2010).
} 
conocer las prácticas de enseñanza. Algunas investigaciones se enmarcan en la didáctica general, otras en las didácticas especiales por contenidos que se han desarrollado profusamente en los últimos años, y otras en distintas disciplinas que miran la enseñanza con diversos intereses de conocimiento y acción.

Consideramos pertinente parafrasear la distinción que realiza Ardoino (2005) a propósito de la investigación educativa, diferenciando entre “investigación sobre" e "investigación en" educación. La "investigación sobre" la educación incluye todos aquellos trabajos que se realizan desde afuera del campo educativo, que son investigaciones aplicadas a la educación pero surgidas originalmente en las ciencias básicas. La "investigación en" educación, por su parte, resalta el estudio partiendo de la especificidad del objeto educación, viendo su complejidad e intencionalidades praxeológicas (elaboraciones de orientaciones para la acción), según expone el autor.

Encontramos diferentes trabajos en la bibliografía pedagógica ${ }^{39}$ que analizan las características de las investigaciones que se realizan en educación. A pesar de las particularidades de cada estudio, se reitera la diferencia entre investigaciones que buscan ampliar la inteligibilidad de los procesos educativos y aquéllas otras que además pretenden orientar la práctica. En este segundo grupo también se abre un abanico de opciones que se generan en función de las características que adopta esa intervención en la práctica.

En este sentido, sostenemos que las investigaciones didácticas son aquéllas que buscan mayor inteligibilidad de los procesos de enseñanza y a su vez elaborar normas para mejorarlos. No obstante, como dijimos, la didáctica toma aportes de otras investigaciones que aunque no posean "intencionalidades didácticas" aportan saberes para que ella trabaje en el fortalecimiento de su componente normativo.

En segundo lugar coincidimos con Davini (2008) cuando plantea que la base normativa de la didáctica se conforma con valores y concepciones pedagógicas que sirven de brújula a los proyectos y a las prácticas de enseñanza. Aparece de esta manera, en el plano específicamente didáctico, la

\footnotetext{
39 Podemos citar: Shulman (1989); Astolfi (1993); Furlán y Pasillas (1993); Díaz Barriga (1998).
} 
asociación ya enunciada entre normas y valores. Cualquier norma didáctica debe tenerlos en cuenta, buscando su adecuación a ellos y su alcance. La definición de la norma se asienta en un posicionamiento político-valorativo.

En tercer término, consideramos que en la conformación de la norma aparece la contemplación de cuestiones generales, con cierto grado de reproducibilidad, y lo contingente, lo inédito. En la elaboración de la normatividad didáctica, el didacta debe contemplar ambos tipos de elementos porque hay aspectos que son compartidos por distintas prácticas de enseñanza, que se pueden comparar, pero hay otros que son singulares, propios de cada situación. Ambos, entonces, deben ser contemplados en la construcción de orientaciones didácticas para la enseñanza.

Aparecen en esta consideración elementos similares a aquéllos que Schwab (1974) resalta para la modalidad cuasi-práctica de acción en el curriculum. La contemplación de diferentes situaciones problemáticas aumenta la complejidad en el análisis y en la intervención, exigiendo que las alternativas de solución que se delineen posean aspectos comunes a distintos casos y otros singulares.

Por último, figura otro eje de consideraciones en la constitución de la norma que podemos conceptualizar como "el sujeto y su contexto". Contexto que aporta un marco de sentidos a las acciones y a las interpretaciones de las acciones, pero a su vez imprime condicionamientos exteriores al sujeto y que, desde nuestra perspectiva, merecen ser tenidos en cuenta para pensar la norma en la didáctica.

Por otra parte, sabemos que el término curriculum es polisémico. Consecuentemente, la disciplina que se ocupa de su estudio no está claramente delimitada. Reconocemos la existencia de diversas conceptualizaciones, algunas más tradicionales que asocian al curriculum al plan de estudios o a los contenidos que deben ser transmitidos por la escuela; otras más amplias, como pueden ser las que problematizan las relaciones entre el curriculum prescripto y el curriculum real, o aquéllas otras que miran las tensiones entre curriculum, 
Estado y sociedad. Pero hay que estar atentos a los peligros que conllevan las definiciones que profesan que todo lo que pasa en la práctica educativa es curriculum, en tanto esto podría tender a la disolución misma del campo, dado que se pierde la capacidad discriminativa que debe poseer todo concepto.

Díaz Barriga $(1991,1994)$ sostiene que el término curriculum emerge de la mano de la pedagogía pragmática en la sociedad industrial estadounidense y si bien aparecen algunas ideas a principios del siglo $\mathrm{XX}$, el campo se desarrolla y especializa al finalizar la II Guerra Mundial. En cambio, Hamilton (1993; 1999) considera que el término curriculum aparece asociado por primera vez a las prácticas educativas en los colegios europeos protestantes del siglo XVII; mientras que Egan (2000) le asigna un sentido curricular a la educación desarrollada en los diálogos que tanto Aristóteles como Platón mantenían con sus discípulos en la antigua Grecia.

No obstante esta diversidad de definiciones, al igual que hicimos para el caso de la didáctica, nos inclinamos por una conceptualización que considere al curriculum genéricamente como una propuesta formativa. Todo curriculum expresa aquello que una sociedad particular, en un momento histórico determinado, considera que es valioso transmitir a las jóvenes generaciones ${ }^{40}$.

Para el caso del curriculum específicamente y hasta donde hemos podido indagar, no se presenta en la producción teórica curricular una discriminación entre "normativo" y "prescriptivo"41 sino que ambos términos se utilizan indistintamente. No obstante, las reflexiones sobre las diferencias que se pueden asignar a las normas y a las prescripciones que se generan en el campo

\footnotetext{
${ }^{40}$ Distintos autores acuerdan con esta definición, entre ellos podemos citar a: Lundgren (1992); Kemmis (1993); Salinas Fernández (1997).

${ }^{41}$ Como un ejemplo actual de esta indiscriminación podemos hacer referencia al Marco General de Política Curricular vigente para la Provincia de Buenos Aires que abarca a todos los niveles y modalidades del sistema educativo, en el que se explicita y fundamenta que "[...] los nuevos diseños curriculares elaborados a partir de la Ley de Educación Provincial № 13.688 [...] se asumen como comunes, prescriptivos, paradigmáticos y relacionales [...]" (2007, p.15. La negrita figura en la edición consultada). Analizando la caracterización que se brinda para "prescriptivos" encontramos rasgos que en los términos que estamos utilizando en esta tesis, la vincularían a lo normativo, como por ejemplo cuando se hace referencia al lugar del docente en la interpretación y uso profesional de los Diseños Curriculares para la programación de sus clases. (Para más información, se puede consultar el informe final del proyecto "Programación de la enseñanza en la escuela primaria: discursos y prácticas", Programa de Incentivos a la Investigación, Ministerio de Ciencia, Tecnología e Innovación Productiva de la Nación, H588).
} 
de la didáctica, pueden ser utilizadas -como venimos haciendo- para el caso del curriculum.

En este sentido, consideramos que la normatividad es inherente al curriculum y a su elaboración como propuesta formativa en tanto éste se formula para ser llevado a la práctica $y$, por ello, debe orientarla hacia la consecución de las intencionalidades formativas que se propone.

Por otro lado, en lo que respecta a la teoría curricular, Stenhouse plantea que el curriculum debe ser entendido como una ciencia normativa. Este posicionamiento obliga a considerarlo como un campo que debe retomar la comprensión pero con un sólido conocimiento de lo que sucede en las escuelas y en las aulas. "[...] Las teorías a gran escala son muy útiles como andamiaje para el avance del conocimiento, pero cuanto más satisfactorias las encontremos desde el punto de vista lógico, tanto menos probable es que sean adecuadas [...]" (1991, p.110) a las circunstancias de la práctica.

Para este autor, el curriculum se conceptualiza en la tensión compleja que se entabla entre nuestras aspiraciones y los intentos por hacerlas realidad. Consideramos que este "hallazgo" de Stenhouse y posiblemente de otros autores comprendidos en la perspectiva práctica, impide pensar al curriculum como un objeto y como una teoría que pueda abstraerse de su compromiso para con las prácticas educativas.

Gimeno Sacristán (2012) realiza un breve repaso histórico por el campo del curriculum y concluye que en la actualidad se destaca como problemática el carácter regulador del curriculum con respecto a las prácticas educativas. El curriculum como proyecto de formación que define una sociedad en un momento histórico particular para sus jóvenes generaciones implica, como dice el autor, una confianza en la educación, en sus posibilidades de transformación de esos sujetos, en la concreción de las intenciones y deseos formativos que sintetiza. El curriculum también implica una regulación sobre las prácticas de enseñanza, sobre cómo podrían o deberían llevarse a cabo y sobre qué deberían enseñar. El curriculum, aun cuando lo veamos como algo naturalizado en nuestra vida cotidiana, es un invento social que se ha ido asociando 
fuertemente a la educación escolar y que la organiza en términos de sujetos, espacios, tiempos y saberes que circulan -y que no circulan- en ella.

De esta manera y con cierta provisionalidad, a partir de lo expuesto podemos plantear que la didáctica, el curriculum y la escuela se unen en la representación y en la concreción de la utopía educativa de la modernidad ${ }^{42}$.

Cabe mencionar también el trabajo de Dussel (2010), quien avanza en el análisis del curriculum como norma. En primer lugar, para la autora es una norma en tanto expresa una cierta regulación sobre las prácticas escolares. El curriculum prescripto $\mathrm{u}$ oficial sintetiza aquello que se debe enseñar, orienta en cómo se debe hacer, establece formas de vinculación entre los docentes, los estudiantes y el saber, etc. Aparece también una norma en el curriculum oculto o vivido que regula aquellas formas de comportamiento y valores que quedan por fuera del prescripto pero que se aprenden en la escuela.

En tercer lugar, al pensar al curriculum como norma, la autora problematiza los aspectos en común que pueden existir entre la vinculación de los sujetos con el curriculum como norma y aquélla otra que se da entre los sujetos y las normas sociales en las sociedades latinoamericanas. Si bien estas consideraciones representan una línea de indagación que se aleja de nuestros intereses actuales, resulta pertinente mencionarla por la conclusión que extrae la autora.

En este sentido, para Dussel, la historia de los países latinoamericanos, la influencia de las dictaduras, los regímenes democráticos que se han alternado, etc., conducen en líneas generales a una percepción de la norma como aquello que se enuncia para no cumplirse, para violarse o regular a los más débiles ${ }^{43}$.

“[...] En términos de la normativa curricular, esto se expresa como el dejar a un lado, desconocer $u$ "olvidar" lo que dice el currículum que debe

\footnotetext{
42 Para ampliar esta temática se puede consultar: Bolívar Botia (2008). Retomamos estas cuestiones en el desarrollo de la tesis, aunque de manera colateral, porque visualizamos que aquí se abre una posible línea de continuidad para nuestras preocupaciones.

${ }^{43}$ Dussel recupera el trabajo de: O’Donnell, G. (2002). "Las poliarquías y la (in)efectividad de la ley en América Latina". Méndez, G. O’Donnell y P. S. Pinheiro (eds.), La (in)efectividad de la ley y la exclusión en América Latina. Buenos Aires: Paidós.

En una línea similar aunque no estrictamente pertinente a los fines de esta tesis, se puede consultar el trabajo de Fumagalli (2008).
} 
enseñarse, en vez de discutir y confrontar para cambiar la norma, si es que creemos que es inadecuada o injusta [...]" (Dussel, 2010, p.6).

Esta línea de estudio aporta elementos para entender el funcionamiento real del curriculum en las instituciones educativas y sus efectos en la modificación o no de las prácticas educativas. 


\section{CAPÍTULO II:}

\section{DIDÁCTICA Y CURRICULUM EN LA ARGENTINA}

Nos abocamos en este capítulo al análisis del complejo proceso de articulaciones y desarticulaciones que se fueron dando en nuestro país en el período comprendido entre 1960 y 1990 entre la didáctica, que se venía desarrollando como tradición teórica, y el curriculum, que primero ingresa a fines de los años '60 proveniente de los Estados Unidos y que después va incluyendo aportes de otros países, sobre todo con el retorno de la democracia en 1983. Nos interesa visualizar cómo impacta el curriculum en la tradición de la didáctica denominada "general", cómo ésta última lo recibe y qué modificaciones sufre en consecuencia a lo largo del período mencionado, focalizando la atención en torno al comportamiento de su componente normativo.

\section{II - 1 - El desarrollo de la didáctica en la Argentina.}

La didáctica se desarrolló en la Argentina como disciplina con anterioridad a la entrada de la teoría curricular norteamericana. Hacia finales de los años '60 y en el período de estudio comprendido en esta tesis, además del mencionado ingreso del curriculum como disciplina, tuvieron lugar otros procesos, entre ellos: las críticas hacia el tecnicismo, la expansión de las didácticas especializadas en campos de conocimiento, las revisiones epistemológicas en la didáctica.

Como profundizamos en el capítulo $\mathrm{V}$, en aquellos años circularon en nuestro país diversos textos de didáctica "general", destinados principalmente a la formación inicial de maestros y de aquéllos que ya estaban en ejercicio. Algunas de estas obras que podemos mencionar son: 
$\checkmark$ STÖCKER, Karl. (1954). Principios de didáctica moderna. (Biblioteca de Cultura Pedagógica). Buenos Aires: Kapelusz.

$\checkmark$ MANGANIELlO, Ethel M. (1956). Didáctica general. Desarrollo del programa de la asignatura correspondiente al 4to. año del ciclo del Magisterio (3a.ed.). Buenos Aires: Librerías del Colegio.

$\checkmark$ THIRIÓN DE VERÓN, Esther. (1963). Curso de didáctica general. De acuerdo con el programa oficial de la asignatura correspondiente al primer año del ciclo de magisterio (4to. año normal). Buenos Aires: Troquel.

$\checkmark$ NÉRICI, Imídeo Giuseppe. (1966). Hacia una didáctica general dinámica. (Biblioteca de cultura pedagógica). Buenos Aires: Kapelusz.

$\checkmark$ IBARRA PÉREZ, Oscar. (1968). Didáctica moderna: la enseñanza y el aprendizaje. Madrid: Aguilar.

$\checkmark$ MATTOS, Luiz Alves de. (1973). Compendio de didáctica general. (Biblioteca de cultura pedagógica). Buenos Aires: Kapelusz.

A pesar de las similitudes y diferencias que guardan estas obras entre sí, las consideramos incluidas en un momento del desarrollo histórico de la didáctica que conceptualizamos como normativo. Para fundamentar esta afirmación consideramos pertinente un breve recorrido por el desarrollo histórico de la disciplina, no circunscripto sólo a nuestro país.

Manganiello (1968), por ejemplo, reconoce el origen griego de la palabra didáctica, diciendo que proviene de $\delta \_\delta a \xi \varepsilon ı v$ (didaskein) que significa "enseñar" y su uso ha derivado en "arte de enseñar". Para la autora, es Ratke el primero que utiliza la expresión en su libro de 1629 llamado Principales aforismos didácticos ${ }^{44}$. Luego la didáctica se generaliza con el trabajo de Comenio.

Otros autores como Hamilton (1999) rastrean antecedentes más remotos

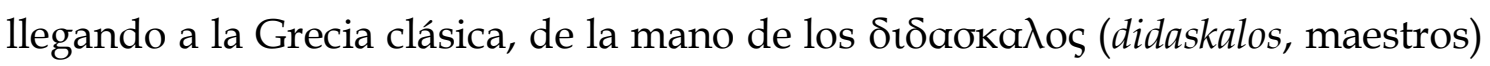
que se ocupaban de la instrucción de los niños mayores con diferentes títulos y responsabilidades.

No obstante, ubicamos en el siglo XVII el nacimiento de la didáctica como disciplina, aun cuando se puedan reconocer diversos antecedentes y la existencia de prácticas de enseñanza previas.

\footnotetext{
${ }^{44}$ Bolívar Botia (2008) sostiene también estas afirmaciones.
} 
Ratke planteaba para la didáctica un conjunto de prescripciones o máximas que indicaban qué debía hacerse en la enseñanza, cómo debía procederse para lograr el aprendizaje, cómo debía enseñarse, etc. (Hamilton, 1999), otorgándole un sentido activo a la instrucción y pasivo al aprendizaje. No obstante, la didáctica así entendida puede ser pensada todavía como un oficio de artesanos.

Esta situación disciplinar comenzó a cambiar cuando en $1632^{45}$ apareció la Didáctica Magna, considerada la obra más conocida de Comenio y el hito fundacional de la didáctica ${ }^{46}$. Esta obra sustentaba el ideal pansófico, a saber, enseñar todo a todos, lo que implícitamente instalaba en el campo de preocupaciones una tecnología instructiva eficiente, con potencialidad para desplegarse en "la totalidad de un sistema educativo a gran escala" 47.

Las pretensiones de universalidad también se pusieron de manifiesto en el interés por encontrar un método único, universal, válido para la enseñanza de cualquier contenido. Se prescribían determinados contenidos a ser enseñados a los alumnos, había una meticulosa organización y secuenciación de los mismos en los tramos escolares, y se delineaba el método didáctico adecuado, eficaz y rápido para enseñar todo a todos.

En las preocupaciones metodológicas de Comenio, como en otros aspectos de su obra, es posible establecer vinculaciones con el contexto del siglo XVII. Por ejemplo, el método de las ciencias en general cambió de la mano de Bacon -de quien Comenio tomó el desarrollo del método inductivo- y

\footnotetext{
${ }^{45}$ Comenio había comenzado a escribir la Didáctica Magna en lengua checa en 1627 (Ravecq, 1957). La edición sueca se publicó en 1632 y la edición latina en 1657. Posiblemente sea esta última la más divulgada. Recordamos que el latín era la lengua de los intelectuales hasta el siglo XVIII y la traducción a ella contribuía con la difusión de las obras.

${ }^{46}$ Entre los autores que sustentan esta afirmación podemos citar a: Barco (1989); Camilloni (1993); Martínez Bonafé (2004); quienes reconocen en la obra de Comenio el surgimiento oficial de la didáctica aunque prácticas didácticas y de enseñanza hayan existido con anterioridad. Díaz Barriga (1991), por su parte, sostiene que es más conveniente contextualizar la obra de Comenio y pensar en el surgimiento de la didáctica como producto de una época: el siglo XVII y el surgimiento de la ciencia moderna. Retomamos estas consideraciones en el capítulo siguiente.

${ }^{47}$ Reconocemos que no es posible hablar de la existencia de sistemas educativos formales hasta entrado el siglo XIX. No obstante, consideramos que al menos en el imaginario de los pensadores de la época y sobre todo en aquéllos vinculados a la Reforma Protestante ya estaba el germen de una institución social destinada a la educación de toda la población (Ravecq, 1957).
} 
Descartes -de quien recuperó el ordenamiento de un "método certero" que eliminaba el error ${ }^{48}$.

En la Didáctica Magna se organizaba una normativa fuerte con el propósito de regular el funcionamiento de la educación institucionalizada en su conjunto, desde el "macro-sistema" hasta la vida en las aulas. El mismo Comenio resaltaba varias características ventajosas para su método cuando decía qué era indispensable hacer en el aula de clases para enseñar de una manera rápida, fácil y eficaz. El método era el que permitiría alcanzar estas características en la enseñanza, a partir del disciplinamiento de la conducta y asentado en el empirismo de Bacon y el realismo pedagógico de Ratke.

Los primeros pasos en la didáctica nos marcan de esta manera la centralidad del docente y de su accionar apoyado en las prescripciones metodológicas. Esta característica también aparece en otros trabajos de la época. El "deber ser" de las acciones que deben desarrollar el docente y el alumno -normativa bifronte en términos de Barco (1989)-49 para el alcance de los fines establecidos, estaba claramente estipulado. Pero, una cuestión a destacar es que esta normativa no se realizaba al margen de los fundamentos y fines que orientaban el rumbo de la educación. En toda la obra de Comenio puede leerse que esa finalidad estaba representada por Dios, evidenciándose esa cosmovisión religiosa del mundo que inundaba otras áreas de la vida.

Comenio era un militante religioso y esta condición tiñó con fuerza su pensamiento. Desde las primeras líneas de la Didáctica Magna se pueden leer las características que debía poseer todo hombre para preciarse de tal y cómo la formación espiritual del sujeto se constituía en las intencionalidades que debía

\footnotetext{
${ }^{48}$ Díaz Barriga (1991) analiza algunas semejanzas que hay entre los planteos metodológicos de Comenio y de Descartes.

Pardo (1997) plantea el cambio del sentido del método que venía desde los griegos con la introducción de las ideas de Descartes. Este trabajo a los fines de esta tesis puede ser analizado en vinculación al giro instructivo conceptualizado por Hamilton (1999).

Ravecq (1957) detalla el conocimiento que Comenio tenía de las obras de otros pensadores previos y contemporáneos que no quita originalidad a su trabajo pero que lo ubica en un clima de época.

${ }^{49}$ Davini (1996) reconoce que en la obra de Comenio y en la de otros pensadores de la época, como por ejemplo en Herbart, a quien comentamos en las próximas líneas, la didáctica se ligaba a la producción de un conjunto de reglas de acción que disciplinaban la conducta del docente y de los alumnos, y al problema de los fines y valores de la educación, que guardaban una cierta normatividad en pos de la construcción del mundo deseado.
} 
alcanzar la educación escolar. Esta formación se complementaba con otros ideales vinculados a la instrucción de los fundamentos y fines de las cosas que existen y se crean en el mundo.

El conocimiento de sí mismo (que Comenio retomó de los griegos), de los objetos y de los demás, junto con la práctica de las costumbres honestas y el cultivo de los sentimientos religiosos, eran los tres núcleos constitutivos de ese ideal hacia el que debía tender "la formación permanente" 50 de la persona y la educación escolar particularmente. Asimismo, esos tres núcleos habían sido colocados por la naturaleza en todos los hombres y estaban como potencia sin desarrollar o, como decía el mismo Comenio, en forma de semilla ${ }^{51}$. Entonces, la educación era la responsable de cultivar ese potencial. En la Didáctica Magna son numerosas las referencias a la naturaleza y a su comportamiento para explicar la educación; es muy conocida aquella referencia a que el docente debía ser un sol que irradiaba con sus rayos a todos los estudiantes.

Este ideal de sujeto al que apuntaba Comenio, según Narodowski (1994), era el motor que le daba sentido a todas las acciones, era la utopía que estructuraba, ordenaba y organizaba la totalidad del pensamiento pedagógico moderno.

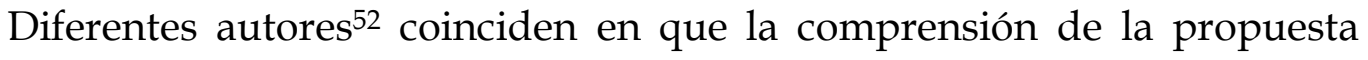
metodológica comeniana debe inscribirse en el contexto de las concepciones filosóficas, pedagógicas y políticas que le daban sentido. Es precisamente esta vinculación entre el método para la enseñanza y el contexto político y cultural, la que sustenta la conceptualización de un momento normativo en la constitución de la didáctica como disciplina. Como expusimos en el capítulo precedente, esta forma de entender lo normativo en la didáctica es la que

\footnotetext{
50 La expresión "formación permanente" no es una categoría usada literalmente por Comenio. En otra de sus obras llamada Pampédia, el autor expandía las acciones educativas y abarcaba los espacios formativos posteriores a la escuela, que comprendía también la escuela maternal de 0 a 6 años. Asimismo, presentaba una idea de autoeducación en el marco filosófico de que el mundo entero era una escuela para el hombre y duraba toda la vida. (de la Mora, 2000).

${ }^{51}$ La expresión no es azarosa ni nos corresponde. Es el mismo Comenio quien utiliza ésta y tantas otras que le permiten referenciar cada afirmación, frase o comentario a sus correlativos naturales.

52 Entre ellos podemos citar a: Barco (1989); Davini (1996); Civarola (2005); Araujo (2006); Pruzzo (2006); Cols (2007).
} 
también nos ayuda a entender lo prescriptivo en su oposición, como vemos en los próximos apartados.

Por su parte Herbart, discípulo de Kant, tenía pretensiones sistémicas y bregaba por una teoría general de la pedagogía, aunque también incluía un grupo de etapas formales de la instrucción, que podían traducirse en actividades para el aula de clase y para el planeamiento de la enseñanza (Hamilton, 1999). En este sentido, se le reconoce una importante influencia en el pensamiento didáctico y en la organización del aula a partir del método global (Dussel y Caruso, 1999).

La pedagogía científica propuesta por Herbart, considerado su fundador, se asentaba en la filosofía práctica como fuente dadora de finalidades educativas y en la psicología en tanto disciplina que informaba cómo debería ser el proceso de instrucción (Cols, 2007) 53 .

Dussel y Caruso (1999) indican que la pedagogía herbartiana se sustentaba en tres principios capitales, a saber, gobierno, instrucción y disciplina. El primero ocupaba un lugar central y de él dependían los otros dos principios. Para organizar la clase era fundamental mantener el orden y conducirla. Herbart se preocupaba tanto por el cuerpo como por el alma, vigilaba y castigaba. La instrucción, por su parte, era la actividad espiritual que se encargaba de la motivación de los alumnos y de despertar el interés. Por último, la disciplina se disponía formar el carácter y la voluntad; el autor proponía una obediencia reflexiva y elegida por el alumno en oposición a una obediencia ciega y fundada en el temor.

Por otra parte, el método instruccional herbartiano estaba compuesto por las siguientes etapas:

\footnotetext{
53 "...Cuando decía psicología, pensaba en algo abstracto, en mecanismos generales, no en una psicología infantil específica, y menos aún en una psicología experimental. El suyo era un sistema psicológico: la lógica de la psique era comprensible desde el punto de vista "lógico" más que desde el punto de vista "psico"..." (Dussel y Caruso, 1999, p.125).

La interrelación entre estudios psicológicos y pedagógicos así como la importancia asignada a los intereses del niño, son cuestiones que para Ali Jafella vinculan la propuesta de Herbart con aquéllas otras resaltadas posteriormente por la escuela nueva. "...Aunque no se lo considera precursor de la Escuela Activa, su obra fue uno de los primeros anuncios sobre nuevas interpretaciones acerca del desarrollo psicológico de los niños y sus influencias en el plano educacional" (Ali Jafella, 2006, p.43). La autora menciona la influencia de Herbart en filósofos de la educación norteamericana como Dewey.
} 
“1- Claridad en la presentación del contenido (etapa de demostración del objeto); 2- asociación de un contenido con otro asimilado anteriormente por el alumno (etapa de comparación); 3- sistema, por el cual el nuevo elemento es colocado dentro de un todo ordenado (etapa de generalización); 4método o aplicación a situaciones concretas de los conocimientos adquiridos (etapa de aplicación)" (Cols, 2007, p.80).

Cols (2007) considera que la difusión del trabajo de Herbart se realizó hacia fines del siglo XIX de la mano de sus seguidores, quienes serían los responsables de enfatizar el componente metodológico de la obra, llevando la estructura de los pasos formales a un extremo en el que se descontextualizaba de la teoría educativa que la sustentaba y le daba sentido. Cuestiones como éstas dan lugar a ciertas críticas que acusan a la didáctica de poseer un tinte formalista.

De la vasta propuesta pedagógica herbartiana, nos interesa focalizar la atención en al menos dos cuestiones que consideramos relevantes para este trabajo. Una de ellas se vincula al planteamiento de un método de enseñanza que en su desenvolvimiento involucraba a los tres polos del triángulo didáctico ${ }^{54}$ y que se enmarcaba en una teoría educativa mayor. La segunda cuestión se refiere al establecimiento de un método universal que pueda ser aplicado independientemente de la diversidad de estudiantes y de contenidos, es decir, a todos los sujetos y a todos los saberes (Dussel y Caruso, 1999). Cuestión que, como vimos, también es compartida por Comenio al expresar su intencionalidad de generar un método universal para enseñar todo a todos; un primer "todo" que incluía la totalidad de conocimientos disponibles en la época, y un segundo "todos" que buscaba incluir a todos los hombres que debían transitar por un proceso educativo para cultivar su humanidad.

El recorrido histórico precedente -aunque lejos de ser exhaustivopermite visualizar la ligazón existente entre los tres componentes epistemológicos -explicación, norma y utopía- de la didáctica y la pedagogía. Asimismo, esta articulación, sólo separable a los fines analíticos, es

\footnotetext{
${ }^{54}$ Dussel y Caruso (1999) sostienen que Herbart es uno de los primeros pedagogos en trabajar con los tres polos -docente, alumno y contenido- del triángulo didáctico, toda una innovación para la época, aún cuando seguía conservando para el maestro cierta centralidad, similar a la que le asignaba Comenio pensándolo como el sol.
} 
indispensable para la conformación de las disciplinas, la producción de conocimiento y la intervención en las prácticas educativas tendiente al alcance de los fines establecidos 55 .

Asimismo, otro rasgo que caracteriza a la didáctica como disciplina es su temprana asociación con la escolarización y con los problemas que ella le fue presentando. Los procesos de escolarización que las sociedades implementaron para la atención de la población generaron temas y problemas novedosos para los que progresivamente la didáctica fue ensayando respuestas. Los maestros encargados de la enseñanza a grandes masas de población demandaban un conjunto de saberes relativos a qué y cómo enseñar determinados contenidos ${ }^{56}$.

La enseñanza es una práctica social y, por tanto, una construcción humana tendiente a dar una particular respuesta a la necesidad de transmitir ciertos conocimientos en la sociedad. En este sentido, Pineau et al (2001) plantean que la escuela moderna es una invención social e histórica, como otras, contingente pero no un fenómeno inevitable ${ }^{57}$.

Diversos estudios ${ }^{58}$ inscriben el desarrollo de la enseñanza y de nuevos dispositivos para la transmisión de la cultura seleccionada en la emergencia de los Estados Nacionales. Éstos requerían formar a los ciudadanos que debían saber desenvolverse en las nuevas estructuras de gobierno y de participación ciudadana. Además, entre las primeras finalidades que orientaron a la escuela pública estuvo la formación de mano de obra para desempeñarse en las industrias que comenzaron a florecer después de la Revolución Industrial.

Pineau (1996) expone que aproximadamente entre 1880 y 1930 se produce la expansión de la escuela como fenómeno educativo hegemónico en todo el globo. La escuela se transforma en un símbolo de progreso, y a partir de

\footnotetext{
${ }^{55}$ Algunos autores que sustentan esta postura son: Gimeno Sacristán (1978); Contreras Domingo (1990); Davini (1996); Silber (1997); Feldman (2008).

${ }^{56}$ Barco (1989) y Basabe (2007) entienden la didáctica como una disciplina escolarizada.

Dussel y Caruso (1999), por su parte, analizan los planteos metodológicos herbartianos como una forma de dar respuesta a la organización de los nuevos sistemas educativos.

${ }^{57}$ En un sentido similar, Gimeno Sacristán dice "...la educación no es algo espontáneo en la naturaleza, no es mero aprendizaje natural que se nutre de los materiales culturales que nos rodean, sino una invención dirigida, una construcción humana que tiene un sentido y que lleva consigo una selección de posibilidades, de contenidos, de caminos..." (Gimeno Sacristán, 1998, p.40).

${ }^{58}$ Entre ellos podemos mencionar: Hamilton (1996); Pineau et al (2001); Dussel (2004); Cols (2007).
} 
entonces, una multiplicidad de hechos sociales son explicados como sus éxitos y como sus fracasos: el desarrollo nacional, el progreso económico, la aceptación de los sistemas o prácticas políticas, se deben fundamentalmente a lo que el sistema de educación formal hace con los grupos de población que transitan por sus aulas.

En esta vinculación con la escuela, el discurso normativo de la didáctica mantiene en el maestro su interlocutor privilegiado hasta principios del siglo $\mathrm{XX}$, cuando las pedagogías escolanovistas ponen en el centro de la escena al alumno, sus intereses, actividades y el respeto por su desarrollo. A los fines de esta tesis nos interesa destacar la articulación que se produjo en el pensamiento de diferentes autores incluidos en la corriente ${ }^{59}$ escolanovista, entre lo metodológico y la concreción de un proyecto político-educativo. Es esta condición la que nos permite sustentar su pertenencia a un amplio momento normativo en la didáctica que, como ya dijimos, se caracteriza por la convivencia de la explicación, la norma y la utopía.

Cols (2007) sostiene que esta corriente tuvo una importante producción metodológica y que los métodos se conformaban en articulación con las finalidades educativas, lo que permitía insertar lo metodológico en un proyecto educativo más amplio. Aun cuando pudieran apreciarse disparidades entre los diferentes autores al conceptualizar las finalidades que debía alcanzar la educación, ésta era una cuestión sobresaliente y que diferenciaba este posicionamiento de otros vigentes en la época. También la escuela nueva mantuvo preocupaciones vinculadas a dotar de una base científica al pensamiento pedagógico y didáctico, así como asentar los métodos y técnicas sobre los conocimientos psicológicos.

Tanto Cols (2007) como Feldman (2008) coinciden en la relevancia de los aportes metodológicos de la escuela nueva, aunque éstos quedaron opacados en una propuesta metodológica rigurosa y estructurada de la clase y son aún hoy

\footnotetext{
${ }^{59}$ Basabe (2007) considera que en el campo de la didáctica se han ido configurando distintas corrientes. Definidas éstas como entidades de variado alcance, engloban grandes teorías, teorías individuales y grupos de teorías entre las que, según la autora, se halla el movimiento de la Escuela Nueva, compartiendo algunos supuestos y preocupaciones.
} 
menos valorados por los educadores. Al hablar de la escuela nueva, muchos autores recuperan la centralidad del alumno, el desarrollo personal, el nuevo rol del docente, el valor formativo de la experiencia, entre otros aspectos.

Ali Jafella (2001), por su parte, localiza las transformaciones metodológicas llevadas a cabo por la escuela nueva en el marco de la oposición a la escuela tradicional. Las metodologías grupales de la escuela nueva se asentaban en los supuestos de actividad y libertad de los alumnos; por el contrario, la escuela tradicional era caracterizada por la memorización de los conocimientos, el enciclopedismo y el intelectualismo exacerbado.

En otro trabajo, Ali Jafella (1999) plantea la relevancia de la consigna "aprender a aprender" para la escuela nueva. Ésta propiciaba el trabajo de los estudiantes, la contemplación de sus intereses y motivaciones, el trabajo en equipos, ubicando al docente en un lugar de guía u orientador, también en oposición a la centralidad asignada al mismo por la escuela tradicional.

Carli (2002) sostiene que el movimiento de la escuela nueva tuvo impacto en nuestro país en la formación de los docentes, en el impulso de experiencias educativas y de algunas reformas parciales en el sistema educativo. La ubicación del alumno en el centro de la escena fue el punto que contrastó con los discursos normalistas positivistas de la etapa anterior y fundadores de nuestro sistema educativo. No obstante, este movimiento no logró generar una alternativa real que reemplazara al sistema educativo y se produjeron articulaciones diversas y complejas entre escolanovismo y normalismo.

Carli (2002) y Ali Jafella (2002) coinciden en que el movimiento de la escuela nueva se articuló con el sistema educativo tradicional. La pedagogía tradicional ocupaba un lugar hegemónico desde la fundación del sistema educativo, además, la democratización en términos políticos y sus correlatos educativos, que se produjo con la asunción de Hipólito Yrigoyen en 1916, aumentaba su solidez a pesar de las críticas que se le podían realizar. Posteriormente, a partir de 1960, la pedagogía tecnicista retomó aquellos aspectos de la educación criticados por la escuela nueva, en un intento de corresponderse con el desarrollismo económico. 
Asimismo, Ali Jafella (2002) sostiene que la escuela nueva no tuvo en el ámbito universitario de nuestro país a principios del siglo XX la significatividad deseada, primero por la influencia del positivismo y luego por la difusión de filosofías alemanas y francesas de cuño metafísico. Este punto podría revisarse, aunque no específicamente en esta tesis, ya que por un lado, Caruso y Dussel (2009) aluden al conocimiento y difusión de la obra de Dewey que impulsó Nelson con participación en la Universidad Nacional de La Plata; y por otro lado, Carli (2002) destaca la importancia de Rezzano como representante de la escuela activa europea en nuestro país, que se desempeñó como inspector de escuelas y docente de la Facultad de Humanidades y Ciencias de la Educación de nuestra Casa de Altos Estudios desde 192060. La "reforma Rezzano" ponía el eje en el "niño laborioso", instalando labores escolares infantiles que no tenían un sentido productivo ni tampoco utilitario, pero sí resaltaban la actividad del niño y la organización de la misma.

Para enriquecer este análisis cabe una mención a algunos estudios que apuntan a dar cuenta de la recepción que se produjo de la obra de Dewey, por ejemplo, considerado como uno de los pedagogos de la escuela nueva. Baste aquí sólo una mención a una línea de indagación que demanda más profundidad, no obstante su continuación implicaría corrernos del eje estructurante de esta tesis. Sí es rescatable la complejidad de mediaciones que se realizan de la obra de un autor en un contexto cultural diferente a aquél de producción.

Caruso y Dussel (2009) plantean, por un lado, que la obra de Dewey tuvo simpatizantes y opositores desde comienzo del siglo XX en nuestro país. Algunos adeptos fueron Nelson y Jascalevich, en la década del '10; en la década del '40, Luzuriaga contribuye a popularizar la obra de Dewey con la traducción y publicación en nuestro país de muchos de sus trabajos. Estos casos apuntaron a un conocimiento profundo de la totalidad de la obra del filósofo

\footnotetext{
${ }^{60}$ José Rezzano (1877-1960) recibió el título “Doctor Honoris Causa” en 1929, de reciente creación en el marco de la Universidad Nacional de La Plata. Se desempeñó además como Decano de la Facultad de Humanidades y Ciencias de la Educación (UNLP) entre 1931 y 1936. Tuvo por su cargo en ese período participación en el Consejo Superior de la Universidad que estaba bajo la presidencia de Ricardo Levene (Castiñeiras, 1985).
} 
norteamericano. Otras tendencias como el catolicismo, el marxismo (como Terán y Ponce) y el espiritualismo liberal, se opusieron a la obra de Dewey y a su difusión en el sistema educativo.

Por otro lado, Caruso y Dussel (2009) sostienen que se produjo una difusión parcial de la obra de Dewey en revistas destinadas a los docentes. Se difundió un Dewey pedagogo y didacta pero apolítico. Desde 1920, Revistas como La Obra o El Monitor de la Educación Común, lo difundieron como representante del escolanovismo y expusieron algunas referencias aisladas a su labor pedagógica y de reforma educativa. Pero básicamente se lo desgajó de las ideas filosóficas y políticas que sustentaban sus propuestas pedagógicas. Lo pedagógico quedaba en estos artículos como un espacio de accionar técnico que podía tener inserción en diferentes regímenes políticos.

El análisis que realizan Caruso y Dussel (2009) puede contribuir a dar sustento al esfuerzo de otros pensadores de la didáctica61 por entender la producción metodológica de la escuela nueva en coherencia con la concreción de un proyecto político-educativo más amplio.

Es interesante también, aunque para profundizar en otra oportunidad, el trabajo que realiza Finocchio (2007). La autora estudia diferentes revistas destinadas a los docentes y destaca la vinculación estrecha que se produjo en las décadas del '20 y '30 entre la Revista La Obra y la escuela nueva. Esta revista destinó editoriales y diversos artículos para la difusión de sus ideas, en oposición a la visión oficial difundida en El Monitor de la Educación Común. En 1926 La Obra adhirió a la Liga Internacional de la Nueva Educación.

A su vez, Finocchio informa que la revista contó desde sus inicios y hasta los años '60 con dos secciones destinadas a la práctica docente: "Didáctica práctica" y "La escuela en acción". A partir de 1928, Clotilde Guillén de Rezzano se hizo cargo de la supervisión de los artículos que se publicaban en la sección "Didáctica práctica".

Retomando lo ya planteado con respecto a la importancia metodológica de la escuela nueva, restaría analizar, por un lado, el impacto que estas dos

\footnotetext{
${ }^{61}$ Como por ejemplo: Cols (2007); Davini (2008); Feldman (2008).
} 
secciones recibieron de las ideas escolanovistas, y por el otro, específicamente en qué medida estas ideas influyeron en las herramientas concretas que la Revista aportaba para el trabajo diario de los docentes. A partir de lo planteado por Finocchio, sabemos que La Obra contó con un número importante de maestros suscriptores y lectores, lo que permite pensar en las altas probabilidades que tenía la revista y las líneas teóricas y prácticas en ella publicadas de impactar en el desarrollo de la enseñanza.

En correspondencia con lo planteado por Ali Jafella (2002), para Feldman (2008) en la década del '70, junto con el auge del tecnicismo y el conductismo, se reavivó la disputa "escuela nueva vs. escuela tradicional" en nuestro país. Se recuperaron $\mathrm{y}$ enfatizaron aquellos aspectos tradicionales del sistema educativo, criticados por el escolanovismo.

“[...] el auge del conductismo revivió la polémica. El conductismo ofreció una nueva tecnología para la transmisión cultural y, según muchos, para el control social. La lucha contra los mecanismos de control implicados en los dispositivos pedagógicos terminó dirigiéndose contra los métodos estructurados. De modo casi reactivo, muchos planteos didácticos cobraron un cariz más crítico y descriptivo. Las nuevas tendencias aportaron un nuevo campo de saber y nuevas maneras de mirar la educación que promovieron un gran avance pero, simultáneamente, disminuyeron su capacidad de influir de modo práctico y sistemático sobre las acciones de enseñanza; en parte, por un cierto abandono de las preocupaciones normativas y técnicas y, también, porque surgen propuestas de trabajo más complejas y sofisticadas [...]" (Feldman, 2008, pp.67-68).

En un trabajo reciente, Feldman (2010b) realiza un estudio interesante y que consideramos pertinente a los fines de nuestro recorrido por la didáctica. Analiza el intuitivismo y su articulación a lo largo de la historia con rasgos de diferentes corrientes teóricas así como con procesos de las prácticas escolares que le permitieron sobrevivir.

Para el autor, la pedagogía intuitiva ha formado parte por mucho tiempo de la pedagogía oficial y de la formación docente, logrando una pervivencia a lo largo del tiempo en el sistema educativo de nuestro país e integrándose con las condiciones particulares de cada época. Analizar la didáctica en perspectiva histórica le posibilita fundamentar "[...] una escasa coincidencia entre los rasgos dominantes de la enseñanza en nuestras escuelas y las recomendaciones de los 
promotores de la planificación científica, la administración racional, la instrucción programada o la tecnología instruccional de base sistémica [...]" (2010b, p.37).

Los trabajos de Pestalozzi y de Comenio defendían el principio intuicionista y la apreciación sensible como base del conocimiento. Estas ideas se constituyeron en pilares sobre los que se edificó la moderna escuela de masas. Así, la pedagogía intuitiva fue perviviendo a lo largo de los años en el sistema educativo argentino, aunque su desarrollo la fue alejando de su planteo original, según expone Feldman.

“[...] Pero, como suele sucederle a la base filosófica de las pedagogías con la extensión escolar de las propuestas, la enseñanza intuitiva que se expresaba en las lecciones de cosas perdió el holismo organicista de la filosofía original, que fue reemplazado por una preceptiva mecanicista [...]" (Feldman, 2010b, p.41).

Feldman (2010b) dice que Decroly y Montessori también se apoyaron en principios del asociacionismo sensualista. La influencia de la pedagogía intuitiva se hizo sentir de esta manera hasta aproximadamente la década del '60 en los curricula para la escuela primaria en nuestro país.

Para Feldman (2010b) se presentaron algunas fracturas importantes con estas concepciones intuitivistas dominantes y de pregnancia continuada en el sistema educativo. Una de las críticas al intuitivismo provino de aquellas corrientes que comenzaron a defender que el aprendizaje se producía por una búsqueda activa por parte del alumno, la solución de problemas y el ensayo de estrategias de solución para responder a las situaciones de enseñanza (Una didáctica basada en la psicología de Jean Piaget, la obra de Aebli que analizamos en el capítulo $\mathrm{V}$ de esta tesis, puede interpretarse como un ejemplo de estas oposiciones. El autor sostiene que sólo basándose en la psicología genética piagetiana es posible cuestionar el intuicionismo).

A diferencia de la opinión de Aebli con respecto a Dewey, para Feldman (2010b) el pragmatismo que impulsó este filósofo también contribuyó a reemplazar las nociones del intuitivismo por aquéllas otras de actividad, experiencia y resolución de problemas. Una concepción afín a estos planteos 
aparece ya en 1957 en los Programas para las Escuelas Primarias del Ministerio de Educación de la Provincia de Buenos Aires.

La formación de maestros en nuestro país, expone Feldman, mantuvo lazos importantes con la pedagogía tradicional, al menos hasta 1967 cuando dejó de dictarse en las Escuelas Normales y pasó a ser impartida en los Institutos Superiores de Formación Docente.

“[...] El viraje del método hacia el cajón de los medios y los recursos es ya imparable: retirado cualquier rasgo de esencialidad, el viejo método didáctico, centro de la reflexión pedagógica durante 300 años, se comienza a fundir provisoriamente en el planeamiento y conducción del aprendizaje. Las didácticas que prosperaron a partir de 1980 ya siguieron otros caminos, asociadas al definitivo triunfo de las teorías cognitivistas y el constructivismo [...]" (Feldman, 2010b, p.48) ${ }^{62}$.

En síntesis podemos decir que Feldman identifica ciertos rasgos de una pedagogía intuitiva que persisten en el tiempo, desde las propuestas de Comenio hasta las didácticas generales que circulan en nuestro país en los años '60, como el trabajo de Stöcker que el mismo autor cita. Como analizamos en el capítulo $\mathrm{V}$, también en la obra de Nérici se realizan alusiones al intuitivismo.

“[...] Uno de los productos de estos cambios consiste en la dilución de la primacía intuitivista como base pedagógico-didáctica oficial para la educación primaria. Los nuevos currículum, elaborados a partir de ese momento [1970], expresan esta tendencia que coincide con el ingreso y avance de dos corrientes competitivas entre sí: la tecnología instruccional y las pedagogías operatorias, luego denominadas constructivistas. Estas corrientes se integraron con diferentes valoraciones al discurso pedagógico de nuestro país y, no obstante las profundas diferencias que las caracterizan, coincidieron en ofrecerse a la vida pública como alternativas válidas frente a la "educación tradicional". Sin embargo, las pedagogías intuitivas probablemente continúan siendo una forma extendida de pedagogía popular. Lograron una articulación entre método y dispositivo escolar que no es tan sencillo reconstruir [...]" (Feldman, 2010b, p.52).

A partir de lo expuesto anteriormente, consideramos que el análisis de Feldman se convierte en un aporte para fundamentar la existencia de un gran primer momento normativo en la constitución de la didáctica como disciplina.

\footnotetext{
${ }^{62 “[. . .] ~ Y a ~ f i n a l i z a n d o ~ e l ~ s i g l o, ~ l a s ~ p e d a g o g i ́ a s ~ c o n s t r u c t i v i s t a s ~ y ~ l a s ~ p e d a g o g i ́ a s ~ c r i ́ t i c a s, ~ s u m a d a s ~ a ~ l a ~}$ proliferación de las "didácticas especiales", centradas en disciplinas de conocimiento, contribuyeron grandemente al definitivo desprestigio de la idea de "método". (Un abandono que todavía no dio respuesta a los problemas para los cuales los métodos fueron diseñados) [...]" (Feldman, 2002, p.74).
} 


\section{II - 2 - Didáctica y curriculum entre 1960 y 1976: la irrupción de la teoría curricular63.}

En este apartado analizamos un proceso importante en el marco de esta tesis consistente en la llegada y difusión de la teoría curricular norteamericana a la Argentina y su consecuente contacto con la didáctica. Tratamos de caracterizar, desde una perspectiva histórica, los cambios que se produjeron en la didáctica como disciplina así como también en el ámbito educativo en general, que condicionaron la incorporación de nuevos discursos teóricos y estrategias de intervención.

En los años '60, es posible identificar una crisis en el pensamiento didáctico. Díaz Barriga (1991) analiza que en toda América Latina se produjo un agotamiento de esta disciplina y de sus modelos tradicionales. Esta crisis estuvo influida por dinámicas internas y por factores externos entre los que aparecen como más relevantes los asociados a las políticas del desarrollismo y las transformaciones profundas que las mismas demandaban a nivel social y en el sistema económico y productivo, tendientes a la modernización industrial de corte capitalista.

Teniendo en cuenta el estudio de Aroskind (2003), podemos decir que entre lo que el autor denomina el derrocamiento del primer gobierno peronista en 1955 y el derrocamiento del segundo en 1976, se evidenció, a nivel mundial y en todo el arco ideológico, confianza en el progreso y en la capacidad de las políticas públicas de lograr los cambios que se necesitaban para que los países "que estaban en vías de desarrollo" alcanzaran los niveles "de desarrollo" que ya habían logrado otros.

En este contexto, la didáctica no tuvo capacidad para dar respuestas eficientes a las nuevas demandas sociales y educativas que la industrialización generó. Se sumaron, además, otros factores que apoyaron la difusión de

\footnotetext{
${ }^{63}$ La periodización de los apartados II-2, II-3 y II-4 está tomada de Palamidessi y Feldman (2003). Si bien los autores no utilizan estrictamente estas denominaciones, tomamos de ellos la periodización, el sentido y la caracterización de cada uno de ellos.

Esta periodización también es apoyada por Cols et al (2002).
} 
modelos pedagógicos provenientes de los países industrializados. Díaz Barriga (1991) menciona la tecnología educativa, el curriculum y la evaluación ${ }^{64}$ como aquellas disciplinas que resultaron más pertinentes que la didáctica para orientar el rumbo de la educación. Especialmente la tecnología educativa -que abordamos más detenidamente con Chadwick (1992) en el capítulo VI- tuvo un desarrollo importante y se convirtió en la mejor opción instrumental y científica para formar aquellos recursos humanos necesarios para la industria.

Específicamente para el caso de Argentina, Aroskind (2003) plantea que la inestabilidad institucional del período y los diversos conflictos económicos, sociales y políticos truncaron muchas veces diversos proyectos que tenían en la mira el progreso del país.

En relación con los conflictos sociales propios del período, se puede decir que desde 1955 a 1973 prosperó la acción colectiva y la exteriorización de la protesta, que, según Gordillo (2003), fue transitando de una etapa de resistencia a otra de confrontación. Fueron años definidos por la inestabilidad política y la incapacidad de generar un modelo alternativo al peronismo. Su proscripción con la "Revolución Libertadora" no hizo más que conseguir los efectos contrarios a los buscados, potenciando la identidad peronista y las prácticas de resistencia (Aroskind, 2003; Gordillo, 2003). En los años previos a la última dictadura militar, se produjeron diversas tensiones y contradicciones generadas por las dificultades para encauzar la movilización de la sociedad civil en los tradicionales moldes de la participación nacional y popular (Svampa, 2003), como planteamos en el próximo apartado.

Además, Aroskind (2003) analiza el predominio en nuestro país de una perspectiva "imitativa del progreso" en las dirigencias políticas y empresariales, basada fundamentalmente en la incorporación de conocimientos, bienes tecnológicos y de capital -que a pesar de los avances no logaron el nivel de desarrollo autóctono deseado-, y formas de vida de los países "más

\footnotetext{
${ }^{64}$ En otro trabajo, Díaz Barriga (1994) analiza la conformación de un "nuevo pensamiento pedagógico" que contiene estas tres vertientes -tecnología educativa, teoría curricular y evaluación-, con una base funcionalista, conductista y pragmatista, coherente con la consolidación de la sociedad industrial norteamericana entre 1850 y 1920.
} 
avanzados". A pesar de que se atenuaron las características intervencionistas y estatistas, para el autor, en los años comprendidos entre 1955 y 1975 se mantuvieron los rasgos básicos del modelo económico impuesto por el peronismo.

Por otro lado, como evaluación del período y tratando de pensar en procesos políticos que tuvieron efecto en el núcleo temático de esta tesis, resulta relevante lo que plantea Aroskind (2003) en relación con la capacidad real del aparato estatal de llevar adelante políticas económicas y sociales a largo plazo. Para el autor, el Estado tuvo limitaciones importantes en materia de planificación y de sostenimiento de las políticas públicas, dando como resultado políticas específicas o la transferencia de recursos que no lograron el alcance de las metas deseadas. Esta caracterización general puede ser útil para analizar el rol jugado por los cuadros de profesionales en ciencias de la educación que se desempeñaron en ámbitos gubernamentales para la implementación de políticas educativas, como postulamos en las próximas páginas.

A su vez, la Universidad pública también tuvo un impulso importante hasta el Golpe de Estado de 1966 y, específicamente, el desconocimiento de la autonomía universitaria que concluye en los acontecimientos conocidos como la "Noche de los bastones largos". El desarrollo científico y tecnológico recibió impulso con la creación de organismos estatales a finales de los años '50, como el Instituto Nacional de Tecnología Agropecuaria (INTA), el Instituto Nacional de Tecnología Industrial (INTI), la Comisión Nacional de Energía Atómica (CNEA) y el Consejo Nacional de Investigaciones Científicas y Técnicas (CONICET).

Según Aroskind (2003) estas instituciones tuvieron efectos dispares sobre la actividad económica. El INTA logró dinamizar el sector agropecuario, la CNEA produjo avances relevantes en materia de energía nuclear, y el CONICET albergó especialistas de diversas disciplinas, con reconocimiento internacional. No obstante, esta última institución no logró una articulación suficiente con la producción de bienes y servicios tanto públicos como privados. 
En términos de la vinculación entre la didáctica y el curriculum, si bien podemos hablar de características propias en cada país de América Latina, también podemos afirmar que se produjeron procesos comunes en cuanto a la difusión de la teoría curricular norteamericana. Por ejemplo, a pesar de las diferencias que existen entre Argentina y México, Furlán (1997) y Furlán y Gvirtz (1999) destacan que la teoría curricular norteamericana ha influido en ambos países desde los años '60. Estos autores analizan la publicación y difusión que tuvieron diferentes obras curriculares norteamericanas de la mano de Organismos Internacionales, especialmente de la Agencia Internacional para el Desarrollo de los Estados Unidos, que apoyaron los procesos de planificación educativa y social que proponía el desarrollismo.

Los autores destacan el desfase entre la estructura del sistema educativo en el contexto de producción y aquélla propia del contexto de recepción. Es decir, las obras curriculares norteamericanas se produjeron en el contexto de un sistema educativo altamente descentralizado; no obstante, la estructura educativa de América Latina era centralizada en aquellos años. Furlán y Gvirtz señalan que en las Universidades, considerando la autonomía de la que gozaban, hubo una apropiación de estas obras pero en el resto del sistema educativo se produjeron varias dudas y "[...] usos heteróclitos de los términos $[\ldots]^{\prime \prime}(1999$, p.4).

Estas complicadas relaciones cambiaron sus características en los años ' 80 con el ingreso de la teoría curricular inglesa de la mano de las traducciones españolas. Si bien podemos decir que en términos de sistema educativo, estos dos países anglosajones contaban con una estructura descentralizada que se reflejaba en la producción que ingresó a nuestro país, la diferencia sustancial radicaba en que en Norteamérica el eje estaba puesto en la institución y en Inglaterra el eje lo conformaba el profesor, como profundizamos más adelante.

Por su parte, en Brasil, las relaciones entre la didáctica y el curriculum corren por caminos diferentes, como informa Martins (2012). Las incumbencias de ambas disciplinas están más diferenciadas que en la Argentina ya que el campo del curriculum comenzó a delimitarse y autonomizarse de las cuestiones 
técnicas de la enseñanza y a ocuparse más exclusivamente de los contenidos, su selección y organización curricular a partir de la década de 1970. Barbosa Moreira (1999) aporta una periodización complementaria cuando dice que para el caso brasilero se visualiza un tecnicismo prevaleciente en la didáctica y el curriculum en el régimen autoritario posterior a 1964, seguido de una renovación temática en la década de 1980 en donde influyeron -entre otras- la sociología del curriculum (renovación que también se produjo en nuestro país).

Vinculado a lo planteado por Díaz Barriga (1991), Furlán y Gvirtz (1999) destacan otro elemento que enriquece el análisis: aluden a la influencia de la tradición francesa en la Argentina que durante los años '60 contribuyó a cambiar la denominación de "pedagogía" por la de "ciencias de la educación" .65

Esta influencia se hace sentir en la Universidad Nacional de La Plata, donde la formación de Profesores en Pedagogía y Ciencias Afines data de principios del siglo XX, con Víctor Mercante y Joaquín V. González. La Sección Pedagógica primero en la Facultad de Ciencias Jurídicas y Sociales entre 1906 y 1914, la Facultad de Ciencias de la Educación entre 1914 y 1920, así como también la Facultad de Humanidades y Ciencias de la Educación a partir de 1920, emitían el título de "Profesor en Pedagogía y Ciencias Afines". A partir de 1930 la carrera se denominó "Profesorado en Filosofía y Ciencias de la Educación". El plan de estudios de 1953 otorgaba el título de "Profesor o licenciado en Pedagogía". No obstante, en 1959, siendo Ricardo Nassif director del Departamento de Ciencias de la Educación, se creó la carrera de Profesorado en Ciencias de la Educación. Luego, en 1969, el plan de estudio que le siguió ofreció los títulos de Profesor y Licenciado en Ciencias de la Educación, denominaciones que se mantienen hasta la actualidad (Southwell, 2003).

Por su parte, en 1958 se creó la carrera de Ciencias de la Educación en la Facultad de Filosofía y Letras de la Universidad de Buenos Aires, en reemplazo

\footnotetext{
${ }^{65}$ Complementariamente, podríamos mencionar que Schwartz (2000) analiza algunos cambios en la didáctica en el marco de la hegemonía del positivismo. La autora dice que el quehacer didáctico va perdiendo su apoyo en la filosofía de la educación y en la pedagogía, y son las ciencias de la educación, especialmente la psicología y la epistemología, las que lo sustentan.
} 
de la carrera de Pedagogía, de corte más filosófico y generalista. Este cambio de denominación y de orientación en la carrera contribuyó a la formación de profesionales especializados que se desempeñaron, al menos muchos de ellos, en las oficinas nacionales de planificación que llevaba adelante el Estado desarrollista (Palamidessi y Feldman, 2003; Feeney, 2007; Suasnábar y Palamidessi, 2007) ${ }^{66}$.

Con respecto al desarrollismo, Suasnábar (2004) analiza diferentes facetas de este proceso que marcó la política de los países latinoamericanos y, especialmente, de la Argentina entre 1955 y 1970. El autor plantea que el desarrollismo, como el nombre que se le asignó a las ideas y propuestas de la Comisión Económica para América Latina (CEPAL), aunó concepciones y sujetos diversos en su implementación. En materia de política educativa, articuló ideas sobre el planeamiento educativo, las teorías del capital humano y la formación de recursos humanos, que tuvieron una disímil difusión.

A pesar de estas diferencias, las propuestas de la CEPAL apuntaban a encaminar a los países de la periferia hacia el desarrollo, generando condiciones para entrar en un proceso de industrialización, donde el Estado asumía un rol protagónico. Pero estas propuestas fueron encontrando diferentes realidades latinoamericanas con las que tuvieron que articular en su implementación dando lugar, siguiendo a Suasnábar, a un espacio amplio de posiciones aun en el marco institucional de la CEPAL. Para el autor, se contribuyó de esta manera a la conformación de un pensamiento latinoamericano a finales de los años '60 y principios de los '70.

\footnotetext{
${ }^{66}$ Furlán (1997) habla de un proceso de pedagogización de las Universidades mejicanas. Consideramos que esto nos permite ver, como venimos desarrollando, algunos puntos de contacto entre diferentes países de América Latina en cuanto a la implantación del modelo desarrollista así como también a la difusión de la teoría curricular norteamericana.

A su vez, Furlán dice que el desarrollismo trajo consigo la generación de oficinas gubernamentales, un impulso de la planificación y proyectos de reforma educativa a nivel nacional; así como también la modificación de la orientación profesionalizante que tenían las universidades latinoamericanas y la introducción de la organización por departamentos.

Avolio (en Furlán y Avolio, 2011), por su parte, informa que el cambio de denominación -de pedagogía a ciencias de la educación- de la carrera, implicó la priorización de la formación científica y el inicio de la conformación de teorías como sociología de la educación, psicología de la educación, etc. La formación filosófica que caracterizaba a la vieja carrera de pedagogía, pasó a un segundo plano en los nuevos planes de estudio.
} 
Específicamente en lo que respecta al planeamiento educativo, Suasnábar señala que si bien se puede identificar en 1958 el año fundacional de la propuesta conocida como "planeamiento integral de la educación", a partir de una reunión sustanciada en Washington y organizada por la Organización de Estados Americanos (OEA) y la Organización de las Naciones Unidas para la Educación, la Ciencia y la Cultura (UNESCO), las tendencias sobre el planeamiento educativo se venían desarrollando en los países centrales desde la segunda posguerra. El aumento de la demanda por educación y la expansión de los sistemas educativos requerían planificación y racionalización del proceso que, a su vez, pusiera en sintonía la educación con el desarrollo capitalista.

Suasnábar informa que estos organismos internacionales organizaron diferentes cursos y seminarios para América Latina en los que tuvieron ocasión de participar diferentes sujetos que posteriormente integrarían las instancias nacionales de planificación. Para el caso argentino, "[...] el Consejo Nacional de Desarrollo (CONADE) en 1961 durante el gobierno de Frondizi no sólo marcaría el momento de cristalización a nivel estatal de la estrategia del planeamiento sino también el desarrollismo en su vertiente político-educativa [...]" (2004, p.39) ${ }^{67}$.

Desde otra perspectiva de análisis, Zoppi y Aguerrondo (1991) estudian el clima de reformas educativas en la Argentina desde principios de los años '60, en el que posteriormente impactó la tradición curricular norteamericana, coincidente en líneas generales con lo ya expuesto para América Latina. Se proponía, entre otras cuestiones: la descentralización del sistema educativo; la transferencia de las escuelas primarias de la nación a las provincias y la creación del Consejo Federal de Cultura y Educación. Este impulso de reformas contó también, como mencionamos previamente, con el trabajo de diferentes profesionales que brindaban su asesoramiento científico.

\footnotetext{
${ }^{67}$ Avolio (en Furlán y Avolio, 2011) brinda una opinión coincidente en este punto cuando informa que egresó como Licenciada en Ciencias de la Educación en 1961 y dice que en esos años se comenzaba a conocer la teoría curricular, no se pensaba mucho en el asesoramiento institucional y ya tenían mucha influencia la OEA y los organismos de planeamiento educativo creados en los ámbitos ministeriales. La OEA, dice la autora, dictaba un curso sobre planeamiento educativo en Chile que fue realizado por algunos de sus colegas en aquellos años.
} 
Entre 1968 y 1971 tuvo lugar la "Reforma Educativa"68 impulsada por el gobierno militar de Onganía. A pesar de su fracaso y de su derogación al final del gobierno de facto, el discurso pedagógico-didáctico relativo a la teoría curricular, a la formulación de objetivos operacionales a partir de las taxonomías y la teoría de la evaluación, se lograba instalar.

Para Palamidessi y Feldman (2003) estas cuestiones se convirtieron en el discurso técnico-pedagógico oficial, lo que contribuyó a su instalación. A su vez, reafirmando lo ya mencionado, para estos autores, aquel nuevo grupo profesional, egresado de la Universidad, comenzó a ocupar posiciones en los ámbitos nacionales y provinciales de diseño del curriculum, desplazando a los directores y docentes que se desempeñaban previamente ${ }^{69}$.

De la mencionada "Reforma Educativa" pervivieron también los cambios relativos a la formación docente. Southwell (1995) analiza estas transformaciones e informa que esta preparación especial pasó del nivel secundario al terciario o superior no universitario en 1967, quedando a cargo de los Institutos Superiores de Formación Docente. El plan de estudios retomaba los dos últimos años de la escuela media y agregaba otros tres en los Institutos Superiores.

La autora destaca otros aspectos con respecto a la reforma de la formación docente que cobran interés para esta tesis. Uno de ellos se refiere a la introducción del término "curriculum", que comenzaba a reemplazar a denominaciones previas como las de programa y plan de estudios. El otro aspecto se refiere a la concepción tecnicista que empezaba a afianzarse en esos años y que ubicaba al docente en un lugar de especialista dedicado a la transmisión de contenidos. Se produjo una articulación compleja entre la

\footnotetext{
${ }^{68}$ Esta Reforma impulsada por el gobierno militar de Onganía, intentó recuperar una reforma previa en el sistema educativo, a saber, la Reforma Saavedra Lamas ingeniada por Mercante entre 1916 y 1917, en la que se buscaba implantar la escuela intermedia (de 11 a 14 años), entre la primaria y la secundaria. Por la oposición de la mayor parte de la opinión pública y de los maestros y profesores, el proyecto fue abandonado cuando cayó el gobierno de Onganía. (Zoppi y Aguerrondo, 1999; Palamidessi y Feldman, 2003).

${ }^{69}$ Zoppi y Aguerrondo (1991) plantean que estas reformas educativas y la implantación del diseño del curriculum como práctica para el mejoramiento de la educación en la década del ' 70 ha estado a cargo generalmente de docentes reconocidos por su trayectoria profesional. La diferencia que visualizamos entre los autores podría deberse a un período de transición en la constitución profesional del campo, entre los maestros y los nuevos egresados de las carreras universitarias de educación.
} 
perspectiva espiritualista que influyó desde principios del siglo $X X$ en la conformación del sistema educativo argentino y el paradigma tecnocratista emergente a finales de los años '60 con asignaturas como evaluación, planificación del curriculum, tecnología educativa, etc.

Asimismo, Southwell (1995) analiza que la concepción de maestro que se instalaba desde el modelo desarrollista coincidía con la de un "práctico idóneo". El docente quedaba en este esquema del lado del sujeto que aplicaba las decisiones curriculares y normativas emanadas de los expertos o especialistas que se ubicaban en un lugar externo al curriculum.

Los maestros en preparación se convirtieron, a su vez, en un público consumidor de literatura curricular junto con los futuros profesores estudiaban en las Universidades, donde se mantenía una formación de corte científicopositivo.

Encontramos así dos tensiones en las que se filtró -con distintos niveles de protagonismo- la teoría curricular: por un lado, el paso al nivel superior no universitario de la formación docente que se oponía a la educación normalista previa; por el otro; los textos curriculares que buscaron reemplazar a los manuales de didáctica general que se leían en las Escuelas Normales.

Según explican Zoppi y Aguerrondo (1991), la educación hasta los años '60 presentaba un carácter formalista, memorístico, verbalista y enciclopedista. A medida que avanzaba la década, en los planes y programas del nivel primario que elaboraron las jurisdicciones provinciales fueron apareciendo elementos renovados en los que se puede apreciar, según analizan las autoras, la influencia de la escuela nueva con autores como Dewey, Decroly y Montessori.

En este contexto de reformas y renovaciones pedagógicas es en el que impactaron las teorías curriculares, aunque para las autoras:

“[...] el modelo didáctico propuesto no varió demasiado en relación con los anteriores programas o planes de estudio escolares: la propuesta siguió centrada en los contenidos informativos organizados en unidades temáticas determinadas para cada grado, con la única evidente novedad de incorporar exhaustivas listas de actividades para su desarrollo" (Zoppi y Aguerrondo, 1991, p.71). 
A partir de lo expuesto podemos analizar el ingreso de la teoría curricular norteamericana de la mano de distintas publicaciones. Estos trabajos, además de sistematizar una postura con respecto al curriculum, ofrecieron aspectos instrumentales que ejercieron influencia en la política educativa de nuestro país. Recordamos aquí lo expuesto con respecto al ingreso en los ámbitos nacionales y provinciales de diseño curricular de los profesionales formados con la bibliografía curricular.

En este clima de reformas y a los fines de esta tesis, resulta relevante analizar cómo queda configurada la didáctica general. Díaz Barriga (1994) arriesga que se produjo la conformación de "una nueva didáctica", influida por la teoría curricular, la tecnología educativa y la evaluación; un trípode -como mencionamos- esencial del pensamiento educativo norteamericano que acompañó el proceso de industrialización de la sociedad desde finales del siglo XIX. La "antigua didáctica" de reminiscencias idealistas, como la denomina el autor, fue reemplazada por nuevos principios eficientistas propios de este movimiento educativo.

Estas tres vertientes teóricas del pensamiento pedagógico norteamericano habían acompañado a la transformación de la escuela para responder a las necesidades de una sociedad industrializada en pleno auge. La búsqueda de la eficiencia en el sentido de lograr que la educación respondiera a las necesidades sociales, económicas y políticas acompañaba la producción del conocimiento disciplinar.

Asimismo, en estas concepciones educativas confluye el trabajo de Taylor titulado "Scientific Management in Education" de 1913 que, para Díaz Barriga, es un punto nodal al momento de "[...] rastrear los fundamentos de la elaboración curricular [...]" (1994, p.19).

Contextualizando el estudio en nuestro país, en lo que respecta al campo pedagógico -en términos amplios- podemos decir que la teoría curricular norteamericana impactó en procesos y dinámicas teóricas que se venían desarrollando. 
“[...] esta difusión e importación de literatura curricular se produce en medio de un intenso proceso de renovación del pensamiento pedagógicodidáctico argentino: los replanteos vinculados con la obra de Jean Piaget, la modernización del currículo para la enseñanza de las ciencias que realiza el Instituto Nacional para el Mejoramiento de la Enseñanza de las Ciencias (INEC), la propuesta de áreas curriculares integradas, los debates sobre los métodos globales de enseñanza, la introducción de la matemática moderna y la gramática estructural, la educación no diferenciada por género, el cuestionamiento de la tradición nacionalista y patriótica [...]" (Feeney, 2007, pp.178-179) $)^{70}$.

Para sintetizar, podemos afirmar que la apropiación de la teoría curricular norteamericana se produjo en el marco de un movimiento mayor de reformas que cuestionaban las tradiciones pedagógicas vigentes en la Argentina hasta los años '60.

Con respecto a los trabajos sobre curriculum que se difundieron en nuestro país, podemos mencionar a los siguientes autores: Tyler, Taba, Bloom, Schwab, Doll, Johnson. Analizamos algunas de estas obras en los capítulos VI y VIII de esta tesis.

Feeney (2001) y Palamidessi y Feldman (2003) informan que éstos y otros trabajos sobre curriculum fueron traducidos por editoriales como Kapelusz, Troquel, Marymar, El Ateneo, Paidós y Losada desde mediados de los años '60. Esto obviamente favoreció la circulación y lectura de estos autores en los espacios institucionales de formación de maestros y profesores.

A su vez, en nuestro país se publicaron trabajos sobre curriculum a partir de 1971. Los autores citados mencionan las siguientes obras como las primeras publicadas en el país:

$\checkmark$ COMBETTA, Oscar. (1971). Planeamiento curricular. Buenos Aires: Losada.

$\checkmark$ SARUBBI, María Irma Rosa de. (1971). Curriculum. Objetivos, contenidos, unidades. Buenos Aires: Stella ${ }^{71}$.

$\checkmark$ GALACHO, Horacio Roberto. (1973). Planeamiento escolar: fundamentos y técnicas para la elaboración de planes por el maestro. Buenos Aires: Kapelusz.

$\checkmark \quad$ AVOLIO, Susana. (1975). La tarea docente. Buenos Aires: Marymar.

\footnotetext{
${ }^{70}$ Estas referencias también figuran en: Palamidessi y Feldman (2003).

${ }^{71}$ Feeney (2007) analiza las dos primeras obras sobre curriculum que se publican en la Argentina en 1971.
} 
Considerando el impacto que la teoría curricular produjo en la didáctica, Palamidessi y Feldman (2003) hacen un análisis de los principales ejes que, desde su perspectiva, caracterizaron estos primeros trabajos nacionales sobre curriculum. Comentamos estos aspectos aquí a los fines de cumplir con lo que nos propusimos para este capítulo y los retomamos críticamente en el capítulo VII de esta tesis.

Para estos autores, los primeros textos nacionales sobre curriculum se caracterizaron, principalmente, por poseer tres ejes estructurantes. El primero de ellos se conformaba con la concepción misma de curriculum. Por oposición al "programa" y "plan de estudios", que se estructuraban en torno a la materia que se enseñaba, el curriculum estaba pensado como un plan integral que organizaba la vida en la escuela ${ }^{72}$. En consonancia con lo planteado por Tyler, estas obras exponían que el curriculum expresaba una metodología racional y sistemática para la planificación de las experiencias educativas.

El segundo eje se refería a la división del trabajo pedagógico. De esta manera, se encontraban los expertos que se ocupaban del diseño y de la fundamentación científica del curriculum y, por otro lado, los docentes encargados de la concreción del curriculum en el aula.

En tercer lugar y como expusimos previamente, la teoría curricular que arribó a nuestro país acompañó un discurso de modernización. La teoría y el diseño del curriculum apuntaban a cambiar la educación para adecuarse a las nuevas demandas de la sociedad.

Por otra parte, Palamidessi y Feldman (2003) sostienen que la recepción de la teoría curricular norteamericana se realizó diferencialmente. Para ellos es posible configurar dos grandes grupos: uno que tomó favorablemente la teoría curricular y, básicamente, el esquema tyleriano prioritario en ella. Se trataba de

\footnotetext{
72 "[...] En una publicación destinada a docentes de educación básica "Dialoguemos acerca del cambio educativo" se encuentra: "....Antes: programas (...'organizados por materias, no introducen al alumno en la realdad sociológica, no favorecen la creatividad no los trabajos grupales que apunten a los intereses de los alumnos'); ahora: curriculum ('...conjunto de actividades que desarrolla el alumno que además de contenidos tiene objetivos, actividades, experiencias, recursos, equilibrio entre humanidades y ciencias, integración en áreas, control y ajuste permanentes...')" [...]" (Boletín "El docente frente al cambio", Ministerio de Educación de la Provincia de Buenos Aires, 1970; citado en Southwell, 1995, p.12. El subrayado figura en cursiva en la edición consultada).
} 
trabajos que intentaban hacer coincidir las nuevas lecturas curriculares con la estructura del sistema educativo argentino. Otro grupo tomó distancia y cuestionó el esquema tyleriano; realizó asimismo un análisis crítico de la escuela, el rol de los docentes, la metodología de la enseñanza, el contenido, etc. Este grupo estaba integrado principalmente por profesores de la Universidad de Córdoba ${ }^{73}$.

A su vez, para Zoppi y Aguerrondo (1991) el análisis de la producción curricular arroja la convergencia de dos tradiciones: una de ellas era la que defendía la idea del curriculum como plan de formación, con un sustrato técnico en su formulación y que fue la que logró finalmente imponerse en nuestro medio a lo largo de la década de 1970; la segunda era la que entendía el curriculum como un proyecto que se construía sobre la marcha a partir de la participación de todos los sujetos involucrados y que se asentaba en los supuestos de la escuela nueva.

Recordamos que previamente aludimos a la reactivación en esta década de las disputas entre la escuela tradicional y la escuela nueva. Asimismo, el triunfo de una concepción más técnica de curriculum puede ayudar a explicar por qué la obra de Schwab ingresa con la de otros colegas norteamericanos (El Ateneo traduce su trabajo más conocido sobre curriculum en 1974), pero se populariza años más tarde.

Según señalan Zoppi y Aguerrondo (1991) la vertiente curricular más técnica fue la que le dio el marco a la formación de diferentes profesionales en nuestro país y, a su vez, ayudó a entender la planificación del curriculum como la de "paquetes curriculares".

“[...] Estos paquetes son planes totalmente estructurados que indican, prescriben, los caminos didácticos para el logro de los objetivos. Los caminos están propuestos en el mismo proyecto: están todas las indicaciones dadas, desde las preguntas o consignas que tiene que formular

\footnotetext{
73 “[...] Este grupo, constituido por Eduardo Remedi, Alfredo Furlán, Gloria Edelstein, Susana Barco y Azucena Rodríguez, desarrolla una visión crítica de los procesos educativos articulando la reflexión pedagógica con perspectivas sociológicas, antropológicas e históricas [...]" (Palamidessi y Feldman, 2003, p.17. La numeración de las páginas se corresponde con la versión mimeografiada y traducida del artículo citado).

Retomamos estas cuestiones en el capítulo VII de la presente tesis al analizar las obras de Edelstein y Rodríguez (1974); Avolio (1975); y Barco (1975).
} 
el docente, el modo en que tiene que organizar los grupos, el tipo de material que tiene que presentar (cuestionarios, películas, etc.). Todo eso se elabora y se compra en esos "paquetes" que son «los proyectos educativos armados para el logro de determinados objetivos».

La mayoría de los documentos curriculares que se gestaron en nuestra realidad a partir de 1970 responden a este último modelo. Son "paquetes" armados que señalan por lo general objetivos y contenidos para cada grado, incluyendo una cantidad de actividades sugeridas [...]" (Zoppi y Aguerrondo, 1991, p.73).

Esta propuesta de carácter técnico en el campo del curriculum no logró, tal como explican las autoras, impactar en el mejoramiento de las prácticas educativas según sus propósitos iniciales. Además, por la influencia que dicha propuesta curricular ha tenido en profesionales del campo de la didáctica general, podemos decir que esta última disciplina también adoptó el mismo carácter técnico.

Las autoras sostienen que para explicar este fracaso hay que apelar a la pluricausalidad. No obstante, plantean que se puede arriesgar que una causa importante del fracaso del curriculum-documento -como lo llaman- para mejorar la educación podría vincularse a la convivencia -no siempre bien resuelta- de un marco conceptual-referencial de corte filosófico-pedagógico universal y de componentes didácticos (a saber, objetivos, contenidos, experiencias, evaluación, etc.) de carácter específico y surgidos en el marco de la tecnología educativa.

A su vez, la incorporación de contenidos a los nuevos curricula se realizó al margen de las "estructuras conceptuales". Este proceso impidió enmarcar cada contenido en los supuestos desde los cuales se pensaban los procesos de enseñanza y de aprendizaje. Estas cuestiones resultaban sustanciales para el mejoramiento de la educación (Zoppi y Aguerrondo, 1991, p.80).

En tercer lugar, la concepción de curriculum-documento también dificultaba la producción de cambios y mejoras reales en las prácticas educativas.

Según sostienen estas autoras, se configuró en este escenario un lugar para el docente, que adoptaba características similares en la escuela nueva y en la escuela tradicional. Si bien presentaban características diferentes, como 
sabemos, en torno al curriculum, estas dos vertientes terminaron demarcando un lugar de pasividad para el docente, en el que perdió su necesaria participación y capacidad de decisión como sujeto en la interacción en el triángulo didáctico.

La difusión de las ideas escolanovistas colocó al docente al servicio de los deseos y necesidades del alumno. Según entendemos, quedó relegada la capacidad profesional del maestro para diseñar y llevar a la práctica la enseñanza. Por su parte, para la escuela tradicional, el docente quedó también en un lugar de pasividad frente a las propuestas curriculares diseñadas por otros, que le llegaban para que las implementara.

Acompañando esta concepción triunfante en la década del '70, del curriculum-documento, apareció la idea de mayor racionalización de los procesos de enseñanza y de aprendizaje así como los de planificación de las instituciones educativas. Furlán (1997) expone algunos datos de su trayectoria que ejemplifican este proceso en nuestro país, aunque aclara que también es propio de México. El autor cita una jornada de trabajo realizada por profesores de la Universidad Nacional de La Pampa a fines de 1974 y principios de 1975, cuando todavía la institución no estaba intervenida por el Gobierno de Isabel Martínez de Perón. La jornada de capacitación docente desarrollada en la Facultad de Ciencias Exactas de la mencionada Universidad tenía el propósito de acompañar un proceso de revisión académica que buscaba una mayor racionalización de los objetivos y de las estrategias así como también responder desde la institución a las nuevas necesidades formativas que presentaba la sociedad. En este contexto, el curriculum se presentaba como el campo disciplinar y profesional que más elementos aportaba para responder a las demandas de la práctica.

Por su parte, Cols (2000a) analiza cómo se va complejizando la noción del concepto de "enseñanza" a lo largo de los años y expresa algunos sentidos convergentes con las cuestiones que estamos desarrollando. En primer lugar, 
plantea la visión del docente como técnico ${ }^{74}$ que se fue instalando progresivamente y que se sustentaba en tres vertientes: la profesionalización de la docencia, la adquisición de un carácter científico para la misma y el logro de la eficacia de la enseñanza.

En segundo lugar y como un aspecto pertinente para esta tesis, Cols plantea que el conocimiento acerca de la enseñanza fue perdiendo su carácter normativo, propio de la pedagogía y la didáctica, y fue ganando en neutralidad y objetividad. En este sentido, en la década del '70 se fue imponiendo una perspectiva metateórica técnica, en términos de Kemmis (1993) ${ }^{75}$, que entendía que la enseñanza era un problema técnico y que, por tanto, se resolvía buscando los mejores medios para alcanzar los objetivos previamente estipulados por fuera del sistema educativo o de manera a priori.

Sintetizando algunos rasgos centrales de este período, consideramos que es de destacar que se fue acentuando el carácter técnico de la intervención tanto en el campo de la didáctica como del curriculum. La teoría curricular norteamericana, con las características que expusimos, impactó en la producción didáctica sesgando sus rasgos en el mismo sentido. La didáctica, en parte porque los profesionales que a ella pertenecían recepcionaron el curriculum, fue adquiriendo algunos matices novedosos, como por ejemplo: el rol del docente como técnico, el alcance eficaz de los objetivos establecidos, una mayor racionalización en la planificación de la enseñanza y del curriculum.

\footnotetext{
${ }^{74}$ En los análisis de la tradición técnica de formación docente realizados por Pérez Gómez (1993b) y Davini (1995), encontramos que el maestro se convirtió en un técnico que solamente debía poner en juego las estrategias o métodos didácticos pensados por otros y -tal vez- a prueba de él en tanto se restringían las posibilidades de resignificación y recontextualización de dichas propuestas.

${ }^{75}$ Kemmis (1993) específicamente habla de tres perspectivas metateóricas que permiten comprender la teorización curricular, a saber, técnica, práctica y crítica.

También autores como Salinas (1997) y Grundy (1994) conceptualizan racionalidades, como lo hace el primer autor citado retomando a Giroux; o perspectivas conceptualizadas sobre la base de la asociación conocimiento-interés que realiza Habermas, como es el caso de la segunda autora citada.

Cabe destacar que en todos los casos, se trabaja con tres perspectivas que se constituyen sobre la base de una serie de supuestos epistemológicos que condicionan la producción de teorías y prácticas curriculares.
} 
Se fue gestando así una didáctica tecnicista como lo expresan diferentes autores $^{76}$ que estudian la historia de la didáctica, o una "didáctica preceptiva" como expresa Camilloni (2007d).

\section{II - 3 - Didáctica y curriculum: sus relaciones durante la última dictadura militar (1976-1983).}

Siguiendo a Puiggrós (1998), podemos afirmar que la represión dictatorial, el desastre económico-social y la política neoliberal fueron los tres flagelos que golpearon a la educación a partir del golpe militar del 24 de marzo de 1976. Para la autora, la combinación de estos factores puso a la educación pública frente a su crisis más grave de la historia, profundizando problemas endémicos, como la deserción y la repitencia escolar, y provocando la reaparición de problemas educativos casi superados, como el analfabetismo.

Tal como dice Puiggrós (1998), la educación fue considerada por la dictadura autodenominada "Proceso de Reorganización Nacional" como la arena que había dado lugar al florecimiento de la "subversión". Por tanto, se pensó en una articulación clave entre las propuestas educativas, la política económico-social y la brutal represión llevada a cabo.

La dictadura construyó un enemigo muy amplio y ambiguo que se encarnaba en los grupos de izquierda, en las movilizaciones sindicales, en las proclamas políticas, en las ideas universitarias, en la guerrilla, en artistas y escritores, y en todo accionar que de una $u$ otra manera no se ajustaba a lo que se consideraba "la doctrina de seguridad nacional" que se intentaba imponer (Vezzetti, 2002; Novaro y Palermo, 2003).

Sin embargo para otros autores, como por ejemplo Tedesco (1983), el espacio educativo evidenció una relativa autonomía de las relaciones de fuerza que se manifestaban en otros espacios sociales y las propuestas en este ámbito

\footnotetext{
${ }^{76}$ Camilloni (1996); Davini (1996; 2008); Cols (2003b).
} 
no fueron homogéneas en parte por la movilidad que sufrió la conducción del Ministerio de Educación entre 1976 y 1982.

Uno de los puntos de partida del autor se vinculó al reconocimiento del carácter explícito que siempre tuvo en la Argentina el debate ideológico. Esto le permitió analizar que para las teorías reproductivistas la educación se conformaba como un aparato ideológico del Estado y contribuía a la reproducción y dominación de la sociedad, mientras que para los sectores más conservadores la escuela se transformaba en una agencia subversiva.

Otro supuesto que guía el análisis de Tedesco se refiere a la mediación que existe entre el texto pedagógico y curricular y a la real transformación de la práctica educativa a partir de él y sus prescripciones. De esta manera, es necesario prestar atención a las mediaciones que ejerce la estructura burocrática del sistema educativo y a los diferentes sujetos que desde su marco conceptualreferencial y desde su lugar en la estructura social van tamizando las propuestas curriculares en su implementación práctica.

Bruera, Catalán, Llerena Amadeo, Burundarena y Licciardo fueron los cinco ministros de educación del período dictatorial. Con respecto a las propuestas educativas de aquellos años, Tedesco plantea que a pesar de los diferentes ministros de educación se puede decir que todos compartían la concepción de lo reactivo y de la necesidad de implantación del orden. No obstante, también existieron matices: mientras para Bruera la instalación del orden era un paso necesario para el posterior desarrollo de la creatividad y la participación, valores contrapuestos a las propuestas económicas y sociales que buscaban limitar la participación a las reglas del libre mercado; para Llerena Amadeo el orden se transformaba en un fin en sí mismo; se buscaba ampliar la responsabilidad de la familia y de la iglesia católica en la formación de los sujetos, más en consonancia con el repliegue del Estado que también se proponía para otras esferas de la sociedad.

"[...] las sucesivas administraciones de la dictadura militar en el área de educación coincidieron en las líneas básicas: restablecer el orden como condición previa para una libertad individual coherente con el liberalismo económico y el auge de la patria financiera; subsidiariedad del Estado y estímulo a la iniciativa privada como metas a las cuales se llegaría después 
de un período de fuerte monopolio ideológico y político-estatal; transferencia de las instituciones educativas; represión en la comunidad educativa y restauración de los valores religiosos y políticos occidentales y tradicionales [...]" (Puiggrós, 1998, pp.130-131. La cursiva figura en la edición consultada).

Otra característica de la constitución y del funcionamiento del sistema educativo durante los años que van de 1976 a 1982 se refiere a la descentralización. Sabemos que el proceso de descentralización es prolongado y comenzó en los años '60 con la delegación del Estado Nacional a las Provincias de la responsabilidad por la provisión del servicio educativo y la ampliación de la oferta educativa privada, y que encontró en la Ley de Transferencia No 24.049 sancionada en 1992, una instalación oficial y ampliada en todo el sistema educativo (Tiramonti, 2010).

Durante el período dictatorial, según Puiggrós (1998), la descentralización educativa de las escuelas primarias a las provincias y a las municipalidades se realizó sin los fondos necesarios para su mantenimiento, habilitando un claro proceso de privatización de la educación. Consideramos que esta tensión entre lo público y lo privado en materia educativa representa un eje de análisis interesante para estudiar la educación y el curriculum en los últimos 50 años de la historia argentina.

Si bien Tedesco (1983) reconoce que en el momento de la publicación de la obra que estamos consultando no se contaba con estudios precisos, los datos disponibles le permitieron afirmar que las acciones de descentralización en el período dictatorial estuvieron sustentadas en postulados autoritarios que favorecieron la adecuación de las propuestas educativas a las posibilidades de cada sector social, más que el aumento de su real participación en la definición curricular como podía (y puede) plantear otra corriente en defensa de la descentralización educativa.

Ya Tedesco vislumbraba una tensión entre lo nacional y lo particular que, sostenemos, sigue recorriendo el curriculum y no ha alcanzado aún una resolución desde la teorización actual. Como él mismo expresaba: "La transferencia de escuelas a las provincias y la descentralización curricular en su 
conjunto siempre contiene un riesgo significativo desde el punto de vista de la función de la escuela en torno al objetivo de la unidad nacional [...]" (1983, p.55).

En este sentido, la elaboración de Contenidos Mínimos por parte del Consejo Federal de Cultura y Educación en 1976 puede interpretarse como un intento de resolución de aquella tensión, definiendo algunos lineamientos comunes para todas las jurisdicciones. Éstas comenzaron a partir de aquí diferentes procesos de reforma curricular ${ }^{77}$.

A los fines de brindar una caracterización general y sin abundar en detalles que exceden los objetivos de esta tesis, podemos decir que el análisis realizado por Tedesco (1983) le permite afirmar que las reformas curriculares de la dictadura fracturan líneas clásicas dentro del sistema educativo argentino. En este sentido, estudió algunos documentos curriculares nacionales publicados entre 1961 y 1977 y encontró la exacerbación de los valores ético-religiosos, el énfasis en la familia como núcleo educativo primario, la desaparición del fomento de valores democráticos, etc.

Asimismo, Tedesco (1983) informa que la deserción escolar se convirtió en una temática que evidenció cierta preocupación en el período dictatorial. No obstante, según el estudio realizado por el autor, se manejaron diferentes porcentajes para dar cuenta del nivel real de deserción, producto de la utilización de diferentes metodologías; se propusieron además distintas estrategias de solución como parte de la política educativa aunque no se realizó una evaluación sólida de sus efectos reales en el abordaje del problema.

En el momento de pensar el curriculum desde una perspectiva teórica, podemos decir que aparece un desafío que enfrenta este "objeto importado" con novedosas condiciones en comparación con aquéllas que lo vieron nacer en el sistema educativo norteamericano.

Zoppi y Aguerrondo (1991) sostienen que estos cambios en materia de planificación curricular no dieron los resultados esperados en lo que se refiere a las adecuaciones y adaptaciones regionales, y se terminó por convalidar la

\footnotetext{
${ }^{77}$ Al respecto se puede consultar: Tedesco (1983); Zoppi y Aguerrondo (1991); Palamidessi y Feldman (2003).
} 
propuesta que tenía vigencia hasta el momento. Tedesco, por su parte, considera que al final del período se habría producido un deterioro en la calidad de los aprendizajes y "[...] un agudo proceso de profundización de la segmentación interna de la escolaridad básica [...]" (1983, p.59).

En lo que respecta a la escuela media, este autor también realiza un estudio de las modificaciones que se produjeron (o que se intentaron implantar) tanto a nivel de los contenidos como de la estructura curricular. Sostiene que la reforma de los contenidos en el nivel medio durante la dictadura tuvo características autoritarias y se revalorizó la formación general con saberes preindustriales, dejando por fuera todo lo que tuviera relación con el mundo del trabajo (aun cuando en las primeras gestiones de Bruera y Catalán se dio un lugar no muy extendido a un bachillerato laboral; y en la corta gestión de Burundarena se valorizaron las vinculaciones con el aparato productivo). Por otra parte, se volvió a impulsar la organización del curriculum de la escuela media por materias. Estas modificaciones se realizaron en un clima que pretendía en primera instancia instalar el orden, los signos visibles del disciplinamiento (rígidas normas extensibles incluso a vestimenta, estilo de corte de pelo, etc.), prohibir la participación estudiantil, etc., dando lugar a un vaciamiento de los contenidos socialmente significativos.

Por otro lado, a pesar de la fuerte censura ideológico-política que ejerció la dictadura militar en aquellos años, algunas editoriales como Troquel, Marymar y El Ateneo siguieron traduciendo y editando textos curriculares de origen norteamericano con un sesgo técnico-instrumental (Palamidessi y Feldman, 2003).

Estos autores realizan una caracterización del campo educativo durante la última dictadura militar, y si bien no se refieren directamente a las relaciones entre la didáctica y el curriculum, encontramos algunos rasgos que es interesante remarcar.

“[...] Durante este período, el sistema educacional fue un blanco privilegiado de la represión militar: la desaparición o expulsión de profesores y estudiantes; la prohibición de ciertos libros, la imposición de normas que reforzaban formas tradicionales de relación y autoridad. El gobierno militar y la Iglesia católica coincidieron en la necesidad de 
"limpiar" y "ordenar" el sistema educativo: eliminar la oposición existente en las escuelas y universidades, reformar los planes de estudio, combatir la difusión de ideas 'subversivas'. Buena parte de su accionar estuvo guiado por un sentido de "guerra" contra la subversión del "orden". Las Universidades fueron cerradas y luego funcionaron intervenidas por autoridades designadas por el poder militar [...]" (Palamidessi y Feldman, 2003, p.6).

Según argumentan, la situación afectó profundamente al desarrollo de la teoría educativa en general y, en particular, a la incipiente teoría curricular. Lejos de expandirse, sufrió un retroceso, un debilitamiento determinado por el exilio de profesores, la expulsión de otros profesionales de las Universidades y Centros de producción académica, la prohibición de literatura de corte crítico que ya circulaba en países de Europa. Algunos rasgos tecnicistas y "visualizados como neutrales" de la teoría curricular que ya se conocía en el país hasta 1976 se mantuvieron y difundieron, y otros fueron censurados radicalmente.

En la década de 1970 se fueron configurando y acentuando, como venimos exponiendo, ciertas características para la didáctica y el curriculum como disciplinas que las acercaron a aquellas connotaciones prescriptivas que abordamos en el capítulo I de esta tesis. Además de lo expuesto, cabe agregar que Davini (1996), en la diferenciación ya aludida para los términos "normativo" y "prescriptivo", reserva aspectos de anclaje nacional. En este sentido, el término "prescripción" alude principalmente a las reglas elaboradas por la didáctica tecnicista que tuvo auge entre las décadas del '60 y '70. Se trató de una prescripción neutralizada $\mathrm{y}$, por tanto, despojada de todo debate utópico-político ${ }^{78}$.

La racionalidad tecnológica que sustentaba estos modos de entender, planificar y ejecutar los fenómenos educativos, se apoyó en el conocimiento supuestamente válido científica y técnicamente, un conocimiento experimental y causal. Para esta racionalidad, no era posible derivar juicios de valor o evaluativos, enunciados sobre el deber ser, de premisas descriptivas o acerca del

\footnotetext{
${ }^{78}$ Araujo caracteriza el enfoque tecnológico del curriculum con las mismas connotaciones. Dice que “...se trata de una postura eminentemente prescriptiva que anula cualquier debate ideológico y todo componente utópico..." (Araujo, 2006, p.53).
} 
ser educativo. Al hacerlo, dejaría el razonamiento "[...] susceptible de recibir mortalmente el dardo acusatorio de haber incurrido en la 'falacia naturalista', y que además pondría definitivamente en 'jaque mate' su pretendida neutralidad y avaloración [...]" (Angulo Rasco, 1994a, p.97) ${ }^{79}$.

En segundo lugar, el "deber ser" disciplinar en el planteo tecnicista ${ }^{80}$ se presentaba como el camino a seguir para alcanzar determinados fines ${ }^{81}$, pero éstos no se encontraban en la agenda de discusión de la didáctica y menos aún de la escuela y del docente ${ }^{82}$. La concepción de ciencia sustentada por la racionalidad tecnológica obligaba a colocar los fines y fundamentos de la educación por fuera del campo científico. Qué fines debía alcanzar la escuela y cuál era el ideal de sujeto a formar, eran cuestiones discutibles por la filosofía de la educación e impuestas a las prácticas como aspectos externos, lejos de los espacios de decisión de los sujetos involucrados en la enseñanza.

Carr (1996) analiza la visión instrumental medios-fines que atravesaba al enfoque tecnicista y plantea la existencia de una diferenciación entre hechos y valores. La teoría educativa debía ocuparse de hechos en tanto es posible emitir sobre ellos explicaciones objetivas en el marco de la ciencia. La cuestión de los fines de la educación debía ser apartada de las incumbencias de la teoría educativa en tanto involucraba juicios subjetivos, opiniones, y no existían criterios científicos para optar por una u otra.

\footnotetext{
${ }^{79}$ En otro texto, el mismo autor plantea: “[...] las proposiciones factuales no pueden, por pura cuestión epistemológica, justificar y legitimar las varias instancias valorativas que se traslucen y fundamentan los dilemas educativos [...]" (1994b, p.120).

80 Las consideraciones sobre la racionalidad tecnicista o tecnológica son tomadas de distintos autores, entre los que podemos mencionar: Carr y Kemmis (1988); Grundy (1994); Davini (1996); Salinas Fernández, 1997; Feldman (2008).

${ }^{81}$ Resta por profundizar en este contexto la utilización del término "utopía" que se erige, desde la perspectiva antes mencionada, como uno de los tres componentes constitutivos de la didáctica. Consideramos que su uso puede ser sometido a crítica desde aquellas concepciones que asocian la utopía a ideales de justicia y libertad, y consideran que los mismos pueden haber sido perseguidos en el plano denotativo del discurso, aunque no realmente ni alcanzados por las reformas sociales asentadas en la racionalidad tecnológica.

${ }^{82}$ Como caso local que ejemplifica en parte este postulado más teórico, podemos citar una transcripción que realiza Tedesco (1983, pp.53-54) de las directivas que la Subsecretaría de Educación da a conocer a las escuelas el 20 de febrero de 1978. En estas directivas se postulaba con claridad que los docentes no tenían que intervenir en la formulación de objetivos y contenidos. Su función era educar y de allí no debían apartarse, debían conocer los objetivos y contenidos preestablecidos y con ellos realizar su trabajo en el aula adecuando sus actividades y propuestas de evaluación.
} 
En este contexto, la eficiencia también estaba presente, por lo que resultaba necesario prescribir acciones de manera rigurosa para alcanzar los objetivos propuestos.

Estas consideraciones sustentaban una idea central en este modelo: la enseñanza era un problema técnico. Era fundamental explicitar las leyes que regían las situaciones de enseñanza para, a su vez, regular y predecir su desenvolvimiento y el de las acciones de los docentes ${ }^{83}$.

Por otra parte, si la enseñanza era un problema técnico, la teoría educativa en general, y la didáctica en particular, quedaban ceñidas a "ciencias aplicadas".

La didáctica se convertía en este esquema en una disciplina aplicada de la psicología que, especialmente en su vertiente conductista, era la disciplina básica que aportaba saberes y criterios de intervención. Este rasgo se sustentaba en el modelo estándar de las ciencias empírico-analíticas que perseguían un interés técnico. Al mismo tiempo, la asociación con la psicología brindaba a la didáctica la posibilidad de transformarse en una disciplina científica, valorada desde los cánones de las ciencias naturales y del positivismo en términos más amplios $^{84}$.

No obstante, la ubicación de la didáctica como disciplina aplicada de la psicología desdibujaba funciones específicas de esta teoría de la enseñanza que aún en la actualidad se intentan reconceptualizar y fortalecer. Una de ellas tiene que ver con la producción de un corpus propio de conocimientos teóricos. Defendemos, como hemos mencionado, las vinculaciones interdisciplinarias, pero los aportes de otras disciplinas deben ser resignificados, precisamente, desde sus finalidades con respecto a la enseñanza. Además, la didáctica, produce saberes específicos.

Otra función que se desdibujaba en el planteo de ciencia aplicada se refiere a la modalidad de intervención. Desde la concepción que hemos

\footnotetext{
${ }^{83}$ Entre los autores que analizan estas cuestiones podemos citar a: Carr y Kemmis (1988); Angulo Rasco (1994b); Carr (1996).

84 Diferentes autores tratan estas cuestiones, entre ellos: Camilloni (1996); Basabe (2007); Feldman (2008).
} 
expuesto de la didáctica como una teoría normativa, sostenemos que ésta debe intervenir en la enseñanza. Pero esta intervención lejos está de caracterizarse por la extrapolación de prescripciones desde las disciplinas básicas, sino más bien que la didáctica elabora normas a partir de las fuentes y con las características que hemos explicitado en el capítulo I.

Por último, pensar que la didáctica es una disciplina aplicada y que la enseñanza es un problema técnico, elude la cuestión de los valores, que es central desde la perspectiva que sustentamos en esta tesis. No podemos evitar en este complejo entramado hablar de los valores que se concretan explícita o implícitamente en las prácticas cotidianas de la enseñanza.

No obstante los rasgos señalados, cabe aclarar que no toda la producción teórica comprendida en estos años ni todos los autores de extracción norteamericana perseguían aportar elementos para la constitución de una didáctica como ciencia aplicada de la psicología. Aparecieron otros ejemplos desde supuestos epistemológicos alternativos. Feldman (2008), por ejemplo, rescata el trabajo de Bruner publicados en 1969 y titulado Hacia una teoría de la instrucción, especialmente el capítulo "Notas sobre una teoría de la instrucción", y el de Skinner de 1970 denominado Tecnología de la enseñanza ${ }^{85}$.

Desde otra perspectiva, pero abordando cuestiones de la constitución teórica y epistemológica de la didáctica y del curriculum, podemos referir, aunque colateralmente, a las relaciones entre la teoría, la práctica y la técnica.

Cols et al (2002) destacan que el curriculum se ha ocupado de los problemas relativos a su diseño y desarrollo desde la sistematización teórica que realizó Tyler. No obstante y a pesar del impulso que progresivamente fue teniendo el curriculum como centro de las políticas educativas -desde los años '60 en Estados Unidos y desde los '80 en Argentina hasta la actualidad-, esta expansión del campo no ha estado acompañada de un desarrollo teórico similar. Es decir, la producción teórica curricular no ha prosperado a la par del

\footnotetext{
${ }^{85}$ Bruner, J. (1969). "La educación como invención social” y "Notas sobre una teoría de la instrucción". En J. Bruner, Hacia una teoría de la instrucción. México: UTEHA. Versión original, Towards a Theory of Instruction. Cambridge, Massachusetts: Harvard University Press, 1966.

Skinner, J. (1970). Tecnología de la enseñanza. Barcelona: Labor. Versión original, The Tecnology of Teaching. Nueva York: Appletons-Century-Crosfts.
} 
trabajo de los especialistas en materia de reformas educativas, aun cuando en nuestro medio, a diferencia de lo que ocurre en otros países, es importante la interpenetración entre el campo del planeamiento curricular y el académico a partir de los años '70 con el desempeño de especialistas en las agencias de diseño.

“[...] las prácticas curriculares no enriquecieron la reflexión sobre el currículum ni la posibilidad de identificar y analizar las tradiciones que marcan estos procesos. Es necesario también, problematizar el lugar de los actores en la elaboración curricular, la dimensión política y técnica de los procesos de diseño y las posibilidades y límites de los diferentes modelos o alternativas curriculares.

La escasa exploración y reflexión acerca de la variedad de alternativas curriculares posibles, generan un riesgo de naturalización de la alternativa oficial y la convierte en la única disponible y posible [...]" (Cols et al, 2002, p.1).

Podemos decir que las relaciones entre teoría y práctica se han vuelto un punto de preocupación de las prácticas educativas en su conjunto. Hay diferentes trabajos que abordan estas relaciones, que buscan reflexionar sobre los sentidos que se les asignan a la teoría y a la práctica ${ }^{86}$. Pero también, hablar de la teoría y la práctica, y sus relaciones, se ha convertido en una especie de "lema pedagógico" 87 que recibe la responsabilidad de los fracasos de las teorías educativas y de las reformas educativas y curriculares en el lenguaje común de los sujetos involucrados en la educación.

Díaz Barriga (1991) plantea algunos puntos a tener en cuenta para pensar las relaciones, siempre complejas, entre la teoría y la práctica. Pareciera que el campo del curriculum ha estado acompañado, desde sus inicios, con la síntesis

\footnotetext{
${ }^{86}$ Podemos citar: Carr y Kemmis (1988); Carr (1996); Gimeno Sacristán (1997).

${ }^{87}$ Los lemas pedagógicos, según Camilloni, “...consisten en esquemas prácticos de pensamiento y acción. Son una expresión concentrada de la cultura que, como los refranes y los proverbios, emplean metáforas e implican juicios de valor. Estos lemas han sido estudiados por los filósofos analíticos que, entre sus estudios sobre el lenguaje informal, incluyeron el lenguaje en la educación como un caso particular...". La autora también plantea que los lemas tienen un carácter afectivo y práctico; en algunos casos, dos lemas pueden ser contradictorios aunque no así sus efectos prácticos (Camilloni, 2007e, p.46).

"Esta necesidad de diferenciación surge con evidencia cuando se analiza la historia de la didáctica, en la que doxa y episteme se han confundido permanentemente. Los filósofos analíticos hicieron un aporte sustancial en este sentido, que podríamos denominar "sanitario". Sus trabajos de denuncia sobre el empleo de lemas pedagógicos en el discurso de la disciplina brindaron un instrumento de gran valor para el ejercicio de una de las suertes de "vigilancia epistemológica" aplicables a los nuevos desarrollos de la didáctica" (Camilloni, 1993, p.35. El subrayado figura en cursiva en la edición consultada).
} 
tyleriana, por una escisión entre el desarrollo instrumental del curriculum como parte de las políticas curriculares y la reflexión teórica.

Asimismo, para el autor, habitualmente se piensa que existe una independencia entre la teoría y la técnica, como si se tratara de dominios diferentes que habilitan clasificaciones de saberes pertenecientes a uno $\mathrm{u}$ otro grupo. Si bien esta separación ha convivido con la didáctica desde su surgimiento, se puede construir un reclamo de articulación entre la teoría y la técnica, reconociendo que hay una mutua implicación entre una y otra. En la enseñanza y en el curriculum estamos en condiciones de postular que la práctica siempre tiene una referencialidad en la teoría y que la teoría se construye enfocando una práctica. Los problemas metodológicos de la enseñanza no pueden ser separados de los supuestos teóricos y epistemológicos que los informan ni de las condiciones socio-históricas particulares en las que surgen.

Si bien este desafío que Díaz Barriga expone es actual, el autor plantea que las políticas propias del desarrollismo contribuyeron a que el pensamiento didáctico fuera sustituido por uno tecnológico, profundizando aquella separación que habitaba en nuestra disciplina desde sus orígenes.

En términos más estrictamente curriculares, también es frecuente aludir a una separación entre la teoría y la práctica, entre lo teórico y lo técnico, entre aquellos que teorizan y aquellos que practican. Numerosos trabajos adjudican estas características a lo que denominamos la racionalidad técnica o la perspectiva tecnicista que tuvo auge en nuestro país en la década del '70.

Dentro de las modalidades técnicas de acción, Feldman (2008) menciona que en términos de planeamiento del curriculum eran frecuentes las estrategias “centro-periferia”. El planeamiento del curriculum o la planificación de reformas educativas, desde esta concepción, sustentaba un centro especializado que planificaba propuestas y soluciones y las irradiaba a todo el sistema educativo entendido como la periferia.

Estas estrategias "centro-periferia", según expone el autor, adoptaron la modalidad conocida como "IDD (investigación, desarrollo y diseminación)". En primer lugar, se producía una investigación, como una suerte de diagnóstico de 
los problemas que se presentaban en el sistema educativo. A continuación, en la etapa de desarrollo, se diseñaban las propuestas, los materiales y todo lo necesario para enfrentar los problemas antes diagnosticados. Por último, la diseminación consistía en la implementación o aplicación de las propuestas planificadas por parte de los docentes.

Según Feldman (2008), el diseño e implementación de los paquetes instruccionales -a los que también referimos en el apartado anterior-, buscaban en la lineal aplicación a la práctica por parte de los docentes el éxito para la solución de los problemas. El docente se veía frente a una variedad de herramientas para implementar en el aula que eran pensadas por otros actores. Tal es así que muchos autores ${ }^{88}$ hablan de paquetes instruccionales o curriculares a prueba de docentes, universales y ajenos a toda vinculación valorativa.

Feldman también sostiene que estos paquetes brindaban a los docentes una serie de materiales, recursos, estrategias, etc., que estaban en correspondencia con la filosofía subyacente a la innovación educativa que se intentaba llevar a cabo. "[...] Como los diseñadores sospechaban de las habilidades de los maestros, prepararon paquetes "a prueba de profesores". Los paquetes parecian proveer alguna seguridad contra la incompetencia y eran consistentes con la aproximación por objetivos [...]" (2008, p.51).

En este contexto, los docentes se convertían en buenos administradores de estos paquetes previamente diseñados. No obstante, distintos trabajos de reflexión teórica y la recuperación de la propia experiencia de los docentes,

\footnotetext{
${ }^{88}$ Contreras Domingo (1990); Kemmis (1993); Angulo Rasco (1994a); Elliot (1995).

Contreras Domingo, por ejemplo, caracteriza así a los curricula y propuestas de cambio en educación que tienen -en un nivel más o menos explícito- la pretensión de que se lleven a la práctica o se apliquen tal como fueron pensados y diseñados a partir de la clara especificación de las actuaciones a realizar y los logros a alcanzar. De esta manera, se pretende limitar o hasta se anular las posibilidades de decisión y creatividad del docente o de adecuación del curriculum a su práctica cotidiana de enseñanza.

Kemmis, por su parte, utiliza la expresión en cuestión cuando realiza una mirada crítica sobre la obra de Tyler. Dice que este teórico del campo del curriculum concebía un papel de responsabilidad para los docentes en la toma de decisiones educativas, tal como también lo planteaba la perspectiva práctica, no obstante la tecnología instruccional que se asentaba en su método racional no lo tenía en cuenta y los curricula diseñados en su seno podían caracterizarse como "paquetes curriculares".

Por otro lado, Elliott habla de curricula a prueba de profesores para referirse a aquellos conformados en el marco del modelo de objetivos, con una fuerte tendencia a la especificación del programa de estudios desde instancias centrales de decisión.
} 
puso en evidencia la ingenuidad que había detrás de este tipo de innovaciones y que era imposible excluir a los docentes ${ }^{89}$.

Tomando a Feldman (2010b), podemos enriquecer el análisis que venimos desarrollando a partir de considerar otra serie de transformaciones a nivel curricular en nuestro país en la década del '70. Para el autor, en esos años se produjo un cambio desde un orden moral patriótico en el curriculum hacia otro orden universal y científico. Estos cambios impactaron a nivel del trabajo en el aula y de los recursos utilizados para la enseñanza.

La utilización de láminas en el aula, un recurso que venía impulsado ya desde Comenio, también sufrió en el marco de este cambio curricular su transformación. Las láminas con su claridad y esquematismo, representaban la realidad en el espacio del aula, ordenaban el mundo y también, de alguna manera, lo simplificaban, según expone Feldman (2010b). Además, iban acompañadas del interrogatorio como una técnica de enseñanza destacada. Esto facilitaba "dirigir" la atención de los alumnos hacia los aspectos que se deseaban resaltar.

No obstante, los cambios acaecidos en el curriculum en los años '70 conllevaron una transformación en el plano del conocimiento. En este sentido, ese conocimiento adquirió nuevas características relativas a los procesos y a las estructuras de las disciplinas, ya no tan fáciles de representar por medio de láminas, y requirió la introducción de nuevos soportes textuales, como por ejemplo, enciclopedias, revistas, libros, etc.

La base intuitivista que acompañó la formación del sistema educativo argentino desde la sanción de la Ley de Educación No 1420 comenzaba a fragmentarse en la década del '70. Como alternativas a esta pedagogía tradicional, se exponían la tecnología instruccional y la pedagogía operatoria, luego llamada constructivista, según analiza Feldman (2010b). Para el autor, el tecnicismo fue el principal acusado por los males del sistema educativo y la

\footnotetext{
${ }^{89}$ Recuperamos estos aspectos en el capítulo VIII al analizar los trabajos de Schwab (1974) y Stenhouse (1991).
} 
pedagogía intuitivista, más tradicional, pasó a un segundo plano. El autor lo expresa así:

"[...] Quizá porque el "tecnicismo", una versión por demás imprecisa de los males pedagógicos, se convirtió en el centro de la atención crítica sobre el poco satisfactorio estado de la enseñanza en las escuelas argentinas. Como se mencionó, no hay evidencias sistemáticas de que en los niveles básico y medio de nuestro país la enseñanza esté orientada mediante pedagogías por objetivos, graduación escalonada de la tarea y principio de dominio, dosificación de refuerzos o evaluación objetiva -por mencionar algunos rasgos-. Da más bien la impresión de que "el tecnicismo" es una figura que se confunde con "tradicional", "directivo", "pasivo", "libresco". (Todas ellas características duramente criticadas por los promotores de la tecnología instruccional, y la mayor parte de ellas también, dicho sea de paso, por los pedagogos intuitivistas)" (2010b, p.52).

Este recorrido le posibilita a Feldman arribar a conclusiones coincidentes con nuestros supuestos en esta tesis, en tanto postula que la didáctica a partir de estos años se volvió más crítica y menos prescriptiva. En correspondencia con los procesos que presentamos en el próximo apartado, para el autor la didáctica perdió su caudal prescriptivo y "[...] El trabajo sistemático sobre la enseñanza y el curriculum quedó limitado al campo de las estrategias definidas por la enseñanza de conocimiento disciplinar, principalmente, trabajando sobre el cruce entre procesos cognitivos y las pautas expertas propias de las distintas áreas [...]" (2010b, p.59).

Para el autor, la misma formación de los profesionales de la educación se fue cargando de un sesgo intelectual, vinculado a la investigación y a la reflexión, perdiendo su valor instrumental y las capacidades para la intervención.

\section{II - 4 - Didáctica y curriculum: la comprensión didáctica y la diversificación del pensamiento curricular a partir de 1983.}

El retorno de la democracia en 1983 implicó la apertura y diversificación en materia de teoría didáctica y curricular. 
En agosto de 1983, unos meses antes de la asunción presidencial de Raúl Alfonsín, la Asociación de Graduados en Ciencias de la Educación (AGCE) organizó unas jornadas denominadas "Coincidencias para la educación en el gobierno constitucional" en las que diversos especialistas de la educación, políticos, educadores, padres, alumnos y sectores de la sociedad intercambiaron y discutieron ideas en torno al convencimiento de que el nuevo gobierno constitucional debía brindar y garantizar una educación democrática.

Las ideas compiladas por Braslavsky y Riquelme en el texto titulado "Propuestas para el debate educativo en 1984", se presentaban como aportes desde la AGCE al Gran Debate Pedagógico que se desarrolló al cumplirse 100 años de aquel otro que dio lugar a la Ley de Educación N 1420 y que marcó las tendencias de política educativa desde el surgimiento del sistema educativo.

El trabajo en su conjunto puede ser interpretado como una instancia histórica de apertura para el debate educativo en el que se discutieron diversos temas, como por ejemplo: acceso y permanencia en la educación; calidad de la educación y del curriculum; la formación profesional de los jóvenes y adultos; la educación de adultos y la participación política; la formación de los docentes en los diferentes niveles del sistema educativo; capacitación, actualización y perfeccionamiento docente; centralización-descentralización del gobierno del sistema educativo; etc. En el tratamiento de estos temas también intervinieron diferentes sujetos, como los ya mencionados, lo que significó una apertura a la pluralidad de opiniones y de voces autorizadas a presentar problemas y propuestas de solución para la educación a principios de los años '80.

En 1984 se sancionó la Ley No 23.114 por la cual se convocó a la realización del Congreso Pedagógico. Entre los objetivos principales se hallaba la creación de un estado de conciencia sobre la importancia de la educación para el rumbo del país y la habilitación de la pluralidad de voces y sujetos para plantear temas, problemas y soluciones educativas. Las pautas de organización del Congreso dan cuenta de la realización de diversas Asambleas Pedagógicas en las que se preveía discutir localmente las cuestiones educativas e ir elaborando informes consensuados parciales que pasaban a una instancia más 
abarcadora de discusión hasta llegar a la Asamblea Pedagógica Nacional que se concretó entre el 27 de febrero y el 6 de marzo de 1988 en Embalse, Provincia de Córdoba.

La Asamblea Pedagógica Nacional abordó y plasmó en el Informe Final dictámenes sobre los siguientes temas: 1- objetivos y funciones de la educación, concebida como permanente para la democratización y la afirmación nacional en el contexto de la liberación latinoamericana; 2- objetivos y funciones de la educación para la realización plena de la persona en una sociedad participativa y pluralista; 3- las formas de la educación incluyendo los niveles del sistema educativo, las distintas modalidades de educación, la formación de los docentes, la educación no formal y los efectos educativos de distintas instituciones sociales; 4- la distribución de los servicios educacionales y su rendimiento; 5- los aspectos pedagógicos que entre sus aspectos centrales incluye el tratamiento del curriculum y de distintos componentes curriculares; 6la administración de la educación; 7- gobierno y financiamiento de la educación. Para el tratamiento de estos temas, se conformaron siete comisiones y cada una elaboró dictámenes en consenso de la mayoría y/o en disenso por la minoría.

Asimismo, la Comisión Honoraria de Asesoramiento, integrante del Congreso Pedagógico, elaboró un Informe sobre posibles reformas del sistema educativo dirigido al por entonces presidente de la Nación, Raúl Alfonsín.

Estos informes plasmaron el espíritu de la mencionada Ley que buscaba una amplitud de temáticas educativas abordadas, una pluralidad de voces y sujetos que pudieran libremente dar a conocer sus opiniones. En una perspectiva histórica significó una revitalización de sujetos y temáticas en comparación al período dictatorial precedente.

Por otra parte y haciendo foco en cuestiones más específicas para esta tesis, se evidenciaron, como analizan Zoppi y Aguerrondo (1991), una serie de cambios en torno a los contenidos escolares que figuraban en los documentos curriculares. No obstante, como la mayoría de los cambios en educación, fueron progresivos. Convivían, según lo plantean las autoras, elementos de distintas 
configuraciones. Por un lado, se presentaban conceptos generales que organizaban la secuencia de los temas que se debían enseñar y objetivos para el alumno en función de los diferentes niveles educativos; y por el otro, se seguía planteando un listado de contenidos informativos a partir de los cuales se tenían que formular las actividades y los recursos.

La actualización de los contenidos escolares con el retorno de la democracia en 1983, es también un aspecto destacado por Palamidessi y Feldman (2003). Los autores agregan, además, la aparición del debate acerca de las funciones reproductoras o democratizadoras de la educación y de la estructura de participación en las instituciones educativas.

Muchas de estas temáticas comenzaron a visualizarse a partir del ingreso de literatura de corte crítico y, también, proveniente de disciplinas no estrictamente didácticas o curriculares pero que miraban cuestiones educativas. Por ejemplo, la política de la educación, la sociología de la educación o la antropología, realizaron aportes valiosos para la comprensión de las prácticas escolares aunque, como expusimos en el capítulo I, no presentaban un interés explícito en la generación de normas o principios para el mejoramiento de las prácticas educativas. No obstante, la didáctica incorpora estas categorías a su estructura teórica condicionando su constitución epistemológica.

A su vez, Palamidessi y Feldman enfatizan las posibilidades de actualización en materia académica en las ciencias sociales en su conjunto y específicamente en el curriculum con el retorno de la democracia.

"[...] En ese contexto, el sistema educativo fue considerado como un vehículo central en la modificación de la cultura autoritaria. La democratización de la educación se realizó a través de la expansión de la matrícula, el incremento de la participación en el gobierno escolar (Centros de Estudiantes, Consejos de Escuela) y la promoción de pedagogías centradas en el alumno.

Al mismo tiempo, se produce la normalización de las Universidades y la renovación de sus cuerpos de profesores. Este proceso fue muy significativo en el campo de la Educación, las Humanidades y las Ciencias Sociales, especialmente afectadas por la represión militar. Esto produjo una actualización de enfoques teóricos y de la literatura especializada. Las carreras de Ciencias de la Educación y los Institutos de Formación Docente modifican y actualizan sus planes de estudio. Por primera vez, algunas 
Universidades crean cátedras específicas de Curriculum ${ }^{90}[\ldots]^{\prime \prime}$ (Palamidessi y Feldman, 2003, p.7).

Asimismo, se conocieron en temas curriculares los debates norteamericanos entre la tradición tyleriana y el movimiento reconceptualista, así como también autores ingleses, en muchos casos a partir de ediciones españolas y mejicanas. Este movimiento representó una ampliación de las temáticas que se estaban considerando en el mundo en el campo curricular ${ }^{91}$.

Cols (2000a) destaca un movimiento de renovación similar en lo que respecta a la didáctica, que es interesante mencionar para visualizar cómo impactaron en esta disciplina diferentes corrientes teóricas. En primer lugar, la autora menciona que las transformaciones producidas en la teoría y en la política curricular contribuyeron a postular nuevas visiones acerca del docente y de la enseñanza, aunque en esta última de una manera indirecta. A su vez,

\footnotetext{
${ }^{90}$ Como ejemplo podríamos mencionar que en la Facultad de Humanidades y Ciencias de la Educación de la Universidad Nacional de La Plata (FaHCE, UNLP), se creó "Diseño y planeamiento del curriculum". Esta asignatura ha estado destinada a la formación pedagógica de los estudiantes que cursan los distintos profesorados en esta Casa de Estudios. Según el estudio de Garatte (2008), entre 1983 y 1984 se llevó a cabo una reforma de la formación pedagógica que incorporó "Fundamentos de la educación", "Fundamentos psicológicos de la educación", "Diseño y planeamiento del curriculum", como asignaturas comunes a todos los profesorados y dependientes del Departamento de Ciencias de la Educación, y "Prácticas de la enseñanza" específica para cada carrera.

Según los registros de Memoria Académica de BIBHUMA (Biblioteca de FaHCE, UNLP), el primer programa de "Diseño y planeamiento del curriculum" data de 1985 y Edith Láttaro era la docente responsable del mismo.

Entre 2000 y 2002 se produjo una nueva modificación de esa formación pedagógica, pasando a estar integrada por las siguientes asignaturas: "Teoría de la educación" (equivalente a "Fundamentos de la Educación"), "Psicología y cultura en el proceso educativo" (equivalente a "Fundamentos psicológicos de la educación"), "Didáctica y curriculum" (equivalente a "Diseño y planeamiento del curriculum"); y las "Prácticas de la enseñanza". No obstante, en estos años diferentes profesorados modifican también sus planes de estudios incorporando diferencialmente el cursado obligatorio y optativo de estas materias en sus curricula.

Para el caso de la carrera de Ciencias de la Educación (FaHCE, UNLP), podemos decir que encontramos (en los registros de Memoria Académica de BIBHUMA) ente 1978 y 1985 el programa de un seminario optativo denominado "Los contenidos de los programas curriculares de la escuela primaria" a cargo de Mabel Olga Cepeda. Con posterioridad, las carreras de Profesorado y Licenciatura en Ciencias de la Educación contaron con una asignatura específica sobre curriculum a partir de la sanción del plan de estudios de 2002, llamada "Teoría y desarrollo del curriculum" ubicada en el 20 año. También existe desde entonces un seminario optativo denominado "Curriculum y sociedad" que se dicta en la orientación "Educación, sociedad e institución educativa" del 50 año de las carreras.

${ }^{91}$ Podemos decir que Feeney (2007) coincide con estas afirmaciones cuando sostiene que en la década del '80 emergieron, por un lado, obras como las de Schwab y Stenhouse que focalizaban su crítica en el enfoque técnico precedente; y por otro, trabajos que evidenciaron un descentramiento de las preocupaciones del diseño curricular, apareciendo temáticas más macro o de vinculación del curriculum con procesos sociales, históricos y políticos.
} 
también menciona que el cuestionamiento a la perspectiva técnica y racional que se realizaba desde el movimiento reconceptualista y desde la perspectiva práctica aportó a la renovación del campo curricular.

El avance hacia formas más descentralizadas de gestión curricular y la confección de diseños curriculares más abiertos fueron otros dos aspectos que para la autora han impactado en la generación de nuevas visiones acerca del docente y su rol en la enseñanza y en la institución.

Por otra parte, se sumaron a la configuración de este nuevo lugar del docente los trabajos denominados de "epistemología de la práctica", especialmente los aportes de Schön ${ }^{92}$. Cols plantea que las consideraciones de este autor sobre la reflexión en la práctica y la formación de un profesional reflexivo han influido en el rol del docente pero también en la formación de nuevos profesionales. A su vez, en esta misma línea, la autora sostiene que es importante el trabajo de Mendel $^{93}$ y sus críticas a la lógica de la acción, aunque desde otra perspectiva teórica.

Por último, Cols menciona el impacto que ha tenido la sociología de la educación y del curriculum en la generación de nuevas visiones sobre la enseñanza y la acción del docente. Planteos en su mayoría de sesgo crítico, han contribuido a explicitar las relaciones de poder y la ideología que construyen y que se construyen en las prácticas escolares. Desde estas perspectivas, la escuela y el docente en particular ocuparon un lugar político, lejos de la neutralidad que les quisieron imponer las posturas tecnicistas ${ }^{94}$.

Amantea et al (2004) también aluden a las corrientes que se dieron a conocer en nuestro país con la recuperación de la democracia y a los impactos de las mismas en la didáctica. En coincidencia con algunos de los autores ya

\footnotetext{
92 Schön, D. (1992). La formación de profesionales reflexivos. Hacia un nuevo diseño de la enseñanza y el aprendizaje en las profesiones. Barcelona, Paidós.

${ }_{93}$ Mendel, G. (1999). "El acto: una aventura”. Mimeo.

${ }^{94}$ Especialmente, Cols (2000a) cita los siguientes trabajos en esta línea:

Apple, M. (1995). “La política del saber oficial: ¿Tiene sentido un curriculum nacional?”. En: Volver a pensar la educación. Vol.I Política, educación y sociedad. Congreso Internacional de Didáctica. Madrid, Morata.

Popkewitz, T. (1989). “Los valores latentes del curriculum centrado en disciplinas”. En: Sacristán, J. G. y Pérez Gómez, Á. (comp.). La enseñanza: su teoría y su práctica. Madrid, Ediciones Akal Universitaria. Popkewitz, T. (1994). Sociología política de las reformas educativas. Madrid, Morata.
} 
citados, este aporte reafirma que se produjo una renovación conceptual en la didáctica y el curriculum en nuestro país en la década del '80.

Cols et al (2002) reconocen, por su parte, que el impacto que estos enfoques y teorías tuvieron en la didáctica en los años '80 condujeron a un proceso de revisión epistemológica y de reconceptualización que se extiende hasta nuestro días.

Además de lo ya mencionado, a partir de este escrito es posible agregar las contribuciones de los estudios acerca de la enseñanza, específicamente del pensamiento del profesor y los enfoques etnográficos, a la didáctica. Por otro lado, el aporte de la psicología educacional constructivista, que contribuyó a la ampliación de los problemas didácticos y a la modificación de las concepciones sobre la enseñanza.

“[...] Sin pretensión de exhaustividad, es importante señalar algunos de los intereses que paulatinamente se fueron ubicando en la agenda del pensamiento didáctico, más allá de las diferencias en los enfoques: el abandono de los modelos "directos" o causales de enseñanza, la importancia de las representaciones y concepciones de los estudiantes y el contenido escolar; el replanteo del contenido desde puntos de vista epistemológicos y psicológicos; la búsqueda de estrategias y contextos de enseñanza que promuevan procesos de construcción de significados por parte de los alumnos [...]" (Cols, 2000a, p.10).

Consideramos oportuno mencionar dos experiencias que tuvieron lugar en nuestro país en la década del '80 para visualizar a partir de ejemplos concretos los cambios que se produjeron en esos años en el pensamiento didáctico y curricular en particular, y educativo en general. En primer lugar, nos parece interesante aludir a los llamados "talleres de educadores", tomados como propuestas de trabajo con docentes, desarrolladas por investigadores provenientes de la antropología y adheridos a una perspectiva interpretativa. En segundo lugar, referimos brevemente a la propuesta curricular del Plan de Formación de Maestros de Enseñanza Básica (conocido por sus siglas MEB).

La propuesta de los talleres de educadores permite visualizar la presencia de aspectos normativos en investigaciones y trabajos con docentes radicados en una perspectiva interpretativa y concluir que esta convivencia responde a la concepción de la educación como una acción práctica. 
Achilli (1996; 2000) plantea que los talleres de educadores englobaban experiencias muy diversas generadas en América Latina desde la década del '70, que poseían como rasgo común una concepción de aprendizaje basada en el trabajo colectivo y la integración entre la teoría y la práctica. Los antecedentes de estos talleres pueden ubicarse en las tareas desarrolladas por Vera y Argumedo a fines de los '70, como modalidades críticas de capacitación docente frente a otras más transmisivas o directivas que, a su vez, influyeron en diferentes actividades desarrolladas por la Red Latinoamericana de Investigaciones Cualitativas de la Realidad Escolar (Achilli, 1996; Batallán, 2007).

A pesar de algunas diferencias que en los casos particulares adquirieron los talleres de educadores, en líneas generales buscaban: 1- constituirse en un espacio de perfeccionamiento docente y de investigación de la propia práctica áulica e institucional; 2- recuperar mediante la investigación las prácticas y significaciones de los docentes en tanto protagonistas; y 3- entender a los docentes como profesionales-intelectuales de la educación.

Para Achilli, la importancia de trabajar con las prácticas de los docentes, siendo éstos sus protagonistas, radica en "[...] la intención de construir conocimientos que posibiliten o colaboren en la elaboración de propuestas de cambio. Unir la investigación a determinada función o servicio social" (1996, p.66).

Ambas autoras mencionadas destacan los aportes teóricos y metodológicos de la antropología sociocultural para el desarrollo de los procesos investigativos que, en los talleres de educadores, tenían la característica de ser intensivos en tanto se trataba de "[...] una investigación implementada en pequeña escala, con prolongada interacción con los sujetos, con el uso de estrategias dirigidas a un acceso de la información exhaustivo y a su análisis interpretativo simultáneo y "en profundidad" [...]" (Achilli, 2000, p.66).

Achilli conceptualiza el trabajo en los talleres de educadores como una espiral en la que se iba profundizando progresivamente en el conocimiento de determinado aspecto de la práctica cotidiana de los docentes. Para la autora, en este contexto cobraba especial relevancia la tarea del equipo de 
investigación/coordinación destinada a facilitar y orientar la construcción y apropiación de conocimientos.

Los denominados "encuadres" ayudan a comprender la dinámica de trabajo en los talleres de educadores. En primer lugar aparecen los encuadres constitutivos que involucraban aquellos aspectos que hacían a la conformación del grupo de docentes participantes y de investigadores/coordinadores. En segundo lugar, se mencionan los encuadres de funcionamiento en los que el equipo de coordinación garantizaba el tiempo, el espacio y la concreción de las actividades previstas. Finalmente, estaban los encuadres metodológicos en los que el equipo de coordinación, mediante una serie de procedimientos, orientaba el trabajo grupal.

Como síntesis, podemos decir que si bien en los talleres de educadores no aparece como finalidad explícita la construcción de "conocimiento didáctico", el establecimiento de normas o la elaboración a partir de la investigación de postulados acerca de cómo debían ser las prácticas de enseñanza, sí se perseguía la generación de condiciones para que los maestros pudieran acceder a mejores comprensiones sobre su propia realidad, a analizar y comparar las interpretaciones personales con las grupales y a conformar proyectos de mejoramiento de las prácticas.

En segundo lugar, cabe una breve referencia al MEB encabezado principalmente por Ovide Menin cuando se desempeñó como Director de Enseñanza Superior de la Nación entre los años 1987 y 1989. Se puede decir que esta modificación curricular para la formación docente es relevante porque se inspiró en corrientes prácticas y críticas. Además, se enmarca en una transformación más amplia que involucra el carácter normativo del curriculum.

Para Davini (1998), el MEB se inscribió en una tendencia pedagógica que agrupó producciones orientadas a la modificación de las relaciones de poder en las escuelas, a revertir el autoritarismo y el verticalismo instaurados por las dinámicas políticas de la segunda mitad de la década del '70. Dicha tendencia partía de la premisa de que la modificación de la práctica se lograba a partir de la reflexión crítica sobre ella. Asimismo, el MEB perseguía una implementación 
progresiva de sus instancias de formación docente inicial y de formación continua o perfeccionamiento en servicio de los maestros.

En el marco de las consideraciones anteriores, cabe destacar que el MEB intentó torcer el rumbo de modelos propios de la formación de docentes y de lógicas curriculares fortalecidas por la vigencia -durante más de una década- de un esquema tecnocrático. No obstante las vicisitudes de diversa índole que acortaron su permanencia, contribuyó a fortalecer y enriquecer un clima de crítica y reflexión que se estaba gestando en la década y favoreció las dinámicas de discusiones en el campo educativo que tendrían lugar en los años ' 9095 .

A su vez, a diferencia de planes de estudios anteriores para la formación docente, el MEB mostraba, según Davini, una mayor regulación explícita de la enseñanza y las prácticas docentes. Podemos decir que con el correr de los años se fue instalando una tendencia que continúa hasta nuestros días: "los diseños curriculares-libro" (Cols et al, 2002, p.11). Éstos postulaban lo máximo deseable que se debía enseñar y aprender en las escuelas perdiendo, como contrapartida, fuerza normativa en lo que respecta a la orientación y regulación de las prácticas.

Para la autora, esta creciente regulación se ponía en evidencia en distintas dimensiones que contrastaban con las propuestas anteriores: 1- la idea del curriculum como documento-texto; 2- la participación de distintos especialistas en la elaboración del curriculum y de los materiales de apoyo complementarios, así como también en la mediación entre los docentes y el discurso del gobierno; 3- un docente investigador con capacidad de teorizar la práctica y practicar la teoría, buscando las estrategias adecuadas para la transmisión y recreación de los conocimientos; 4- la ampliación de la formación inicial de los docentes a partir de la regionalización del curriculum y el diseño de espacios de educación no formal, tendientes a modificar las estrategias de

\footnotetext{
${ }^{95}$ Es interesante mencionar que Davini realiza un estudio comparativo del MEB y el Programa para la Transformación de la Formación Docente (PTFD). Para la autora, ambos proyectos, a pesar de sus cortas implementaciones, dejaron huellas para las decisiones curriculares posteriores; se opusieron a gramáticas anteriores y evidenciaron una creciente regulación explícita de la enseñanza y las prácticas docentes (Davini, 1998).
} 
transmisión y a abrir la institución al medio circundante 96 ; 5- la definición de la propuesta curricular como "diseño", oponiéndose explícitamente a la idea de plan de estudios y valorizando modalidades de articulación curricular; 6- una pedagogía con formas de clasificación débiles y fronteras flexibles.

“[...] Sin embargo, esta flexibilidad -propia de las pedagogías invisibles- se plantea dentro de una regulación explícita, en la que se distingue lo que hay (y lo que no hay) que transmitir y la especificación de las formas en que debe transmitirse [...]" (Davini, 1998, p.97. La cursiva figura en la edición consultada).

A los fines de esta tesis, resulta relevante abrir algunos interrogantes en torno al avance de un discurso prescriptivo sobre las prácticas de enseñanza en el marco de una tendencia para la formación docente y de una perspectiva curricular explícitamente opuesta al tecnicismo. Cabe indagar si este alto nivel prescriptivo de la práctica no entraba en contradicción con aquellas otras formulaciones que propugnaban por la autonomía y profesionalización de la formación docente y/o por la generación de espacios de discusión y producción en las instituciones formadoras.

A su vez, la presencia de especialistas y la elaboración de documentos que acompañaban y complementaban el curriculum ponían de manifiesto prescripciones que en diseños anteriores permanecían implícitas o disgregadas en resoluciones diversas. Cuerpos de expertos aparecían en escena configurando una nueva división profesional en el sistema educativo, conciliando lineamientos provenientes de políticas internacionales con finalidades democráticas y de mejoramiento de las prácticas educativas.

A partir de estas consideraciones acerca del MEB, podemos hablar de una dinámica diferente en el campo de la didáctica y en el del curriculum en lo que respecta a la constitución de la normatividad en la década del '80. Mientras

\footnotetext{
${ }^{96}$ En este sentido, Vilte et al informan que el MEB tuvo un alto impacto en lo que se refiere a la movilización pedagógica del cuerpo docente en la Escuela Normal de Tilcara, Jujuy. Los autores dicen que si bien no se lograba un eje que articulara las acciones, existían iniciativas desde diferentes cátedras para integrar a la comunidad y resignificar lo regional, muchas motivadas por las instancias de autocrítica de las prácticas docentes que no tenían en cuenta a los sujetos que aprendían o que no se abrían a la realidad socio-cultural circundante a la institución. En el trabajo citado, el MEB se menciona como una propuesta que posibilitó -junto con otros condicionantes- modalidades participativas de trabajo (Vilte et al, 1998).
} 
que para el caso de la didáctica habíamos hablado de un desplazamiento del componente normativo por la influencia de lenguajes descriptivos y las críticas al tecnicismo, para el caso del curriculum parece que el movimiento es inverso, al menos en un nivel implícito. Como concluyó Davini, se observó en el MEB un aumento de las regulaciones explícitas de la enseñanza en comparación con modelos curriculares anteriores. Decimos que en un "nivel implícito" porque estas regulaciones convivían con planteos democratizadores de las relaciones entre los sujetos en el ámbito escolar y con la declaración de la apertura de espacios institucionales para la participación de la comunidad educativa.

Recuperando todo lo dicho, podemos plantear que estas cuestiones que puntualizamos en las líneas precedentes se enmarcan en un movimiento más amplio de críticas al tecnicismo ${ }^{97}$. Éstas pueden ubicarse en diferentes ámbitos de las ciencias sociales pero, específicamente en lo que respecta a la didáctica, podemos decir que aparecieron hacia fines de los años '60 y principios de los '70 originando distintas tendencias teórico-prácticas que proponían una visión diferente de la naturaleza de los problemas didácticos. En nuestro país, la dinámica del campo disciplinar y los procesos histórico-políticos antes referidos contribuyeron a que estas críticas encontraran suelo fértil algunos años más tarde.

Entre las críticas más destacadas se encontraban las de la corriente práctica, pertinentes para esta tesis por su ubicación temporal y su relevancia para pensar las concepciones en torno a la normatividad. Esta corriente otorgaba un lugar privilegiado al análisis de la práctica, la construcción de problemas desde la práctica y la resolución conjunta por medio de la deliberación entre los sujetos involucrados en ella98.

Hasta estos años es posible visualizar la hegemonía de una didáctica tecnicista que ha resultado incapaz de alcanzar el mejoramiento de las prácticas

\footnotetext{
${ }^{97}$ En efecto, como en distintas áreas de las ciencias sociales, el positivismo que alimentó estos planteos tecnicistas ha recibido varias críticas. La teoría social crítica también se enfrentó al positivismo que impregnó las ciencias sociales en su conjunto además de la didáctica; no obstante, no profundizamos en ella en esta oportunidad porque hacerlo excedería los límites del recorte temático y temporal de esta tesis.

${ }^{98}$ Schwab (1974), Stenhouse (1991), y Grundy (1994) son autores representativos de esta tendencia, más ligados al curriculum, pero con influencia en la didáctica.
} 
educativas. Lo mismo ha sucedido con las propuestas curriculares. Seguramente debemos reconocer el logro de otras de sus finalidades, como por ejemplo, la racionalización de las prácticas, sobre todo las vinculadas al diseño de la enseñanza y del curriculum; la adecuación entre fines o metas propuestas y la evaluación; las posibilidades de controlar el desempeño y el alcance de los objetivos a partir de determinados criterios; la centralidad de una formación profesional técnico-instrumental que optimizara el trabajo en el aula; las prescripciones con pretensiones de generalización; etc.

No obstante sus ventajas -evaluadas siempre desde la racionalidad técnica que subyace a estos planteos-, aparecía desde la corriente práctica la posibilidad de trabajar desde las críticas a este enfoque, buscando capturar la especificidad de la práctica y sus sujetos, e impactar realmente en ellos tendiendo a su mejoramiento. Paralelamente, la incidencia de lenguajes descriptivos provenientes de la sociología y la antropología99, así como condiciones particulares, contribuyeron a que la didáctica fuera adquiriendo progresivamente elementos de tinte comprensivo, perdiendo la centralidad prescriptiva tan asociada al movimiento tecnicista precedente. A su vez, la ponderación de los sujetos de la práctica con posibilidades y capacidad de decisión y acción debilitaba la prescripción de reglas universales para intervenir, en tanto se consideraba que las mismas dañaban los márgenes de actuación reconocidos. Se generó así una "problemática impasse metodológica" (Davini, 1996, p.50) tanto en la investigación didáctica como en la realización de las prácticas de enseñanza.

Presentamos a continuación algunas de las perspectivas desde las que se analiza esta inflexión, central para esta tesis, y que también aparece en la reflexión epistemológica y metodológica en la que profundizamos en el próximo capítulo.

\footnotetext{
${ }^{99}$ Desde campos afines, los trabajos de Delamont (1984); Jackson (1992); Woods (1995); entre otros, ofrecieron descripciones de las prácticas de enseñanza y la vida del aula que contribuyeron a este desplazamiento.
} 
Diferentes autores ${ }^{100}$ acuerdan con que el caudal interpretativo que produjo la corriente práctica no ha repercutido directamente en propuestas de intervención para el mejoramiento de las prácticas educativas. Aparece aquí una tensión -aún hoy irresuelta- relativa, por un lado, a la generación del componente normativo a partir del componente comprensivo $\mathrm{y}$, por otro lado, al impacto directo o indirecto que la didáctica espera tener en las prácticas de enseñanza y en los docentes, cuestiones que ya adelantamos en el primer capítulo de esta tesis.

Las corrientes de corte práctico e interpretativo rompieron con el núcleo del razonamiento de la perspectiva técnica en tanto invirtieron las relaciones entre la teoría y la práctica. Se buscaba atender a la demanda propia de la singularidad y complejidad de las situaciones partiendo del reconocimiento de que la dinámica de la vida social exige la reflexión y acción de los mismos sujetos que diariamente trabajan en la enseñanza. Se puede definir la modalidad práctica como aquélla que demanda por parte de los sujetos un razonamiento in situ, con el cual deben decidir los cursos de acción más apropiados en el marco de determinadas circunstancias, sopesando tanto los medios como los fines (Kemmis, 1990).

En este sentido es que Schwab (1974) planteaba que todo caso concreto poseía características específicas que no podían ser abarcadas por ningún principio general. Al mirar lo particular de cada caso, emergía la complejidad; multiplicidad de factores, variables, intereses que condicionaban y -a su vez- se encontraban condicionados por los diferentes espacios de la práctica101.

Recuperando algunos de los planteos anteriores y a propósito de la reflexión didáctica, Feldman (2008) informa que otra de las reacciones contra la ideología tecnicista fue el rechazo de la concepción instalada a mediados del

\footnotetext{
${ }^{100}$ Podemos mencionar a: Salinas Fernández (1995); Candau (1996); Davini (2008); Feldman (2008).

${ }^{101}$ El interés práctico apunta justamente a la comprensión de las situaciones concretas, de los sujetos que interaccionan en ellas y de las acciones correctas o adecuadas en cada contexto; con estos planteos se entra directamente a la esfera de lo moral (Grundy, 1994).

Gimeno Sacristán también describe la racionalidad práctica en oposición a la técnica y destaca el lugar de los sujetos en la selección de "...la acción moralmente informada acerca de lo que es conveniente en cada momento. Éste es un saber que no se compone de reglas, sino de principios aplicados con sabiduría (phronesis)..." (Gimeno Sacristán, 1998, pp.71-72. El subrayado figura en cursiva en la edición consultada).
} 
siglo $\mathrm{XX}$, que entendía a la educación como un sistema tecnológico de producción. Esta metáfora llevaba a la valoración de los productos en función de las entradas al sistema, primaban criterios de eficiencia y eficacia para el alcance de los objetivos, pero los fines no eran problemáticos en sí en tanto provenían de ámbitos y disciplinas externos al sistema.

Por su parte, la corriente práctica cuestionaba estos supuestos desde la consideración de la educación como una práctica humana y social orientada por valores. Las elecciones cotidianas de los docentes, destinadas a resolver las situaciones con las que se enfrentan en el aula, son complejas y en muchos casos dilemáticas.

El estudio de Mancovsky (2000) puede ser interpretado como una perspectiva que aborda esta complejidad. La autora analiza los juicios de valor de los docentes en la interacción del aula y cómo éstos contribuyen a la comunicación pedagógica y a la generación de particulares recorridos escolares en los estudiantes. Recuperando aportes de la ética analítica, la autora sostiene que los juicios de valor que realizan los docentes pueden ser analizados en la intersección de tres tipos de enunciados: 1- descriptivos; 2- persuasivos; 3prescriptivos. Desde esta perspectiva, los juicios de valor contienen información sobre hechos, sentimientos, actitudes, estados subjetivos, etc.; intentan a su vez influir en el comportamiento de los sujetos que los oyen o conocen; $\mathrm{y}$, además, buscan orientar ese comportamiento hacia determinadas finalidades.

Desde la convicción de que no es posible educar aisladamente de los valores, la autora afirma que este conocimiento sobre los juicios de valor y sus efectos nos ayuda a enriquecer nuestra reflexión sobre la práctica docente. Además, los valores son necesarios para configurar espacios seguros dentro del proceso formativo, desde los cuales los alumnos conozcan el mundo, se inserten en él y experimenten sus propias formas de ocuparlo.

“[...] "Educar -nos sugiere bellamente Philipe Meirieu- debe concebirse como el movimiento por el cual los hombres permiten a sus hijos vivir en el mundo y decidir su suerte en él. Movimiento, acompañamiento <acto> nunca acabado que consiste en <hacer un lugar> al que llega y ofrecerle los 
medios para que lo ocupe, a su modo" [...]" (Meirieu, 1996; citado en Mancovsky, 2000, p.110) $)^{102}$.

Por último, Feldman (2008) señala otro punto en el que la concepción técnica encuentra limitaciones, a saber, la implementación de las propuestas de enseñanza y curriculares. Las escuelas evidencian muchas dificultades para llevar a la práctica los planes elaborados por los especialistas.

Con el impacto de la corriente práctica y de las perspectivas teóricas que comentamos en este apartado, consideramos que se visualiza el debilitamiento ${ }^{103}$ del componente normativo en la didáctica, cuestión central para esta tesis. Por los motivos detallados, dicho componente se desdibujó con el impacto de esta corriente, poniendo en riesgo la postulación de cualquier orientación para la práctica.

No obstante, también podemos formular ciertas limitaciones que conllevó esa mirada de lo particular tan característica de esta corriente. Las formas de actuación situada no tuvieron posibilidades de propagarse hacia otros casos o probarse en otras situaciones, cayendo en el peligro de legitimar prácticas individuales en su propio contexto sin la confrontación crítica con las condiciones socioeconómicas, las ideologías o las finalidades culturales que las prácticas perseguían ${ }^{104}$.

\footnotetext{
${ }^{102}$ Meirieu. P., Frankenstein pédagogue, Paris: ESF. 1996. (En español: Frankenstein educador, Madrid: Laertes. 1998).

${ }^{103}$ Específicamente, Feldman (2008) habla de un debilitamiento de los enfoques de la didáctica general. No obstante, consideramos que es un planteo compartido por los otros autores que citamos.

104 "[...] se corre el riesgo de fortalecer irracionalismos peligrosos. En lo científico, llevaría a legitimar posiciones fenomenológicas y naturalísticas, según las cuales las teorías serían construcciones siempre específicas que surgirían del "dato" del contexto particular. Bajo el amparo de la comprensión empírica de las situaciones y su "intransferibilidad" se corre el riesgo de proteger hallazgos de dudoso valor.

En lo político, significaría un retorno al particularismo basado en la ilusión de la transparencia, que obtura la comprensión de las regularidades socio-culturales" (Davini, 2008, p.51).

Schwab (1974) para el caso del curriculum y de la intervención en él, postulaba un modo de actuación cuasi-práctico que superaba, de alguna manera, la singularidad de cada situación a partir de la construcción de criterios de intervención o de reforma curricular considerando propuestas válidas o potencialmente válidas para distintas situaciones. Esto puede ser interpretado como la posibilidad de construir normas, no universales aunque sí contemplando varios casos, al interior de una racionalidad aparentemente no propicia para ello.
} 
La revisión de estos desarrollos en la didáctica abre la puerta para un nuevo desafío en el que coinciden diferentes autores ${ }^{105}$ : la construcción de alternativas de acción de "textura abierta" (Frigerio, 1991, p.27) que dejen ciertos márgenes a los docentes para su resignificación en las prácticas de enseñanza. Estos posicionamientos rescatarían una disciplina normativa y, por tanto, con una responsabilidad directa sobre su objeto de estudio.

Aparecen, a su vez, algunas líneas interesantes para seguir indagando que, consideramos, exceden los objetivos propuestos para esta tesis. Específicamente nos referimos a los marcos referenciales desde los cuales los sujetos interpretan las normas para ponerlas en juego en sus propias prácticas de enseñanza.

En síntesis, consideramos a partir de todo lo expuesto que tanto para el caso de la didáctica como del curriculum, en la década del '80 se produjo la recepción de diferentes corrientes teóricas que ya se habían desarrollado en el mundo pero que aquí se retrasó su conocimiento como consecuencia de la dictadura militar, y este proceso contribuyó a la ampliación del caudal explicativo/comprensivo y, consecuentemente, a la relegación del componente normativo.

Feldman y Palamidessi (1994), en una defensa del curriculum como texto normativo que sirva para la regulación y orientación de las prácticas educativas, reconocen cómo diferentes conceptos (especialmente ponen el ejemplo del curriculum oculto) y teorías contribuyeron al enriquecimiento disciplinar pero progresivamente colaboraron en que se fuera descuidando el valor instrumental.

“[...] El curriculum es, entonces, producto de un acuerdo intersubjetivo con diferentes grados de explicación y complejidad. Como todo texto, es pasible de diversos usos y lecturas, pero, como toda materialidad, impone, de hecho, límites a la interpretación. Por su carácter normativo el texto curricular debe proponerse particularmente restringir los márgenes de interpretación ya que, de otro modo, se diluye su capacidad regulativa.

Limitar la polisemia en el texto curricular no implica que éste cierre el campo al desarrollo o se constituya como un paquete cerrado "a prueba de profesores". Simplemente, señala la exigencia de un lenguaje curricular 105 Salinas Fernández (1995); Candau (1996); Davini (1996; 2008); Cols (2003a); Araujo (2006); Feldman
(2008). 
claro, que permita su desarrollo en la práctica y facilite una acción deliberativa sobre la base de significados compartidos [...]" (Feldman y Palamidessi, 1994, p.70).

Sostenemos que aquí se presenta una tensión compleja de resolver a los fines de esgrimir que estas disciplinas son de carácter normativo: se trata de hallar un equilibrio entre regular la práctica para satisfacer las intencionalidades formativas propuestas y los márgenes de interpretación que le deben quedar al docente para su actuación profesional, lo cual implica la interpretación de la norma ${ }^{106}$.

\section{II - 5 - Didáctica y curriculum: algunas notas actuales para concluir.}

Palamidessi y Feldman (2003) destacan que al final de los años '80 el curriculum en nuestro país fue ampliando sus áreas de incumbencias y sus preocupaciones, abarcando temas y problemas que tradicionalmente ocupaban a la pedagogía y a la didáctica. También postulan que con la reapertura democrática la didáctica se presentaba como una disciplina de poco prestigio académico que concentraba el tratamiento de la enseñanza y de la institución educativa. Por su parte, los trabajos de política y sociología de la educación, brindaban muy buenas herramientas conceptuales para analizar los rasgos autoritarios instalados en el período anterior pero no aportaban elementos para encarar el mejoramiento de las escuelas. En este contexto, para los autores, el curriculum juega en un espacio de intersección o de "lengua franca" (p.13), posibilitando la comunicación y el intercambio entre los sujetos de los distintos campos involucrados.

Para Feeney, en nuestro contexto nacional, "[...] estamos obligados a integrar la teoría curricular a la didáctica general" (2007, p.191). La didáctica representa para la autora un horizonte de sentido que se desarrolló como

\footnotetext{
${ }^{106}$ Tensión similar enuncia Terigi (1999) en el análisis de las características de las políticas curriculares. Para la autora se da una dinámica entre el control que dichas políticas intentan ejercer sobre las prácticas a las que se refieren y la apropiación que de las mismas realizan los docentes, resignificándolas, adecuándolas a sus prácticas educativas concretas.
} 
campo disciplinar ${ }^{107}$ en la Argentina con anterioridad a la entrada del curriculum, y que siguió "filtrando" las categorías y los modos de pensar aún en las obras curriculares nacionales.

Según Feeney no es posible hablar de un campo del curriculum en la Argentina. La autora toma la concepción de campo académico de Bourdieu ${ }^{108}$ y entiende que la producción curricular nacional no se ajusta a las "reglas de juego", como demandaría la presencia de un campo intelectual.

“[...] En relación con el currículo, podemos decir que no existe un grado de capital cultural acumulado cuya posesión funcione como requisito para ingresar al campo. Se pone de manifiesto una débil estructuración y una baja autonomía relativa del «campo» de los estudios curriculares en la Argentina, que impacta de tal forma que la decisión acerca de qué se investiga y cómo, y la evaluación de esas producciones, vienen impuestas desde afuera, desde otros campos disciplinares con mayor tradición en nuestro país, tales como el de la didáctica y la política [...]" (Feeney, 2007, p.188).

Feeney caracteriza el curriculum como un "satélite de la didáctica y de la política", visualizándolo en una relación de dependencia con respecto a las otras disciplinas. A su vez, expresa que el impacto que ha tenido la teoría curricular en la tradición de didáctica general en nuestro país impide estudiar la didáctica al margen del curriculum. Consideramos que esta afirmación es central para esta tesis y, de alguna manera, sustenta el ejercicio que venimos haciendo en este capítulo para entender las relaciones entre didáctica y curriculum.

Finalmente, la autora afirma -aunque esto sea controvertido- que en nuestro país y considerando las vinculaciones entre la tradición didáctica y la curricular, es necesario integrar la teoría curricular al campo de la didáctica ${ }^{109}$.

\footnotetext{
${ }^{107}$ Feeney utiliza la noción de "campo disciplinar" desde aportes de Bourdieu y lo entiende como: 1- un campo se configura a partir de una red de relaciones entre las posiciones; 2- se puede comparar el campo con un juego; 3- existen reglas de juego comunes y compartidas por los sujetos que lo conforman; 4- hay un capital cultural acumulado que le permite a su poseedor ejercer poder y legitimarse dentro de un campo particular.

La autora complementa la definición anterior con un aporte de Schwab para quien un campo disciplinar se caracteriza por poseer producción discursiva sobre su objeto de estudio y así plantear temas, problemas y debates que repercuten en el mismo.

${ }^{108}$ Bourdieu, P. (1983). Campo del poder y campo intelectual. Buenos Aires: Folios.

${ }^{109}$ Es importante citar aquí a Camilloni $(1996 ; 2007 c)$ cuando dice que el curriculum es un objeto del que se ocupa la didáctica. A su vez, la autora presenta la posibilidad desde algunas perspectivas teóricas de reemplazar a la didáctica por el curriculum, siendo éste último uno de sus objetos que ha cobrado un impulso importante en los últimos años.
} 
Complementariamente, Cappelletti y Feeney (2000) reconocen las vinculaciones que el curriculum mantuvo con la didáctica y también con la sociología de la educación y con la política educativa. A propósito de esta última, es de destacar que el impulso que las reformas e innovaciones educativas tuvieron en Argentina desde el año 1989 contribuyó a que una temática central en la didáctica fuese "cómo diseñar el curriculum".

Este proceso les permite -en parte-fundamentar que el curriculum sea un satélite también de la política educativa. Pero además mencionan la baja producción teórica curricular en nuestro país en los años '90, que no ha acompañado este proceso de diseño y transformación educativa.

Lo planteado aquí representa, consideramos, una hipótesis sobre la forma en la que se vincula la didáctica con el curriculum en nuestro país en la actualidad. Palamidessi y Feldman (2003) presentan una postura con algunas diferencias, pero sin defender la autonomía de los estudios del curriculum.

En primer lugar, podemos decir que estos autores también reconocen una desproporción entre la difusión del término curriculum y los usos que se le han dado en las reformas educativas de los '90, y la producción teórica sistemática en la disciplina. Expresan, además, que la teoría curricular en la década del '80, como vimos, ofreció categorías útiles para analizar los rasgos autoritarios del sistema educativo, los efectos de la dictadura en la educación, la necesaria democratización, etc. No obstante, estos discursos carecían de potencialidad para mejorar las prácticas educativas reales de las escuelas. Con otros términos y en el marco de otras argumentaciones, estamos reiterando esta tensión central entre los aspectos comprensivos y los normativos en la didáctica y el curriculum.

Consideramos que quedan aspectos por indagar pero exceden el período seleccionado para esta tesis. Las relaciones entre la didáctica y el curriculum, tal como las estamos analizando, apoyan estas hipótesis, sobre todo la propuesta por Feeney (2007) en cuanto a que no es posible estudiar la didáctica general sin considerar el impacto que en ella ha tenido la teoría curricular. 
No obstante, es posible pensar algunas diferencias que presentan la didáctica y el curriculum en torno a la configuración de su componente normativo. En la didáctica, como dijimos, el componente normativo se ha ido desdibujando en la década del '80, y el estado de reconceptualización por el que atraviesa esta disciplina, lo sigue revisando aún en nuestros días. Por su parte, en la teoría curricular aparece un fenómeno similar de engrosamiento del caudal interpretativo, pero sostenemos que el curriculum como texto normativo no pudo abstraerse de sus responsabilidades con respecto a las prácticas educativas.

Quedan así algunas indagaciones pendientes acerca de cómo se configuran estas características normativas en una racionalidad crítica tanto para el caso del curriculum como proyecto de formación general como para los niveles más específicos de programación de la enseñanza. Esta tensión es difícil de resolver, sobre todo si tomamos los aportes de Bolívar Botia (1999) cuando expresa que las teorías críticas pueden ser mejor pensadas como una plataforma con categorías para el análisis minucioso que como propuestas sistemáticas de intervención, vertiente esta última que iría en contra de los sentidos de la crítica.

Específicamente en lo que respecta a la didáctica, podemos mencionar algunos planteos que se generan en este momento de reconceptualización que está atravesando.

Salinas Fernández (1995), por ejemplo, sostiene que en la actualidad el discurso didáctico está atravesado por una serie de cuestiones significativas. Por un lado, nos encontramos con una expansión disciplinar importante en cuanto a la diversidad de producciones y temas concernientes al objeto de estudio, con el consecuente peligro de desdibujar el objeto así como también que el término pierda su capacidad de discriminación ${ }^{110}$.

Por otro lado, el discurso de la didáctica se encuentra en un estado de cierto "relativismo epistemológico" acompañado de un abandono del carácter

\footnotetext{
${ }^{110}$ Terigi (1999) plantea algo similar para el caso del curriculum. La autora expone que en la actualidad el campo curricular abarca una multiplicidad de temáticas, llegando, en algunos casos, a utilizarse como sinónimo de lo educativo. De esta manera, el propio concepto se halla en peligro perdiendo su potencialidad discriminativa.
} 
propositivo de la teoría. La influencia de la corriente práctica y el lugar que en la misma se le asigna al docente como práctico reflexivo imprimió un giro a la disciplina, como vimos. Según expresa el autor, la didáctica se encuentra en esta reubicación ante el desafío de cómo se puede enseñar -lo que representa el desarrollo de su faz normativa histórica-, pero queriendo diferenciarse de un discurso psicologicista - del que se deriva cómo enseñar a partir de saber cómo se aprende- y de otro socio-político crítico -que enfatiza la explicación de las funciones sociales de la escuela.

Según Salinas Fernández, la potencialidad explicativa, comprensiva o transformadora que en la actualidad los desarrollos teóricos de la didáctica esgrimen como alternativa a la potencialidad normativa, lleva a la disciplina a una posición que puede caracterizarse por dos extremos igualmente novedosos. Por una parte la didáctica se encuentra abandonando sus intenciones en cuanto al estudio y la regulación de las prácticas del aula, dejando de lado los esfuerzos comenianos en torno al método de enseñanza. Por otra parte, la didáctica corre el riesgo de posicionarse en la construcción de un discurso crítico en torno a la educación como proceso socio-histórico de reproducción cultural.

Retomando la cuestión de la "base normativa" -parafraseando a Davini (1996; 2008)- es de interés situar el debate en los deslizamientos teóricos que Salinas Fernández conceptualiza para la didáctica en los últimos años.

“[...] resulta complicado elaborar un discurso didáctico que, recién abandonado el reduccionismo psicologicista (cómo aprende el niño según las últimas investigaciones $\mathrm{y}$, por tanto, cómo se debe enseñar), se sitúa ante una teoría sociológica crítica (qué funciones desempeña la escuela en las sociedades capitalistas postindustriales) y a partir de ello, o a pesar de ello, se enfrenta ante el problema de cómo se puede enseñar" (1995, p.54).

Candau (1996), por su parte, propone la revisión crítica de una didáctica instrumental y la construcción de una didáctica fundamental. La primera está conformada por un conjunto de reglas de carácter universal acerca del cómo hacer, desvinculado del contexto social y político en el que se lleva a cabo la enseñanza, de los contenidos que se transmiten y de los fines que se persigue. En la crítica a esta didáctica tecnicista resta el desafío de la construcción de un 
campo disciplinar -que la autora denomina didáctica fundamental- sustentado en al menos cuatro pilares: 1- la consideración del proceso de enseñanza y de aprendizaje desde una perspectiva multidimensional que contemple la faz técnica, humana y política; 2- la explicitación de los supuestos teóricos, epistemológicos, metodológicos que subyacen a la construcción del conocimiento; 3- la necesaria relación teoría y práctica; y 4- la búsqueda de una eficiencia pedagógica no desgajada de una transformación social adecuada a la mayoría de la población del país.

Sin profundizar en otro tipo de comparación, nos presentamos una similitud entre Salinas Fernández (1995) y Candau (1996) en el punto de postular algunas características comunes para el campo de la didáctica. Ambos autores están en contra de una disciplina que postule reglas universales acerca del cómo hacer en las prácticas de enseñanza. Pero el abandono de este tipo de pretensiones no está acompañado por una renuncia del componente normativo. Por el contrario, postulan una disciplina que intervenga, que posea un discurso de carácter propositivo, que diga cómo actuar en las prácticas, porque es adecuado en un determinado contexto áulico, institucional y social.

Por otro lado, Davini (2008), como ya expusimos, sigue sosteniendo las caracterizaciones realizadas por ella misma sobre la didáctica algunos años antes. Las necesidades de las prácticas de enseñanza y de los docentes demandan a la didáctica establecer ciertos criterios básicos y metodológicos para la acción, pero esta disciplina, en los últimos tiempos, se ha distanciado de estas intencionalidades.

En este corrimiento de la función normativa de la didáctica, además de los factores y procesos ya mencionados en esta tesis, la autora enuncia algunos otros que denomina extra didácticos y que contribuyen a esta situación, a saber: el fracaso de las utopías modernas, la crisis del sistema educativo y el debilitamiento del discurso y las propuestas de la pedagogía.

No obstante, es necesario que la didáctica brinde dichos criterios para la orientación de la acción y de los sujetos, permitiéndoles a estos últimos hacer ejercicio de su profesionalidad, tendiendo al mejoramiento de la enseñanza. La 
ausencia de estas intervenciones didácticas convalidaría una práctica educativa artesanal o intuitiva, en abierta contradicción con un punto esencial que se refiere a la educación como proceso social y de carácter público, por lo tanto,

“En la nueva perspectiva de la didáctica debiera plantearse, respecto de la normativa, un mínimo de acuerdo que, aun reconociendo que supone marcos teóricos a probar, represente conocimientos públicos, es decir que puedan compartir y utilizar otras personas y no sean patrimonio de la intuición intransferible del sujeto que investiga o que enseña" (Davini, 1996, p.51).

También es interesante la forma en la que Cols (2003a) plantea este desafío para la didáctica. Nuestra disciplina debe trabajar en la construcción de principios con cierto grado de generalidad, referidos a la buena enseñanza en articulación con interpretaciones sobre el trabajo del docente en el aula y la manera en la que se lleva a cabo la enseñanza.

Por su parte, Araujo (2006) sostiene que la producción didáctica de la década del '90 contempla el dilema explicación-proyección/proposición aunque deja de lado el tratamiento universal del método y la prescripción uniforme para el desarrollo eficaz de la enseñanza.

Nos permitimos poner un paréntesis a estas reflexiones que retomamos en la segunda parte de la tesis, para avanzar ahora sobre algunas problemáticas que se presentan en la reflexión epistemológica y metodológica con respecto a la normatividad. Tratamos a su vez de establecer permanentemente conexiones con lo acaecido históricamente, como vimos hasta aquí, en la didáctica y el curriculum. 


\section{CAPÍTULO III: \\ CONSTRUYENDO CRUCES ENTRE LAS DISCIPLINAS: APORTES PARA \\ ENRIQUECER EL DEBATE EN TORNO A LA \\ NORMATIVIDAD ${ }^{111}$}

El eje que da estructura a este capítulo se configura a partir de lo que hemos denominado cruces entre las disciplinas. Los conceptualizamos como aquellos puentes que hemos tendido con el propósito de utilizar problemas y esquemas interpretativos surgidos en los planos epistemológico y metodológico acerca de la normatividad, para analizar las distintas posturas que en torno al mismo aspecto aparecen en la didáctica y el curriculum.

La especificidad de la normatividad y las distintas posiciones que se generan en su conformación en cada caso constituyen el núcleo de dichos cruces. De esta manera, el recorrido por la didáctica y el curriculum realizado en el capítulo II se utiliza como criterio desde el cual mirar los problemas y esquemas interpretativos que con respecto a la normatividad aparecen en la reflexión epistemológica y metodológica en las ciencias sociales, así como en la sociología de la ciencia y del conocimiento, para luego con ellos enriquecer el análisis en nuestras teorías de base.

En segundo lugar, sostenemos que indagar acerca de la constitución de la didáctica y el curriculum como teorías normativas demanda categorías teóricas disciplinarias e interdisciplinarias pero, además, elementos metateóricos que conduzcan a un conocimiento más profundo o de segundo orden.

Considerando que estos cruces entre las disciplinas constituyen el eje que estructura y da sentido al presente capítulo, tomamos la conceptualización de eje que utiliza Barco (1996). La autora habla de "un eje curricular" que adopta las características de una Banda de Moebius, que a medida que se va desarrollando conforma una helicoidal que en su vacío interior dibuja el eje. A

\footnotetext{
${ }^{111}$ Cabe mencionar que este capítulo recupera para su elaboración los avances que se lograron en la tesis de maestría ya mencionada en la introducción, pero profundizando y ampliando su alcance en vistas a abordar el nuevo objeto de estudio.
} 
los fines de nuestro trabajo, el movimiento del eje nos permite organizar y vincular las posturas y reflexiones acerca de la normatividad, y enriquecer su reflexión en la didáctica y el curriculum a partir de categorías propias de los planos epistemológico y metodológico. No descartamos la posibilidad de que los análisis suscitados aporten elementos para la reflexión en estos últimos campos y en las ciencias sociales en general.

Los cruces que abordamos son los siguientes:

1 - Carácter de la norma en una teoría normativa.

2 - Aspectos que constituyen la norma.

3 -Relaciones entre aspectos normativo/prescriptivos y descriptivo/interpretativos en la conformación de una teoría normativa.

4 -Disponibilidad de saberes interdisciplinarios para realizar una reflexión de segundo orden.

5 - Teorías de alcance intermedio o teorías cercanas a la práctica.

Cabe mencionar que hacemos aquí un tratamiento de carácter más conceptual de estos cruces entre las disciplinas, reservando para los capítulos que integran la segunda parte de esta tesis el diálogo crítico entre los mismos y el análisis que surge de las obras de didáctica y de curriculum que integran el corpus empírico.

\section{III - 1 - Carácter de la norma en una teoría normativa.}

Como definimos en la introducción, entendemos la epistemología como la teoría que se ocupa de las condiciones de producción y de validación del conocimiento científico, ofreciendo la posibilidad de realizar un ejercicio crítico sobre la ciencia (Klimovsky, 1994). La metodología, por su parte, se ocupa de la reflexión sobre los supuestos y métodos involucrados en la producción de conocimiento científico. Como ya explicitamos, el punto de confluencia se produce cuando sostenemos que toda forma de entender la metodología 
conlleva un posicionamiento epistemológico (Klimovsky, 1994; Piovani et al, 2008).

En este sentido, la reflexión epistemológica y la metodológica consisten en un trabajo de análisis metateórico sobre una ciencia en particular y que, como planteamos en el cruce 4, requiere de la disponibilidad y articulación de saberes interdisciplinarios; entre ellos aquéllos específicos de la ciencia sobre la que se reflexiona y aquéllos otros metateóricos que permiten el ejercicio persistente y creador con el que Vasilachis (2008) identifica la reflexión epistemológica.

Haciendo foco especialmente en la normatividad, podemos decir que se ha producido una transformación en la forma de entenderla en la segunda mitad del siglo XX. En líneas generales, se ha pasado de una concepción normativista a priori ligada a la hegemonía de la visión estándar o canónica de la ciencia, expresada en la obra de autores como Popper -y en cierta medida en la sociología de la ciencia mertoniana en los años '40- a un planteo de epistemología a posteriori (Martínez y Olivé, 1997112) asentado en la interpretación de las prácticas científicas.

La sociología de la ciencia, para Merton, se dedicaba a estudiar la estructura cultural de la ciencia porque ésta era una institución social autónoma. La norma se entendía como el ethos de la ciencia que era internalizado por los científicos durante su formación y aplicado sin mayores cuestionamientos para alcanzar el conocimiento válido ${ }^{113}$. La comunidad científica defendía ese ethos, conformado por un conjunto de prescripciones de carácter moral y técnico, con prohibiciones y castigos en vistas a la ampliación del conocimiento científico comprobado, como una de las metas institucionales de la ciencia.

Por estas consideraciones, la propuesta de Merton va a ser definida por Bloor (1998) como sociología del error, ya que la sociología de la ciencia debía

\footnotetext{
${ }^{112}$ Los autores utilizan esta expresión para dar cuenta de las funciones que consideran adecuadas para la epistemología naturalizada. Sin profundizar en ella en esta tesis, recuperamos la mirada explicativa que los autores le asignan a la epistemología a posteriori sobre las formas en que las ciencias han construido sus conocimientos.

${ }^{113}$ Entre los autores que así lo analizan podemos citar a: Merton (1970); Prego (1992); Kreimer (2005).
} 
explicar las causas que contribuían a la producción de conocimiento científico falso. Se suponía que la aplicación correcta del ethos de la ciencia conducía a la producción de conocimiento válido y comprobado, pero su incorrecta aplicación derivaba en conocimiento falso que demandaba una explicación sociológica que diera cuenta de la interferencia social externa en el normal desarrollo del trabajo científico.

Desde finales de los años '60 con la revolución cognitivista y hasta mediados de los años '70 con el movimiento heterogéneo denominado "sociología de la ciencia posmertoniana", se han producido diversos cambios en la forma de entender la epistemología, sus incumbencias y alcances. En lo que respecta a nuestros intereses, se produjo aquí una transformación sustancial en la concepción de la normatividad. Progresivamente se ha transitado hacia perspectivas que indagan la apropiación que realizaban los científicos de esas normas. La nueva mirada que se configuró dejó de entender la ciencia como un corpus normativo y empezó a pensar la adquisición de las normas como parte de un proceso interpretativo mediado por la comunidad científica ${ }^{114}$.

Prego (1992) señala que la postura de Merton se enmarcaba en la filosofía estándar de la ciencia, fortalecida por el pensamiento neopositivista y el reconocimiento de que el conocimiento científico poseía un status epistemológico de privilegio.

Hacia fines de los años '60, como ya mencionamos, se produjo un cambio en estas concepciones que el autor ubica en el campo metacientífico y describe así: "[...] momento de la transición en la consideración de la cualitativa socialidad intrínseca de la ciencia [...]" (Prego, 1992, p.12). Este campo metacientífico comprendía aquellos estudios metateóricos ${ }^{115}$ tradicionalmente realizados por la epistemología y los cambios en él producidos habilitaban la potencialidad de los estudios sociológicos, cuestionando la imagen consolidada de ciencia, y retomando un camino ya iniciado en el plano filosófico por el denominado giro

\footnotetext{
${ }^{114}$ Entre los autores que lo analizan de esta manera podemos citar a: Prego (1992); Olivé (2004); Kreimer (2005).

${ }^{115}$ Follari (2000) en un sentido similar, se refiere a una reflexión de segundo orden que toma a las ciencias como objeto y que es llevada a cabo por una epistemología "débil"; denominación que adquiere al perder el carácter normativizante tradicional con posterioridad a la difusión de la obra de Kuhn.
} 
kuhniano. Este tipo de estudios abarcaba reflexiones y análisis que se realizaban sobre el conocimiento científico, incluidas la filosofía, sociología de la ciencia, sociología del conocimiento, historia de la ciencia, entre otras disciplinas.

La obra de Kuhn, Estructura de las revoluciones científicas, apareció publicada en 1962, pero sus mayores efectos se sintieron con su difusión en la década del '70 de la mano de la sociología del conocimiento científico (Valero Matas, 2004).

Prego, retomando a Toulmin, dice que esta transición se incorporaba en un proceso mayor de transformación cultural, en el que aparecía la crisis de la concepción heredada de ciencia ${ }^{116} \mathrm{y}$, consecuentemente, la emergencia de la nueva filosofía de la ciencia. Para el autor, en un plano sustantivo aparecieron una serie de transformaciones que vale citar:

\begin{abstract}
“[...] la llamada carga teórica de la observación; el papel de los elementos presuposicionales en la constitución del conocimiento científico, el problema de la irrefutabilidad de las teorías, la discontinuidad (noacumulativa) en el desarrollo de la ciencia, el peso de la tradición teórica en el desempeño cotidiano de la investigación; el reconocimiento de la problemática heurística y la indagación en torno a la diversidad y peculiaridad de los patrones de razonamiento en uso efectivo por las comunidades de investigadores; el lugar del elemento tácito, no articulado, en la orientación de la actividad científica" (Prego, 1992, p.13. La cursiva figura en la edición consultada).
\end{abstract}

La enumeración, aunque somera, de estas transformaciones nos permite dimensionar su magnitud, no sólo para la reflexión metateórica sino también para la misma producción de conocimiento científico en las ciencias sociales. Para Prego fue significativo el hecho de que las primeras formulaciones hayan surgido de la mano de la historia de la ciencia, primero porque se enfatizaba la aparición de un momento descriptivo frente a la orientación normativista arraigada en la visión clásica y en la popperiana especialmente; segundo porque frente a las generalizaciones propias del período clásico emergieron el análisis de casos y los trabajos más específicos y contextuales, rasgos propios de los desarrollos kuhnianos.

\footnotetext{
116 "Concepción heredada del conocimiento científico" es una expresión que Prego toma de Hilary Putman, 1960, primer Congreso Internacional de Lógica, Metodología y Filosofía de la Ciencia, Stanford, California.
} 
Se generaron cambios también en lo que respecta a la presencia de un conjunto único de criterios que regía las transformaciones teóricas producidas, una metodología neutral desde el punto de vista teórico y la concepción de la ciencia como un proceso acumulativo y lineal.

Contra la visión mertoniana que defendía un estado de acumulación permanente y no problemática en la investigación científica, Kuhn y sus seguidores postularon un proceso de acumulación durante los períodos de ciencia normal, pero también rupturas y revoluciones al abandonar un paradigma ${ }^{117}$ y adoptar otro inconmensurable respecto del anterior.

En este sentido, Kreimer (2005) plantea que estas críticas a la acumulación del conocimiento se relacionaron con los postulados kuhnianos relativos a la validez de un paradigma. Ésta ya no estaba dada por su carácter de verdad intrínseca sino que se asentaba en la creencia que tenía depositada la comunidad científica en el paradigma. Desde este punto de vista, el análisis sociológico no podía dejar de abordar las fuentes de legitimidad de un paradigma.

En el campo de la sociología de la ciencia en la década del '60, Prego (1992) describe la oposición entre la sociología norteamericana de corte estructural-funcionalista y la sociología inglesa. En ambos contextos se produjeron matrices diferentes que articularon, por tanto, significados distintos en la recepción del impacto que tuvo la obra de Kuhn. Así, la perspectiva mertoniana buscó reiterar el papel de los elementos consensuales en el desarrollo del conocimiento científico, mientras que para la tradición inglesa emergente Kuhn representaba una suerte de "recurso interpretativo flexible" que permitía abrir nuevos interrogantes y alejarse de la tradición mertoniana:

“[...] veía en Kuhn una representación de conjunto cuyo mayor valor radicaba en la integralidad con que ilustraba la posibilidad teórica de reconducir sistemáticamente la construcción de los cuerpos conceptuales de

\footnotetext{
117 “[...] Su concepto clave es el de PARADIGMA. Según la posdata de 1969 a su libro apenas citado, paradigma puede entenderse en un doble sentido: a) a nivel más general, como un conjunto de generalizaciones simbólicas, modelos heurísticos, valores comunes y soluciones ejemplares compartidas por una comunidad científica en un momento dado; b) en un sentido restringido, como decisión ejemplar relativa a la solución exitosa de algún tipo específico de problema científico" (Archenti y Piovani, 2007, p.34. La tipografía "versales" figura en la edición consultada).
} 
la ciencia a categorías de sustancia social y cultural, a la vez que éstas parecían adoptar una característica y definida significación cognitiva" (Prego, 1992, p.27).

Para Prego, esta última característica contribuyó a que el nuevo movimiento en sociología de la ciencia adquiriera un carácter diverso. No obstante, señala algunos elementos que estuvieron en el origen de la nueva configuración que considera centrales para interpretar los rumbos posteriores y la forma en la que los mismos aparecieron resignificados en mayor o menor medida. Consideramos importante detenernos en ellos aunque más no sea someramente.

El primero de estos elementos comunes se constituyó en la oposición al ethos normativo mertoniano. Éste es criticado desde el planteo que hace Kuhn articulando "[...] los componentes metodológicos y las presuposiciones teóricas, con la consecuente introducción del elemento de variabilidad histórica y contextual del repertorio evaluativo a través del cual se actualizan los juicios de la comunidad científica [...]" (Prego, 1992, p.29). La nueva mirada que se configuró para la sociología del conocimiento dejó de entender a la ciencia como un corpus normativo y empezó a pensar la adquisición de las normas como un proceso interpretativo y mediado por la comunidad científica, como adelantamos.

El segundo aspecto que estuvo presente en el origen de las oposiciones a la sociología de la ciencia de Merton se relacionó con el carácter local de las normas y las tradiciones que permitieron asociar los compromisos de la comunidad científica con una manera específica de producir ciencia.

La tercera característica destacada por Prego (1992) y emplazada en esta nueva configuración de la sociología del conocimiento se refiere al lugar que desempeñaba el conocimiento tácito en los aprendizajes, en la socialización de los científicos en una comunidad y en los saberes que la misma empleaba. A estas cuestiones Kuhn dedicaba parte de su trabajo.

La recuperación del punto de vista del actor se constituye en el cuarto aspecto que sustentaba el nuevo movimiento, y adquirió, dice Prego (1992), características particulares en el análisis metateórico. Por un lado aparecía en el 
trabajo del científico social que buscaba interpretar su objeto de estudio, y por el otro en el análisis metateórico del sociólogo del conocimiento. Presente en ambas instancias estaba la preocupación por la comprensión de los significados subjetivos sin atribuir sentidos externos que pudieran emparentarse con la tradición normativista que se intentaba dejar atrás.

A su vez, se demandaba articulación entre la perspectiva metateórica y el conocimiento técnico de la especialidad sobre la que se reflexionaba. Fueron criticadas las posturas que desconocían las ideas científicas que formaban parte de sus objetos de estudio, en parte vinculado a esta idea de no imponer interpretaciones o sentidos externos a la propia comunidad.

Por último, el quinto rasgo se refiere al consenso y se vincula con la socialidad de la ciencia y el lugar que desempeñaba la comunidad científica. Dice Prego (1992) que el punto de vista del actor no se refiere al individuo particular sino a la comunidad científica como sujeto. Asimismo, Kuhn también reconoce la existencia de consenso entre los científicos en el período de ciencia normal, no obstante el mismo se disuelve con las revoluciones y cambios de paradigmas.

Las nuevas orientaciones cognitivistas fueron armando así su propuesta para la sociología del conocimiento en clara oposición al trabajo previo de Merton. Se incluían también aquellas perspectivas más interpretativas que progresivamente fueron consolidándose como "la alternativa cualitativa"118 para el estudio de los fenómenos sociales.

Prego (1992) alude a un primer momento cognitivista en el período que denomina de transición, en el que se tomó la obra de Kuhn y se rescataron de ella casi exclusivamente los elementos cognitivos o, dicho de otra manera, aquellos aspectos que permitieron sustentar desde la obra kuhniana el movimiento cognitivista y la oposición a la perspectiva estructural-funcionalista mertoniana en la sociología de la ciencia. Posteriormente, el giro interpretativo intentó tomar distancia de estas primeras formulaciones, recuperando de la

\footnotetext{
118 Retomamos más adelante estas cuestiones con el debate cuantitativo-cualitativo. Para profundizar, se puede consultar: Archenti y Piovani (2007); Piovani et al. (2008).
} 
obra de Kuhn otros elementos, como por ejemplo, aquéllos que se referían al lugar de las normas y la ciencia normal. Este giro realizó otra lectura de Kuhn, destacando aspectos inicialmente poco considerados y que volvió la mirada autocrítica sobre las propias producciones de los primeros autores cognitivistas.

Retomamos en los próximos apartados algunas consecuencias del giro interpretativo y otros movimientos que le siguieron, pero baste aquí plantear estas cuestiones para visualizar los cambios que se produjeron en torno al enfoque normativo de la ciencia119.

Por otra parte, en lo que respecta a la reflexión metodológica, podemos pensar que tanto en el enfoque estándar como en el no estándar ${ }^{120}$, aparece ese lugar de prescripción/normatividad desde el que la metodología dice cómo las ciencias sociales -en nuestro caso- deben investigar sus objetos de estudio. A pesar de esta observación, encontramos una serie de trabajos que se ocupan de reflexionar acerca de si le corresponde a esta disciplina un carácter prescriptivo y/o descriptivo.

Marradi (2007b), por ejemplo, sostiene que se la puede postular como una disciplina normativa ya que brinda orientaciones acerca de lo que es oportuno hacer en cada situación específica. No obstante, tales orientaciones no deben basarse en un modelo abstracto de cómo hacer ciencia, sino que deben partir de la información brindada por la historia y la sociología de la ciencia, disciplinas que realizan un estudio empírico de las prácticas científicas.

Schuster (2007) plantea que soluciones actuales buscan conciliar en una postura intermedia o en una suerte de conjunción entre los aspectos normativos y descriptivos que conviven en la metodología. Estas propuestas superadoras articularían la definición de normas acerca de cómo deben ser las prácticas con indagaciones empíricas acerca del trabajo real de los científicos.

\footnotetext{
119 Según Prego, Law -representante de lo que se denomina "cognitivismo secundario"- es uno de los primeros autores en llamar "teoría o enfoque normativo" a la sociología que se desprende del estructural-funcionalismo. (Law, John (1973): "Theories and Methods in the Sociology of Science: an Interpretative Approach", en Social Science Information, vol. XIII, N 4-5, (agosto de 1974, pp.163-172), pp.164-165; citado en Prego, 1992, p.58).

${ }^{120}$ La caracterización que realizamos de estos enfoques en la metodología está tomada principalmente de Archenti y Piovani (2007); y de Marradi (2007a).
} 
Estos estudios permiten concluir que las normas derivadas de la epistemología y la metodología para la orientación del trabajo de los científicos no pueden desconocer el aporte de la investigación empírica de las prácticas reales. Si bien lo profundizamos a continuación, baste aquí explicitar que la formulación de las normas no puede realizarse al margen del conocimiento de las prácticas, modificándose de esta manera su carácter abstracto y a priori.

\section{III - 2 - Aspectos que constituyen la norma.}

En este apartado y recuperando el desarrollo realizado previamente, pretendemos explorar los aspectos que intervienen en la constitución de la norma en los planos epistemológico y metodológico, reservando un lugar especial para la investigación empírica, sustentado en la importancia que adquirió la descripción e interpretación de las prácticas científicas en las críticas a las prescripciones abstractas y con pretensiones de universalidad.

Diferentes autores, entre los que podemos incluir a Schuster (2001), Olivé (2004) y Kreimer (2005), por ejemplo, permiten afirmar que a partir de las rupturas que se produjeron en el plano metateórico en las décadas del ' 60 y '70 hubo una recuperación de las prácticas científicas que comenzó a cambiar ese carácter a priori de la prescripción.

Schuster (2001) sostiene que la filosofía de la ciencia debe reservarse un rol normativo que pueda decir qué es lo que está bien y qué lo que está mal. No obstante, esta normatividad no debe constituirse al margen de las prácticas científicas reales. Este autor observa que en los años '70 se produjo un corrimiento de la tradicional postura normativa de la epistemología, en parte provocado por el ingreso de científicos sociales al campo. Esto ocasionó una recuperación importante de las prácticas científicas cuya explicación y análisis se instaló en el centro de las preocupaciones metateóricas. Posturas más actuales, entre las que aparece la del autor, propugnan la articulación de estos dos componentes que permanecieron separados $\mathrm{y} / \mathrm{o}$ valorizados 
alternativamente. Así, para Schuster, tanto la epistemología como la metodología deben decir qué es lo que se debe hacer, pero sin desconocer las condiciones reales de trabajo de los científicos y lo que las ciencias han alcanzado.

Por otra parte, el trabajo de Olivé (2004) resulta interesante para este análisis en tanto focaliza su atención en el giro practicista. Desde esta perspectiva, se reserva un lugar para la interpretación de las normas por parte del sujeto, en oposición a aquella relación lineal que proponía la perspectiva estándar.

Olivé (1985), por otra parte, postula que Merton se inscribía en una concepción tradicional que separaba las incumbencias de la sociología de la ciencia de aquellos problemas de la teoría del conocimiento como disciplina filosófica. De esta manera, cada disciplina tenía sus objetos de estudio y sus campos de injerencia, sin traspaso de límites ni cruzamientos. La sociología de la ciencia abarcaba la dimensión social del conocimiento mientras que la teoría del conocimiento se ocupaba de los problemas referentes a la naturaleza y validez del conocimiento.

En este sentido, distingue entre una sociología del conocimiento estrecha y una amplia. La primera establecía una tajante distinción entre las reflexiones filosóficas y sociológicas acerca del conocimiento. Frente a estos posicionamientos, desde 1960 se desarrolló una sociología del conocimiento amplia.

"[...] entendida como una disciplina integral en la que están elaborados
sistemáticamente tanto conceptos sociológicos como conceptos
epistemológicos que se encuentran estrechamente relacionados, y que
permite entender y explicar problemas sobre la génesis, aceptación y
desarrollo del conocimiento, de una manera ventajosa con respecto a las
teorías sociológicas o epistemológicas tradicionales" (Olivé, 2004, pp.63-64).

Para Olivé, en la sociología del conocimiento amplia han influido diferentes fuentes, entre ellas, la sociología, la filosofía y la historia, y en los últimos tiempos han cristalizado en lo que se conoce como "estudios sociales de la ciencia". Como otros autores ya mencionados, destaca la influencia central de 
Kuhn. Se concentra en la dimensión normativo-valorativa de la ciencia y en la reflexión en torno a las normas (epistémicas, metodológicas, éticas) que en los estudios sobre la ciencia se generó a partir del llamado giro practicista.

El autor reconoce que no existe consenso en torno al concepto de práctica. No obstante, su uso ha reemplazado a otros conceptos en la sociología del conocimiento y en la filosofía de la ciencia, como por ejemplo, el de estructura normativa o el de paradigma. "[...] las prácticas son sistemas de acciones que necesariamente se realizan con la participación del cuerpo, que están sujetas a normas y valores, y están guiadas por representaciones [...] (Olivé, 2004, p.66).

Esta conceptualización lo lleva a plantear que los sujetos interpretan las normas que guían sus prácticas. En este sentido, para el paradigma estructuralfuncionalista mertoniano, la conducta era correcta o incorrecta en tanto se ajustaba o no al ethos de la ciencia. Hay aquí un sentido de norma como lo correcto, lo valorado como tal, a la que debe ajustarse la conducta y, a su vez, la que sirve para juzgarla. La actividad científica se concebía como enmarcada en un conjunto de normas explícitas, conocidas por todos y comprendidas unívocamente.

Por su parte, el enfoque practicista presenta un cuestionamiento a este sentido de las normas y a cómo éstas operan en la práctica científica, según Olivé (2004). Este problema ha sido uno de los principales temas de debate en la última parte del siglo XX y a principios del actual.

“[...] en el paradigma «practicista» se considera que las normas no son reglas que determinen la acción, sino que, como decía Kuhn [...] más bien constituyen valores que orientan la acción, pero que son incompletos, que requieren de complementación, y esa complementación depende de una interpretación que cada agente debe hacer" (Olivé, 2004, p.74).

En el mismo sentido, los valores son considerados omnipresentes e indispensables en toda actividad humana, incluyendo a la ciencia. No obstante, para el paradigma practicista los valores no son universales ni permanentes, sino que van cambiando en cada momento histórico y adquieren particulares connotaciones en los contextos pragmáticos de cada comunidad científica y en 
la aplicación que de ellos se hace en la valoración de cada instancia, método, objeto, etc. del proceso de investigación.

A su vez, para este enfoque interesa el acuerdo que los miembros de la comunidad científica tengan acerca de determinados valores y normas y del sentido que las mismas adquieren. Estos sentidos compartidos se aprenden en el transcurso de lo que podríamos llamar socialización profesional, es decir, de la mano de otros científicos que ya han alcanzado un cierto grado de dominio en una práctica particular.

Por último, podemos aludir al trabajo de Kreimer (2005), destinado a caracterizar las investigaciones de laboratorio, pero que permite inferir la importancia que comenzó a tener la interpretación de las prácticas científicas en el plano metateórico. En el “Estudio preliminar” que el autor realiza del libro de Knorr Cetina, titulado La fabricación del conocimiento, se destaca la importancia que tuvo el giro constructivista para la sociología del conocimiento al permitirle estudiar diversas causas de origen social que influyen en el proceso de producción del conocimiento científico.

En la segunda mitad de la década del '70, cuatro investigadores de las ciencias sociales (entre ellos sociólogos y antropólogos) ingresaron a cuatro laboratorios norteamericanos para hacer una investigación in situ de los modos en los que se producía la ciencia. Los investigadores fueron:

“[...] el francés Bruno Latour, quien investigó en el laboratorio Salk, el británico Michael Lynch, quien trabajó -igual que Latour- sobre un laboratorio dedicado a la neurobiología, la estadounidense Sharon Traweek, quien investigó un departamento de física de partículas, y la suiza/alemana Karin Knorr Cetina, que lo hizo en un instituto de microbiología y proteínas vegetales en Berkeley [...]" (Kreimer, 2005, p.23).

Las características que asumen estos trabajos le permiten a Kreimer hablar de "investigar la ciencia mientras se hace", que junto con "el giro practicista" (Olivé, 2004) o "la epistemología a posteriori" (Martínez y Olivé, 1997), son algunas de las expresiones que, desde distintos puntos de análisis, permiten visualizar los aportes de las prácticas y las interpretaciones que de las normas realizan los sujetos, como relevantes para la confección de lo normativo. 
Teniendo en cuenta lo expuesto en este apartado podemos concluir que a partir de las transformaciones que se producen en los planos epistemológico y metodológico a partir de los años '60 y '70, la constitución de la normatividad incluye otros aspectos además del corpus teórico-disciplinar. Especialmente nos referimos a la consideración de los saberes provenientes de la investigación empírica sobre las prácticas científicas. Cómo se comportan los científicos, cómo llevan a cabo sus investigaciones, qué factores intervienen en la producción de conocimiento, cómo se validan los saberes, etc., son algunas preguntas que aparecen orientando líneas de investigación cuyos resultados luego conformarán las normas que busquen orientar dichas prácticas.

\section{III - 3 - Relaciones de aspectos normativo/prescriptivos y} descriptivo/interpretativos en la conformación de una teoría normativa.

Nos interesa analizar en este apartado las relaciones que se ponen de manifiesto entre aspectos normativo/prescriptivos y descriptivo /interpretativos en la conformación de una teoría normativa. Partimos del reconocimiento de la existencia de estos distintos tipos de aspectos en la teorización didáctica, curricular, epistemológica y metodológica.

En términos generales, podemos decir que, mirando desde una perspectiva histórica la constitución de cada disciplina, se ha producido la prevalencia de algunos de estos aspectos, mientras que algunas propuestas actuales buscan una articulación más equitativa. Consideramos que la exposición presentada en el capítulo II acerca de la didáctica y el curriculum, ejemplifica este proceso.

En lo que respecta a las perspectivas epistemológicas y metodológicas consultadas, es posible hablar de la existencia de un momento normativo, de carácter a priori y abstracto, en el que se fijaban reglas acerca de cómo debían comportarse los científicos en sus investigaciones. A partir de las fracturas en estas concepciones, como vimos precedentemente, se priorizó un tipo de 
indagación empírica que resaltara las prácticas reales que llevaban a cabo los científicos.

Sin embargo, teniendo en cuenta las indagaciones efectuadas, podemos decir que no se explicita en la reflexión epistemológica y en la metodológica una diferencia entre un momento normativo y otro prescriptivo, como sí se destaca para el caso de la didáctica. La mayoría de las veces el término "normativo" está usado con el sentido que en la didáctica se le asigna a lo "prescriptivo", aunque existen algunas excepciones.

Por ejemplo, Mardones (1991) plantea que en los años '70 la sociología y la historia de la ciencia dejaron de lado las recomendaciones normativas para considerar los aspectos históricos y sociales. Se está hablando de las "recomendaciones normativas" en el sentido de técnicas para la acción o prescripciones cerradas a las interpretaciones subjetivas, que debían ser aplicadas a la práctica. A su vez, como vimos, la inclusión de los aspectos históricos y sociales dio lugar a explicaciones que contemplaron los factores cognitivos y sociales en la labor científica, sobre todo con posterioridad a los trabajos de Kuhn y Bloor.

También autores como Prego (1992) y Olivé (2004) hablan de una sociología normativa de la ciencia para caracterizar la obra de Merton. Las orientaciones normativas asociadas a la sociología de la ciencia mertoniana y rechazadas por la sociología del conocimiento científico posterior, fueron criticadas por su universalidad, por la forma en la que se pensaba la relación con los sujetos, pero no por su desvinculación de un proyecto político más amplio o de un corpus de valores tal como aparecía en las conceptualizaciones acerca de la normatividad en la didáctica.

Por otro lado, en los planos epistemológico, metodológico, didáctico y curricular se produjo una suerte de giro interpretativo, para algunos autores, o giro practicista según otros, que se opuso a las posturas precedentes más afines a enunciados prescriptivos generales. A pesar de los matices que dichos giros evidenciaron en la producción de cada autor, recordamos que otra característica 
común se refería al énfasis puesto en la descripción e interpretación de las prácticas y de los sentidos que los sujetos les asignaban a las normas.

Prego (1992), como ya mencionamos, resalta dos características que se fueron afianzando en las nuevas perspectivas de análisis metateórico: lo descriptivo y lo específico. La obra de Kuhn desde la historia de la ciencia fue significativa por la relevancia que adquirió lo descriptivo frente a la orientación normativista y lo específico frente a la elaboración de enunciados generales y generalizables.

Kreimer (2005), por su parte, plantea que "los trabajos de laboratorio" ponen en marcha una nueva metodología de investigación que les permite conocer la ciencia mientras se hace, a diferencia de momentos anteriores en los que se daba cuenta de la ciencia hecha.

Estas líneas de indagación se desprendieron del trabajo inicial de Bloor y, si bien introdujeron revisiones al planteo de su antecesor, como es el caso de Latour, enfatizaron el carácter descriptivo e interpretativo de las investigaciones orientadas a las prácticas científicas y sociales.

En lo que respecta a la reflexión metodológica, también encontramos la presencia de aspectos normativo/prescriptivos y de otros descriptivo /interpretativos en el seno de un debate muy difundido entre lo cuantitativo y lo cualitativo, especialmente en el campo de las ciencias sociales.

Archenti y Piovani analizan la complejidad de este debate más allá de las estigmatizaciones encerradas en su denominación. Destacan la centralidad que en la década del '60 adquirió la tensión descripción/explicación y normatividad/prescripción, en el contexto de lo que Giddens ${ }^{121}$ conceptúa como la "disolución del consenso ortodoxo" (1979; citado en Archenti y Piovani, 2007, p.30).

Los autores plantean que el debate metodológico en el siglo XX ha estado atravesado por la controversia entre lo cuantitativo y lo cualitativo, y ha sido heredero de discusiones anteriores.

\footnotetext{
${ }^{121}$ Giddens, Anthony (1979) Central Problems in Social Theory. Action, Structure and Contradiction in Sociological Analysis. London: Macmillan.
} 
La investigación realizada por Piovani et al. (2008) les permite afirmar que las denominaciones "métodos cuantitativos", "investigación cuantitativa", "métodos cualitativos", "investigación cualitativa", son de origen reciente. No obstante, son construcciones que albergan sentidos diversos que se han ido cristalizando en diferentes momentos para caracterizar a las investigaciones desarrolladas en las ciencias sociales. A su vez, como muchas otras antinomias y estereotipos que se construyen, tienen su utilidad pero no siempre permiten una adecuada comprensión de los objetos a los que se refieren y del entramado histórico, político y social que los sustenta. Asimismo, ambas perspectivas se encuentran en un momento de autocrítica y el debate cuantitativo/cualitativo transita hacia una etapa de triangulación metodológica o uso de métodos múltiples, considerada por algunos autores como un intento de superación de la antinomia, aunque no libre de cuestionamientos ${ }^{122}$.

Teniendo en cuenta estas consideraciones, a los fines de este trabajo utilizamos preferentemente las siguientes expresiones: enfoque estándar (en lugar de métodos cuantitativos) y enfoque interpretativo (en lugar de métodos cualitativos).

Si se entiende la metodología como la teoría que se ocupa de estudiar los modos en que las ciencias -sociales en nuestro caso- producen y validan sus conocimientos, se comprende que aquella controversia no pueda darse al margen de ciertos supuestos ontológicos ${ }^{123}$, es decir, de ciertas concepciones acerca de la realidad que se estudia. Desde esta perspectiva, hablar de enfoques metodológicos demanda, por un lado, ubicarlos en la intersección entre las ciencias y sus respectivos objetos de estudio; y por el otro, enmarcarlos en determinadas tradiciones teórico-epistemológicas.

\footnotetext{
${ }^{122}$ Para más detalles sobre la triangulación metodológica, sus puntos fuertes y las críticas que recibe, se puede ver: Archenti y Piovani (2007); Piovani, et al. (2008).

${ }^{123}$ Taylor y Bogdan (1986) plantean que las perspectivas positivista y fenomenológica -tal como ellos las denominan pero coincidentes con los nombres aquí utilizados- construyen la mirada desde posicionamientos diferentes, se preguntan por objetos distintos y, por tanto, demandan metodologías disímiles para el abordaje de los mismos. Los positivistas buscan explicaciones causales por lo que los métodos empleados arrojan información susceptible de análisis estadístico. Los fenomenólogos buscan aproximarse a los motivos que están detrás de las acciones de los sujetos a partir de la interpretación.
} 
A los fines de esta tesis y considerando el período histórico abarcado en ella, en la reflexión epistemológica visualizamos, por un lado, la alternancia en la ponderación de aspectos explicativos y generales, más vinculados a las características de las ciencias naturales, con metodologías afines, y otros aspectos más interpretativos de las acciones de los sujetos, anclados en la especificidad de las ciencias sociales. Por otro lado, encontramos algunos paralelismos con la investigación educativa en general y didáctica en particular.

En este sentido, nos proponemos recuperar de la vasta historia de los métodos en las ciencias sociales aquellos elementos que consideramos centrales a los fines de entender los problemas que la reflexión metodológica ha tenido que enfrentar en torno a la normatividad. Para ello, focalizamos la atención en el tránsito desde los enfoques estándar hacia otros más interpretativos en la investigación específica sobre la enseñanza.

El enfoque de la efectividad de la enseñanza -también conocido como modelo de proceso-producto- fue uno de los principales programas de investigación sobre la enseñanza que se ha desarrollado en la última mitad del siglo XX. Estas investigaciones educativas estaban asentadas en una perspectiva tecnicista, con un fuerte componente prescriptivo y estudiaban el aula y la escuela con la intencionalidad de establecer regularidades empíricas que luego permitieran explicar y también prescribir los comportamientos a llevar a cabo por docentes y alumnos para alcanzar las finalidades propuestas ${ }^{124}$.

Este enfoque -como adelanta su nombre- buscaba establecer correlaciones positivas entre los estilos de enseñanza de los maestros y los resultados en los aprendizajes alcanzados por los estudiantes. Lograrlas permitía -entre otras cuestiones- realzar aquellas estrategias de enseñanza que alcanzaban mejores resultados académicos en los alumnos y generalizarlas, ya sea a través de programas de formación inicial de docentes o de actualización

\footnotetext{
${ }^{124}$ Estas perspectivas de investigación consideran que la enseñanza es un problema técnico. Entre otros autores, se puede consultar: Carr y Kemmis (1988).

También podemos mencionar que en el ámbito local este tipo de indagaciones se llevaron a cabo con anterioridad por Mercante desde el seno del positivismo en las primeras dos décadas del siglo XX. Las indagaciones empíricas realizadas por este pedagogo sustentaron las prescripciones acerca del desempeño esperado por los profesores en ejercicio y en formación. Para más detalle puede consultarse: Picco (2007).
} 
y/o perfeccionamiento en servicio, persiguiendo en última instancia el mejoramiento de la calidad de la educación.

En este contexto, la metodología principal del modelo proceso-producto permitía registrar en el salón de clases la forma en la que se comportaban los docentes, lo que ellos hacían, y los resultados que lograban los estudiantes, así como también aquello que sucedía en la interacción a partir de una serie de categorías estandarizadas. La observación y el registro, sumados a la evaluación de los aprendizajes a través de test y postest, permitían identificar aquellas modalidades de enseñanza que eran más eficaces, siempre bajo el supuesto de que entre ambas partes -estrategias de enseñanza y aprendizajes realizados- se producía una correlación positiva.

Desde una mirada más actual estas afirmaciones pueden considerarse limitadas en cuanto al número de variables en las que se sustentaban o a la estrecha dimensionalización del objeto de estudio. De todas formas -y como todo proceso histórico- en su momento, al menos en Estados Unidos, daban respuestas, por un lado, al Informe Coleman que, divulgado en 1966, postulaba que diferentes tipos de docentes no hacían la diferencia en cuanto al rendimiento académico de los estudiantes; así como también a las exigencias en el mejoramiento de la calidad de la educación como coletazo del lanzamiento del Sputnik en 1957, entre otras cuestiones. Tal vez es en este sentido en el que Shulman (1989) plantea que el modelo proceso-producto fue exitoso en los objetivos que se propuso.

Podemos decir que estas investigaciones tienen puntos de contacto con el positivismo, entendido como marco epistemológico de las metodologías estándar o cuantitativas. Entre otras cuestiones, esta perspectiva persigue la explicación de las conductas individuales con arreglo a las normas que gobiernan la estructura social. El descubrimiento de éstas permite el acercamiento de las ciencias sociales a las explicaciones propias de las ciencias naturales.

Esta concepción -habitualmente llamada canónica- comienza a fracturarse con la consideración de los aspectos sociales e históricos en la 
ciencia, que configura una base teórico-epistemológica diferente. Específicamente, en materia educativa podemos decir que la apertura de la "caja negra del aula", como metáfora que se utiliza para caracterizar los enfoques de investigación posteriores a los de proceso-producto, no se refiere a la posibilidad de investigar en la escuela, cuestión que ya cubría el cuestionado modelo, sino a la posibilidad de realizar descripciones detalladas de lo que allí sucedía, considerando las dimensiones sociales, culturales, políticas, las dinámicas que se generaban en la interacción entre los sujetos, etc.

La crisis del modelo proceso-producto o de la investigación positivista en términos más generales, pone en escena una serie de trabajos que buscan dar cuenta de estos sucesos del aula de una manera más naturalista, menos encasillada en formatos teóricos, con la intención de recuperar lo que sucede y no tanto lo que debería pasar o cómo debería ser una práctica educativa. Se trata de distintas indagaciones comprendidas en un enfoque amplio, que Erickson denomina interpretativo, que centran su interés prioritariamente “[...] en el significado humano en la vida social y en su dilucidación y exposición por parte del investigador" (1990, p.196) ${ }^{125}$.

La interpretación hermenéutica ${ }^{126}$ fue tomada y perfeccionada por diferentes teóricos en un intento de constituir una base epistemológica alternativa para las ciencias sociales. Se persigue el reconocimiento de que éstas tienen un objeto de estudio con características particulares y que, por tanto, requiere de una metodología acorde ${ }^{127}$.

\footnotetext{
${ }^{125}$ Además, el autor plantea que prefiere el término "interpretativo" a otros como cualitativo en tanto evita la connotación de no cuantitativo, connotación que no quiere subrayar en tanto existe cierto grado de cuantificación en este tipo de investigaciones. Esta cuestión también aparece en el debate cuantitativo/cualitativo en la reflexión metodológica. Por otra parte, el término "interpretativo" es más inclusivo que otros, como etnográfico o estudio de casos.

${ }^{126}$ Mardones (1991) expone que a la corriente positivista se opone una tendencia anti-positivista que surgió en Alemania principalmente y que se denomina hermenéutica. Un punto fundamental de esta corriente radica en la importancia asignada a la comprensión de las manifestaciones de la conducta humana como parte de la interioridad. A diferencia del positivismo, la interioridad de los sujetos se manifiesta, sale al exterior a través de las acciones y es necesario comprenderla.

${ }^{127}$ Carr y Kemmis (1988); Archenti y Piovani (2007).
} 
En consonancia con los virajes de la investigación antropológica en

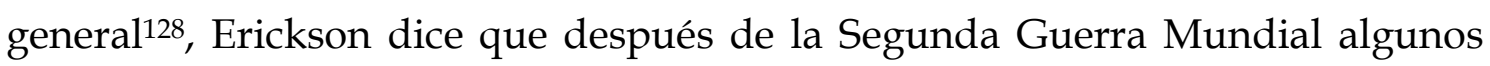
antropólogos comenzaron a abordar problemas educativos y sus investigaciones alcanzaron gran difusión en las décadas del '60 y '70. Estos estudios preocupados por las mediaciones socio-culturales que influían en el acontecer cotidiano de la escuela, como aquellos otros interesados por las mediaciones cognitivas a través de las cuales los docentes y estudiantes se relacionaban en el mundo del aula, estaban comprendidos dentro del enfoque interpretativo.

Pérez Gómez (1993a) señala que considerar a la realidad social como un proceso histórico en permanente construcción es uno de los supuestos básicos de la perspectiva interpretativa de investigación en la enseñanza:

“No existe pues una única realidad en el ámbito de lo social en general y de lo educativo en particular, sino múltiples realidades que se complementan mutuamente. Desde cada una de éstas se ofrecen perspectivas diferentes, matizadas de forma singular por cada sujeto o grupo. Los individuos son agentes activos que construyen de forma condicionada el sentido de la realidad en que viven" (Pérez Gómez, 1993a, p.119).

Podemos decir que el desafío de la investigación interpretativa en educación está en acceder a esas múltiples realidades que los sujetos construyen. Realidades pensadas en términos de procesos sociales amplios que los atraviesan a ellos y a sus singularidades, pero también como construcciones de significados que producen los mismos sujetos para darle sentido al mundo en el que viven. Este reto conlleva además el hacer visible la invisibilidad que la vida cotidiana tiene para los propios sujetos, hacer que lo familiar se vuelva extraño, como una posibilidad de revisarlo y reflexionar sobre ello (Erickson, 1990) $)^{129}$.

\footnotetext{
${ }^{128}$ Múltiples autores aluden a estos procesos. Entre ellos, podemos mencionar: Assael, Edwards y López, 1992; Achilli, 2000; Guber, 2001; Archenti y Piovani, 2007; Piovani et al., 2008;

129 Ésta es una de las cinco respuestas que el autor considera necesarias para la investigación educacional. Las otras cuatro son: adquirir un conocimiento específico a través de la documentación de determinados detalles de la práctica concreta; considerar los significados locales que tienen los acontecimientos para los sujetos que participan en ellos; poseer un conocimiento comparativo de los diferentes medios sociales; y por último, tener un conocimiento comparativo más allá de las circunstancias inmediatas del medio social (Erickson, 1990, pp.200-202).
} 
A su vez, los procesos de enseñanza y de aprendizaje se concretizan cotidianamente a partir de las acciones de docentes y alumnos. Éstos tienen sus propios sentidos, saberes, creencias, motivos, por los cuales se comportan de una manera y no de otra. Por tanto, la investigación pretende captar ese bagaje simbólico y, a su vez, que sus resultados contribuyan a facilitar la reflexión, aumentar el conocimiento de la propia práctica y, según los casos, producir modificaciones en ella.

La investigación interpretativa sabe que las prácticas de enseñanza y de aprendizaje, en este caso, tienen algo de reproducible y algo de contingente. Es decir,

“[...] dentro del enfoque interpretativo en la investigación didáctica, se propone una utilización siempre hipotética y contextual del conocimiento adquirido en la investigación educativa, ya que se presupone la singularidad en parte irreductible de las situaciones de enseñanzaaprendizaje, por efecto de las interacciones siempre algo imprevisibles de los individuos y grupos que componen dicho espacio ecológico social. Se afirma, por tanto, que la teoría no dicta directamente la práctica" (Pérez Gómez, 1993a, p.135. La cursiva figura en la edición consultada).

En este sentido, el conocimiento producido por la investigación interpretativa en un contexto particular, puede ser utilizado para aumentar la comprensión y mejorar la intervención de los sujetos en otros contextos pero no en su totalidad ni de manera directa, ya que se respeta la capacidad de los sujetos que intervienen en las prácticas indagadas y sus juicios referidos a la utilidad del conocimiento producido.

Vinculado a estas cuestiones, encontramos un aspecto importante para este trabajo y nuestras preocupaciones actuales, a saber, la influencia que el conocimiento producido por la investigación tiene para la modificación de las prácticas de enseñanza.

Pérez Gómez sostiene que la investigación interpretativa posee "[...] un valor instrumental, de apoyo intelectual en el análisis de la realidad y en la deliberación, para adoptar decisiones prácticas, cada vez más coherentes y razonables" (1993a, p.132). 
Shulman (1989), a propósito del modelo de ecología del aula, dice que sus resultados pueden ser cuestionables para quienes pretenden contar con un corpus de conocimientos útiles para orientar la práctica. No obstante, la investigación interpretativa aporta elementos válidos para quienes la entienden como una fuente de críticas y de nuevos problemas.

Teniendo en cuenta lo planteado hasta aquí con respecto a la reflexión metodológica en torno a la investigación en las ciencias sociales en general y en la enseñanza en particular, podemos identificar los momentos normativo/prescriptivo y descriptivo/interpretativo como dos tradiciones que se construyeron y comenzaron a instaurarse en las distintas disciplinas configurando novedosas relaciones con sus respectivos objetos de estudio. En este sentido, hablar de "tradiciones" nos permite visualizar aquellos componentes resaltados, valorados y dignos de ser transmitidos por cada tradición. Por otro lado, es posible reconocer el peso normativo que la tradición deposita sobre los sujetos, sus formas de entender la disciplina y sus responsabilidades con respecto al objeto de estudio.

Aparece, entonces, otro sentido de lo normativo, ahora ligado a las tradiciones en tanto marcos simbólicos que regulan la acción individual. Si bien no es el sentido principal con el que construimos esta tesis, consideramos dedicarle un espacio de este apartado por su significación y por la posibilidad de constituirse en una línea futura de indagaciones.

Para Goodson (1995) las tradiciones surgen en un determinado momento histórico. El autor toma de Williams ${ }^{130}$ el concepto de tradición selectiva que le permite enfatizar la idea de tradición construida en un determinado período histórico, seleccionando una serie de cuestiones valoradas en ese momento y que refleja su organización. También retoma a Hobsbawm ${ }^{131}$, de quien recupera el concepto de tradición inventada para hablar de ellas como un conjunto de prácticas regidas por reglas aceptadas explícita o implícitamente, que intentan

\footnotetext{
${ }^{130}$ Williams, Raymond (1961). The Long Revolution. Londres: Penguin.

131 Hobsbawm, E. y Ranger, T. (ed.) (1985). The Invention of Tradition. Cambridge, England: Cambridge University Press, 1.
} 
propagar a través de la repetición una serie de valores y normas de comportamiento, lo que las liga a un pasado común (Goodson, 2000).

Es interesante asimismo el sentido que le asigna Davini a las tradiciones cuando las utiliza para conceptualizar "[...] configuraciones de pensamiento y acción [...]" (1995, p.20) en la formación docente. Para la autora, estas tradiciones aunque

“[...] construidas históricamente, se mantienen a lo largo del tiempo, en cuanto están institucionalizadas, incorporadas a las prácticas y a la conciencia de los sujetos. Esto es que, más allá del momento histórico que como matriz de origen las acuñó, sobreviven actualmente en la organización, en el currículum, en las prácticas y en los modos de percibir de los sujetos, orientando toda una gama de acciones" (1995, p.20. La cursiva figura en la edición consultada) $)^{132}$.

En este sentido, recuperamos el trabajo de Fattore para quien la tradición tiene un peso normativo importante. “[...] La tradición no sólo representa lo que «se hace» en una sociedad, sino también lo que «debería hacerse» [...]" (2007, p.16). Las tradiciones son características de la modernidad que las construyó como una forma de dar legitimidad al nuevo orden frente a la caída de las ofertas simbólicas premodernas. Así, las tradiciones cobran fuerza como fuente de significados colectivos. La autora conceptualiza para la actualidad un orden post-tradicional en el que las tradiciones así entendidas agotan su sentido.

“[...] Estos quiebres generan espacios de oportunidad en los que los propios sujetos son los responsables de “...producir, representar y combinar por sí mismos sus propias biografías". (Fattore, 2007:23). Desaparece el peso normativo de la tradición, caen las certezas por ella

\footnotetext{
${ }^{132}$ Además de las tradiciones, la autora alude a tendencias que no se han consolidado ni se han institucionalizado en las prácticas formativas de docentes. A los fines del análisis actual, nos ocupamos exclusivamente de las tradiciones pero mencionamos las tendencias en el capítulo II apartado II-4.

Por otro lado, debemos aclarar que utilizamos el término "tradiciones" en el sentido que le asigna Davini y que hemos expuesto. No desconocemos que Goodson $(1995 ; 2000)$ también utiliza el término. Al igual que para Davini, las tradiciones para Goodson surgen en un determinado momento histórico, aunque el autor inglés se concentra en el análisis de las tradiciones de asignaturas en los curricula escolares. Distingue tres: académica, utilitaria y pedagógica. Dice que el estudio histórico de las asignaturas define ciertas tradiciones que "[...] a menudo pueden relacionarse con los orígenes de las clases sociales y los destinos ocupacionales de sus alumnos [...]" (Goodson, 2000, p.145). Consideramos que este modo de referirse a las tradiciones, vinculándolas a las asignaturas escolares, nos lleva a un análisis curricular e histórico diferente del que proponemos aquí.

En otros trabajos, utilizamos algunos de estos sentidos asignados a las tradiciones para referirnos a la creación y recreación de las mismas por parte de los proyectos de extensión universitaria entendidos como protocurriculum en lo que respecta a la formación en general y la formación de formadores en particular (Coscarelli y Picco, 2006; 2009).
} 
provistas, y queda en los individuos la exigencia de tomar decisiones y hacerse cargo de las consecuencias [...]" (Coscarelli y Picco, 2009, p.82).

Las tradiciones, entonces, ocupan el lugar de bisagras, articulando pasado, presente y futuro. Permiten reducir las incertidumbres, contener y vincular a los sujetos y proyectarse sobre el futuro buscando predecirlo (Coscarelli y Picco, 2009).

Altamirano (2006) -entre otros- también reconoce la polisemia del término cuando analiza la tradición normativa en la definición de lo que significa "ser intelectual". El autor destaca que aparecen elementos prescriptivos que marcan qué debe ser un intelectual más que describir qué es. Asimismo, este tipo de definiciones ejerce un rol de clasificación de la realidad en tanto permite juzgar si una persona es o no un intelectual, y si cumple su misión como tal o la traiciona.

Teniendo en cuenta estos aportes podemos mencionar la presencia de otro tipo de normatividad. Hasta este punto hemos hablado de un momento prescriptivo en el desarrollo de las disciplinas involucradas en el que la prescripción se pone en juego en la relación entre la disciplina y su objeto de estudio, marcando la primera de una manera abstracta y generalizable el rumbo del segundo. Por su parte, el momento descriptivo/interpretativo que le sigue, enfatiza otros componentes de la relación entre la disciplina y su objeto, priorizando los sentidos que los sujetos les asignan a sus acciones, las prácticas, los procesos de investigación o de enseñanza, según los casos.

En este sentido, la visión estándar de ciencia y el enfoque interpretativo que analizamos en algunas perspectivas metodológicas, pueden ser pensados como dos tradiciones, con sus respectivos pesos normativos, aunque éstos se configuren de manera disímil. Lo normativo puede entenderse como emanando de un determinado marco simbólico de referencia y que debe ser analizado en la mediación que sufre en la práctica por los sujetos y sus contextos socioculturales.

Tanto en la concepción estándar de ciencia como en el enfoque interpretativo, encontramos prescripciones/normas acerca de cuáles se 
consideraban las mejores formas de producir y validar el conocimiento en las ciencias sociales. Ambos enfoques se sustentan en sendas tradiciones teóricoepistemológicas y articulan una serie de ideas acerca de las características del objeto de estudio, la mejor forma de abordarlo y el tipo de resultados que serán considerados científicos.

En la didáctica y, específicamente en la investigación didáctica, también encontramos tendencias que nos permiten establecer algunos paralelismos con el desenvolvimiento de la investigación en las ciencias sociales en general, ya que se esbozan ambas tradiciones y se postula cuál es la mejor manera de investigar en la escuela, cuáles son los objetos de estudio que deben configurar y con qué intencionalidades, tal como vimos precedentemente.

Por último, como parte de las relaciones que podemos establecer entre los aspectos normativo/prescriptivos y aquéllos descriptivo/interpretativos, consideramos pertinente aludir a algunas propuestas de articulación de los mismos que se generan en la reflexión epistemológica y metodológica, de manera similar a como lo analizamos oportunamente como parte del momento de reconceptualización de la didáctica.

Estas propuestas de articulación parten del reconocimiento de la presencia de ambos aspectos en las prácticas científicas. Al igual que lo mencionado para el caso de la didáctica, se trata de planteos que no se corresponden en todos los casos con los años comprendidos en este estudio (ya que muchos de ellos son más recientes), pero evaluamos conveniente su inclusión porque permiten revisar críticamente los debates en torno a la normatividad aquí presentados.

Ya mencionamos el caso de Schuster (2001), para quien la filosofía de la ciencia debería reservarse un rol normativo que considere las prácticas científicas reales. Con respecto a la metodología, el mismo autor, en otro trabajo, plantea una postura similar (Schuster, 2007). Esta disciplina debería conjugar aspectos normativo/prescriptivos y descriptivo/interpretativos, que le permitan articular las normas acerca de cómo deben ser las prácticas de 
investigación con indagaciones empíricas acerca del trabajo real de los científicos.

Por su parte, Marradi reserva para la metodología un carácter normativo. En este sentido, esta disciplina debe brindar "[...] indicaciones acerca de lo que es oportuno hacer en cada situación específica [...]" (2007b, p.54). Para cumplir con este cometido, dice el autor, debe valerse de la información que le aportan la sociología y la historia de la ciencia acerca de las prácticas científicas reales. Las normas que la metodología elabora no deben tener un carácter abstracto y general, sino que deben conformarse a partir de considerar las características de las prácticas que llevan a cabo los científicos en su labor cotidiana.

Interpretamos que aparece de esta manera una diferenciación afín a aquélla que nosotros planteamos entre los términos normativo y prescriptivo. La definición de lo normativo brindada por el autor permite recordar las consideraciones ya expuestas acerca de las características de las situaciones prácticas y el uso del razonamiento práctico para resolver cuál es el curso de acción más adecuado. Lo prescriptivo, por el contrario, se vincula con la elaboración de indicaciones con pretensión de generalidad y aplicabilidad lineal.

Por otra parte, consideramos que en el caso particular de las ciencias sociales es posible analizar la articulación entre aspectos normativo/prescriptivos y descriptivo/interpretativos en función de la intervención. Si bien lo vimos en estos términos para el caso de la didáctica y del curriculum, consideramos que es una problemática también presente en el recorrido que realizamos por los campos epistemológico y metodológico, sobre todo cuando estos últimos se preguntan acerca de la articulación de los aspectos antes mencionados.

Silber (1996) plantea que hablar de "intervención" nos remite a analizar lo que "viene entre" la pauta dicha y la acción, y se concreta en una práctica social para su mejoramiento, conservación o transformación. En este sentido, la norma o lo normativo se constituye en una parte de la intervención en tanto da cuenta de cómo deben ser los objetos a los que se dedica o cómo deben 
comportarse los sujetos y las prácticas que estudia. A su vez, este aspecto se asienta en aquel corpus de conocimientos o componente explicativo que informa cómo es el objeto. Agregamos también que en la intervención estos dos aspectos se conjugan con el utópico, con los valores y finalidades que la guían como una forma de trascender lo dado y lo consuetudinariamente aceptado.

Junto con Camilloni (1996) defendemos que la didáctica, cuando enfoca la enseñanza -su objeto de estudio- debe hacerlo como una tarea de intervención social. En este sentido, toda intervención desde esta disciplina conjuga marcos teóricos, mandatos políticos y sociales y principios éticos que el sujeto debe articular en una propuesta de formación en función de una práctica concreta (Furlán y Pasillas, 1993). Consideramos que estas afirmaciones valen igualmente para el caso del curriculum por las razones ya expuestas previamente.

Así, desde un marco referencial social-intervencionista (Shapiro, 1990) la formación de sujetos pedagógicos tiene consecuencias importantes para las prácticas sociales propias del contexto socio-político-cultural en el que los sujetos se constituyen como participantes activos.

Por su parte, encontramos también diferentes perspectivas epistemológicas y metodológicas que buscan articular el aspecto prescriptivo con el descriptivo, diciendo cómo deben comportarse los científicos o cómo deben investigar pero sin desoír los aportes de la sociología y la historia de la ciencia.

Consideramos que la articulación de estos aspectos habilita la introducción de la intervención como categoría de análisis. En algunos casos está más problematizada, en otros menos, pero aparece como una forma de influir en las prácticas científicas o de enseñanza, sociales en última instancia, a las que las teorías se dedican.

Follari (2000) afirma que la ciencia tiene la posibilidad de intervenir en el ámbito social en el que se desarrolla. La investigación científica afecta -o al menos puede hacerlo- al objeto con el que trabaja. Para el autor, la cercanía entre el lenguaje de las ciencias sociales y el de la vida cotidiana de los sujetos 
(cuestión a la que aludimos en el capítulo I de esta tesis), debe ser interpretada como una forma de encontrarse en mejores condiciones para facilitar la apropiación del lenguaje científico por parte de la sociedad y contribuir a su autorreflexión.

En un plano de mayor generalidad, y excediendo lo específicamente abordado en esta tesis, podemos preguntarnos por la responsabilidad que le cabe a la ciencia en general y a las ciencias sociales en particular por el rumbo de la sociedad.

\section{III - 4 - Disponibilidad de saberes interdisciplinarios para realizar una reflexión de segundo orden en una disciplina.}

La reflexión acerca de la normatividad y, en términos más amplios, las características de una disciplina y su vinculación con las prácticas de las que se ocupa, tal como lo hemos planteado en esta tesis, es un ejercicio que involucra un plano metateórico sobre la disciplina de la que se trate. En este sentido, resulta interesante detenernos a analizar los saberes que están involucrados en este tipo de reflexión, destacando los puntos de confluencia entre las teorías aquí abordadas.

Distintos autores, con diferentes niveles de explicitación, ponen en diálogo saberes filosóficos o epistemológicos y saberes disciplinarios para realizar las reflexiones de segundo orden sobre las características teóricas en términos generales y sobre la normatividad en particular.

Teniendo en cuenta la opción que realizamos en el capítulo I de esta tesis por la expresión "investigación en", a partir del análisis de Ardoino (2005), en esta oportunidad preferimos hablar de "reflexiones epistemológicas en las teorías" y no de "reflexiones sobre". Pensamos que la utilización de la preposición "en" nos permite estudiar las teorías desde sus propios problemas y respuestas a la cuestión de la normatividad. 
En lo que respecta a este cruce en particular, los autores consultados que problematizan las relaciones interdisciplinarias al realizar una reflexión de segundo orden coinciden en postular una complementariedad entre los saberes epistemológicos y aquéllos específicos de una disciplina empírica. Aparecen ciertas diferencias que, a los fines de este trabajo, las entendemos como propias de las perspectivas de estudio adoptadas.

Este tratamiento abona la reflexión en torno a la normatividad en tanto el tipo de relación que se conceptualice entre los saberes epistemológicos y filosóficos y los conocimientos y prácticas científicas reserve para los primeros un lugar de prescripción a priori; adopte una mirada descriptiva y en algunos casos comprensiva; o se ubique en un espacio intermedio de articulación de ambos aspectos.

Por ejemplo, para Schuster (2001), el origen profesional no representa una limitación para encarar los problemas filosóficos que se les presentan a las teorías científicas. Tanto el filósofo de la ciencia como el representante de una teoría social -como puede ser para nosotros el didacta- van a "tener que estudiar" al iniciar un análisis metateórico. Podemos decir que se visualiza una complementariedad de saberes epistemológicos, filosóficos y disciplinarios. No es posible iniciar una reflexión metateórica sin involucrarse en los problemas y en la estructura conceptual de una disciplina empírica particular, como tampoco abordar una reflexión de segundo orden sin saberes epistemológicos y filosóficos.

En una línea similar se ubica el trabajo de Mardones (1991), quien sostiene la importancia de una formación pluridisciplinar para aquéllos que se dedican a los problemas epistemológicos de las ciencias: conocer de epistemología no alcanza para realizar una reflexión metateórica en una disciplina, pero tampoco saber de una disciplina permite hacer tal trabajo.

En este sentido, Mardones propone un diálogo permanente entre una epistemología que denomina general y las diferentes teorías científicas. La riqueza radica en la complementación de perspectivas. La primera comprende el estudio de la producción del conocimiento científico, una epistemología 
comparada, así como las relaciones entre la ciencia y las condiciones sociopolíticas en las que se desarrolla (lo que se corresponde con una perspectiva externalista). Por su parte, los científicos particulares no son totalmente conscientes de los factores sociales, políticos, culturales, etc., que influyen en sus prácticas, ni los únicos autorizados a explicar las normas que rigen su actividad.

Por otro lado, encontramos elementos comunes en la postura de Follari (2000) quien plantea que en la actualidad lo científico es parte constitutiva de lo epistemológico. Sostiene que el carácter tradicionalmente normativo de la epistemología ha ido desplazándose hacia un lugar más reflexivo, ocupado por una epistemología general. Las epistemologías disciplinarias no pueden desconocer los procesos específicos de producción de conocimientos en cada campo así como tampoco los condicionantes cognitivos y sociales de la actividad científica.

Ardoino (2005) también defiende una vinculación entre la epistemología y la disciplina cuando afirma que estos saberes no pueden separarse en las ciencias humanas. Ya no es posible, como en otros tiempos o como algunos planteos actuales pretenden, desconocer la dimensión ética y política de las disciplinas.

Piovani, por su parte, defiende la mutua implicación de la investigación empírica y la reflexión filosófica sobre la ciencia:

“[...] la investigación empírica de los fenómenos humanos (y no sólo de ellos), puede beneficiarse de la reflexión filosófica acerca de la ciencia y del conocimiento en general; al mismo tiempo que no tiene ya mucho sentido plantear dicha reflexión sin acercarse e involucrarse -no sólo especulativamente- con aquello sobre lo que se reflexiona" (Piovani, 2006, p.195).

La visualización de esta complementariedad entre saberes epistemológicos y disciplinarios, le permite a Lores Arnaiz plantear que la epistemología "[...] es siempre una toma de conciencia acerca del proceso de crear o justificar conocimiento [...]" (1986, p.135). Se constituye en el análisis y reflexión de los problemas generados por los conceptos, métodos, teorías y por el 
desarrollo de la ciencia misma. Se trata de un proceso de análisis metateórico que puede surgir en una determinada ciencia o puede provenir de la filosofía, motivado por alguna crisis que ponga en cuestión los fundamentos o marcos conceptuales-referenciales de las disciplinas, para el primer caso, o ciertas crisis más generales acerca del conocimiento o la realidad, para el segundo.

Para esta autora, la epistemología no participa en la comprobación empírica que se haga de los conocimientos construidos, pero sus elaboraciones deben contrastarse permanentemente con los resultados alcanzados en la ciencia.

Desde otra perspectiva de análisis, es interesante citar a Prego (1992) en tanto ubica estas relaciones interdisciplinarias al realizar estudios metateóricos, en la etapa histórica abordada en este trabajo. Las críticas producidas en la década del '60 a la filosofía de la ciencia mertoniana y la consecuente recuperación del componente cognitivo a la luz de la influencia de la obra kuhniana, dejó sin posibilidades de obviar la importancia del conocimiento técnico en los análisis de la especialidad.

Este movimiento se encontraba en vinculación con la oposición, también generada en ese período de transición y marcada por Prego, a las normas universales resaltadas por Merton. Esto conllevó la recuperación de las tradiciones locales que guiaban las prácticas concretas de los científicos y, por qué no, de los saberes y puntos de vista de éstos para el ahondamiento en los análisis metateóricos: “[...] esta demanda por el contexto del actor frente al uso de 'criterios externos' se corresponde [...] con el desarrollo de una orientación con énfasis descriptivo por oposición a la impronta normativista del análisis filosófico clásico" (1992, p.32. El subrayado figura en cursiva en la edición consultada).

Encontramos entonces, en el aporte de este autor, un momento histórico en el que el diálogo entre epistemólogos y científicos se volvió necesario a la luz de las nuevas orientaciones metateóricas que se fueron suscitando, y se corresponde con el núcleo de este trabajo, a saber, las relaciones entre los aspectos normativo/prescriptivo y descriptivo/explicativo. 
Lo mencionado es válido para pensar la reflexión epistemológica en la didáctica. Camilloni (1996) recupera el posicionamiento de Piaget ${ }^{133}$ a propósito del origen de la reflexión epistemológica situado en las crisis disciplinarias. La didáctica como disciplina está atravesando un período de crisis y de reflexiones epistemológicas que involucra -entre otras cuestiones- la definición de su propio campo.

Los trabajos de esta disciplina que analizamos en la segunda parte de la tesis representan producciones con un cierto grado de reflexión metateórica. Si bien con diferentes niveles de profundidad, al estudiar la didáctica, sus límites, posibilidades e incumbencias, se pone en evidencia la reflexión en torno al componente normativo en tanto el mismo define el carácter de la disciplina en su vinculación con el objeto de estudio al cual se dedica.

Hablar de la normatividad en la didáctica también es un trabajo que demanda saberes epistemológicos y didácticos porque se inscribe en una problemática general de las ciencias sociales, a saber, si les corresponde o no intervenir y, en caso afirmativo, cómo intervenir.

Cabe recordar algunos trabajos ya citados que ponen en evidencia esta necesaria articulación de saberes disciplinarios en la reflexión más o menos directa acerca de la normatividad en la didáctica.

Camilloni (1993) problematiza el carácter epistemológico de la didáctica como disciplina. Retomando a Ferry ${ }^{134}$, acuerda con el autor que la pedagogía y la didáctica son saberes sobre un saber-hacer, lo que carga a la disciplina de complejidad y la funda en la permanente articulación entre la teoría y la práctica.

Tomando como eje del análisis las relaciones entre la didáctica y las prácticas de enseñanza a las que se dedica, la autora analiza en primera instancia los supuestos epistemológicos del positivismo y del neopositivismo, a partir de los cuales a la didáctica le corresponde el lugar de ser una teoría práctica no científica.

\footnotetext{
${ }^{133}$ Piaget, Jean. (1970). Naturaleza y métodos de la epistemología. Buenos Aires: Proteo.

${ }^{134}$ Ferry, Giles. (1983). Le trajet de la formation. Les enseignants entre la théorie et la pratique. Paris: Dunod. [Trad. Cast.: El trayecto de la formación. México: Paidós. 1991.].
} 
La concepción de didáctica de Camilloni, que mencionamos en diferentes oportunidades, la lleva a afirmar que esta disciplina no puede despojarse de su imbricación valorativa o sus responsabilidades normativas para ajustarse a los criterios científicos planteados por el positivismo. Entonces, sostiene que es necesario discutir la conveniencia de utilizar estos supuestos para el estudio de la didáctica y de las ciencias sociales en general.

A continuación, plantea que hay que adoptar en el análisis otras corrientes epistemológicas que posibiliten comprender estas disciplinas en su especificidad. Es por este motivo que se introduce en la teoría crítica en tanto ésta “[...] recupera para las ciencias sociales la relación esencial de conocimiento y valor, también se propone rearticular los dominios del ser y del deber ser [...]" (1993, p.32). Desde este marco, la didáctica puede erigirse como una disciplina científica rigurosa ya que cuenta con suficientes criterios para validar y justificar sus conocimientos y normas para la comprensión y regulación de la enseñanza.

Consideramos que este trabajo de Camilloni parte de un análisis de la didáctica como disciplina, recupera saberes propios de un plano epistemológico y con ellos sustenta su concepción de didáctica como una ciencia normativa e impregnada de valores.

Por su parte, Feldman (2008) reconoce la enseñanza como una acción práctica, más vinculada al obrar que al hacer y, por tanto, a las características que ya le asignamos a este tipo de acciones en los dos capítulos anteriores. Este supuesto lleva al autor a revisar críticamente distintas modalidades de pensamiento y acción -prioritariamente la técnica y la práctica- buscando aquélla que mejor pueda sustentar a la educación como una práctica social.

Visualizamos que también en el planteo de Feldman aparecen saberes epistemológicos y de las ciencias sociales que le permiten problematizar la enseñanza como una praxis. Esto define, por un lado, el carácter de la didáctica como disciplina y, por el otro, la potencialidad de la misma para influir sobre el rumbo de las prácticas a las que se dedica. 
Por último, cabe recordar que Basabe (2007) y Feldman (2008) plantean si a la didáctica le corresponde limitarse a brindar buenas y detalladas interpretaciones acerca de las prácticas de enseñanza o si, además, debería elaborar normas para guiar su rumbo, inclinándose por esta última opción.

En síntesis, sostenemos que en las tres investigaciones citadas aparece una articulación de saberes epistemológicos y didácticos para analizar -con diferentes niveles de profundidad- la normatividad en la didáctica. Si bien el carácter normativo de esta disciplina puede no presentarse como el núcleo central del trabajo, sí aparece colateralmente en tanto, suponemos, siempre es una preocupación de los autores.

Por último, con respecto al caso del curriculum, observamos que se presenta una situación en parte diferente. Por un lado, como ya expusimos, se presenta una carga fuerte de saberes epistemológicos para construir las perspectivas metateóricas ${ }^{135}$ como forma de entender la complejidad y diversidad de teorías curriculares. Como desarrollamos con más detalle en el capítulo VIII, Kemmis (1993) le atribuye a Schwab la creación de una nueva teoría curricular opuesta a la perspectiva teórica o técnica y, al mismo tiempo, la formulación de un nuevo supuesto para anclar la construcción de nuevas teorías curriculares, lo que se convierte en el primer paso metateórico en el campo del curriculum. También otros autores continúan abonando este esquema conceptual con aportes filosóficos, como Grundy (1994), que recupera a Habermas. Reiteramos entonces que la formulación y la ampliación de este esquema para entender la construcción teórica curricular recupera aportes filosóficos y epistemológicos.

Por otro lado, en la bibliografía consultada encontramos autores como Feldman y Palamidessi (1994), Cols (2004) o Dussel (2010), quienes afirman que el curriculum es un texto normativo. Posiblemente por las mismas características del curriculum que ya mencionamos, no hemos hallado textos que realicen una reflexión epistemológica o de segundo orden sobre la normatividad como

\footnotetext{
135 Entre otros autores, mencionamos en este trabajo a: Kemmis (1993); Grundy (1994); Salinas Fernández (1997).
} 
componente disciplinar constitutivo. Pero siempre se rescata que el curriculum, en tanto propuesta formativa, busca concretarse en la práctica y, por esto mismo, persigue su orientación para el alcance de sus finalidades.

\section{III - 5 - Teorías de alcance intermedio o teorías cercanas a la práctica.}

Las teorías de alcance medio -tal como las denomina Merton- merecen una atención especial ya que nos permiten, según entendemos, establecer algunas pautas para examinar las teorías de la didáctica y el curriculum y, más específicamente, su componente normativo.

Kreimer (2005) sostiene que este tipo de teorías son las que le permiten a Merton estudiar empíricamente la ciencia como una institución social, tal como él la conceptualiza, además de proponer algunos cambios conceptuales que hubieran sido difíciles de observar en un nivel macro de la mano de corrientes como el funcionalismo o el marxismo, predominantes hasta la década del ' 40 y con pretensiones de explicación más totalizadoras.

Estas teorías también son retomadas por Knorr Cetina (citado en Kreimer, 2005) y por Latour (1992a,b). Knorr Cetina las utiliza para estudiar procesos socio-cognitivos en el ámbito del laboratorio y visualizar dinámicas propias de ese espacio hasta entonces considerado como una "caja negra" del trabajo científico, en relación con procesos sociales más amplios.

Latour, por su parte, plantea los estudios de alcance medio como una articulación de las teorías macrosociales con los estudios microsociales de laboratorio que ellos proponen y realizan. Considera, por un lado, que las teorías macrosociales han fracasado en su intento de comprender el contenido de la ciencia o las prácticas micro del laboratorio; por el otro, sostiene que muchos estudios más micro, de la mano de la etnometodología, la microsociología o el interaccionismo simbólico, al contrario, explican muy bien el contenido de la ciencia pero fallan en dar cuenta de sus vinculaciones con la sociedad. 
Para Prego, por otra parte, la tarea de la sociología hoy debe centrarse en la elaboración de teorías de alcance medio. Plantea el desafío de generar teorías especiales aplicadas a campos limitados de datos, sin descuidar el avance progresivo hacia la construcción de un sistema conceptual integrado, que articule las teorías anteriores. Las teorías de alcance medio son "[...] menos imponentes pero mejor fundadas [...]" (1992, p.17) para trabajar en ciencias sociales. Si bien la comparación con la física y algunas otras ciencias exactas tienta a construir un sistema de teorías generalizables, hay que considerar las características de la propia disciplina y de su objeto que invalidan este tipo de planteos.

A su vez y en relación con estas cuestiones, Prego plantea una cierta desproporción que se le suele presentar al sociólogo entre los problemas sociales que demandan urgente tratamiento y el corpus de conocimientos y destrezas acumulado. Las posibilidades de resolución de los problemas prácticos son disímiles según el momento histórico y las características de la situación con la que se trabaje. Los problemas prácticos demandan también investigaciones rigurosas pertinentes.

En lo que respecta al campo educativo, también encontramos autores que hablan de la elaboración de teorías cercanas a la práctica y basadas en que la educación y la enseñanza son prácticas sociales.

Tal es el caso, por ejemplo, de Gimeno Sacristán quien considera que los estudios de las ciencias de la educación y la pedagogía se ubican en una zona de indefinición intermedia, "[...] en constante proceso de constitución, en la medida en que quieren seguir los desarrollos del pensamiento de las ciencias sociales y a la vez comprometerse con las precisiones que requiere la práctica [...]" (1998, p.162). Para el autor, el saber académico sobre la educación suele estar alejado de las circunstancias particulares en las que se desenvuelven las prácticas y de los saberes que sobre la educación tienen los prácticos. A su vez, los planteos más generales de las ciencias sociales carecerían de un enfoque adecuado para el estudio de las prácticas. Por su parte, los prácticos y su "saber hacer", suelen 
estar al margen de los desarrollos de las complejas teorizaciones sobre la educación.

También encontramos cierta afinidad en el planteo de Stenhouse (1991) realizado a propósito de su consideración de los estudios del curriculum como una ciencia normativa. Las grandes sistematizaciones teóricas son importantes, favorecen la comprensión de los procesos, y es necesario que sean coherentes, estén lógicamente construidas y sólidamente fundamentadas. No obstante, dice el autor, todas estas virtudes no alcanzan para informar la práctica y llama la atención acerca de su adopción acrítica para desarrollar la enseñanza. Estas teorías y teorizaciones deben cruzarse, por ejemplo, con un conocimiento del funcionamiento institucional.

Consideramos oportuno sistematizar algunos sentidos de "práctica" desarrollados específicamente en el campo educativo, que aglutinan elementos ya mencionados en este capítulo. Por ejemplo, Kemmis (1990) sostiene que:

1. La práctica es intencional $y$, por tanto, no puede comprenderse sin referencia a las intenciones y teorías que la orientan.

2. El sentido y la importancia de la práctica se construyen socialmente por lo que son interpretados por el propio sujeto practicante y por otros.

3. Su construcción tiene una dimensión histórica con referencia, por un lado, a la propia historia de una situación particular, y por otro, a tradiciones más profundas de las prácticas educativas.

4. La práctica educativa tiene -por último- una dimensión política que demanda atención. Poder visualizar la práctica en términos de micropolítica permite abordar las relaciones de poder, los mecanismos de toma de decisiones, las imposiciones y negociaciones, etc.

También Gimeno Sacristán (1997) aporta dimensiones interesantes para considerar la peculiaridad de la práctica educativa y, en cierta forma, ampliar sus sentidos habituales. De esta manera: 
1. Las prácticas educativas no pueden reducirse a las prácticas escolares en una sociedad. Las prácticas educativas son consideradas como experiencias antropológicas de cualquier cultura.

2. Aun en el contexto escolar, las prácticas educativas incluyen aquellas que se desprenden de la institucionalización de la educación.

3. A su vez, existe una gran variedad de prácticas educativas circunscriptas al aula y a la escuela.

Para el caso específico de la enseñanza, Basabe y Cols (2007) realizan un análisis que permite entenderla en su transformación desde una actividad espontánea y natural hasta una práctica social y cultural, institucionalizada, y de relevancia para la continuidad de las sociedades. En el recorrido histórico que llevan a cabo se concreta una historia de la didáctica a partir de las transformaciones sufridas por su objeto de estudio.

En la segunda parte de la tesis, pretendemos poner en diálogo la caracterización de los cinco cruces entre las disciplinas realizada en este capítulo con el análisis del corpus empírico. 


\section{CAPÍTULO IV: METODOLOGÍA}

Nos proponemos en este capítulo presentar la estrategia metodológica general que hemos seguido en la investigación, en particular con relación a la conformación del corpus empírico y su análisis, objeto de la segunda parte de la tesis. En concordancia con la definición de metodología que expusimos en la introducción, nos abocamos en las próximas líneas a analizar los supuestos y métodos que aparecen en nuestra investigación.

\section{IV - 1 - Construcción del objeto de estudio y caracterización general de la perspectiva de abordaje.}

Como explicamos en la introducción de la presente tesis, nuestro objeto de estudio está conformado por la normatividad en la didáctica, enriqueciendo el análisis con categorías de perspectivas epistemológicas y metodológicas contemporáneas y de obras de didáctica y de curriculum. Estas dos últimas dimensiones se articulan permitiendo profundizar en la cuestión de la normatividad entre 1960 y 1990 en la Argentina.

Siguiendo a de Alba, entendemos que en esta tesis hemos realizado un "proceso de delimitación-construcción del objeto" a partir de la visualización progresiva de "[...] campos de observación y de problematización [...]" (1991, p.147).

En este sentido, el estudio previo realizado en la tesis de maestría nos permitió visualizar una posible continuidad en la problematización de nuestros intereses en torno a la revisión del material empírico que nos aportara una nueva mirada sobre la constitución de la normatividad en la didáctica.

Como explica de Alba retomando los aportes de Bourdieu, este proceso de delimitación-construcción del objeto se realiza desde una determinada 
perspectiva epistemológica y teórica que nosotros desarrollamos a lo largo de toda la tesis pero principalmente en la primera parte.

Sostenemos que la formulación inicial de las preguntas de investigación en torno al objeto de estudio ha sido un paso central en este proceso, como lo es para toda investigación interpretativa (Erickson, 1990). Tal como lo plantean de Alba (1991) o Flick (2007), estas preguntas iniciales sirven más como anticipación de sentido o como supuestos hipotéticos desde los cuales interrogar la realidad, y se van modificando a lo largo de la investigación, alertando a su vez sobre la relevancia de estar atentos a la emergencia de resultados nuevos, inesperados y a veces sorprendentes.

En este sentido, nuestras preguntas de investigación evidencian una serie de supuestos vinculados a la constitución de la normatividad en la didáctica y el curriculum desde la reflexión epistemológica y desde el propio material empírico. Dichos supuestos se van revisando permanentemente y en algunos casos quedan contradichos con los datos empíricos, como analizamos en la segunda parte de esta tesis.

Consideramos que este ejercicio es posible por basar la metodología utilizada en una relación dialéctica entre el marco conceptual-referencial y los referentes empíricos (de Alba, 1991); en nuestra investigación, esta vinculación está dada fundamentalmente por la primera y la segunda parte de la tesis.

También adoptamos el "método del extrañamiento" tal como lo conceptualiza Sztulwark. El autor rechaza cualquier distancia acrítica que se pueda tomar del objeto de estudio por los sesgos positivistas que la acompañan y propone este "[...] extrañamiento [que] implica sobre todo un estar al acecho y un perseguirse a uno mismo en las propias comodidades mentales [...]" (2007, p.19) ${ }^{136}$.

En este sentido, el método del extrañamiento favorece un ejercicio permanente tendiente, por un lado, a la explicitación de los supuestos teóricos, epistemológicos y metodológicos que se van poniendo en juego en el proceso

\footnotetext{
${ }^{136}$ Consideramos que con un sentido similar Ardoino (2005) plantea la relación que sostiene necesaria entre "distanciación" e "implicación" en la investigación-acción en las ciencias sociales en general y las ciencias de la educación en particular.
} 
investigativo $\mathrm{y}$, por el otro, a la consecuente adopción de una postura fundamentada.

Por otra parte y en consonancia con lo ya expuesto en la presentación de la primera parte de la tesis, como en toda investigación interpretativa, la finalidad está depositada en la generación de explicaciones comprensivistas, más que en la formulación de explicaciones causales. Nos interesa aportar inteligibilidad con relación al objeto de estudio, apelando, por un lado, a la complementación y contrastación de las diferentes líneas teóricas que integran el marco conceptual-referencial; y por otro, a los sentidos y a la racionalidad que expresan los distintos autores de las obras de didáctica y de curriculum que integran la segunda parte.

Asimismo, pretendemos interpretar principalmente las particularidades que adquiere la relación dialéctica expuesta en el párrafo anterior. Para esto trabajamos con distintos niveles de significación cuyos resultados se van revisando a lo largo de todo el proceso de investigación. “[...] Esta metodología se caracteriza por un ir y venir entre aspectos conceptuales y referentes empíricos del objeto. Esto es, se va profundizando en la interpretación a través de niveles de análisis o vueltas analíticas [...]" (de Alba, 1991, p.152).

Si bien lo profundizamos en el tercer apartado de este capítulo al aludir específicamente a la metodología vinculada al análisis del corpus empírico, baste aquí mencionar que esta forma de entender la relación entre el marco conceptual-referencial y el material empírico demanda una revisión constante o diálogo permanente entre las categorías teóricas que se van construyendo y los aportes -en este caso- de las obras de didáctica y de curriculum para adecuarse a lo que de Alba (1991) denomina "la textura del objeto".

Por último podemos decir que el proceso de delimitación-construcción del objeto de estudio está guiado por la intención más amplia y de largo plazo de estudiar la constitución de la normatividad en la didáctica en la actualidad como una veta desde la cual es posible aportar saberes conceptuales e instrumentales para el mejoramiento de las prácticas de enseñanza. En coherencia con de Alba (1991), esta finalidad más amplia está impregnada de 
componentes axiológicos que la ligan a un determinado proyecto político, social y cultural mayor.

Por su parte, Valles (2000) destaca la relación importante entre la investigación documental y la perspectiva histórica. En nuestro caso, el estudio de las obras de didáctica y de curriculum publicadas entre los años 1960 y 1990 nos lleva a considerar algunos procesos históricos más amplios de nuestro país que aporten datos contextuales, por un lado, y a introducirnos en el campo disciplinar, por el otro. En ese sentido, cabe considerar el tratamiento contextual y diacrónico de la didáctica y el curriculum en Argentina, que se presentó en el capítulo II, así como las consideraciones al respecto que realizaremos al analizar el corpus empírico más adelante.

Las obras analizadas se convierten en una fuente, en nuestro caso, para acceder a un mejor conocimiento del objeto de estudio. Éstas nos posibilitan obtener información del posicionamiento del autor en el momento histórico en el que las escribió, así como los elementos que configuran su estructura teórica y su propuesta para la disciplina.

Acordamos con Valles (2000) en que una importante desventaja en el análisis que llevamos a cabo se encuentra en la distancia entre el autor (de las obras de didáctica y de curriculum que integran el corpus empírico) y el lector (nosotros) que puede dar lugar a diferentes interpretaciones. Esta desventaja es propia de todo análisis documental pero intentamos subsanarla con la estrategia metodológica que estamos exponiendo.

\section{IV - 2 - El juicio de los expertos en la conformación del corpus empírico.}

La conformación del corpus empírico se realizó en base al análisis de los datos arrojados por una encuesta a expertos de la pedagogía, la didáctica y el curriculum. Utilizamos una serie de criterios para seleccionar a estos expertos y para que, a través de una encuesta, nos aportaran su saber específico acerca de qué obras de didáctica y de curriculum, nacionales o extranjeras pero con 
impacto en la producción argentina, publicadas entre 1960 y 1990, podían ser representativas para estudiar la constitución de la normatividad.

Estas obras integran lo que, siguiendo a Bernstein (1990; 1993), se denomina contexto primario de producción del discurso pedagógico. En este contexto se producen aquellos saberes especializados sobre el objeto en cuestión que son posteriormente seleccionados y transmitidos en el contexto secundario y que dan cuenta de las características del discurso pedagógico.

En este sentido, con esta investigación nos proponemos ingresar a ese contexto primario de producción de saberes didácticos y curriculares desde la perspectiva teórico-metodológica que exponemos a continuación.

\section{IV - 2-a-Descripción del instrumento y modalidad de administración.}

Para el logro de los objetivos de la investigación consideramos pertinente la implementación de una encuesta a expertos en el tema que nos aportara elementos para la configuración del corpus empírico.

Los encuestados no fueron tomados como casos individuales de estudio, sino que se los incluyó principalmente como expertos (Flick, 2007) en el marco de una selección intencional.

Por otra parte, se construyó y administró un instrumento de carácter semi-estructurado que permitiera acceder a la información puntual que se les requería a los expertos seleccionados.

Siguiendo a Piovani (2007) podemos decir que la encuesta puede ser considerada una forma particular de entrevista, siendo ésta última tomada como un instrumento importante en las investigaciones en ciencias sociales en tanto remite a una suerte de encuentro que posibilita la recolección de información referida al objeto que se está estudiando. El autor presenta una tipología de entrevistas que es útil para caracterizar nuestro instrumento. Retoma una propuesta de Fideli y Marradi (1996; citado en Piovani, 2007)137,

\footnotetext{
${ }^{137}$ Fideli, Roberto y Marradi, Alberto. (1996). Intervista, pp.71-82 en “Enciclopedia delle Scienze Sociali”. Roma: Istituto della Enciclopedia Italiana, vol.V.
} 
quienes utilizan principalmente dos criterios de clasificación: 1- la presencia o no de una interacción cara a cara entre el entrevistador y el entrevistado; 2- el grado de estructuración del instrumento y, por tanto, el grado de libertad que les deja al entrevistador y al entrevistado para preguntar y responder.

Con estos aportes, Piovani presenta un cuadro de doble entrada en el que se mencionan distintos tipos de entrevistas. Para el caso del primer criterio, éste queda configurado con tres posibilidades: presencial, telefónica y virtual; ésta última opción es agregada por el autor al planteo original de Fideli y Marradi. En lo que respecta al segundo criterio, el autor construye un continuum que para sintetizar abarca tres posibilidades: un grado de espontaneidad en la interacción verbal alto, medio y bajo.

Teniendo en cuenta estas consideraciones, el instrumento utilizado en esta tesis para la recuperación de la opinión de los expertos se ubica en la opción virtual / grado de estandarización alto. Podemos decir además que se trató de un "cuestionario autoadministrado" (Piovani, 2007), ya que fue enviado a los expertos o informantes clave por correo electrónico y éstos lo devolvieron al destinatario por el mismo medio.

Archenti (2007) denomina "encuesta autoadministrada" a este tipo de instrumento y sostiene que la respuesta siempre queda sujeta a la voluntad de los informantes clave y la muestra definitiva se termina autoseleccionando. Es así que se construyó inicialmente una "muestra potencial" de cuarenta y cinco (45) informantes clave y la "muestra real" se conformó con diecisiete (17) respuestas. Compartimos con la autora que aquí radica uno de los problemas metodológicos de la utilización de este tipo de instrumentos; no obstante, priorizamos sus virtudes en nuestra investigación, sobre todo las vinculadas a la conformación de una muestra que maximizara la diversidad.

Por otra parte, en lo que respecta al instrumento, éste consta de dos (2) partes principales ${ }^{138}$. En la primera, denominada "presentación", explicamos al encuestado las intencionalidades de la consulta, los propósitos de la tesis doctoral y los criterios que guiaban la selección de obras de didáctica y de

\footnotetext{
${ }^{138}$ Se adjunta en el Anexo I de esta tesis una copia de la encuesta.
} 
curriculum en el marco conceptual-referencial amplio de la tesis. La segunda parte refería a la "encuesta" en sí misma, en la que solicitamos a los expertos que de un total de diecisiete (17) obras, ordenadas cronológicamente, señalaran aquéllas cinco (5) que consideraban más representativas para analizar posturas contrastantes en torno a la normatividad a lo largo del eje normativo/prescriptivo/descriptivo ${ }^{139}$, explicado y fundamentado precedentemente en el instrumento. Asimismo y en coherencia con la caracterización anterior sobre este tipo de instrumentos, dejamos cinco (5) espacios en blanco para que los encuestados incluyeran aquellas obras no mencionadas y que a su juicio eran relevantes para la investigación.

Inicialmente enviamos la encuesta a un grupo piloto de expertos cuyas respuestas y comentarios fueron utilizados para introducir modificaciones o aclaraciones que permitieron mejorar el instrumento.

Por otro lado, es importante referirnos a la conformación de la muestra de expertos consultados con mayor detalle. Tomando el trabajo de Flick y las explicaciones brindadas para las estrategias de muestreo, podemos decir que para la selección de los expertos que pudieran contestar la encuesta, hemos determinado a priori la estructura de la muestra especificando al inicio del proceso de investigación los criterios a partir de los cuales la misma se iba a constituir. Según Flick se trata de criterios abstractos en tanto "[...] parten de una idea de la tipicidad y la distribución del objeto investigado [...]" (2007, p.76).

En este sentido, seleccionamos una muestra intencional de expertos a partir de un conjunto de criterios que permitieron identificar a los expertos en el tema. Teniendo en cuenta la heterogeneidad del campo construimos los siguientes criterios:

1. Institucional: seleccionamos diferentes instituciones educativas de nuestro país, a saber, universidades e Institutos Superiores de Formación Docente -ISFD-).

\footnotetext{
${ }^{139}$ Cabe aclarar que este eje se construye principalmente desde el marco conceptual-referencial y es resignificado a la luz del análisis de los resultados de la encuesta, pasando a conformar los criterios que permiten la selección del corpus definitivo de obras de didáctica y de curriculum para analizar, tal como explicamos en el apartado IV-2-b.
} 
2. Especialidad disciplinar: focalizamos en aquellos profesionales del área de pedagogía, didáctica general y curriculum.

3. Status: incluimos profesores que se desempeñaran en diferentes cargos. En el ámbito universitario consideramos Profesores Titulares, Profesores Adjuntos, Jefes de Trabajos Prácticos y Ayudantes; en el ámbito no universitario contactamos Profesores Titulares, Suplentes y Provisionales que estuvieran a cargo de las asignaturas afines a las disciplinas enunciadas en el criterio 2.

4. Generacional: comprendimos distintas edades entre los expertos con la intención de recoger información de diferentes trayectorias profesionales y de variados contextos de formación.

El tamaño de la muestra se constituyó con un criterio flexible considerando las características del proceso cualitativo de la investigación y apuntando a la saturación.

Las estrategias para la conformación efectiva de la muestra fueron principalmente las siguientes:

1. Selección de los expertos a partir de los criterios anteriormente expuestos. Este trabajo demandó contactar por un lado a potenciales informantes conocidos $y$, por el otro, buscar información por internet sobre las distintas instituciones educativas y los profesionales vinculados laboralmente a ellas.

2. "Bola de nieve": a los primeros informantes clave contactados les solicitábamos que nos dieran referencias para comunicarnos con otros colegas. Esta técnica fue muy útil, permitiéndonos ampliar la muestra potencial de encuestados.

3. "Saturación teórica"140: si bien la muestra real de expertos resultó menor a la muestra potencial, tomamos la decisión de terminarla

\footnotetext{
140 "[...] Glaser y Strauss proponen el criterio de "saturación teórica" (de una categoría, etc.): "El criterio para juzgar cuándo dejar de muestrear los diferentes grupos relevantes a una categoría es la saturación teórica de ésta. Saturación significa que no se encuentran datos adicionales por medio de los cuales el sociólogo pueda desarrollar las propiedades de la categoría" (1967, p.61). El muestreo e integración de material nuevo acaba cuando la "saturación teórica" de una categoría o grupo de casos se ha alcanzado, es decir, cuando no emerge ya nada nuevo [...]" (Flick, 2007, pp.78-79.
} 
en función del criterio de saturación teórica.

IV - $2-b-$ Análisis de los resultados y conformación del corpus de obras de didáctica y de curriculum.

En el proceso de investigación realizamos una definición gradual del corpus de obras de didáctica y de curriculum hasta llegar a la conformación del definitivo. En todos los casos utilizamos el muestreo teórico y su principio básico vinculado con la selección de casos por su relevancia o por su contenido específico, más que por criterios metodológicos abstractos que pudieran relacionar el trabajo con otro tipo de muestreo, como el estadístico por ejemplo (Flick, 2007) $^{141}$.

Flick informa que el muestreo teórico ha sido desarrollado principalmente por Glaser y Strauss ${ }^{142}$. Este tipo de muestreo permite ir seleccionando el material empírico en el proceso mismo de recolección y análisis de los datos.

"[...] los individuos, los grupos, etc., se seleccionan según su nivel (esperado) de nuevas ideas para la teoría en desarrollo, en relación con el estado de elaboración de la teoría hasta ese momento. Las decisiones de muestreo se dirigen a ese material que promete las mayores ideas, visto a la luz del material ya utilizado y el conocimiento extraído de él [...]" (Flick, 2007, p.78).

Estos supuestos guiaron la conformación de un primer corpus ${ }^{143}$ de diecisiete (17) obras de didáctica y de curriculum que incluimos en la encuesta enviada a los expertos. Este listado original se conformó a partir de una exploración preliminar y con la intención de "[...] rastrillar globalmente el discurso en sus fuentes más representativas [...]" (Furlán, 1997, p.141) ${ }^{144}$. Incluye trabajos publicados en formato de libro y un artículo de revista que, como

\footnotetext{
${ }^{141}$ También se puede consultar Valles (2000); Andréu Abela (2001).

142 Glaser, B. G. y Strauss, A. (1967). The Discovery of Grounded Theory: Strategies for Qualitative Research. New York: Aldine.

${ }^{143}$ Armamos este listado en base a una exploración preliminar del campo y con el asesoramiento de la Dra. Estela B. Cols, quien por entonces se desempeñaba como co-directora de la presente tesis.

${ }^{144} \mathrm{El}$ autor construye una muestra de obras de curriculum para analizar la conformación del campo en Estados Unidos y su posterior impacto en la producción mexicana.
} 
fundamentamos en el capítulo correspondiente (capítulo VII), es relevante para la presente investigación.

A medida que íbamos recibiendo y analizando las respuestas de los encuestados, se fue conformando otro corpus en el que, al listado original, se le fueron agregando otros trabajos propuestos.

El cuadro que presentamos a continuación resume este avance progresivo en la conformación del corpus. En primer lugar, aparece el listado de las obras de didáctica y de curriculum tal como fue enviado en la encuesta a los expertos consultados, y una indicación de la cantidad de encuestados que seleccionaron cada obra (en la tercera columna). Agregamos al final el listado de otras obras sugeridas por algunos expertos ordenado de la siguiente manera: en primer lugar la única obra que es elegida por dos encuestados y a continuación el resto de los trabajos en orden alfabético.

\begin{tabular}{|c|c|c|}
\hline $\mathbf{N}^{\mathbf{0}}$ & OBRAS INCLUIDAS ORIGINALMENTE EN LA ENCUESTA & $\begin{array}{c}\text { Encuestados } \\
\text { que } \\
\text { seleccionaron } \\
\text { la obra }\end{array}$ \\
\hline 1 & $\begin{array}{l}\text { TYLER, Ralph W. (1973). Principios básicos del currículo. Buenos } \\
\text { Aires: Troquel. } 1949 .\end{array}$ & 10 \\
\hline 2 & $\begin{array}{l}\text { STÖCKER, Karl. (1964). Principios de didáctica moderna (Biblioteca } \\
\text { de Cultura Pedagógica). Buenos Aires: Kapelusz. } 1954 .\end{array}$ & 2 \\
\hline 3 & $\begin{array}{l}\text { AEBLI, Hans. (1958). Una didáctica fundada en la psicología de Jean } \\
\text { Piaget. Buenos Aires: Kapelusz. }\end{array}$ & 5 \\
\hline 4 & $\begin{array}{l}\text { TABA, Hilda. (1977). Elaboración del currículo (3a. ed.). Buenos } \\
\text { Aires: Troquel. 1962. }\end{array}$ & 13 \\
\hline 5 & $\begin{array}{l}\text { NÉRICI, Imídeo. (1969). Hacia una didáctica general dinámica (1ª ed.). } \\
\text { Buenos Aires: Kapelusz. }\end{array}$ & 5 \\
\hline 6 & $\begin{array}{l}\text { BRUNER, Jerome S. (1969). Hacia una teoría de la instrucción (1a. } \\
\text { ed.). México: UTHEA. }\end{array}$ & 3 \\
\hline 7 & $\begin{array}{l}\text { SARUBBI, Irma R. de. (1971). Curriculum (1a. ed.). Buenos Aires: } \\
\text { Stella. }\end{array}$ & 1 \\
\hline
\end{tabular}




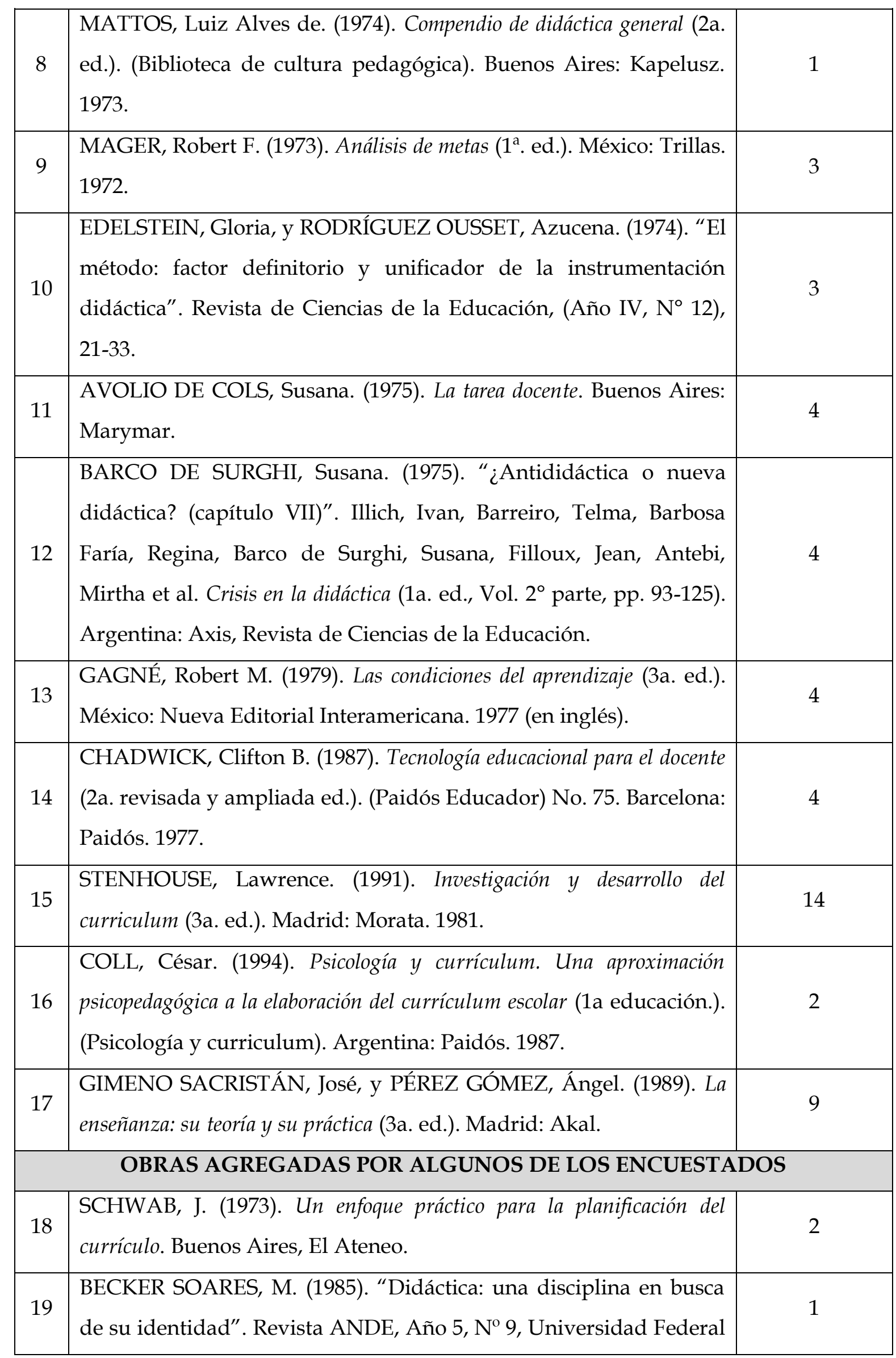




\begin{tabular}{|c|c|c|}
\hline & de Minas Gerais. & \\
\hline 20 & $\begin{array}{l}\text { BERNSTEIN, B., (1989). “Acerca del currículum”. Bernstein, B. } \\
\text { Clases, código y control. Madrid, Akal. }\end{array}$ & 1 \\
\hline 21 & $\begin{array}{l}\text { BLOOM, Benjamin. (1971). Taxonomía de los objetivos de la educación. } \\
\text { Buenos Aires: El Ateneo. }\end{array}$ & 1 \\
\hline 22 & $\begin{array}{l}\text { CARR, W. (1990). Hacia una ciencia crítica de la educación. Barcelona, } \\
\text { Lartes. }\end{array}$ & 1 \\
\hline 23 & $\begin{array}{l}\text { DÍAZ BARRIGA, A. (1996). El currículo escolar. Surgimiento y } \\
\text { perspectivas. Buenos Aires, Aique Grupo Editor. }\end{array}$ & 1 \\
\hline 24 & $\begin{array}{l}\text { DOYLE, W. (1990). "Classroom Knowledge as a Foundation of } \\
\text { Teaching". Teacher College Record. vol. } 91 \text { No3, Columbia } \\
\text { University, Columbia. }\end{array}$ & 1 \\
\hline 25 & $\begin{array}{l}\text { DOYLE, W. (1995). “Los procesos del currículum en la enseñanza } \\
\text { efectiva y responsable”. Revista del Instituto de Investigaciones en } \\
\text { Ciencias de la Educación, Año IV, N N 6, IICE, Facultad de Filosofía y } \\
\text { Letras, Universidad de Buenos Aires. }\end{array}$ & 1 \\
\hline 26 & $\begin{array}{l}\text { ETCHEVERRY, Delia S. (1958). Los artesanos de la enseñanza: la lucha } \\
\text { por la libertad creadora en la escuela argentina. Buenos Aires: } \\
\text { Ediciones Galatea Nueva Visión. }\end{array}$ & 1 \\
\hline 27 & $\begin{array}{l}\text { GIMENO SACRISTÁN, José. (1986). Teoría de la enseñanza y } \\
\text { desarrollo del currículo. Buenos Aires: REI. }\end{array}$ & 1 \\
\hline 28 & JACKSON, Ph. (1975). La vida en las aulas. Madrid, Morata. & 1 \\
\hline 29 & $\begin{array}{l}\text { KEMMIS, S. (1988). El currículum: más allá de la teoría de la } \\
\text { reproducción. Madrid, Morata. }\end{array}$ & 1 \\
\hline 30 & $\begin{array}{l}\text { PINAR, W., REYNOLDS, W., SLATTERY, P., TAUBMAN, P. } \\
\text { (1995). Understanding Curriculum. New York, Peter Lang. }\end{array}$ & 1 \\
\hline 31 & SKINNER, J. (1970). Tecnología de la enseñanza. Barcelona, Labor. & 1 \\
\hline
\end{tabular}

De los diecisiete (17) encuestados, trece (13) marcaron cinco (5) obras de didáctica y de curriculum del listado de las diecisiete (17) obras enviado en la encuesta, tal como se les solicitaba. Otros tres (3) ofrecieron una selección de seis (6) obras, pero de éstos, dos (2) marcaron cinco (5) obras del listado ofrecido en la encuesta y agregaron además una (1) obra, y el tercero marcó seis (6) obras 
del listado que aparecía en el instrumento. Finalmente, el último de los encuestados, marcó siete (7) obras del listado original que figura en la encuesta. En total son cinco (5) los encuestados que propusieron en conjunto las catorce (14) obras que agregamos en el cuadro precedente.

Teniendo en cuenta el desarrollo del marco conceptual-referencial que expusimos en la primera parte de esta tesis, así como también una caracterización general de cada una de las obras antes mencionadas a partir de una exploración preliminar, construimos una serie de criterios que nos aportaron elementos para la selección del corpus definitivo de obras que analizamos en los próximos capítulos. En base a cada uno de estos criterios, tomamos prioritariamente dos (2) obras de cada "tipo" y en los casos en los que el análisis lo ameritaba, incluimos una tercera que justificamos oportunamente.

El primer criterio alude a seleccionar obras que den cuenta de las características de la didáctica general en nuestro país con anterioridad al impacto de la teoría curricular norteamericana que se produjo hacia finales de los años '60. Encontramos obras de autores extranjeros pero que en general han tenido difusión en el ámbito local a partir de publicaciones de la Editorial Kapelusz. Según la información brindada en el cuadro precedente, quedaron incluidas en este grupo: Stöcker ( $\left.\mathrm{N}^{\circ} 2\right)$, Aebli ( $\mathrm{N}^{\mathrm{o}} 3$ ), Nérici ( $\mathrm{N}^{\circ}$ 5), Bruner ( $\mathrm{N}^{\circ} 6$ ) y Mattos ( $\left.\mathrm{N}^{\circ} 8\right)$. La segunda y la tercera obra son aquéllas que analizamos en el capítulo $\mathrm{V}$, por ser las que obtienen la mayor cantidad de selecciones por parte de los expertos consultados.

El segundo criterio se refiere a considerar aquellas obras que son representativas de la teoría curricular norteamericana y que se conocieron en nuestro país desde fines de los años '60 y principios de los '70. Los trabajos del cuadro que quedaron incluidos en este criterio son: Tyler $\left(\mathrm{N}^{\circ} 1\right)$, Taba $\left(\mathrm{N}^{\circ} 4\right)$, Mager ( $\left.\mathrm{N}^{\circ} 9\right)$, Gagné ( $\left.\mathrm{N}^{\circ} 13\right)$ y Chadwick ( $\left.\mathrm{N}^{\circ} 14\right)$. Los primeros dos textos son analizados en el capítulo VI por ser, nuevamente, las obras que obtuvieron mayor cantidad de elecciones en la encuesta a los expertos. Incluimos además el análisis de una tercera obra porque, según lo expuesto en el capítulo II, resulta de interés contrastar trabajos en lo que denominamos la corriente técnica del 
curriculum. En este sentido, seleccionamos la obra de Chadwick. Si bien este texto obtiene la misma cantidad de elecciones que el trabajo de Gagné (ambos son seleccionados por cuatro (4) expertos, mientras que el de Mager es elegido por tres (3) encuestados), consideramos pertinente su inclusión porque el contenido de la obra se relaciona más directamente con los objetivos de esta tesis.

El tercer criterio apunta a considerar textos que den cuenta de las características del pensamiento local en el área de didáctica general con posterioridad al ingreso de la teoría curricular norteamericana y con anterioridad a la última dictadura militar. Del listado original de obras incluido en la encuesta enviada a los expertos entran aquí los siguientes trabajos: Sarubbi ( $\left.\mathrm{N}^{\mathrm{o}} 7\right)$, Edelstein y Rodríguez ( $\left.\mathrm{N}^{\mathrm{o}} 10\right)$, Avolio ( $\left.\mathrm{N}^{\mathrm{o}} 11\right)$ y Barco ( $\left.\mathrm{N}^{\mathrm{o}} 12\right)$. A los fines de esta investigación, en el capítulo VII realizamos el análisis de las últimas dos (2) obras citadas por ser las que obtienen la mayor cantidad de elecciones por parte de los informantes clave. Consideramos relevante incluir también el análisis del artículo de Edelstein y Rodríguez porque, por un lado, realiza una lectura crítica del trabajo de Nérici (analizado en el capítulo V de esta tesis) y, por otro lado, su contenido se vincula directamente con las problemáticas abordadas en esta investigación.

Por último, el cuarto criterio se refiere a aquellas obras de didáctica y de curriculum que se conocen en la Argentina en la década del '80, principalmente con posterioridad al retorno de la democracia, y que revitalizan el campo con variadas lecturas ya mencionadas en el capítulo II. Quedaron incluidos aquí los últimos tres trabajos del listado que figura en la encuesta a los expertos, a saber: Stenhouse ( $\left.\mathrm{N}^{\mathrm{o}} 15\right)$, Coll ( $\left.\mathrm{N}^{\mathrm{o}} 16\right)$ y Gimeno Sacristán y Pérez Gómez ( $\left.\mathrm{N}^{\mathrm{o}} 17\right)$. La primera obra mencionada será analizada en el capítulo VIII por ser la que obtiene la mayor cantidad de elecciones por parte de los encuestados. Como segunda obra a analizar, consideramos pertinente incluir el texto de Schwab (No 18) por diferentes motivos. Uno de ellos responde a que una versión del libro citado en el cuadro precedente aparece como capítulo en el libro compilado por Gimeno Sacristán y Pérez Gómez ( $N^{\circ}$ 17). La significatividad que esta 
compilación ha tenido para la didáctica y el curriculum en nuestro país nos llevó originalmente a incluirla en la encuesta como un posible trabajo para ser analizado. Se trata de una obra publicada originalmente en 1982, que se conoce a nuestro país a mediados de los años '80, que compila trabajos de diversas líneas teóricas que aportan perspectivas renovadas de análisis. Si bien se trata de un trabajo elegido por nueve (9) encuestados no será incluido en el análisis porque al tratarse de una compilación de veintitrés (23) capítulos, cada uno redactado por un autor diferente, resulta muy difícil alinear la producción completa en una única postura o corriente. Esta opinión es sostenida además por dos (2) de los expertos que respondieron la encuesta aunque no seleccionaron la obra.

Otro de los motivos que sustenta el análisis del texto de Schwab se refiere a que, de los catorce (14) textos agregados por los expertos consultados, es el único elegido por más de (1) encuestado.

En tercer lugar, el texto de Schwab se considera valioso para comprender el surgimiento y sentido de la corriente práctica del curriculum y, por tanto, para complementar el análisis del texto de Stenhouse, tal como se desprende del capítulo II de esta tesis.

A partir de estos criterios, el listado de obras que se analizan específicamente (porque también se hará referencia a otros textos no incluidos en el corpus) quedó conformado por los siguientes diez (10) títulos:

\begin{tabular}{|c|l|c|}
\hline $\mathbf{N}^{\mathbf{0}}$ & $\begin{array}{l}\text { Obras que integran el corpus empírico definitivo que se analiza } \\
\text { en la tesis }\end{array}$ & $\begin{array}{c}\text { Capítulo de la } \\
\text { tesis dedicado } \\
\text { prioritariamente } \\
\text { a su análisis }\end{array}$ \\
\hline 1 & $\begin{array}{l}\text { AEBLI, Hans. (1958). Una didáctica fundada en la psicología de Jean } \\
\text { Piaget. Buenos Aires: Kapelusz. }\end{array}$ & Cap. V \\
\hline 2 & $\begin{array}{l}\text { NÉRICI, Imídeo. (1969). Hacia una didáctica general dinámica (1 }{ }^{\text {a }} \text {. ed.). } \\
\text { Buenos Aires: Kapelusz. }\end{array}$ & Cap. V \\
\hline 3 & $\begin{array}{l}\text { TYLER, Ralph W. (1973). Principios básicos del currículo. Buenos } \\
\text { Aires: Troquel. 1949. }\end{array}$ & Cap. VI \\
\hline
\end{tabular}




\begin{tabular}{|c|c|c|}
\hline 4 & $\begin{array}{l}\text { TABA, Hilda. (1977). Elaboración del currículo (3a. ed.). Buenos } \\
\text { Aires: Troquel. 1962. }\end{array}$ & Cap. VI \\
\hline 5 & $\begin{array}{l}\text { CHADWICK, Clifton B. (1987). Tecnología educacional para el docente } \\
\text { (2a. revisada y ampliada ed.). (Paidós Educador) No. 75. Barcelona: } \\
\text { Paidós. } 1977 .\end{array}$ & Cap. VI \\
\hline 6 & $\begin{array}{l}\text { AVOLIO DE COLS, Susana. (1975). La tarea docente. Buenos Aires: } \\
\text { Marymar. }\end{array}$ & Cap. VII \\
\hline 7 & $\begin{array}{l}\text { BARCO DE SURGHI, Susana. (1975). “¿Antididáctica o nueva } \\
\text { didáctica? (capítulo VII)”. Illich, Ivan, Barreiro, Telma, Barbosa } \\
\text { Faría, Regina, Barco de Surghi, Susana, Filloux, Jean, Antebi, } \\
\text { Mirtha et al. Crisis en la didáctica (1a. ed., Vol. 2 parte, pp. 93-125). } \\
\text { Argentina: Axis, Revista de Ciencias de la Educación. }\end{array}$ & Cap. VII \\
\hline 8 & $\begin{array}{l}\text { EDELSTEIN, Gloria, y RODRÍGUEZ OUSSET, Azucena. (1974). “El } \\
\text { método: factor definitorio y unificador de la instrumentación } \\
\text { didáctica". Revista de Ciencias de la Educación, (Año IV, N 12), } \\
\text { 21-33. }\end{array}$ & Cap. VII \\
\hline 9 & $\begin{array}{l}\text { SCHWAB, J. (1973). Un enfoque práctico para la planificación del } \\
\text { currículo. Buenos Aires, El Ateneo. }\end{array}$ & Cap. VIII \\
\hline 10 & $\begin{array}{l}\text { STENHOUSE, Lawrence. (1991). Investigación y desarrollo del } \\
\text { curriculum (3a. ed.). Madrid: Morata. } 1981 .\end{array}$ & Cap. VIII \\
\hline
\end{tabular}

Siguiendo las técnicas de análisis del contenido, como explicamos con más detalle en el próximo apartado de este capítulo, cada obra se constituye como una unidad de análisis en sí misma (unidad física) y su tratamiento se desagrega en los siguientes cuatro (4) aspectos:

1. Datos de edición: se incluyen aquí título de la obra, autor o autores según corresponda, editorial, lugar de publicación, edición que se analiza.

2. Descripción de la obra: se consideran en este ítem los propósitos de la publicación, la estructura y las temáticas principales que se abordan.

3. Caracterización de la obra: el tratamiento de este aspecto contempla la triangulación entre el contenido de la obra, algunos datos 
complementarios del autor, la obra y el contexto de producción en términos generales, y el marco conceptual-referencial que se construye en la presente tesis.

4. Análisis de la obra: organizado a partir de las categorías que se desprenden de los cruces entre la didáctica, el curriculum, y las perspectivas epistemológicas y metodológicas contemporáneas (capítulo III). A su vez, en cada cruce se incorpora el análisis de otras categorías que se fueron construyendo a medida que se avanzaba en el análisis. Se incluye aquí también el examen y la valoración de otros autores que han estudiado directa o indirectamente estas obras (en cierto sentido podrían considerarse fuentes secundarias) y que se constituyen en antecedentes para nuestro trabajo.

\section{IV - 3 - Caracterización del corpus empírico.}

En este tercer apartado nos proponemos explicitar los supuestos metodológicos que subyacen al análisis de las obras de didáctica y de curriculum que integran el corpus empírico.

Cabe recordar lo que mencionamos al principio de este capítulo respecto del diálogo dialéctico y permanente que mantenemos entre el marco conceptual-referencial y el material empírico. Sostenemos que ésta es una estrategia metodológica general ineludible para la construcción de conocimientos en la investigación interpretativa.

Específicamente, abordar un corpus tan complejo de obras de didáctica y de curriculum nos demandó una metodología de análisis adecuada tanto al objeto como a los fines de la investigación. En este sentido, optamos por el análisis del contenido (Krippendorff, 1990; Andréu Abela, 2001), utilizando algunas categorías preconstruidas de estudio, como explicamos a continuación. 
Optamos por la ventaja que presentan las técnicas de análisis del contenido relativas a la articulación de saberes provenientes de diferentes disciplinas, no sólo de la lingüística. Evidencian un desarrollo interdisciplinar que es hoy también indispensable en la investigación (y podemos agregar intervención) en el campo de las ciencias sociales ${ }^{145}$.

El análisis del contenido en un sentido amplio, tomando los aportes de Andréu Abela, "[...] es una técnica de interpretación de textos [...]" (2001, p.2). En nuestro caso, esos textos se conforman por producciones teóricas escritas de la didáctica y el curriculum que albergan un contenido que debe ser leído e interpretado para acceder a un nuevo conocimiento sobre la producción teórica y la conformación de la normatividad.

Adoptamos las técnicas de análisis del contenido cualitativo, que recuperan las ventajas del análisis del contenido cuantitativo, más vinculado a la cuantificación de aspectos manifiestos, pero avanzan hacia la interpretación del sentido latente incorporando otros procedimientos analíticos y el contexto en el que la misma se inscribe (Andréu Abela, 2001; Piovani, 2007) ${ }^{146}$.

“[...] El contexto es un marco de referencias que contiene toda aquella información que el lector puede conocer de antemano o inferir a partir del texto mismo para captar el contenido y el significado de todo lo que se dice en el texto. Texto y contexto son dos aspectos fundamentales en el análisis de contenido [...]" (Andréu Abela, 2001, p.2).

Por otra parte, Andréu Abela expresa que la técnica de análisis del contenido se basa prioritariamente en la lectura como instrumento para una recolección de datos metódica, sistemática y rigurosa. Si bien estas características la acercan a otras técnicas de investigación social, “[...] lo característico del análisis de contenido [...] es que se trata de una técnica que combina intrínsecamente, y de ahí su complejidad, la observación y producción de los datos, y la interpretación o análisis de los datos [...]" (2001, p.2).

\footnotetext{
${ }^{145}$ Furlán (1997) y Feeney (2007) también apuestan, para sus investigaciones, a las técnicas de análisis del contenido, desechando técnicas más cercanas a la lingüística. En ambos casos, como se puede inferir de las referencias que aportamos en diferentes partes de esta tesis, encuentran puntos de contacto con la presente investigación en tanto trabajan analizando producciones teóricas escritas del campo del curriculum.

${ }^{146}$ También Pérez Serrano (1994) informa que en la actualidad tanto el enfoque cuantitativo como el cualitativo aportan a la técnica de análisis del contenido.
} 
Como plantea el autor, esta técnica persigue la explicación y sistematización del contenido de los mensajes comunicativos -en nuestro caso, de los textos de didáctica y de curriculum- en vinculación estrecha con el contexto de producción de los mismos.

Por otra parte, sostiene que una investigación que se realiza mediante la técnica de análisis del contenido debe seguir una serie de pasos en su desarrollo. Estos pasos son los siguientes:

1.- Determinar el objeto o tema de análisis.

2.- Determinar las reglas de codificación.

3.- Determinar el sistema de categorías.

4.- Comprobar la fiabilidad del sistema de codificación-categorización.

5.- Inferencias (Andréu Abela, 2001, p.11).

El primer paso tiene relación con dar respuesta a una serie de preguntas tendientes a la explicitación del objeto de estudio, los propósitos de la investigación, el marco conceptual-referencial, el estado del arte y la unidad de análisis con la que se va a trabajar.

Consideramos que estas preguntas iniciales de la investigación encuentran respuesta en la lectura de la introducción y de la primera parte de la presente tesis. Cabe recordar no obstante que nuestro problema de investigación se constituye en torno a la siguiente pregunta: ¿qué características presenta la normatividad en la didáctica entre 1960 y 1990 en la Argentina?

La construcción de un marco conceptual-referencial ha resultado compleja pero la consideramos fundamental para la configuración del posicionamiento teórico-epistemológico desde el cual leer -en el sentido más amplio del término- los procesos sociales y educativos con los que trabajamos. Este posicionamiento teórico inicial marca una orientación a todo el proceso de investigación que corresponde explicitar. Como advierte Andréu Abela (2001), consideramos que hemos sorteado el riesgo de caer en la confirmación de prejuicios, ideas preconcebidas e interpretaciones poco rigurosas a partir de una amplia revisión bibliográfica que nos fue permitiendo la comparación de diferentes posturas y la construcción posterior de un marco consecuente. 
Por último, en lo que respecta a este primer paso de la investigación, es necesario establecer la unidad de análisis. Siguiendo a Krippendorff (1990), podemos identificar tres (3) tipos de unidades de análisis: de muestreo, de registro y de contexto.

Las unidades de muestreo, en nuestro caso, son las obras de didáctica y de curriculum que seleccionamos con posterioridad al análisis de los datos de la encuesta, tal como explicamos precedentemente.

Dentro de estas unidades de muestreo, se distinguen las unidades de registro que son aquellas que pueden ser analizadas aisladamente en su interior. En nuestro caso y como retomamos a continuación al hablar del sistema de codificación, las unidades de registro son los segmentos de los textos analizados que se relacionaron con las distintas categorías de análisis.

En tercer lugar, las unidades de contexto que distingue Krippendorff, son aquéllas que -como su nombre lo indica- ayudan a caracterizar la unidad de registro por ser más amplias o coincidir en extensión con ella. Son elementos que se vinculan a la unidad de registro y que contribuyen a profundizar su interpretación.

El segundo paso en el proceso de investigación, siguiendo la técnica de análisis del contenido, tal como lo caracteriza Andréu Abela (2001), se refiere a determinar las reglas de la codificación, es decir, establecer aquellas reglas que contribuyen a transformar el contenido del texto en códigos para el análisis.

El establecimiento de estas reglas en el marco de nuestra investigación ha quedado asociado al tercer paso, relativo a determinar el sistema de categorización. Trabajando en ambos pasos paralelamente, se pudo ir determinando la presencia, omisión, frecuencia e intensidad como reglas que contribuyen al análisis del texto según las diferentes categorías.

Siguiendo a Piovani (2007), podemos decir que una vez conformado el corpus definitivo de obras de didáctica y de curriculum, según los procedimientos que expusimos en el apartado anterior, construimos un "esquema de codificación". Consideramos que el mismo recibió aportes teóricos a priori, provenientes del marco conceptual-referencial que expusimos en los 
capítulos I a III, así como otras categorías construidas con posterioridad a la realización de una exploración preliminar de las obras. Es decir, la exploración de obras de didáctica y de curriculum que realizamos para la conformación de la encuesta, así como también las primeras indagaciones realizadas sobre las obras que constituyen el corpus empírico definitivo, nos permitieron elaborar otras categorías ricas para el análisis.

En este sentido, podemos decir que las categorías se fueron delineando progresivamente. En primer lugar con la realización de la tesis de maestría que ya hemos mencionado en diversas oportunidades, en la que pudimos avanzar en el establecimiento de cruces entre la didáctica y perspectivas epistemológicas y metodológicas contemporáneas a propósito de la constitución de la normatividad. En segundo lugar en la construcción del objeto de estudio específico de la presente tesis doctoral, con la profundización conceptual de los cruces anteriores y la incorporación del curriculum como teorización, investigación e intervención (Salinas Fernández, 1997), siempre a propósito de la normatividad. Y en tercer término, a medida que avanzábamos en la lectura analítica de las obras seleccionadas para el corpus empírico.

En este último sentido, muchas categorías se fueron configurando a medida que se avanzaba en el análisis, en ese interjuego entre el marco conceptual-referencial y los emergentes empíricos, como decíamos al comienzo de este apartado. Es por esto que el análisis se concretó en sucesivas etapas de lectura y revisión del material bibliográfico.

El esquema de codificación armado, como explica Piovani (2007), se fue conformando de esta manera en un "cuestionario imaginario" al que las obras fueron respondiendo en el análisis posterior más profundo.

Podemos decir también que las sucesivas lecturas y revisión del sistema de categorización y del material bibliográfico, además de permitir ajustar el esquema de codificación, permitió asignarle confiabilidad (cuarto paso del proceso de investigación que identifica Andréu Abela, 2001) que refiere a la consistencia o estabilidad del sistema de categorización. 
Finalmente, el quinto -la inferencia- implica extraer del texto que se está analizando aquellos sentidos que, en vinculación con el marco conceptualreferencial, conforman explicaciones tendientes a la construcción de nuevos conocimientos.

“[...] Krippendorff (1990:28) lo conceptúa [al análisis de contenido] en los siguientes términos: «Técnica de investigación destinada a formular, a partir de ciertos datos, inferencias reproducibles y válidas que puedan aplicarse a un contexto» [...]" (Pérez Serrano, 1994, p.135) ${ }^{147}$.

${ }^{147}$ Krippendorff, K. (1990): Metodología del análisis de contenido. Barcelona: Paidós Ibérica S.A., p.28. 
SEGUNDA PARTE:

ANÁLISIS DEL CORPUS EMPÍRICO

La segunda parte de esta tesis está conformada por cuatro capítulos: del V al VIII. Como expresamos, están dedicados exclusivamente al análisis de las obras de didáctica y de curriculum seleccionadas y enunciadas en el capítulo precedente.

En este sentido, nos proponemos poner en diálogo los cruces construidos entre la didáctica, el curriculum y las perspectivas epistemológicas y metodológicas, con las obras antes mencionadas. Desde la postura metodológica sustentada, consideramos que la producción de conocimientos se realiza en el diálogo permanente entre el marco conceptual-referencial y los datos que van emergiendo del análisis del material empírico.

Los capítulos que integran esta segunda parte, en coherencia con el desarrollo de la estrategia metodológica, están conformados por dos apartados principales. El primero de ellos es de carácter principalmente descriptivo en tanto da cuenta de cada una de las obras, su contexto de producción, su estructura interna, las temáticas abordan, entre otras dimensiones de interés.

El segundo apartado avanza en el análisis de cada obra tensionando los aspectos sistematizados en el primer apartado con los cruces entre las disciplinas desarrollados fundamentalmente en el capítulo III. 


\section{CAPÍTULO V:}

\section{OBRAS DE DIDÁCTICA PREVIAS AL IMPACTO DE LA TEORÍA CURRICULAR EN LA ARGENTINA}

Estudiamos a continuación las siguientes obras (por orden cronológico):

- AEBLI, Hans. (1958). Una didáctica fundada en la psicología de Jean Piaget. Buenos Aires: Kapelusz.

- NÉRICI, Imídeo Giuseppe. (1969). Hacia una didáctica general dinámica. (Biblioteca de Cultura Pedagógica). Buenos Aires: Kapelusz.

Ambas fueron marcadas por los encuestados como relevantes para la configuración del pensamiento didáctico en nuestro país en la década del '60. Si bien se trata de dos obras extranjeras -la de Aebli publicada originalmente en Suiza y la de Nérici en Brasil- ambas se traducen al español y son publicadas en Buenos Aires.

A partir de las particularidades que analizamos en los próximos apartados podemos decir que estas obras permiten caracterizar parte del pensamiento didáctico en nuestro país con anterioridad al ingreso de la teoría curricular norteamericana. Son obras que podemos incluir en una definición amplia de didáctica normativa, tal como expusimos en los capítulos I y II.

\section{V - 1 - Caracterización de las obras.}

Una didáctica fundada en la psicología de Jean Piaget originalmente se publicó en Suiza en 1951 con el título Didactique Psychologique. Posteriormente, en 1958, fue traducida y publicada en Buenos Aires (Argentina) por la editorial Kapelusz. 
La obra de Aebli ${ }^{148}$ está compuesta por doscientas ocho (208) páginas integradas por: un prefacio, un prólogo, una introducción, catorce (14) capítulos y un listado de bibliografía general.

El prefacio está escrito por Jean Piaget, quien apoya el trabajo de Aebli y reconoce sus méritos en "[...] extraer las aplicaciones didácticas de las investigaciones que pudimos hacer acerca del desarrollo de las operaciones intelectuales del niño [...]" (p.1). Para Piaget, este trabajo se ubica entre las incumbencias de la psicología y de la pedagogía.

Por su parte, Aebli, en el prólogo y la introducción, considera que su obra pertenece a la didáctica general. Ésta es de carácter general porque se ocupa de las adquisiciones intelectuales por parte de los alumnos pero sin concentrarse en ninguna disciplina o asignatura escolar en particular. Dice además que la didáctica es una ciencia auxiliar de la pedagogía.

Los capítulos del libro están agrupados en partes. La primera se denomina "parte histórica" y abarca los dos (2) primeros capítulos. La segunda es la "parte psicológica" y comprende los capítulos III a VI. La "parte didáctica" es la tercera e incluye los capítulos VII a X. Finalmente, la "parte experimental" abarca los capítulos XI a XIV.

Nos concentramos en el análisis de la tercera y cuarta parte del texto de Aebli por considerarlas más relevantes a los fines de esta tesis. No obstante, cuando dicho análisis lo demanda, retomamos los conceptos psicológicos claves de la teoría piagetiana.

Como dijimos, Aebli construye su posicionamiento teórico sobre la derivación de aplicaciones didácticas de la psicología piagetiana. Asimismo, el autor toma distancia de la didáctica tradicional y de la psicología sensualempirista sobre la que ella se asienta. Según sostiene, los principios psicológicos del empirismo defendidos por la didáctica tradicional en sus orígenes en los siglos XVIII y XIX impidieron el desarrollo de la actividad por parte del alumno.

\footnotetext{
${ }^{148}$ Para el caso de esta obra pero también como criterio general de presentación del análisis, se alude al autor y se sobreentiende la referencia directa a la obra que encabeza el capítulo. En caso de que se consulte complementariamente una segunda obra del mismo autor, se explicita oportunamente.
} 
A su vez, Aebli critica las obras de algunos pedagogos de la escuela activa, como por ejemplo Lay, Dewey, Claparède y Kerschensteiner. El autor expresa que en estos autores aparecen puntos emparentados con la psicología tradicional, en tanto a sus propuestas pedagógicas subyace una concepción mecanicista según la cual la mente recibe desde el exterior los contenidos acabados. El tomar distancia de estas posturas habilita a Aebli a dedicarse, en la "parte psicológica" de su libro, a exponer los fundamentos piagetianos, sobre todo de la teoría de la asimilación, considerada por él como un resumen de toda esta corriente.

En la tercera parte del libro, llamada "parte didáctica", Aebli asigna importancia a la construcción de operaciones de pensamiento en los alumnos como la finalidad principal de la enseñanza. Más allá de las asignaturas en particular con las que se trabaje en la escuela, la enseñanza debe promover la ejecución de determinadas operaciones que, según las investigaciones piagetianas, serán ejecutadas primero por los alumnos efectivamente en la realidad y posteriormente serán interiorizadas o representadas simbólicamente.

Aebli considera que el docente juega un rol importante en la generación del ambiente para que los alumnos puedan construir por sí mismos las operaciones de pensamiento que deben adquirir en la escolaridad. "[...] $E l$ primer problema didáctico que tenemos que resolver será, por consiguiente, precisar cómo puede ser provocada la investigación por el niño, y después orientada hacia su fin $[\ldots]^{\prime \prime}(\mathrm{p} .105)$.

La respuesta a este planteo didáctico también se apoya en la psicología de Piaget en tanto se postula presentar a los alumnos posibles problemas como aquellos esquemas anticipadores que los ponen en la situación de tener que hallar la operación que los resuelve o el conjunto de operaciones que se articulan en su resolución.

"[...] Al decir formación del pensamiento se dice formación de operaciones, y al decir formación de operaciones se dice construcción de operaciones. La construcción de las operaciones se efectúa durante el curso de la investigación, y toda investigación parte de un problema. [...]" (pp.109-110. La cursiva figura en la edición consultada). 
En líneas generales, Aebli plantea que las intervenciones del maestro tienen que ayudar a los alumnos a resolver el problema por sí mismos, explorando caminos a veces desconocidos para ambos. A su vez, expone que el problema que se presenta a los estudiantes no puede ser tan sencillo de manera tal que lo resuelvan a partir de los conocimientos y operaciones que ya saben; pero tampoco debe ser lo suficientemente complejo y alejado de sus saberes previos como para que no vean ni siquiera motivación a partir de sus posibilidades de resolverlo.

Para Aebli, estos problemas que tiene que plantear el maestro a sus alumnos deben ser del dominio de la acción práctica, lo que conlleva una serie de ventajas: 1- resulta más accesible al conocimiento de los alumnos y permite una mejor comprensión por parte de éstos, tanto en los casos en los que pudieron construir las nociones anteriores más generales necesarias para entenderlos, como en los casos en los que dicha comprensión es aún precaria o errónea; 2- permite evitar en el comienzo de un tema o de una unidad, simbolismos especiales no fáciles de comprender desde el principio; y 3posibilita a los alumnos establecer relaciones entre los conocimientos previos y las situaciones que viven cotidianamente.

Estas ventajas de los problemas prácticos valen tanto para problemas reales, en los que los alumnos pueden efectivamente manipular el material en las situaciones en las que surgen, como para problemas ficticios, como la mayoría de los que construye la escuela.

Además, Aebli avanza en la explicación de orientaciones o prescripciones acerca de cómo debe desarrollarse el aprendizaje, de las características de las clases, del tipo de intervenciones del docente, de las particularidades de la evaluación de los aprendizajes, etc., todas cuestiones planteadas coherentemente con los postulados piagetianos.

Si bien los ejemplos que expone el autor se refieren en general a la matemática, cuestión que se debe a que en esta área se puede apreciar más fácilmente el papel que juegan las operaciones, no se descuidan orientaciones para la enseñanza en ciencias naturales, geografía, historia e idioma nacional. 
Por último, en la "parte experimental" del libro, Aebli explica un experimento desarrollado en una escuela pública de Zurich, con dos grados, en uno de los cuales se trabajó con el método tradicional y en el otro con el método sustentado en los principios psicológicos de Piaget. El autor describe la experiencia con la intención de que otros experimentadores puedan replicarla, pero principalmente para que en su lectura los docentes reciban detalles de cómo se llevó a cabo la experiencia, cuáles fueron las lecciones en el "grupo tradicional" y en el "grupo moderno", y cómo es posible enseñar en base a la psicología piagetiana.

Tal como lo plantea el autor, todo el experimento demuestra la superioridad de los métodos activos o modernos en comparación con los tradicionales en lo que respecta a los logros de los alumnos.

Por su parte, el trabajo de Nérici titulado Hacia una didáctica general dinámica, fue publicado originalmente en 1966 en Brasil. La primera edición en español se publicó a través de la editorial Kapelusz en 1969, en Buenos Aires; y se corresponde con la traducción de la décima edición en portugués. En 1973 se publicó la segunda edición en español, que es la que analizamos en esta oportunidad.

De manera similar a otros textos de didáctica que se publicaron en la misma época en la Argentina, este libro de Nérici se destinaba a estudiantes de magisterio y a docentes en ejercicio.

El libro consta de un índice, dieciséis (16) capítulos desarrollados en quinientas treinta y dos (532) páginas, y la bibliografía general de la obra expuesta en cinco (5) páginas.

Nérici sostiene que la didáctica se ocupa de estudiar y orientar la enseñanza. Entiende a esta última como aquel proceso que se desarrolla en el sistema educativo, enmarcado a su vez en la educación como proceso social más amplio.

La educación interviene en la preservación de la cultura y de la sociedad misma, así como también en la integración del individuo a la sociedad en la que 
vive. A su vez, permite la expansión de las capacidades de los individuos y el reconocimiento que cada uno debe realizar de sus propias posibilidades, autolimitándose.

Nérici plantea:

“El estudio de la didáctica es necesario para que la enseñanza sea más eficiente, más ajustada a la naturaleza y a las posibilidades del educando y de la sociedad. Puede decirse, además, que es el conjunto de técnicas destinado a dirigir la enseñanza mediante principios y procedimientos aplicables a todas las disciplinas, para que el aprendizaje de las mismas se lleve a cabo con mayor eficiencia.

La didáctica se interesa no tanto por lo que va a ser enseñado, sino cómo va a ser enseñado [...]" (p.53. La cursiva figura en la edición consultada).

La didáctica así entendida busca, fundamentalmente, intervenir en la enseñanza para el logro eficiente del aprendizaje. Este último proceso debe realizarse en el marco de curricula ${ }^{149}$ y programas integrados con la realidad, y orientado por los métodos activos de enseñanza.

“[...] La didáctica es ciencia y arte de enseñar. Es ciencia en cuanto investiga y experimenta nuevas técnicas de enseñanza, teniendo como base, principalmente, la biología, la psicología, la sociología y la filosofía. Es arte, cuando establece normas de acción o sugiere formas de comportamiento didáctico basándose en los datos científicos y empíricos de la educación; esto sucede porque la didáctica no puede separar teoría y práctica [...] didáctica deriva del griego didaskein (enseñar) y tékne (arte), esto es, arte de enseñar, de instruir [...]" (p.54. La cursiva figura en la edición consultada).

La didáctica, tal como la conceptualiza Nérici, tiene en el docente su destinatario privilegiado. El autor sostiene que el maestro es indispensable para lograr una enseñanza y un aprendizaje de calidad. Además, brega por un docente "[...] convencido de su misión de educador y convenientemente preparado [...]" (p.96).

Nérici se preocupa por la diversidad de dimensiones involucradas en el trabajo docente, que se concentra en el aula pero que no se reduce a ella, abarcando también la institución y la comunidad circundante a la escuela.

\footnotetext{
${ }^{149}$ Como vemos en diferentes partes de la obra de Nérici, aparecen las expresiones "currículo" y "currículos" como sinónimo de "plan de estudios". Podemos pensar que la publicación de la obra en Brasil desde la que se realiza la traducción al español, es posterior al conocimiento de la teoría curricular. Retomamos más adelante estas relaciones.
} 
Para el autor, el maestro debe desempeñar tres funciones, a saber: técnica, didáctica y orientadora. La función técnica se refiere a los conocimientos suficientes relativos al ejercicio de la docencia. El profesor debe conocer su asignatura, su especialización, pero también debe poseer una amplia cultura general dinámica acorde a la época. La cultura general le posibilita responder las preguntas de los estudiantes, establecer relaciones, articular con otras áreas, etc.

El autor expresa también la importancia de la formación didáctica para los profesores. Dice que si bien se creía que para enseñar bastaba con saber la disciplina, en su época ya se había demostrado la importancia, para la enseñanza, del conocimiento didáctico (incluidas las técnicas de enseñanza) y el conocimiento evolutivo del alumno.

La función didáctica del docente debe poder dirigir la enseñanza de manera tal de orientar el aprendizaje activo por parte del alumno. El docente debe poder utilizar diferentes métodos y técnicas para favorecer el aprendizaje, pero además debe involucrar a los alumnos en el proceso de enseñanza y de aprendizaje, en la planificación de las actividades y en la preparación del material didáctico.

El estudiante es uno de los seis elementos didácticos que menciona Nérici y que desempeña un lugar importante en el esquema teórico que plantea. Es entendido como el centro y la razón de ser de la escuela, por tanto, toda la empresa educativa se debe adecuar a él. Los otros cinco elementos didácticos -a saber: profesor, objetivos, materia, métodos y técnicas de enseñanza y el medio geográfico, económico, cultural y social- se organizan para que el alumno alcance los objetivos de la escolaridad.

Por último, la función orientadora es una función importante que apunta a que el docente sea capaz de conocer a sus estudiantes más allá de la asignatura que enseña, y que pueda orientarlos para incorporarse plenamente a la sociedad.

El autor elabora también diferentes preguntas que le sirven al docente para hacer una autoevaluación. Las preguntas incluyen diversos aspectos de las 
tres funciones que le competen al maestro. Esta autoevaluación debe ser previa a la culpabilización del alumno toda vez que los resultados alcanzados no coincidan con los esperados.

Por otra parte, Nérici aborda el "planeamiento didáctico" como otra de las cuestiones que le incumben a la didáctica.

"El planeamiento es una exigencia que se impone día a día en todas las actividades humanas. El trabajo docente no escapa a esta exigencia, máxime si tenemos en cuenta las consecuencias morales y sociales que él implica.

El planeamiento didáctico se hace necesario por razones de responsabilidad moral, económica, adecuación laboral y eficiencia. El profesor necesita saber, para llevar a cabo su planeamiento, qué, por qué, a quién y cómo enseñar" (p.127. La cursiva figura en la edición consultada).

La importancia del planeamiento se sustenta en su relevancia para el desarrollo diario de las actividades humanas y, más específicamente, en las responsabilidades morales y sociales que posee el docente en su práctica. Según entendemos, este posicionamiento resulta coherente con las consideraciones expuestas por el autor en todo su libro y, a su vez, parece que se aparta de una concepción puramente eficientista o referida exclusivamente al logro de los objetivos de aprendizaje. Si bien Nérici dice que la enseñanza persigue el logro del aprendizaje, el planeamiento así entendido parece ampliarse e insertarse en una práctica cargada de responsabilidad.

El planeamiento didáctico evidencia un tiempo de reflexión y de previsión de las acciones de enseñanza por parte del docente para lograr el aprendizaje. Algunos de sus objetivos son: aumentar la eficiencia de la enseñanza, asegurar el control, evitar improvisaciones, proporcionar secuencia y progresividad al trabajo, dispensar atención a los aspectos centrales de la materia, etc. (p.128).

Por otra parte, en cuanto a la finalidad propuesta para la didáctica referida a guiar la enseñanza, Nérici avanza sobre algunas orientaciones puntuales para el docente explicitando la importancia de aprovechar el tiempo de la clase escolar con la mayor eficiencia posible. 
Enumera, por un lado, una serie de "principios didácticos"150 a los cuales califica como "[...] prácticamente aplicables a todas las situaciones de enseñanza [...]" (p.158). Son así orientaciones de cierto nivel de generalidad que apuntan al plan de clase y al tratamiento del contenido por parte del docente.

Por otro lado, enuncia las "directivas didácticas"151, de carácter más preciso que los principios y más enfocadas hacia el logro de la eficiencia en la clase. Estas directivas, en su mayoría, se destinan a orientar la labor del docente en el aula y en la interacción con los estudiantes.

Nérici explicita en diferentes oportunidades de su libro la importancia de alcanzar la eficiencia en la clase. No obstante, también enfatiza la capacidad creadora del docente y el armado de un plan de clase que sea flexible. Para el autor, una buena clase debe ser sentida, vivida y creada por el docente, puede además utilizar algunos de los principios y directivas explicados, pero puede haber dos clases buenas que se basen en principios y directivas distintas. "[...] Hacemos esta observación a fin de advertir acerca del peligro de trasformar una clase en tecnicismo puro y simple, que puede matar el espíritu de la misma [...]" (pp.181-182. El subrayado figura en cursiva en la edición consultada).

Asimismo, Nérici dedica parte de su libro al tratamiento de los métodos y de las técnicas de enseñanza. Para definir el método, el autor recurre a su sentido etimológico, a saber, "camino para llegar a un fin". Los métodos de enseñanza son intermediarios en la relación entre el docente y los alumnos.

\footnotetext{
${ }^{150}$ Los principios didácticos que explica Nérici son diecisiete (17). Baste como ejemplo la denominación de los primeros cinco (5): "[...] 1- Partir de lo próximo a lo remoto; 2- Partir de lo concreto para llegar a lo abstracto; 3- Partir de lo conocido para llegar a lo desconocido; 4- Individualización; 5- Libertad: autoactividad, autodisciplina, autonomía [...]" (pp.158-159).

${ }^{151}$ Las directivas didácticas que trabaja Nérici son veinte (20). Baste como ejemplo la caracterización de las primeras cinco (5): "[...] 1- El profesor debe favorecer la manifestación de las opiniones de los alumnos; las más interesantes, las que hayan despertado mayor atención, podrán servir como tema para los debates; 2- Al finalizar cada clase o cada unidad, es aconsejable indicar las lecturas fundamentales; 3- El profesor debe evitar que se conozca su opinión cuando, presentado un asunto nuevo, éste suscita controversias. La revelación de su punto de vista al respecto no favorece el libre examen de la cuestión por parte del alumno. [...]; 4- Cuando un tema suscita dudas, el profesor no debe darle solución inmediata. Debe, eso sí, favorecer el debate entre los alumnos u orientar la investigación acerca del mismo; 5- El profesor, sin exageración ni afectación que provoquen inhibiciones en el alumno, debe inculcar en él el hábito de la expresión verbal y escrita, correcta y precisa. Empero, el profesor no debe corregir ya mismo, "sobre la marcha", sino de un modo indirecto, a fin de no inhibir al alumno [...]" (p.163. El subrayado figura en cursiva en la edición consultada).

La directiva Nro. 3 de Nérici se corresponde con un principio de procedimiento elaborado por Stenhouse (1991).
} 
Para el autor, el método es más amplio que las técnicas y representa el planeamiento general de la enseñanza en base a determinado criterio y destinado al logro de un fin. El método reúne ordenadamente una serie de técnicas destinadas al logro del aprendizaje en los alumnos.

En este sentido, las técnicas son más precisas, permiten concretar un momento de la clase, y utilizan una serie de recursos didácticos para el logro del aprendizaje.

A pesar de estas precisiones, el autor reconoce que existen controversias acerca del sentido de estos términos. A su vez, aclara que dependiendo de la extensión que se le asigne a cada término, algunos métodos pueden ser tomados como técnica y algunas técnicas como métodos.

Como último componente del planeamiento didáctico y del proceso de enseñanza, Nérici aborda la verificación del aprendizaje, que es la comprobación de lo que el alumno aprendió sobre un determinado contenido en un período de tiempo determinado. La evaluación, por su parte, es una apreciación sobre el aprendizaje.

A la verificación mencionada le asigna un lugar importante como parte final del proceso de enseñanza que comienza con el planeamiento del curso y también como instancia que permite valorar la utilidad de los esfuerzos realizados tanto por el docente como por los alumnos.

Como hace el autor con los diferentes componentes analizados en su trabajo, aquí alude a la autoevaluación y ofrece diferentes fichas; caracteriza también distintos tipos de pruebas que se pueden utilizar para la verificación de los aprendizajes. Expone tipos, ejemplos, posibilidades, se explaya en la descripción de los tipos de evaluación, analiza los resultados de una prueba, brinda elementos acerca de cómo valorar los ítems de una prueba, los errores de los alumnos, etc., todos elementos que aportan al lector herramientas para la planificación y desarrollo de las clases. 


\section{V - 2 - Análisis de las obras: la aparición de algunos emergentes que permiten caracterizar una didáctica normativa.}

V-2 - a-Carácter de la norma en una teoría normativa.

En el trabajo de Aebli consideramos que se presenta una normatividad fuerte y clara orientada a generar desde la enseñanza un ambiente propicio para que el niño investigue por su cuenta y vaya progresivamente construyendo las operaciones de pensamiento que la escolaridad debe lograr.

Aparecen en el libro diferentes menciones como las siguientes, referidas a orientar las tareas del maestro: "crear situaciones psicológicas", "apelar a los esquemas anteriores de que el niño dispone y a partir de ellos desarrollar la nueva operación", "presentar el material adecuado a esta actividad intelectual" (p.102). De esta manera se plantea cómo debe estructurarse la situación de enseñanza con "buenos" problemas y cómo debe ser el trabajo del docente en dicha estructuración, a partir de un principio psicológico relativo a cómo el niño construye las operaciones de pensamiento. No obstante, parece que siempre se va dejando un margen para la resignificación de estas propuestas por parte del docente; es decir, consideramos que se dibuja un cierto margen de autonomía siempre relativa- del docente, que tiene la responsabilidad de diseñar y poner en marcha los aspectos más específicos de la enseñanza, por ejemplo, los referidos al problema de la presentación, la situación psicológica o el ambiente de la clase para guiar el trabajo del estudiante.

Consideramos que en la "parte experimental" del libro, con la descripción de las lecciones que se dictaron en clases reales a partir de los principios psicológicos emanados de la perspectiva piagetiana, parece que la prescripción hacia la enseñanza y hacia el accionar del docente en el aula específicamente, da un paso más. No obstante, el autor aclara que el nivel de detalle de las lecciones es tal para mostrar que la propuesta del libro puede ser llevada a la práctica. 
Recuperando lo expuesto en el capítulo I de esta tesis, podemos decir, por un lado, que estas orientaciones didácticas que se desprenden del trabajo de Aebli se acercan a aquellas orientaciones de una didáctica normativa en los términos en los que las postula Camilloni (2007d). En este sentido, se trata de orientaciones acerca de cómo se puede proceder en el aula para alcanzar las finalidades de la escolaridad, reservando un cierto margen para la resignificación en los diferentes contextos particulares en los que se desempeñan los distintos docentes.

No obstante, desde otra perspectiva, esta dependencia de la psicología piagetiana defendida por Aebli -que analizamos con más detenimiento en el próximo cruce- acerca la didáctica a una perspectiva tecnicista, transformándola en una disciplina aplicada, según los términos del análisis histórico que realizamos en el capítulo II.

Por estos motivos, parece que no hay una correlación directa entre la didáctica como disciplina aplicada y la elaboración de "recetas cerradas" para ser implementadas sin mediaciones por los docentes, como se pretende en ciertas perspectivas tecnicistas de la educación, algunas de las cuales analizamos en el capítulo VI.

Por su parte, el trabajo de Nérici presenta orientaciones muy claras para el trabajo del docente en el aula (en materia de planeamiento, metodología, evaluación, etc.) pero siempre enmarcadas en el explícito reconocimiento de los necesarios márgenes de autonomía del docente en los que podría poner en juego su profesionalidad, creatividad, personalidad, para adecuar dichas orientaciones a su práctica concreta. El autor dice que todo docente puede tener "su propia manera de enseñar" (p.324) siempre y cuando respete ciertos aspectos considerados fundamentales de todo proceso de enseñanza.

Específicamente, en lo que respecta al planeamiento didáctico vemos, por un lado, que esta práctica se conceptualiza como central en el accionar del docente en el aula y en la escuela, y como un espacio de trabajo profesional, de reconocimiento hacia la previsión, reflexión, análisis y evaluación que el 
docente realiza al proyectar su enseñanza en lo que denominamos desde Jackson (1968), el momento preactivo de la clase.

Por otro lado, podemos decir que Nérici incluye el planeamiento didáctico dentro de las incumbencias de la didáctica como disciplina. Podemos ver en esta obra -pero también en otras de didáctica como las citadas al comienzo del capítulo II de esta tesis- que la didáctica se ocupa del planeamiento didáctico desde antes de que el curriculum como campo disciplinar hablara del planeamiento educativo.

Cabe mencionar aquí que para Nérici el curriculum se entiende como un proyecto formativo definido en una instancia exterior a la escolar. A nivel de la escuela, el autor habla de planeamiento escolar. Asimismo, explicita la importancia que debe tener la coordinación entre las diferentes asignaturas del curriculum en vistas a lograr una formación coherente para los estudiantes de cada uno de los niveles del sistema educativo. Parece que el curriculum conserva la idea de propuesta integral que se propone formar un determinado tipo de sujeto $\mathrm{y}$, en torno a esta intencionalidad, coordina la totalidad de sus componentes; mientras que la enseñanza se desarrolla en su interior.

Por otra parte, para Nérici la "clase" se define como "[...] un determinado periodo de tiempo vivido entre el profesor y el alumno y en cuyo transcurso aquél orienta las actividades de éste procurando hacer que alcance ciertos objetivos predeterminados [...]" (p.139). Asimismo, al plan de clase lo define como un trabajo de anticipación que lleva a cabo el docente acerca de lo que va a hacer y de lo que van a hacer sus alumnos en la clase, para evitar en la medida de lo posible la improvisación; el plan de clase es una "norma de trabajo" (p.139). Según entiende, el docente puede apartarse de esta norma toda vez que considere que es necesario darle lugar a las motivaciones espontáneas de los alumnos. Lo planificado posee cierta plasticidad que permite decidir otros rumbos para la clase aun cuando éstos se aparten de lo definido inicialmente.

En este sentido, Nérici no está pensando en un docente que ejecuta un plan de clase diseñado por otros y tampoco se trata de un plan de clase que se debe trasladar linealmente a la práctica. Son cuestiones que aparecen ya 
planteadas en la década del '60 y que, como postulamos en el capítulo VIII de esta tesis, son desarrolladas con nuevos matices por los autores pertenecientes a la perspectiva práctica en la didáctica y el curriculum.

A su vez, en este carácter que la norma didáctica adquiere en la obra de Nérici también ocupa un lugar importante el alumno. El autor pone en cuestión el lema "enseñar todo a todos" que funda la didáctica comeniana, porque considera que es necesario respetar las diferencias individuales de los alumnos.

Para dar cuenta del carácter de la norma didáctica es importante también mencionar el lugar que el autor le asigna a los diferentes criterios que la didáctica elabora para orientar las decisiones que el docente debe tomar con respecto a la enseñanza. Al referirse por ejemplo a los métodos y técnicas de enseñanza, a los materiales didácticos, a los compendios, o a las evaluaciones, Nérici explica criterios tendientes a explicitar las características que debe poseer un buen componente didáctico en tal o cual situación, y luego será el docente el que tomará las decisiones que estime convenientes inmerso en su contexto ${ }^{152}$.

Si bien lo seguiremos delineando con los diferentes trabajos de corte más epistemológico que analizan la didáctica como disciplina, consideramos aunque sea provisoriamente- que en estas cuestiones radica el valor instrumental de la didáctica ${ }^{153}$.

Además, en relación con estas consideraciones se puede destacar la diversidad de aspectos del proceso de enseñanza sobre los que interviene la didáctica. Por ejemplo, Nérici avanza sobre objetivos, métodos y técnicas, evaluación, materiales didácticos -y discrimina: compendios, experimentos, pizarrón, etc.- dirección y disciplina del curso.

\footnotetext{
152 Podemos arriesgarnos a plantear que este tipo de criterios aparece también en Tyler (1973) como vemos en el capítulo VI y en Stenhouse (1991) como exponemos en el capítulo VIII.

${ }^{153}$ Es nuestra intención rescatar el valor instrumental de la didáctica como disciplina hacia el accionar del docente en la enseñanza. Vemos en el capítulo VII de esta tesis que Edelstein y Rodríguez (1974) y Barco (1975) critican a Nérici por el tratamiento instrumental que realiza del método en esta misma obra. Consideramos que se trata de dos perspectivas de estudio diferentes, aunque complementarias, y fundamentar nuestro acuerdo explícito con estas autoras nos demandaría otro tipo de análisis que involucre, entre otras cuestiones, una mayor focalización en lo metodológico y una revisión del contexto de recepción que contribuyó a la difusión del método como un recurso más, desgajado de sus fundamentos (como plantean autores como Feldman, 2010b).
} 
Por último, cabe mencionar la diferencia que establece el autor entre normas, principios y directivas. Las normas son de carácter general y tienden a orientar el accionar del "[...] docente como educador [...]" (p.521) más allá de la asignatura que enseñe y de las prácticas áulicas. La mayoría de ellas en su denominación comienza con un verbo en infinitivo y luego presentan una breve explicación, la cual generalmente dice "el docente debe..." o "el profesor tiene el deber de..." o "el profesor debe preocuparse por..."154.

Estas normas se refieren a diferentes aspectos del quehacer docente, abarcando el comportamiento personal (por ejemplo: “[...] 41- Estar siempre disponible; 42- Ser optimista [...]" -p.533); el trabajo institucional que involucra el aula pero no excluyentemente (por ejemplo: “[...] 36- No separar la escuela de la comunidad [...]" -p.531); o la interacción personal con el alumno (por ejemplo: “[...] 26- La comprensión debe estar presente -p.528-; 28- Llevar a la reflexión; 30Fijar en cada clase lo fundamental del tema -p.529-; 35- Atribuir responsabilidades [...]" -p.531).

Además de estas normas generales, Nérici presenta los principios didácticos y las directivas didácticas. Las normas poseen un mayor nivel de generalidad que se pone en evidencia también cuando el autor aclara que son normas que guían el trabajo del docente como educador.

Además, las normas generales dan lugar a pensar que mantienen vinculaciones con las intencionalidades más amplias de la educación y guían el trabajo del docente hacia su concreción. En este sentido, parece que se convierten en un referente de la acción del docente, es decir, el docente adecua su comportamiento de acuerdo a estas normas. Y además, estas normas tienen vinculación con valores más amplios, cuestión que nosotros destacamos en el capítulo I de esta tesis al conceptualizar la constitución de la norma.

Por su parte, los principios y las directivas ya desde su enunciación llevan el adjetivo de "didácticos" o "didácticas", y se refieren más

\footnotetext{
${ }^{154}$ Basten como ejemplo las primeras cinco (5) normas generales que trabaja Nérici: “[...] 1- Planear el trabajo docente; 2- Mantener buenas relaciones con los colegas; 3- Orientar los estudios; 4- Indicar qué hacer; 5- Dar informes precisos [...]". (pp.521-522).
} 
específicamente al trabajo del docente frente a la enseñanza. En este sentido, estas dos orientaciones que elabora Nérici son más específicas.

A su vez, a diferencia de lo que sucede con las normas generales, el autor aclara -como ya mencionamos- que los principios y directivas didácticas deben ser seguidos para lograr una buena y eficiente enseñanza, pero no es necesario que se sigan todos, sino que el docente puede seleccionar cuáles quiere seguir en cada clase.

$V-2-b-$ Aspectos que constituyen la norma.

Como ya mencionamos, en la obra de Aebli la normatividad que se construye tiene una explícita y exclusiva referencialidad en los avances de la investigación de la psicología de Piaget. Recordamos que para el autor la didáctica es una aplicación de la psicología piagetiana y que el conocimiento de esta última disciplina por parte del docente es indispensable para fundamentar su labor en el aula.

Apoyándose en esta teoría, el autor logra aproximarse a la construcción de una teoría didáctica que brinda, por un lado, un corpus teórico psicológico para explicar la enseñanza y las finalidades que la misma debe perseguir en materia de aprendizaje de los alumnos. Por otro lado, aporta un bagaje instrumental con respecto a cómo debe desarrollarse la enseñanza para lograr la construcción de operaciones de pensamiento en los alumnos.

A partir del análisis realizado, consideramos que no aparece una discusión acerca de las finalidades de la enseñanza o de la escuela, sino que estas intencionalidades quedan subsumidas en los postulados de la psicología, en este caso, ayudar a construir operaciones de pensamiento en los niños. No se presenta primero el análisis de las finalidades que tiende a alcanzar la escuela y luego se piensa cuál podría ser el aporte de la psicología piagetiana, sino que el razonamiento se construye al revés.

“[...] Los principios de esta enseñanza se inspiraron en la psicología de Jean Piaget, a quien debemos uno de los análisis más profundos del desarrollo intelectual del niño. Concebido este desarrollo como construcción continua 
de sistemas de operaciones a partir de conductas más antiguas, el pedagogo trata de poner en marcha proyectos de investigación en el curso de los cuales los niños llegan a construir por sí mismos nociones y operaciones; procura que tales actividades constructivas puedan efectuarse, si es preciso, mediante manipulaciones efectivas y con experiencias reales, y organiza finalmente ejercicios que movilicen, según sus características, las operaciones nacientes (reversibilidad, asociatividad, etc.). El conocimiento exacto del pensamiento infantil le permite guiar del mejor modo posible su desarrollo [...]" (p.202).

En el caso de Nérici, se presenta una situación de referencialidad de la didáctica en la enseñanza y en la educación como proceso social y cultural más general, que es coincidente con las posturas de otros autores de pedagogía y didáctica, cuyos trabajos también se publicaron en aquellos años ${ }^{155}$. Esta vinculación entre la educación y la enseñanza se pone de manifiesto tanto cuando el autor define ambos procesos formativos, como ya mencionamos, como cuando alude a las intencionalidades de los mismos discriminadas en fines de la educación y objetivos de la enseñanza. “[...] Los fines son aspectos más generales y teóricos perseguidos por la educación. Los objetivos son más particulares y prácticos, que tienden a la realización de los fines de la educación a través de todos los niveles de enseñanza [...]" (p.26. El subrayado figura en cursiva en la edición consultada).

En este mismo sentido, Nérici dice:

“[...] La didáctica general, para ser válida, debe estar vinculada a las circunstancias reales de la enseñanza y a los objetivos que la educación procura concretar en el educando. Fuera de eso, será una didáctica de "recetario", de "reglitas", sin la vitalidad necesaria para suscitar actitudes e ideales en el alumno [...]" (p.56).

Podemos vincular estas consideraciones con la didáctica normativa, en tanto tal como la conceptualizamos previamente, es una teoría que busca la concreción de un proyecto educativo más amplio.

Además, las disciplinas en las que se enmarca la didáctica brindan saberes y referencias para delimitarla. Es el mismo Nérici quien al definirla

\footnotetext{
${ }^{155}$ Podemos decir que esta perspectiva que engloba a la enseñanza en la educación como proceso social más amplio, y a la didáctica en la pedagogía, es compartida, entre otros autores, por: Thirión (1965); Manganiello (1968); Mattos (1974).
} 
como ciencia, dice que esta disciplina investiga nuevas técnicas de enseñanza basadas en la psicología, la filosofía, la sociología y la biología. También recordamos que define a la didáctica como arte y que interpretamos esta afirmación desde los espacios de realización que habilita para el docente.

Una cuestión que se presenta claramente es la referencialidad que la didáctica tiene en la psicología. Para Nérici ella aporta diversos saberes relativos a los alumnos; el aprendizaje; la relación entre conocimientos nuevos y los ya existentes; la familiarización del alumno con los temas nuevos; la motivación; la variación de los intereses o motivos desde el nacimiento del individuo hasta la edad adulta; el comportamiento humano, etc. Pero, a diferencia de la propuesta de Aebli, aparecen en el ámbito de preocupaciones didácticas otras temáticas no estrictamente resolubles desde la psicología, como el planeamiento didáctico; la evaluación de la enseñanza y de los aprendizajes; los métodos y las técnicas; las normas, los principios y las directivas didácticas, etc.

No obstante las características que pueden vincular la postura de Nérici con una didáctica normativa, tal como nosotros la conceptualizamos en el marco de esta tesis, aparecen otros elementos que "matizan esta clasificación". Así en primer lugar recordamos que la didáctica persigue la eficiencia en el logro de los objetivos de enseñanza, cuestión que la vincula a una postura más prescriptiva. Aunque esto también podría ser discutible desde el análisis que realiza Feldman acerca de las formas de expresar las intenciones educativas. Este autor se pregunta “ ¿cuál es el problema con la eficacia?" (2010b, p.62) cuando se sostiene que la enseñanza y el aprendizaje son actividades planificadas, sus resultados son en la mayoría de los casos previsibles, y los sujetos involucrados tienen derecho a saber si los objetivos se alcanzaron o no.

En segundo lugar, es interesante analizar la concepción de enseñanza que sustentan tanto Aebli como Nérici para problematizar su vinculación con la didáctica normativa. La enseñanza se define prioritariamente como un proceso que pretende la consecución del aprendizaje por parte de los alumnos. Podemos decir que esta relación ontológica entre la enseñanza y el aprendizaje 
(Fenstermacher, 1989) está presente en la actualidad, pero el análisis apunta a plantear que estos autores no logran una conceptualización de la enseñanza como un proceso con cierta autonomía y que, por esto mismo, se hace más explícita la relación con la psicología.

Como detalla Camilloni (1996), la didáctica históricamente ha mantenido relaciones interdisciplinarias para constituirse como disciplina y las sigue manteniendo en la actualidad, pero las resignifica para alcanzar las intencionalidades que se propone con respecto a la enseñanza. Su vinculación con la psicología es especial toda vez que pretende lograr el aprendizaje, más allá de haberse asociado fuertemente a ella a principios del siglo XX, buscando el status científico de la psicología, sobre todo de base conductista. Pero esta relación, cuando se ha convertido en una aplicación, le ha costado a la didáctica su resignación.

Por otra parte, conceptualizar la enseñanza como lo hace Fenstermacher (1989) aludiendo a la configuración de un triángulo didáctico -docente, alumno y contenido- parece ser una revisión que se produce en la didáctica con posterioridad a estas obras de Aebli y de Nérici. Poggi (1997) y Feldman (2008), por ejemplo, plantean que el armado de este triángulo se realiza con el aporte fundamental de las didácticas especializadas en contenidos, conocidas y desarrolladas en nuestro país desde los años '80.

A su vez, queda aquí planteado que estas didácticas especiales por contenidos tienen mayor cercanía con la enseñanza y comienzan a desarrollar un caudal normativo/prescriptivo que tensiona con una didáctica general que desde la década del '80 aumenta su capacidad interpretativa. Davini (1996; 2008) y Camilloni (2007c) analizan con más detalle estas vinculaciones que nosotros no abordamos porque, como expusimos, escapan al período y a las intencionalidades centrales de esta tesis.

Por otro lado, en cuanto a los aspectos que constituyen la norma, Nérici considera que las "normas de acción" o "formas de comportamiento didáctico" (p.54) se construyen a partir de los datos científicos y empíricos de la educación. Observamos que las normas de acción se construyen a partir de las siguientes 
fuentes: 1- el conocimiento científico producido sobre la enseñanza tomando aportes de otras disciplinas básicas (biología, filosofía, psicología y sociología); 2- el estudio empírico sobre la enseñanza; 3- los objetivos que debe alcanzar la enseñanza (aunque quedaría en un segundo plano la influencia de éstos en la construcción de las normas).

Avanzando hacia lo que el autor postula como un modo más explícito de formulación de las normas, éstas adquieren lo que para nosotros sería un carácter más ceñido a lo técnico. En este sentido, la didáctica pasa a tener un sentido práctico, reuniendo un conjunto de técnicas orientadas a que la enseñanza resulte eficaz, esto es, que logre el aprendizaje.

Lo que comienza planteándose como una disciplina con su carga teórica, con su corpus de conocimientos, y con sus normas de acción para la orientación de la enseñanza, parece que progresivamente a lo largo del libro se va corriendo hacia la configuración de una disciplina preocupada por el logro del aprendizaje, para lo cual enuncia técnicas. No obstante, cuando esta tensión aparece explícitamente en diferentes pasajes del texto, el autor la va resolviendo hacia una articulación entre el arte y la técnica en la didáctica. Las técnicas son el resultado de la investigación que la didáctica desarrolla como ciencia, y el arte incluye ese componente más personal del docente que, según entendemos, es el que le permite crear y desarrollarse en los márgenes de actuación profesional o en los intersticios de la norma.

$V-2$ - c-Predominio de aspectos normativos.

Sostenemos que las obras analizadas de Aebli y Nérici son representativas de un momento normativo en la producción de conocimiento didáctico a pesar de los matices que pueda arrojar el análisis.

En este sentido, para el caso de Aebli podemos decir que ubicamos su trabajo en este momento a partir del explícito reconocimiento por parte del autor de la capacidad de resignificación que los docentes pueden ejercer en la interpretación y utilización de las orientaciones y lecciones que aparecen en 
diferentes partes del texto y principalmente en la "parte experimental", aunque éstas últimas, como vimos, por su nivel de detalle parecen avanzar hacia una reducción de esos espacios de reinterpretación del docente.

No obstante, cabe aclarar que las perspectivas actuales que postulan la construcción de una didáctica normativa rechazan la aplicación directa de la psicología hacia la didáctica, defendida por el autor.

Por su parte, el libro de Nérici también puede ser considerado como parte de un momento normativo en la producción teórica de la didáctica porque, en primer lugar, el autor expresa que la didáctica busca intervenir en la enseñanza para que ésta alcance sus objetivos, pero que son a su vez concreción de las finalidades más amplias de la educación. En vinculación con el desarrollo realizado en los capítulos I y II de esta tesis, podemos decir que se produce aquí una vinculación entre la norma didáctica y la concreción de intencionalidades educativas más amplias que exceden la enseñanza en el aula.

En segundo lugar, recordamos el rol que Nérici explícitamente delinea para el docente en lo que respecta a su espacio de autonomía, a su creatividad, a sus posibilidades de resignificar las orientaciones didácticas, porque la enseñanza tiene una cuota de expresión artística. La predominancia normativa se conjuga con algunos aspectos que desde el marco conceptual-referencial antes desarrollado le asignamos a lo prescriptivo, a saber, aquéllos relativos al logro eficiente del aprendizaje.

Desde una perspectiva actual que busca la reconceptualización de la didáctica y la revisión de su normatividad, como vimos, esta articulación entre lo normativo y lo prescriptivo puede ser recuperada. Sostenemos que los trabajos de Candau (1996); Camilloni (2007d) y Feldman (2010b) avanzan en este sentido.

Es de destacar también que diferentes posturas actuales en la didáctica, como vimos en el capítulo II, buscan fortalecer el carácter instrumental que la didáctica fue perdiendo. En este sentido, por ejemplo, la conceptualización sobre planeamiento didáctico que expone Nérici es recuperada más o menos explícitamente por trabajos más actuales sobre programación de la enseñanza, 
como el de Feldman y Palamidessi (2001) y el de Cols (2004), o sobre planificación didáctica, como el de De Vita (2009). No se retoma textualmente la definición de planeamiento didáctico que brinda el autor, pero sí consideramos que es posible afirmar que hay una recuperación de la capacidad de ofrecer desde la didáctica aspectos instrumentales necesarios para el trabajo del docente en el aula y en la institución.

$V-2-d-$ Disponibilidad de saberes interdisciplinarios para la constitución de la didáctica.

Como dejamos enunciado en el análisis precedente, los trabajos de Aebli y de Nérici recuperan explícitamente saberes provenientes de otras disciplinas para conceptualizar la didáctica. Podemos afirmar además que no aparecen en estos trabajos referencias explícitas a la utilización de saberes epistemológicos o filosóficos para realizar una reflexión de segundo orden. No obstante, estamos en condiciones de plantear que se realiza un tratamiento epistemológico de la disciplina aun cuando éste no se formule explícitamente o en estos mismos términos.

En el caso de Aebli, como ya mencionamos, se trabaja en torno a la formulación de una didáctica como disciplina aplicada de la psicología piagetiana.

Por su parte, en el caso de Nérici, se da cuenta de aspectos teóricos de la constitución de la didáctica como disciplina. En este sentido, el autor recupera la división que realiza Comenio a propósito de la didáctica -a saber, entre matética, sistemática y metódica- aunque marca algunas diferencias con él.

La matética es aquella parte de la didáctica que se ocupa del alumno, de quien aprende. Este conocimiento del estudiante es necesario para el logro eficiente de los objetivos y es el que, desde la perspectiva del autor, impide concretar el ideal pansófico. La sistemática, por su parte, se refiere a los objetivos que deben alcanzarse con la enseñanza y a los contenidos cuyo 
aprendizaje hace posible el logro de los objetivos. Por último, aparece la metódica como la tercera parte de la didáctica que se ocupa del arte de enseñar.

A su vez, Nérici postula que nos encontramos con una didáctica general y con varias didácticas especiales. La didáctica general es aquella disciplina preocupada por la enseñanza, por el logro eficiente del aprendizaje, por la formulación de métodos y técnicas de enseñanza aplicables a cualquier contenido. Por su parte, las didácticas especiales son aquéllas que se formulan en torno a la enseñanza de una determinada materia del plan de estudio escolar o a un determinado nivel del sistema educativo.

También la reflexión teórica sobre la didáctica se evidencia cuando Nérici se inclina por una posición intermedia según la cual esta disciplina es técnica y arte. Por otra parte, como ya expusimos, en la obra de Nérici aparece un enmarcamiento de la didáctica en la pedagogía. Esto también está evidenciando un posicionamiento epistemológico en cuanto a las vinculaciones que mantiene la didáctica y al tipo de dichas relaciones.

$V-2$ - e-Teorías de alcance intermedio o teorías cercanas a la práctica.

En el trabajo de Aebli la didáctica se presenta como una teoría cercana a la práctica pero, como dijimos, al mismo tiempo, aparece como una aplicación de la psicología piagetiana. Esta última disciplina no se conceptualiza como poseyendo finalidades prescriptivas, sino sólo descriptivas.

No obstante, consideramos importante aclarar que, desde el posicionamiento que construimos en esta tesis, entender la didáctica como una teoría intermedia no significa que la misma se convierta en una disciplina aplicada.

En el trabajo de Nérici, por su parte, se aprecia la configuración de una didáctica orientada hacia la práctica. El continuum de definiciones de didáctica que expone el autor le permite avanzar hacia un mayor nivel de explicitación: desde una disciplina que es ciencia y es arte, hasta una disciplina que es un conjunto de técnicas, se va progresivamente configurando una disciplina cada 
vez más cercana a la práctica. En cualquiera de las definiciones que aporta, la didáctica posee una preocupación permanente por la orientación de la enseñanza, aunque va variando el nivel de teorización y el sujeto -didacta o docente- que protagoniza el teorizar o el hacer sobre la enseñanza.

En la producción didáctica más actual, y tal como vimos en el capítulo II, se ha descuidado la veta instrumental constitutiva del saber didáctico. No obstante, no podemos desconocer que hay algunas producciones didácticas, o afines, que evidencian un avance en este sentido, como por ejemplo, los trabajos de Davini (2008); Eggen y Kauchak (1999); y Joyce y Weil (2002). 


\section{CAPÍTULO VI:}

\section{LA TEORÍA CURRICULAR NORTEAMERICANA QUE LLEGA A LA ARGENTINA}

Estudiamos a continuación las siguientes obras (por orden cronológico):

- TYLER, Ralph W. (1973). Principios básicos del currículo. Buenos Aires: Troquel.

- TABA, Hilda. (1974). Elaboración del currículo. Teoría y práctica. Buenos Aires: Troquel.

- CHADWICK, Clifton B. (1977). Tecnología educacional para el docente. (Paidós Educador) No. 75. Barcelona: Paidós.

La pretensión amplia de este capítulo es lograr una caracterización general del pensamiento curricular norteamericano que arriba a América Latina y específicamente a nuestro país desde principios de la década del '70.

Consideramos que el análisis de estas tres (3) obras nos permite conocer posturas contrastantes en lo que se denomina "perspectiva técnica del curriculum". Si bien profundizamos en el desarrollo del presente capítulo, basten aquí algunas menciones introductorias que retoman las justificaciones sobre la pertinencia de estudiar estos tres trabajos.

Los textos de Tyler y de Taba han sido los que más elecciones obtuvieron por parte de los encuestados, a su vez y como quedó explicado en el capítulo II, ambos trabajos constituyen un hito ineludible para estudiar la producción curricular norteamericana. Tyler, por ejemplo, es considerado el iniciador del campo curricular en cuanto a la profesionalización que le imprime. Parafraseando a Terigi (1999), Tyler ayuda con su producción a pasar de la pregunta "¿qué contenidos planificar para la escuela?" a aquélla otra sobre “¿cómo planificar el curriculum?”156.

\footnotetext{
${ }^{156}$ Acuerdan con esta forma de pensar la constitución del campo disciplinar, entre otros, los siguientes autores: Díaz Barriga (1991; 1994); Furlán (1997).
} 
A su vez, con Tyler se inicia un momento claramente curricular en la producción teórica, dejando atrás un momento protocurricular, como exponen Parra y Pasillas (1991). Ese momento protocurricular se caracterizó por una producción dispersa sobre los componentes y aspectos del curriculum en la década del '20 en Estados Unidos. Tanto Tyler como Taba conformaban el grupo de teóricos que trabajaba en aquellos años $\mathrm{y}$, como esta última lo reconoce en la introducción a su libro, a toda esa producción le faltaba la sistematización que el propio Tyler le imprimió al pensamiento curricular años más tarde.

A su vez, como mencionamos en el capítulo II y como se recupera en el capítulo VIII junto a Schwab y Stenhouse, Tyler y Taba son autores posicionados en la perspectiva metateórica técnica del curriculum, pero su producción contrasta con la de otros autores, seguidores suyos, que profundizaron los rasgos más técnicos del modelo de planificación curricular. Es por esto que consideramos que la obra de Chadwick, explícitamente ubicada en el marco de la tecnología educativa y del enfoque de sistemas, puede aportar elementos para la contrastación.

\section{VI - 1 - Caracterización de las obras}

La obra original de Tyler data de 1949 y su traducción al español es publicada por la Editorial Troquel en 1973. Su título en inglés es: Basic Principles of Curriculum and Instruction y en español se publica como Principios básicos del currículo.

El libro está conformado por una introducción, cinco capítulos, un listado breve de "bibliografía en español" y el índice. Comprende en total ciento treinta y seis (136) páginas.

La introducción comienza así: "Este pequeño libro intenta exponer un método racional para encarar, analizar e interpretar el currículo y el sistema de enseñanza de cualquier institución educativa [...]" (p.7). 
A continuación, Tyler expone cuatro preguntas que considera fundamental responder para elaborar cualquier curriculum: 1- ¿qué fines desea alcanzar la escuela?; 2- ¿qué experiencias educativas ofrecen mejores oportunidades para alcanzar esos fines?; 3- ¿cómo se pueden organizar eficazmente esas experiencias educativas?; y 4- ¿cómo se puede evaluar el alcance de los objetivos? El tratamiento de cada una de estas preguntas se constituye en cada uno de los primeros cuatro capítulos del libro. Los pasos a seguir para elaborar un curriculum van estructurando el libro. El quinto capítulo se compone de tres (3) páginas y está dedicado a analizar cómo debe trabajar el personal docente en la elaboración del curriculum.

En la página 133 del libro se presenta la "bibliografía en español” y en una nota al pie de página se aclara "[...] preparada especialmente para esta edición (N. del E.)" (p.133) 157 .

Tyler comienza su trabajo a partir del reconocimiento de que la escuela es una institución finalista y, por tanto, los "[...] propósitos básicos de la educación [...]" (p.9) estructuran toda la planificación del curriculum. Es decir, los contenidos, las actividades, los métodos, la evaluación, etc., se constituyen en medios para alcanzar esos fines.

Los fines de la educación pueden surgir, para el autor, de tres fuentes principales: el estudio de los propios educandos, la vida contemporánea y los especialistas en las disciplinas. Ninguna de estas fuentes por sí sola puede dar una respuesta acabada a los fines de un programa integral de formación. La articulación y complementariedad se vuelven fundamentales.

La primera de las fuentes mencionadas apunta a realizar un estudio de los educandos. Partiendo del supuesto de que la educación busca producir cambios en ellos, son éstos los que también deben ser considerados en el momento de elaborar los fines. Esos cambios que busca producir la educación son definidos por Tyler como cambios de conducta, pero rápidamente aclara

\footnotetext{
${ }^{157}$ Según Cordero Arroyo y García Garduño (2004), el listado de "bibliografía en español" al final del libro fue agregado por Díaz Barriga, quien fue su traductor al español. Por su parte, Díaz Barriga (1994), dice que ese listado fue incorporado por el editor.
} 
que entiende "conducta" en un sentido amplio, abarcando las acciones manifiestas y también el pensamiento y el sentimiento.

El establecimiento de metas educativas a partir de la observación de los educandos surge de la determinación de necesidades, que se definen como aquella diferencia que existe entre el estado actual de los educandos comparándolo con aquel estado o "[...] norma deseable $[\ldots]$ ” (p.13).

Tyler expone que es importante el estudio de las necesidades de los educandos porque de esta manera es posible conocer aquellas necesidades educativas que se satisfacen adecuadamente en el ambiente familiar y en la comunidad, y aquéllas otras que quedan excluidas de estos ámbitos y que, por su relevancia, deben ser abordadas por la escuela.

El autor postula también la investigación de los intereses del alumnado. Recuerda que ellos son importantes en la teoría de la educación progresiva y que una vez identificados reciben especial atención por parte de los educadores. Esta forma de conocer a los estudiantes habilita un aprendizaje activo y posibilita que los alumnos se involucren en hacer y aprender aquello que verdaderamente les interesa.

La segunda de las fuentes consideradas por Tyler para el establecimiento de los fines educativos es el estudio de la vida contemporánea de la sociedad en la que se inserta la escuela. Esta fuente, según detalla el autor, se ha vuelto problemática a partir del acelerado desarrollo de la ciencia y la tecnología en los últimos años.

El autor postula que los estudios de la vida contemporánea se basan en su mayoría en el "[...] análisis de tareas [que] consiste simplemente en el estudio de las actividades que desarrolla un obrero en un campo determinado, para intensificar el adiestramiento en las más difíciles que deba cumplir [...]" (p.22). La complejidad y versatilidad de la sociedad actual requiere que los estudiantes aprendan sus aspectos más importantes. Tyler dice que no es posible malgastar el tiempo aprendiendo cosas que tuvieron validez cincuenta años atrás. La escuela debe enseñar lo que hoy es esencial. 
Por último, el autor señala que los especialistas en las asignaturas se convierten en la tercera fuente que brinda información para la elaboración de los fines para la educación. La pregunta central que los especialistas deben responder es: ¿cuáles son los conocimientos básicos que deben poseer todos los estudiantes independientemente de la carrera que escojan al finalizar la escuela?

Una vez que el estudio de estas tres fuentes ha arrojado una lista importante en cantidad y en calidad de finalidades para la educación, Tyler propone que se seleccionen aquéllas que efectivamente van a ser trabajadas en las escuelas. Para esta tarea indica una selección a partir del tamiz que ofrecen la filosofía y la psicología de la educación.

En primer lugar, juega un rol importante la filosofía de la educación, seleccionando del listado general de finalidades sugeridas, aquéllas importantes y coherentes con un conjunto de valores.

“[...] La filosofía educativa y social adoptada por la escuela puede constituir el primer tamiz. Bastará con escoger, en la lista original de objetivos, los que representen valores más altos y coincidan con la filosofía de la escuela $[\ldots]$

[...] Correctamente formulada, una filosofía pedagógica y social responde a varias preguntas importantes. En esencia, sus enunciados procuran definir la naturaleza de una vida y una sociedad óptimas. Parte de esa filosofía pues, definirá qué valores se estiman esenciales para una vida satisfactoria y eficaz. [...] (pp.37-38).

Por otra parte, la psicología del aprendizaje se convierte en el segundo filtro y aporta elementos acerca de cómo se produce el aprendizaje y, considerando que la escuela pretende producir aprendizajes en los estudiantes, los objetivos que no estén "[...] de acuerdo con las condiciones intrínsecas del aprendizaje carecerán totalmente de valor como metas educativas [...]" (p.41).

Tyler plantea la necesidad de que una vez que se logra una lista breve de objetivos educativos alcanzables en el período escolar, la misma debe estar correctamente formulada para permitir continuar con el proceso de diseño del curriculum. La formulación correcta de los objetivos implica dar cuenta, por un 
lado, de la conducta del estudiante que se desea alcanzar y, por el otro, del área de contenidos en la que la misma debe evidenciarse ${ }^{158}$.

Una vez que el diseñador del curriculum o el docente tiene un listado de los objetivos más importantes y coherentes desde el punto de vista filosófico y psicológico, debe embarcarse en la resolución del segundo y del tercer paso: la selección y la organización de las actividades de aprendizaje por las que transitará el alumno.

Tyler recupera la definición de "objetivo" que mencionamos previamente y desarrolla la idea de "experiencia de aprendizaje" pertinente para pensar el sentido que la asigna el autor a las actividades de aprendizaje.

"[...] La expresión "experiencia de aprendizaje" no se identifica con el contenido del curso ni con las actividades que desarrolla el profesor, sino que se refiere a la interacción que se establece entre el estudiante y las condiciones externas del medio ante las cuales éste reacciona. El aprendizaje ocurre por la conducta activa del que aprende, quien asimila lo que él mismo hace, no lo que hace el profesor. [...]" (pp.65-66. La cursiva figura en la edición consultada).

En esta conceptualización se ponen en evidencia, por un lado, los aspectos internos y propios de cada estudiante que intervienen en el proceso educativo. Cada alumno se ve influido de manera diferente por las situaciones y condiciones propuestas por el docente y vive su propia experiencia de aprendizaje.

Por otro lado, aparece la veta activa del alumno frente al aprendizaje. El docente, dice Tyler, debe tener un conocimiento del alumno para poder presentar las situaciones de aprendizaje que puedan resultar más estimulantes y así suscitar su reacción frente a ellas.

En este marco, Tyler presenta una serie de principios generales para seleccionar y organizar las actividades de aprendizaje que se consideren más adecuadas en función de determinados propósitos. Retomamos estas consideraciones en el apartado VI-2-a-por ser centrales para pensar el carácter de la norma curricular elaborada por el autor.

\footnotetext{
${ }^{158}$ El mismo planteo con respecto a la formulación de objetivos vemos en Taba (1974). A su vez, este posicionamiento lleva a Tyler a desechar otras formas de redactar las intenciones educativas que serán retomadas por otros autores, como Stenhouse (1991) por ejemplo.
} 
El último paso del diseño del curriculum se refiere, como Tyler expone en la introducción, a la evaluación. La misma es un proceso complejo que está presente en diferentes momentos del diseño del curriculum y su propósito principal es establecer si los diferentes planes de formación que se diseñan verdaderamente orientan al docente hacia los resultados previstos. El autor explica que este propósito se asienta en la constatación de que la puesta en marcha del curriculum diseñado genera múltiples variantes teniendo en cuenta el docente, el alumno, el ambiente del aula, etc.

Asimismo, la evaluación permite determinar los puntos fuertes y débiles de un curriculum, pudiendo establecer aquéllos que van a permanecer como aquéllos que se deben modificar para el mejoramiento de la propuesta educativa.

En lo que respecta a la evaluación de los aprendizajes, Tyler expone que dado que los objetivos se refieren a cambios de conducta en los estudiantes, la evaluación deberá permitir tomar una decisión acerca de si el cambio se produjo o no y con qué magnitud.

Por último, Tyler destina unas páginas de su libro para dar cuenta de cómo el personal docente de una escuela debe participar en la elaboración del curriculum. En este sentido, sostiene que todo el personal de la escuela debe trabajar en este proceso de diseño total o parcial, dependiendo de la amplitud y profundidad del cambio que se desea realizar. En cualquier caso, recordamos, el esquema propuesto es válido para orientar las acciones.

Por su parte, el libro de Taba, Elaboración del currículo. Teoría y práctica o su nombre en inglés Curriculum Development. Theory and Practice, se publicó inicialmente en 1962. La primera edición en español fue publicada en 1974 por la Editorial Troquel. Disponemos para el análisis de la tercera edición que apareció en 1977. Se trata de una publicación de seiscientas sesenta y dos (662) páginas que contiene un prefacio, un prólogo, el desarrollo de veinticuatro (24) capítulos, el índice bibliográfico y por último el índice del libro. 
El capítulo 1, según expone la autora, es introductorio al planeamiento del curriculum y el resto de los capítulos se agrupa en cuatro (4) partes. La parte I se denomina "Las bases para la elaboración del currículo" y contiene desde el capítulo 2 hasta el 12. La parte II se titula "El proceso de planeamiento del currículo" y agrupa desde el capítulo 13 hasta el 20. La parte III se llama "La concepción del currículo" y está conformada por los capítulos 21 y 22. Por último, la parte IV se designa como "Los métodos para realizar cambios en el currículo" y comprende los capítulos 23 y 24.

Teniendo en cuenta la extensión de la obra y la complementariedad que se le atribuye a la misma con respecto a la de Tyler, se realiza aquí un tratamiento acotado que pretende destacar las líneas que Taba profundiza en relación con el trabajo de su colega.

En el Prefacio de la obra la autora rescata el trabajo conjunto con Tyler y, al igual que él, se propone la constitución de un sistema de pensamiento curricular que represente un camino seguro para elaborar un curriculum y que integre: los avances del campo, las teorías ajenas a él que puedan enriquecerlo, y los problemas y soluciones corrientes. Plantea, además, que las bases de ese sistema fueron edificándose desde la década del '30, cuando comenzaron a trabajar con Tyler y otros colegas en el mejoramiento de la educación norteamericana.

Taba comienza su libro explicitando la concepción de curriculum con la que trabaja. Reconoce la existencia de diferentes definiciones que se ubican entre aquéllas que plantean el curriculum como las experiencias formativas que los estudiantes reciben en la escuela y la vinculación de ésta última con la sociedad en la que se inserta, y aquéllas más ceñidas a la especificación de objetivos, contenidos y metodologías de enseñanza. La autora plantea que su definición se ubica entre ambos polos.

Esta conceptualización lleva la a analizar extensamente distintas perspectivas teóricas que considera las "bases" para la elaboración del curriculum. Así estudia las funciones de la escuela, la sociedad y la cultura, las 
diferentes teorías del aprendizaje, la inteligencia y el desarrollo mental del niño, la naturaleza del conocimiento y del contenido escolar, etc.

En diferentes partes de la obra aparece la necesidad de construir una ciencia de la educación coherente que brinde un conjunto de explicaciones, leyes y principios articulados para orientar la elaboración del curriculum.

Al igual que la obra de Tyler, la de Taba se estructura en torno al desarrollo de lo que la autora considera siete pasos a seguir en el diseño del curriculum:

“[...] Desde el momento en que se concibe la elaboración del currículo como una tarea que requiere juicio ordenado, es indispensable examinar tanto el orden de adopción de las decisiones, como el modo en que se realizan, para asegurarse de que todos los aspectos importantes han sido considerados. Este libro se basa en la suposición de que ese orden existe y de que, respetándolo, se obtendrá un currículo más conscientemente planeado y más dinámicamente concebido. Este orden podría ser:

Paso 1: Diagnóstico de las necesidades.

Paso 2: Formulación de objetivos.

Paso 3: Selección del contenido.

Paso 4: Organización del contenido.

Paso 5: Selección de las actividades de aprendizaje.

Paso 6: Organización de las actividades de aprendizaje.

Paso 7: Determinación de lo que se va a evaluar y de las maneras y medios para hacerlo. [...]" (p.26)159.

A partir de las bases definidas en la primera parte del libro, Taba se dedica en la segunda al tratamiento de cada uno de los siete pasos precedentes.

Con respecto a las finalidades y objetivos podemos decir que se constituyen en centrales para el diseño del curriculum. Todos los componentes curriculares se estructuran en torno al logro de las intenciones previamente definidas. Al igual que Tyler, Taba defiende las tres fuentes identificadas por él para la formulación de los objetivos, a saber: las necesidades y los intereses del niño, las demandas de la sociedad contemporánea, y los postulados de las disciplinas científicas.

\footnotetext{
${ }^{159}$ En una nota al pie de página se aclara: "Estos pasos son comparables a una secuencia propuesta en un compendio de Tyler (1950) [Hay traducción española: Principios básicos del currículo, Troquel, Buenos Aires, 1973]. Una secuencia similar es descrita por Taba (1945)" (p.26. El subrayado figura en cursiva en la edición consultada).
} 
Por otra parte, también defiende lo que denomina el "modelo bidimensional" para la formulación de los objetivos. En este sentido, explica la importancia de considerar tanto el área de contenido como lo que el estudiante debe hacer con ese contenido.

Por último, es importante mencionar que la autora enuncia una serie de principios para la formulación de los objetivos ${ }^{160}$. Aclara que éstos no intentan imponer inflexibilidad ni prescripción sobre el contenido, sino que por el contrario buscan orientar la formulación de los objetivos, tan importantes en el proceso de diseño curricular.

Por otra parte, el tratamiento del contenido que realiza Taba merece una consideración especial porque, como sostiene Díaz Barriga (1991), el tratamiento que realiza sobre la selección y organización del contenido del curriculum representa un significativo avance en comparación a la obra de Tyler.

Taba comienza planteando un problema curricular central que se refiere a la necesidad de seleccionar los contenidos. Es sabido que no se puede aprender todo en el tiempo escolar del que se dispone. Entonces, la selección y los criterios para orientar esa selección se convierten en una decisión clave -aún en la actualidad-para pensar la elaboración del curriculum. En coherencia con lo ya planteado, podemos decir que para la autora esta decisión debe asentarse sobre una base racional.

"Cuando se trata de enseñar un contenido cada vez más diverso en la misma cantidad de tiempo, se vuelve imposible preservar la unidad, la profundidad o la secuencia en el aprendizaje. Es válido decir que, bajo estas condiciones, cuanto más se "abarca", menos se aprende. Si bien los nuevos contenidos y los nuevos puntos de insistencia son necesarios, también es importante evitar que el currículo se convierta en una especie de cafetería, una mezcla indigerible de misceláneas en lugar de una dieta sistemática de aprendizaje" (p.348).

\footnotetext{
${ }^{160}$ Baste como ejemplo la mención de los primeros cinco (5): 1- la determinación de los objetivos debe dar cuenta de la conducta que se espera de los estudiantes y del tipo de contenido o del contexto en el que dicha conducta se utiliza; 2- los objetivos complejos deben ser determinados con claridad y precisión acerca de las conductas y contenidos involucrados en su alcance; 3- los objetivos deben formularse de manera tal que permitan visualizar diferencias entre los tipos de experiencias de aprendizaje que se requieren para lograr conductas diferentes; 4- los objetivos deben ser concebidos como puntos de continuidad en el desarrollo y no como puntos de llegada o terminales; 5 - los objetivos deben ser reales e incluir lo que es factible de ser trasladado al curriculum y a la enseñanza en el aula.
} 
Taba plantea que son muchos los factores que afectan la consideración del contenido del curriculum: los avances científicos y tecnológicos, los cambios en la sociedad, las transformaciones en distintas regiones del mundo, el aumento de la matrícula escolar, o el lanzamiento del Sputnik ${ }^{161}$ que ha ocasionado la asignación de mayor prioridad a la instrucción científica y matemática. En este sentido, es necesario establecer criterios racionales que permitan determinar qué enseñar y qué no, en las escuelas. El conjunto de criterios debe ser coherente y actuaría, siguiendo a Taba, como un tamiz que permite seleccionar las experiencias válidas para el curriculum.

En coherencia con lo expuesto por Tyler en relación con los objetivos y con las experiencias de aprendizaje, Taba avanza en trabajar con mayor nivel de detalle el hecho de que el curriculum está conformado por "[...] el contenido y las experiencias del aprendizaje, $u$ operaciones mentales que los estudiantes emplean para aprender el contenido [...] (p.350). Si bien la autora reconoce que ambas cuestiones están imbricadas en el proceso de aprendizaje, a los fines de establecer criterios para la selección de contenidos es fundamental diferenciarlas.

La autora explica una serie de $\operatorname{criterios}^{162}$ que adquieren relevancia en el apartado VI-2-a- dedicado al análisis del carácter de la norma curricular. Al igual que los principios ya aludidos que la autora expone para la formulación

\footnotetext{
${ }^{161}$ La educación científica en términos de la producción de conocimiento fue una clara preocupación para Estados Unidos una vez que había perdido la carrera espacial. Carr y Kemmis (1988) analizan el impacto del lanzamiento del Sputnik para la educación norteamericana y localizan en los años '60 la expansión de la perspectiva técnica y de la concepción de la educación como una ciencia aplicada. Para estos autores, el movimiento curricular en ese país se desarrolló a partir de este hecho con la colaboración de los especialistas en las disciplinas para definir los contenidos curriculares.

Este movimiento, según exponen Joyce y Weil, pretendía reemplazar las áreas curriculares convencionales de la escuela norteamericana por las ideas y los métodos de investigación de las disciplinas académicas. Específicamente, lo denominan: “[...] movimiento en pro de la Reforma Académica [...]" (2002, p.198).

A mediados de los años '60, Schwab y sus colaboradores diseñaron el Biological Sciences Curriculum Study (BSCS) en el que el acento estaba puesto en que los estudiantes utilizaran estrategias de investigación científica tal como lo hacían los biólogos en sus laboratorios: puesta a prueba de hipótesis, recogida de información, análisis e inferencias (Camilloni, 2006). Retomamos esta referencia a Schwab en el capítulo VIII.

${ }^{162}$ Baste como ejemplo la mención de los primeros cinco (5) criterios para la selección de contenidos: 1validez y relevancia del contenido; 2 - compatibilidad con las realidades sociales; 3 - equilibrio entre la profundidad y el alcance del contenido; 4- provisiones para alcanzar una amplia gama de objetivos; 5accesibilidad y adaptabilidad a las experiencias de los estudiantes.
} 
de los objetivos, estos criterios tienden a orientar y no a prescribir el proceso de diseño.

Posteriormente, da cuenta de la organización del curriculum, que involucra en primer lugar la secuenciación del contenido y de las experiencias de aprendizaje. Aun cuando desde la perspectiva de la autora se requiere más avance en materia de la teoría curricular sobre estas cuestiones, debe tenerse en cuenta que la secuencia del contenido no determina la secuencia de las experiencias de aprendizaje que requiere, además, la consideración de los aportes de las teorías del aprendizaje así como de la experimentación que pueda en algunos casos hasta superar las limitaciones que puedan imponer dichas teorías.

En segundo lugar, pensar en la organización del curriculum requiere de algunas consideraciones en torno al aprendizaje acumulativo entendido como la exigencia de lograr un desempeño cada vez más exigente. “[...] La progresión acumulativa en el aprendizaje requiere, naturalmente, planificar las experiencias del currículo de modo de presentar un material cada vez más complejo y, al mismo tiempo, la exigencia de reacciones mentales más maduras [...]" (p.389). Al igual que en el punto anterior, la progresión acumulativa demanda tener en cuenta el contenido, pero también la madurez de pensamiento o los sentimientos de los estudiantes.

Según plantea Taba, la organización del curriculum demanda también una consideración con respecto a la integración de los contenidos. La tensión “especialización-integración" requiere una resolución. La autora diferencia entre una articulación horizontal entre las diferentes asignaturas y otra interna a lograr por cada estudiante, que repercutiría en el logro de un aprendizaje más eficaz.

Por otra parte, Taba sostiene que la organización de los contenidos debe realizarse considerando las exigencias lógicas y las psicológicas. Con respecto a las primeras, la autora sostiene que se presentan diferentes criterios posibles y que debe ser seleccionado aquél que mejor se adecue a los contenidos que se desean transmitir. Las exigencias psicológicas, por su parte, apuntan a 
considerar los contenidos en función del logro de un aprendizaje efectivo. Para la autora, ambas exigencias deben combinarse en la organización de la enseñanza.

A su vez, en esta forma de organizar el curriculum que postula Taba debe existir algún enfoque o núcleo organizador que permita considerar lo relevante y lo accesorio de una manera coherente para todas las asignaturas. Una forma que propone la autora se refiere a la formulación de las ideas esenciales.

Por último, Taba se dedica a la evaluación de los resultados del curriculum. Consideramos que su planteo se ubica en una línea similar a la abierta por Tyler. Para la autora, de las múltiples funciones que se le pueden asignar a la evaluación, la más esencial y la menos utilizada se refiere a “[...] otorgar validez a las hipótesis sobre las cuales se basa el currículo [...]" (p.412). Esta consideración pone en evidencia el carácter hipotético de todas las decisiones que se toman en materia curricular y que demandan probar su eficacia en su concreción en las aulas.

Al igual que Tyler, Taba extiende la evaluación a diferentes dimensiones involucradas en el curriculum teniendo en cuenta la coherencia entre este proceso complejo y la perspectiva que orienta a todo el curriculum.

Por otra parte, Taba destaca la importancia de que el curriculum avance en el diseño de "unidades de enseñanza-aprendizaje" como una forma de dar un paso más hacia su concreción. " [...] Es posible que el abismo entre la teoría y la práctica exista debido a que la preocupación no ha sido acompañada por experimentación con el currículo tal como éste funciona en la situación de enseñanzaaprendizaje $[\ldots]^{\prime \prime}(\mathrm{p} .450)$.

Para la autora, la elaboración científica del curriculum debe involucrar el diseño de "unidades piloto". La importancia de diseñar estas unidades radica en buscar una resolución más orientada a las prácticas de enseñanza y de aprendizaje de aquellos problemas planteados teóricamente. Asimismo, pone en juego todos los criterios utilizados para la elaboración del curriculum, a los que va resignificando en este nuevo nivel de concreción, respetando a su vez los pasos ya estipulados para el diseño curricular. 
Por otro lado, consideramos importante realizar una mención a la estructura conceptual para la elaboración del curriculum, que la autora considera relevante. En coherencia con lo expresado en las primeras páginas de su libro, después de realizar un diagnóstico de lo que considera deficiencias y vacíos en los curricula vigente, reconoce la ausencia de una estructura conceptual coherente y sólida para orientar la elaboración del curriculum.

Taba plantea una serie de preguntas centrales que una teoría del curriculum debería estar en condiciones de formular y responder, tanto en el nivel del diseño curricular como en el nivel del diseño de una unidad de enseñanza y de aprendizaje:

1. “QQué es un currículo, qué incluye y qué diferencias existen entre los problemas de un currículo y los de un método de enseñanza?

2. ¿Cuáles son los principales elementos del currículo y qué principios gobiernan las decisiones relativas a su selección y a los papeles que desempeñan en todo el currículo?

3. ¿Cuáles deben ser las relaciones entre estos elementos y sus principios fundamentales y cuáles son los criterios y los principios que deben aplicarse para establecer estas relaciones?

4. ¿Qué inconvenientes y problemas encierra la organización de un currículo y qué criterio debe aplicarse para adoptar decisiones con respecto a los modelos y los métodos para la organización?

5. ¿Cuál es la relación que existe entre un modelo o un proyecto de currículo y las condiciones prácticas y administrativas bajo las cuales funciona?

6. ¿Cuál es el orden para la adopción de decisiones y cómo pasamos de las unas a las otras?" (pp.546-547).

Una teoría del curriculum que logre formular y responder estas preguntas, según plantea Taba, estaría en condiciones de estructurar un proceso complejo de elaboración curricular.

Por último, es posible mencionar que Taba reserva el capítulo final de su libro para "el trabajo en equipo". Plantea la importancia de trabajar en equipos que incluyan a personas con diferentes conocimientos y capacidades para poder dar una buena respuesta al complejo proceso de elaboración del curriculum. Además, la autora propone el trabajo con docentes, involucrándolos en el diseño curricular, considerando su papel preponderante en la concreción práctica de toda propuesta formativa. 
La tercera obra involucrada en el análisis de este capítulo es la de Chadwick titulada Tecnología educacional para el docente. Se trata de un libro publicado originalmente en 1977. Analizamos aquí la publicación de 1992 que se corresponde con la $3^{a}$ edición revisada y ampliada. Según informa el autor en el prólogo, las modificaciones a la versión original son el resultado de una importante ampliación de los conceptos involucrados en su propuesta.

“[...] Nuevas ideas en la evaluación, muchas experiencias en la selección, el uso y la eficacia de los medios de comunicación en la educación, la toma de conciencia de los problemas críticos en el currículum y la necesidad de ligar mejor éste con la tecnología educacional, y los avances notables en la psicología cognitiva, casi han revolucionado el campo" (p.11).

Este párrafo sintetiza los temas que abarca la perspectiva que el autor posee sobre la tecnología educacional. Cabe mencionar que si bien no encontramos en este trabajo alusiones directas a la didáctica y al curriculum, consideramos pertinente su abordaje en tanto en la obra aparecen elementos que han sido usados para la programación de la enseñanza y para el diseño curricular.

El trabajo de Chadwick se ha expandido en América Latina. Él mismo dice en el prólogo de la obra analizada -firmado en septiembre de 1986 en Chile- que ha pasado quince años de trabajo en nuestro continente y eso constituye otro de los aportes a la renovación de su libro. Ha trabajado en Chile y también su propuesta se ha difundido a partir de la Organización de Estados Americanos (OEA).

El libro consiste en el prólogo, ocho (8) capítulos, un (1) vocabulario breve con la definición de algunos de los conceptos centrales utilizados y la bibliografía, desarrollados en ciento setenta y siete (177) páginas.

Chadwick dice: "[...] La tecnología educacional [...] está definida como la aplicación de un enfoque organizado y científico con la información concomitante al mejoramiento de la educación en sus variadas manifestaciones y niveles diversos [...]" (p.15). El autor sostiene que esta disciplina presenta potencialidades para generar soluciones a los diversos problemas que presenta la educación en su tiempo. Principalmente estos problemas se generan porque la educación no ha 
cambiado tan rápidamente como otros sectores del sistema social general. Según el diagnóstico del autor, la educación se enfrenta con necesidades novedosas vinculadas, por un lado, a la mayor cantidad de población a la que se debe brindar un servicio de calidad y, por el otro, al progreso de la sociedad, al aumento consecuente de información disponible en el mundo y a la diversificación de los medios con capacidad para ofrecer dicha información.

"Además, la educación padece defectos internos que las presiones externas han exacerbado [...]" (p.13). Entre estos defectos, Chadwick destaca: la ausencia de claridad en cuanto a las intenciones de la educación y las incongruencias entre estas finalidades a largo plazo y los objetivos pautados para el corto plazo a ser adquiridos en las clases; la indeterminación de la contribución que cada componente del proceso educativo realiza al rendimiento de los aprendizajes de los alumnos; la falta de especificación de los procesos de evaluación; y la alta intensidad de trabajo con un bajo nivel de especialización de las funciones.

Según Chadwick, la aplicación del enfoque de sistemas a la tecnología educacional presenta una serie de ventajas. Dicho enfoque se define como un proceso ordenado, sistemático, lógico, que permite analizar y evaluar el desempeño actual de un sistema, entendido como un todo, con una interrelación entre todas sus partes componentes, en el que las finalidades que el mismo debe alcanzar son fundamentales. Asimismo, este enfoque posibilita generar la información y los medios de autocorrección necesarios cuando los resultados no son los esperados. En otra parte del libro dice que la tecnología educacional puede ser definida como un enfoque de sistemas aplicado a la educación (p.37).

El enfoque de sistemas, la psicología de enseñanza-aprendizaje y la psicología de la comunicación, son las tres "vertientes disciplinarias" -podemos decir- que abonan el crecimiento de la tecnología educacional.

Desde esta perspectiva, la escuela y el sistema educativo en su conjunto se interpretan como un conjunto interrelacionado de partes que actúan de manera combinada, influyéndose mutuamente. 
Este tipo de análisis implica tener en cuenta seis (6) partes, a saber: estructura, procesos, entradas, productos o egresos, ambiente y retroalimentación (p.24). A su vez, involucra un proceso ordenado, lógico y secuenciado que comprende los cinco (5) pasos siguientes: “[...] a) el análisis de sistemas; b) el diseño de sistemas; c) el desarrollo de sistemas; d) la instrumentación de sistemas; y e) la evaluación de sistemas [...]" (p.31).

Los objetivos también adquieren centralidad en el "nuevo modelo de enseñanza-aprendizaje" que Chadwick denomina "modelo tecnológico"163. Este modelo se opone al "modelo tradicional" y no se define por la inclusión de máquinas sino por la utilización de técnicas para el diseño y desarrollo de sistemas educacionales.

El modelo tecnológico para el diseño de situaciones de enseñanzaaprendizaje que presenta el autor, se inicia con la formulación de los objetivos. El resto de los componentes de la propuesta formativa se adecua a su consecución. El autor explícitamente plantea que la enseñanza busca producir un cambio que se denomina aprendizaje, por lo que el diseño de las situaciones de enseñanza-aprendizaje debe tender hacia la producción de este último.

Para Chadwick los objetivos son aquello que expresa lo que se espera del estudiante al final del proceso educativo. A diferencia de los otros dos autores considerados en este capítulo, el autor especifica que el objetivo “[...] debería considerarse como un enunciado de la naturaleza deseada de la conducta de un estudiante al finalizar alguna unidad educacional especifica [...]" (pp.58-59. El subrayado figura en cursiva en la edición consultada). Podemos afirmar que el eje está puesto en los procesos mentales que el sujeto pone en marcha para el aprendizaje de los contenidos.

El autor aclara que el concepto de conducta se ha ido ampliando en los últimos años y comprende tanto las conductas manifiestas como las capacidades, estructuras y procesos internos.

\footnotetext{
163 “[...] El nuevo modelo de enseñanza-aprendizaje ha sido ampliado y estudiado más profundamente. He cambiado todas las referencias a lo «instruccional» por las experiencias de enseñanza-aprendizaje, considerando que con ella se refleja la intención del campo y es más consistente con las correctas expresiones en castellano [...]" (p.11).
} 
A su vez, comparando el modelo tradicional con el tecnológico, el autor expone que su propuesta ofrece "[...] una gama más amplia de conductas, incluyendo destrezas para resolver problemas, creatividad, destrezas intelectuales y estrategias cognoscitivas [...]" (p.53). Plantea la necesidad de excluir la memorización, dando lugar a diversas estrategias de procesamiento de la información, tanto en forma individual como grupal.

Por otro lado, con respecto a la selección y secuenciación del contenido, Chadwick alude al análisis de tarea necesario para diseñar el curriculum. Este análisis es el que juega -de alguna manera- como criterio de selección de los contenidos, pautando qué enseñar y qué no en la escuela. Además, permite saber qué conocimientos y estrategias de pensamiento el estudiante requerirá en su vida adulta, en qué condiciones deberá operar con esos conocimientos y estrategias, y de qué manera éstos pueden incorporarse a la escuela.

No obstante, parece que estas cuestiones están orientadas a definir el trabajo de los diseñadores del curriculum, no de los propios docentes. Las alusiones de Chadwick son a los diseñadores del curriculum o a los planificadores del sistema educativo. En este sentido, incluye el término "función" y aclara que es importante especificar las funciones que cada uno va a cumplir en el sistema educacional para el logro de las finalidades propuestas.

Por último, la evaluación educacional es un punto importante de este modelo tecnológico propuesto por Chadwick. "La evaluación educacional es el proceso de delineamiento, obtención y elaboración de información útil para juzgar posibilidades de decisión [...]" (p.98).

En el modelo de sistema presentado por Chadwick, la evaluación se halla en relación con la retroalimentación. Es decir, con la posibilidad de que la información que se buscó y ponderó en la evaluación en función de los valores implícitos en los objetivos, vuelva a ingresar al sistema para producir los ajustes que se estimen convenientes. 


\section{VI - 2 - Análisis de las obras: la aparición de algunos emergentes que permiten caracterizar la prescripción curricular.}

VI - 2 - a - Carácter de la norma en una teoría normativa y en una teoría prescriptiva.

En consonancia con el marco conceptual-referencial desarrollado específicamente en el capítulo II y a los fines de enriquecer el análisis de las obras de los tres autores aquí expuestas, sostenemos que es necesario establecer algunas diferencias entre los trabajos de Tyler y de Taba, por un lado, y el de Chadwick, por el otro. Si bien consideramos, como ya mencionamos, que las clasificaciones taxativas de los autores y sus obras no son posibles y que el análisis demanda la exposición de los matices, por los motivos que señalamos a continuación planteamos que los primeros dos textos abonan la construcción de una teoría normativa del curriculum, mientras que el tercero se inclina hacia la producción de una teoría prescriptiva.

En la obra de Tyler aparece una tensión entre la norma curricular y los márgenes de resignificación que la misma prevé en su puesta en práctica por parte de los sujetos docentes. No obstante, como ampliamos a continuación, elabora una norma curricular que se transforma progresivamente en prescriptiva a medida que se avanza hacia su concreción.

En este sentido, por un lado, vemos que el autor pretende presentar un trabajo que sirva para el análisis y el diseño del curriculum, con un método de pasos no rígidos ni estáticos, y con la posibilidad de que los docentes y directivos de las diferentes instituciones educativas puedan ir adecuando este esquema a sus necesidades curriculares particulares. No obstante, parafraseando a Kemmis (1990), en manos de lectores poco predispuestos a discernir el libro se transforma en un conjunto de recetas que el autor explícitamente rechaza ${ }^{164}$.

\footnotetext{
164 “[...] Del mismo modo, Schwab cree, evidentemente, que quienes utilizan el método racional tyleriano lo han rebajado por usarlo sin sutileza ni juicio (el tipo de característica sobresaliente que se espera proporcione una formación en la deliberación práctica) [...]" (Kemmis, 1993, p.66).
} 
Vemos en el análisis que esta tendencia destacada por Kemmis es posible y puede ser pensada como aquélla que clausura o constriñe el accionar y la creatividad del docente. Como dice Hlebowitsh: "[...] el Rationale no debía utilizarse de una manera paso a paso o rígidamente lineal [...] [Tyler] estructuró el

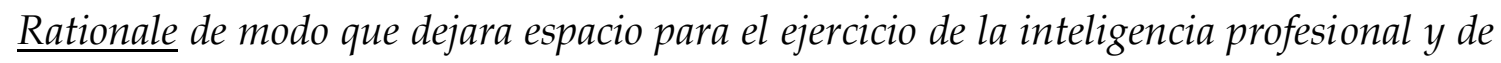
la iniciativa filosófica [...]" (1998, p.173. El subrayado figura en cursiva en la edición consultada).

En primer lugar, Hlebowitsh expresa "[...] Para Tyler, las cuestiones normativas sólo se pueden contestar situacionalmente [...]" (1998, p.178). La implementación del esquema tyleriano no puede desconocer las particularidades del contexto y de los sujetos que lo están utilizando. El mismo Tyler en un trabajo posterior dice: "[...] «La formación del currículum no es un proceso basado en reglas precisas, sino que más bien supone diseño artístico, así como análisis crítico, juicios humanos y comprobación empírica» [...]" (1981, p.24; citado en Hlebowitsh, 1998, p.179)165.

Si bien Tyler reconoce espacios que deben quedar en el diseño del curriculum para la toma de decisiones, tal como le reconoce Schwab (1974), por ejemplo, no brinda los apoyos necesarios para tomarlas. Los complejos procesos decisionales involucrados en el curriculum implican un dominio de la deliberación, cuestión no desarrollada por Tyler. Entonces, frente a esto, en la práctica, el esquema de Tyler se toma como un conjunto de pasos que al ser cumplidos permitirían arribar al curriculum deseado.

Sostenemos que la norma, para que se comporte como tal aun en su puesta en práctica, debe garantizar desde su formulación condiciones para el ejercicio de los márgenes de resignificación que deben ejercer los sujetos. En el caso de Tyler, es importante recordar que en los cuatro (4) pasos centrales que el autor define para el diseño del curriculum se deja abierta explícitamente la posibilidad de especificar o resignificar las orientaciones aportadas. El autor reconoce que lo planificado sufre siempre variaciones en la práctica por la

\footnotetext{
${ }^{165}$ Tyler, R. W. (1981), "Specific Approaches to Curriculum Development», p.24, en H. A. Giroux, A. N. Pena y W. F. Pinar (eds.) Curriculum and Instruction: Alternatives in Education, Berkeley, CS, McCutchan.
} 
diversidad de variables que intervienen (entre ellas: características del docente y de los alumnos, ambiente del aula y de la escuela, imprevistos, etc.). Pero además de estas variaciones que se pueden generar en el momento interactivo (Jackson, 1968), Tyler llama la atención sobre el hecho de que en el momento preactivo o de anticipación de la enseñanza el docente también toma decisiones que adecuen sus orientaciones. En este último sentido, consideramos que se pueden interpretar las alusiones del autor a la toma de decisiones por parte del docente y del diseñador del curriculum en torno a los objetivos, los principios para la selección y organización de las actividades, la selección de los instrumentos de evaluación que mejor se adapten a las finalidades que se persiguen, etc.

Para Tyler, el proceso de diseño del curriculum no es un "[...] método mecánico $[\ldots]^{\prime \prime}$ (p.83), sino que sus orientaciones, formuladas en términos de criterios o principios, demandan especificación práctica. El autor dice: “[...] ¿el orden de los pasos debe ser el mismo que se presenta en este compendio? La respuesta es rotundamente: "no" [...]" (p.131).

Podemos decir que el trabajo de Taba se ubica en una línea similar en lo que respecta al sentido que le asignamos a la norma curricular. La autora explica que los criterios o principios que ella formula no prescriben sino que orientan el proceso de diseño curricular. En este sentido, detalla criterios para la formulación de objetivos, para la selección del contenido, para la secuenciación de las actividades, etc., como vimos precedentemente.

Por otra parte, la norma curricular expuesta en los trabajos de Tyler y de Taba se dirige a un sujeto que puede ser el docente, el directivo o el diseñador del curriculum, según los casos.

Tyler permanentemente apela al lector, que puede ser interpretado como el docente, el directivo o el diseñador del curriculum. Aparecen apelaciones o sugerencias acerca de cómo proceder o invitaciones a realizar actividades para ir avanzando en el diseño del curriculum. Consideramos que se refuerza de esta manera el valor instrumental del trabajo. 
En el libro de Taba el sujeto al que se dirige la norma curricular es más difuso. Las alusiones de la autora no se realizan directamente al docente o al diseñador del curriculum. Sostenemos que la intencionalidad última de Taba está puesta en la configuración de una teoría curricular y, por tanto, son más generales las referencias a los sujetos que deberían luego utilizar las orientaciones normativas de esa teoría.

No obstante, según sostiene Camilloni, la propuesta de Taba le asigna protagonismo al docente en la formulación del curriculum. "[...] Se conoce esta posición como "diseño de abajo a arriba" [...]" (2006, p.13).

Por otro lado, consideramos que cabe en este apartado una mención al lugar que ocupan las intenciones en el diseño del curriculum. En la caracterización de la teoría técnica en el campo curricular y en la descripción de las obras de Tyler y Taba ya aludimos a la centralidad de los fines y objetivos. Ambos autores defienden la importancia de definir los objetivos de manera tal que comprendan el área de contenido con la que se va a trabajar en la enseñanza, y las capacidades de los alumnos involucradas en el aprendizaje de tales contenidos.

A su vez, ambos autores defienden la complementariedad de las tres fuentes detalladas por Tyler para obtener información sobre los fines: la sociedad contemporánea, el niño y las disciplinas. No obstante, con respecto a la primera de ellas, podemos decir que Tyler recurre al análisis de tarea (como lo hace Chadwick también) y dice que no se pueden enseñar contenidos que fueron válidos varios años atrás, sino que se debe enseñar lo que la sociedad necesita en ese momento. Por su parte, Taba apela más a la relevancia de una formación integral para los sujetos y critica el énfasis que en su época fue tomando la educación científica con posterioridad al lanzamiento del satélite Sputnik en 1957.

En relación con los objetivos, aparece en los trabajos de Tyler y de Taba la evaluación. Este par es considerado como una de las grandes ventajas que la racionalidad técnica nos ha dejado como legado (Feldman, 2010b). La relación entre objetivos y evaluación aparece como necesaria para ponderar el 
aprendizaje de los alumnos, para ver los cambios de conducta productos del tránsito por la escuela, para mejorar los objetivos en tanto la evaluación realiza una nueva mirada sobre su planteo, etc.

Siguiendo a Carlino (1999), es interesante el trabajo que Tyler propone con respecto a la evaluación porque amplía considerablemente el término. Antes de su propuesta, la evaluación estaba restringida a los aprendizajes y el rendimiento de los estudiantes, pero su propuesta traslada, a juicio de la autora, la evaluación a todos los componentes curriculares; así es posible evaluar los aprendizajes, los programas, los objetivos, los docentes, etc.

A su vez, tanto Tyler como Taba consideran que la evaluación tiene, entre sus funciones, la validación de las hipótesis curriculares. Consideramos que este planteo es relevante en tanto ubica a los autores en una posición cercana a aquélla que esgrimen otros teóricos asentados en una perspectiva práctica del curriculum, que conceptualizan como problema las relaciones entre el curriculum prescripto y el real.

Cabe aquí analizar las posibles respuestas a la siguiente pregunta: ¿por qué sostenemos que Tyler y Taba son representantes sobresalientes de la perspectiva metateórica técnica del curriculum a pesar de habilitar espacios para resignificar sus propuestas? ${ }^{166}$.

Cuando hablamos de la perspectiva técnica en la elaboración del curriculum aparece una serie de supuestos básicos ${ }^{167}$ que permiten caracterizarla en líneas generales como aquélla que es altamente prescriptiva; que deja escasos márgenes de actuación a los docentes, por lo que éstos quedan reducidos al lugar de técnicos; que postula una linealidad entre el curriculum prescripto y el curriculum real, etc. No obstante, estos supuestos son abiertamente cuestionados cuando los autores apelan a la responsabilidad de los sujetos involucrados en la

\footnotetext{
${ }^{166}$ Feldman expresa de la siguiente manera su opinión sobre Tyler: "[...] una de las más influyentes síntesis teóricas de esta modalidad aplicada a la resolución de los problemas del currículum, proponía los "principios" que contenía lo que él llamaba "su librito" para guía y uso de los equipos de profesores, directivos y asesores de cada escuela, ya que se suponía que eran ellos los responsables por la resolución de este tipo de cuestiones [...]" (2008, p.142).

167 Recordamos que aquí, específicamente para el caso del curriculum y la didáctica, podemos aludir a: Kemmis (1993); Grundy (1994); Salinas Fernández (1997).
} 
práctica para la implementación de sus propuestas y, a su vez, las acompañan de principios que -como su definición expresa- van enmarcando la acción.

Consideramos que lo importante aquí radica en las distintas alternativas que se sugieren al lector para el diseño del curriculum como así también la sistematicidad que ofrecen las propuestas de Tyler y de Taba. Precisamente es esta sistematicidad uno de los aspectos que más ha impactado en el éxito que las mismas han tenido entre los docentes y diseñadores del curriculum, y que más las asocian a la racionalidad técnica.

En primer lugar, vemos que en Kemmis (1990), como ya expusimos, hay una llamada de atención en este sentido, en tanto el autor plantea que la obra de Tyler en manos de lectores poco críticos llega a ser todas aquellas cosas que el propio Tyler no quería. Queda abierta, entonces, en este primer punto, la posibilidad de que la recepción de la obra tyleriana en diferentes contextos haya tergiversado o modificado los sentidos originales propuestos por el autor ${ }^{168}$.

En segundo lugar, encontramos elementos para responder a esta cuestión controvertida en lo que respecta a nuestro país específicamente. El ingreso de la obra de Tyler a la Argentina se realiza paralelamente a la entrada de la obra de Schwab. No obstante, por las condiciones históricas, políticas, sociales y educativas, Un enfoque práctico para la planificación del currículo adquiere mayor reconocimiento en la década del ' 80 .

En tercer término, hay que considerar que la racionalidad medios-fines es un supuesto típico de una perspectiva técnica y este supuesto sí aparece reiteradamente en las obras de Tyler, de Taba y de Chadwick. Se puede pensar si la centralidad que tienen los objetivos definidos al principio del diseño del curriculum no debilita todas las aserciones anteriores sobre el lugar del docente, ejerciendo una suerte de control sobre el rumbo correcto del proceso.

Este modelo de diseño que tiene como decisión primera y primordial los objetivos no tiene aparentemente un carácter recursivo, sino que más bien

\footnotetext{
${ }^{168}$ Podemos decir que esto sucede con la mayoría de las obras pero, las diferencias entre lo que dice el autor y sus usos e interpretaciones posteriores, no forman parte de nuestras preocupaciones actuales. El caso de Tyler es llamativo por lo emblemático de su obra para el campo curricular y por la repercusión que estos análisis ha suscitado entre sus defensores y sus críticos. Para más detalle se puede consultar: Kemmis (1990; 1993); Hlebowitsh (1998); Kliebard (1998).
} 
prima una linealidad. Se tienen en cuenta ciertas mediaciones que pueden ir apareciendo en el proceso de concreción del curriculum prescripto, no obstante, es de destacar el carácter no conflictivo asignado a dichas mediaciones.

Asimismo, consideramos que en la forma de postular los diferentes pasos para el diseño del curriculum y de la instrucción, hay una característica compartida, que se puede leer entre líneas y que ubica a Tyler, a Taba y a Chadwick en la perspectiva técnica. Nos referimos específicamente a la ausencia de conflictos más allá del plano técnico que cada uno de esos pasos conlleva ${ }^{169}$.

En cuarto lugar, si bien Stenhouse (1991) no critica explícitamente a Tyler cuando cuestiona el modelo de objetivos, retoma las dos alternativas de diseño del curriculum desechadas por Tyler, como vemos en el capítulo VIII.

En quinto lugar, distintos autores, como hemos visto, le critican al texto de Tyler su perspectiva ahistórica y apolítica para enfocar el campo del curriculum. Si recordamos los cuestionamientos que la perspectiva metateórica crítica le elabora a la técnica, en los términos en los que lo hace Kemmis (1993) y Grundy (1994), encontramos que la técnica no realiza una lectura de la estructura política y económica de la sociedad. La perspectiva metateórica crítica recupera positivamente la producción de afirmaciones con cierto grado de generalidad que convertirá en lecturas contextuales; pero critica que no utilice categorías relativas a las relaciones de poder, a la hegemonía, a la ideología, etc., para visualizar la configuración misma del tejido social que sobredetermina las prácticas educativas.

Podemos hipotetizar que este carácter de la teoría curricular técnica es justamente el que le permite esgrimirse como una técnica generalizable más allá del contexto particular de producción ${ }^{170}$ y de aplicación.

Por otro lado, Chadwick parte de un diagnóstico de la educación en Latinoamérica y elabora un modelo, con una serie de pasos, que de ser

\footnotetext{
${ }^{169}$ Para mayor detalle de las características del diseño, desarrollo y evaluación del curriculum desde la perspectiva tecnológica, puede consultarse: Contreras Domingo (1990).

${ }^{170}$ Díaz Barriga (1994) sostiene que el curriculum ingresa al escenario mejicano con estas características, primando en muchos casos los aspectos técnicos y a veces los teóricos, pero desconociendo la historia de la constitución del propio campo.
} 
aplicados conducirían a la solución de esos problemas. La clarificación de los objetivos, el establecimiento de las formas de evaluación, la selección de recursos, los caminos a seguir en el aprendizaje, van pautando con claridad cómo debe desenvolverse tanto un diseñador como un docente.

En relación con la comparación que establece entre el modelo tradicional y el modelo tecnológico de enseñanza-aprendizaje, se perfila un corrimiento del lugar del docente que resulta de interés para nuestro estudio. En primer lugar, el docente se corre del lugar de "brindar información" como lo ubica Chadwick en el modelo tradicional, y pasa a desempeñarse como un profesional, con otros especialistas, que diseñan y ponen a prueba la situación de enseñanzaaprendizaje para facilitar el aprendizaje de los alumnos.

Este lugar del docente se refuerza cuando Chadwick alude a los nuevos contenidos que deben incluir los programas de entrenamiento ${ }^{171}$ de futuros docentes y de docentes en ejercicio. En este entrenamiento, el contenido disciplinar que deben recibir los docentes debe ser escaso dado que este contenido pasa a ser ofertado por los materiales en el modelo tecnológico. El punto fuerte del entrenamiento pasa por el conocimiento de metodologías indispensables para llevar a cabo la situación de enseñanza-aprendizaje.

Parece que se produce una contradicción, porque si bien se dice que el docente es una pieza clave para pensar el cambio en educación, luego se le otorga un lugar subsidiario en el diseño, desarrollo y evaluación de situaciones de enseñanza-aprendizaje. El primer lugar lo ocupan los materiales y la configuración de la situación de enseñanza-aprendizaje en sí misma, cuestiones en las que interviene el docente y otros especialistas.

“[...] La tarea del personal docente debería ser participar como miembro de un grupo interdisciplinario de especialistas que intentan estructurar el ambiente para proporcionar a los alumnos la oportunidad de aprender [...]" (p.48). Luego los docentes se ocupan de la implementación de las situaciones de enseñanzaaprendizaje. Chadwick sostiene que el aprendizaje es más importante que la

\footnotetext{
${ }^{171}$ Es tentador en este punto hacer una reflexión sobre la expresión "entrenamiento docente" y no "formación docente". No obstante, sostenemos que puede haber allí una cuestión de traducción dado que en inglés se utiliza la expresión "teachers training".
} 
enseñanza, lo que sostiene la relevancia que se le asigna a la psicología en todo el proceso de entrenamiento docente.

En el planteo de Chadwick se va configurando para el docente un lugar de técnico, duramente criticado desde diferentes corrientes. En el marco de esta tesis, analizamos prioritariamente las críticas emanadas de la perspectiva práctica, que buscaron constituir al docente como profesional de la educación, con capacidad de decisión y acción. No obstante, como dice Cols, “[...] la visión del profesor como técnico aparecía como el único modo de profesionalizar la tarea, dotarla de un carácter claramente científico y asegurar la eficacia de la enseñanza [...]" (2000, p.10). En el modelo tecnológico que estamos analizando, el docente ocupa un lugar clave en la implementación -lo más fiel posible- de situaciones de enseñanza-aprendizaje diseñadas de manera externa al aula y por otros especialistas. Consideramos que aquí se fundamenta el carácter prescriptivo de esta obra.

$V I-2-b-$ Aspectos que constituyen la norma.

En los libros de Tyler y de Taba confluyen diversos elementos de procedencia teórica diversa, que contribuyen a explicar el proceso de diseño del curriculum así como también las orientaciones formuladas por los autores para llevarlo a cabo.

Consideramos que la recuperación de distintas referencias teóricas puede estar en relación con la constitución de un sistema de pensamiento curricular que ambos autores se proponen explícitamente.

En el caso de Tyler, específicamente, hay que sumar al análisis, "la armonización" de la que lo responsabilizan, entre otros, Parra y Pasillas (1991). En primer lugar, podemos decir que la "armonización tyleriana" tiene un carácter histórico e intenta dar cuenta, precisamente, de la importancia que posee para la constitución del campo curricular la elaboración del mencionado sistema de pensamiento. 
Parra y Pasillas (1991) ubican en la Declaración Conjunta de los miembros del Comité de la Sociedad Nacional para el Estudio de la Educación ${ }^{172}$ desarrollada en los años '20, un debate protocurricular, como mencionamos al comienzo de este capítulo, carente del tratamiento integral que recibieron todos los componentes curriculares desde la perspectiva tyleriana.

En segundo lugar, podemos decir que Tyler intentaría armonizar dos vertientes teóricas que, según Furlán (1997), se desarrollaron en el campo educativo desde principios de siglo $X X$ en Estados Unidos, a saber: el planeamiento o desarrollo del curriculum y el diseño de la instrucción.

La traducción al español del título original (Basic Principles of Curriculum and Instruction) del libro de Tyler, no incluye el término "instrucción", cuestión que puede estar en vinculación, como dice Furlán (1997), con las diferentes tendencias teóricas y posiciones profesionales adoptadas por los "expertos" de cada campo en el contexto latinoamericano, aún cuando ambos confluyeran -en última instancia- en la planificación de la enseñanza.

En tercer lugar, la consideración de las tres fuentes para la definición de los objetivos de la enseñanza que Tyler realiza no es más que la integración de tres corrientes en pugna no sólo en Estados Unidos en los años '40, sino que han caracterizado la escolaridad en diferentes sistemas educativos. La vida social contemporánea como fuente de finalidades educativas integra aquella corriente representada por los teóricos de la eficiencia social; la inclusión de la opinión de los especialistas incorpora la tradición humanista; y las necesidades e intereses de los educandos recupera los postulados del progresismo ${ }^{173}$ (Basabe y Cols, 2007).

\footnotetext{
172 "Según Luzuriaga, el Comité estaba integrado por W, Bagley, F. Bonser, W. Kilpatrick y H. Rugg de la Universidad de Columbia, Nueva York; F. Bobbit, W. Charters, G. Counts y Ch. Judd de la Universidad de Chicago; S. Coutis de la Universidad de Michigan; E, Horn de la Universidad de Minnisota, y G. Works de la Universidad de Cornell. Después de deliberar dos años sobre el problema, emitió una "Declaración general" sobre los problemas científicos y administrativos que subyacen en los programas escolares. Esta declaración fue publicada en el anuario de la "National Society for the Study of Education" en su 25 Yearbook. La editorial Losada la publicó en español en 1944 bajo el título "El nuevo programa escolar", reconociendo como primer autor a William Kilpatrick [...]" (Díaz Barriga, 1994, p.51).

${ }^{173}$ Se pueden analizar otras vinculaciones entre la obra de Tyler y los postulados del progresismo, como aquéllas que refuerzan la idea de que Principios básicos del currículo es el resultado del "Estudio de los Ocho Años". Dicho Estudio, comprendido entre 1933 y 1941, buscaba analizar los efectos de la educación progresista de Dewey en los estudiantes universitarios, comparándola con la educación
} 
A su vez, la integración de referencias teóricas aparece explícitamente en la obra de Tyler, y también en la de Taba, en el tratamiento de cada una de las tres fuentes que brindan información sobre las finalidades educativas que la escuela debe alcanzar.

En cuarto lugar, la constitución de un sistema de pensamiento curricular demanda la integración de diferentes referentes teórico-disciplinarios. Podemos decir que Tyler va tomando distintas posturas y en el análisis crítico de las mismas construye y fundamenta su propia posición y su modelo de diseño del curriculum. Taba, además, explícitamente valora el aporte que a la educación realizan diferentes ramas del saber, pero aclara que estos aportes no pueden utilizarse de manera directa, sino que su riqueza radica en la articulación que de los mismos se puede realizar "[...] dentro de la estructura del pensamiento didáctico $[\ldots]^{\prime \prime}(\mathrm{p} .8)$.

Por último, en el caso de Chadwick la pregnancia de las teorías que buscan entender el aprendizaje basadas en modelos de procesamiento de la información y el enfoque de sistemas es explícita y fundamental para la postulación de la tecnología educacional. Con estas dos vertientes teóricas el planteo del autor queda coherentemente armado y adquiere cierto status de universalidad, en tanto se presenta como la posibilidad de mejorar las fallas que tienen los sistemas educativos.

Se puede decir, además, que en el trabajo de Chadwick aparecen elementos de la psicología cognitiva informando el proceso de diseño del curriculum y condicionando sus componentes.

VI - 2 - c - Predominio de aspectos prescriptivos.

En líneas generales las obras de Tyler, de Taba y de Chadwick se encuentran prioritariamente preocupadas por la prescripción curricular. Las explicaciones que los autores brindan acerca del curriculum o los pasos 
involucrados en su diseño se hallan principalmente al servicio de la orientación del docente, del directivo o del planificador del curriculum, o de las situaciones de enseñanza-aprendizaje.

Específicamente en lo que respecta al trabajo de Tyler, podemos decir que si bien las decisiones que puede tomar el docente sobre el diseño del curriculum quedan explícitamente habilitadas, y los profesores y la escuela pueden decidir sobre cuestiones diversas durante todo el diseño y desarrollo curricular, acordamos con Schwab (1974) y con Hlebowitsh (1998) cuando reconocen que a pesar de esta apertura los sujetos no están preparados para decidir, según plantea el primer autor, o las cuestiones a decidir son tan amplias y fundamentales que a falta de criterios se terminan adoptando las medidas consuetudinarias.

En este último sentido, aquellas áreas sobre las cuales decidir, cuestión que habíamos destacado de Tyler y de Taba como signos de apertura en comparación a modelos más conductuales o estrictamente ceñidos a la redacción clara de objetivos, pierden peso y quedan relegadas toda vez que los esquemas se aplican en sus aspectos más prescriptivos.

Aparece aquí un aspecto nodal acerca de las condiciones que debe cumplir la formulación de la normatividad. Es decir, si bien podemos pensar que las orientaciones de Tyler dejan lugar para que el docente tome sus propias decisiones tendientes a la resignificación y adecuación del modelo de diseño del curriculum, cuestiones más cercanas a las características que les asignamos a las normas, la formulación de las mismas no garantiza más que la aplicabilidad del esquema, lo que termina acercando el planteo a lo prescriptivo.

Por su parte, Taba abunda en las explicaciones sobre las orientaciones que brinda para la elaboración del curriculum por lo que, sostenemos, el valor instrumental es más claro para el diseño concreto de un curriculum y de una unidad de enseñanza-aprendizaje.

En el caso de Chadwick queda más configurado el entorno dentro del que pueden tomar decisiones los maestros y alumnos. Hay más esfuerzo en decir qué se puede decidir y qué no para implementar el modelo tecnológico. 
En este sentido, está más claramente planteada la división de tareas entre los docentes y los planificadores. Una vez que los planificadores diseñaron las situaciones de enseñanza-aprendizaje, entran en juego los docentes tomando decisiones relativas a la especificación de esas situaciones.

Además, un espacio que restringe los márgenes de actuación profesional es el que se refiere a un cierto isomorfismo entre los objetivos y los ítems de evaluación. Si bien mencionamos que la vinculación entre objetivos y evaluación es un punto fuerte y positivo del modelo de objetivos, una relación tan estrecha, casi isomórfica, termina siendo perjudicial en tanto deja escasas posibilidades a los docentes para tomar decisiones relativas a qué enseñar y cómo hacerlo.

VI - 2-d - Disponibilidad de saberes interdisciplinarios para la constitución de la teoría y del diseño del curriculum.

En base al análisis realizado consideramos que en los trabajos de Tyler, de Taba y de Chadwick aparecen referencias explícitas a saberes provenientes de diferentes disciplinas que aportan al diseño y desarrollo del curriculum. No obstante, es posible establecer una diferenciación entre los primeros dos autores y el tercero.

Las referencias a diferentes teorías que realizan Tyler y Taba, como disciplinas que aportan saberes para la confección del curriculum, se seleccionan e integran en base a un modelo propio y claro establecido para el diseño curricular.

Por su parte, el texto de Chadwick, abiertamente se posiciona en la tecnología educativa, como disciplina que, con el aporte del enfoque de sistemas, logra generar un modelo sistemático para el diseño de la enseñanza y del aprendizaje. Se produce, sostenemos, un desdibujamiento de disciplinas como el curriculum o la psicología educacional que en Estados Unidos se preocupaban por la instrucción, o de la didáctica que en Argentina y otros 
países de América Latina tenía un desarrollo importante y orientado, como sabemos, a la enseñanza.

Las referencias a otros saberes disciplinarios, especialmente a los de la psicología, parecen tener derivaciones directas sobre el diseño y desarrollo de la enseñanza toda vez que se sostiene que el aprendizaje es más importante que aquélla. Los objetivos de aprendizaje y de los ítems de evaluación tienen un peso de definición técnica relevante y estructuran -con base en la psicologíagran parte de las situaciones de enseñanza.

Queda configurada, de manera más clara que en los autores anteriores analizados en este mismo capítulo, la concepción técnica de que la enseñanza es un problema aplicado y que se resuelve recurriendo a otras disciplinas básicas en este caso la tecnología educativa y el enfoque de sistemas- que detectan los problemas, construyen soluciones, las diseñan e indican a los docentes cómo implementarlas de manera correcta.

VI - 2 - e-Teorías de alcance intermedio o teorías cercanas a la práctica.

Sostenemos que los tres autores analizados en este capítulo realizan construcciones teóricas con una referencialidad directa en las prácticas de enseñanza y de aprendizaje. No obstante, como mencionamos en diferentes oportunidades, el acercamiento a la práctica y la especificidad en la previsión de los acontecimientos se presenta diferencialmente.

En los casos de Tyler y de Taba las referencias a la práctica son claras. Hay preocupación por la efectiva puesta en marcha de lo planificado y, por tanto, la concreción del curriculum prescripto en el real. Parecen evidenciarse aquellas características que mencionamos en los primeros capítulos de esta tesis, acerca de que el curriculum no puede "olvidarse" de su componente normativo o prescriptivo pero, en definitiva, orientador de las prácticas educativas. Toda propuesta formativa busca la concreción de sus finalidades, por lo que elabora orientaciones para su adecuado desarrollo. 
En los esquemas propuestos por estos autores, a pesar de posicionarse en el modelo de objetivos y sustentarse en la perspectiva metateórica técnica, aparecen permanentemente consideraciones acerca de las mediaciones que produce el docente en el pasaje entre el curriculum prescripto y el real. Como le reconoce Schwab (1974) a Tyler, el suyo es un modelo de pasos claros en cuanto al diseño, pero que ofrecen cierta flexibilidad en su puesta en marcha, flexibilidad que podría "expandirse" aun más si el modelo avanzara sobre las “artes de la deliberación".

El esquema propuesto por Chadwick, por su parte, da un paso más en su acercamiento a la práctica. El modelo tecnológico es muy claro, como ya analizamos, en cuanto a la especificación de los pasos involucrados en el diseño de situaciones de enseñanza-aprendizaje, y si bien deja algunas opciones abiertas a la decisión de los docentes, éstas se limitan a la implementación y están acotadas. 


\section{CAPÍTULO VII:}

\section{DESARROLLOS LOCALES DE DIDÁCTICA Y CURRICULUM}

Estudiamos a continuación las siguientes obras (por orden cronológico):

- BARCO, Susana. (1975). “AAntididáctica o nueva didáctica? (capítulo VII)". Illich, Ivan; Barreiro, Telma; Barbosa Faría, Regina; Barco de Surghi, Susana; Filloux, Jean; Antebi, Mirtha et al. Crisis en la didáctica (1a. ed., Vol. $2^{\circ}$ parte, pp. 93-125). Argentina: Axis, Revista de Ciencias de la Educación. 1973.

- EDELSTEIN, Gloria, y RODRÍGUEZ, Azucena. (1974). “El método: factor definitorio y unificador de la instrumentación didáctica". Revista de Ciencias de la Educación, (Año IV, N²12), 21-33.

- AVOLIO, Susana. (1975). La tarea docente. Buenos Aires: Marymar.

El propósito es analizar estos tres trabajos para identificar los aportes a la construcción de una línea de pensamiento local sobre la didáctica y el curriculum, más allá de las diferencias que presentan en cuanto a las perspectivas disciplinarias que desarrollan las autoras y a los formatos en los que se publicaron sus ideas. A pesar de estas diferencias, nos interesa especialmente analizar qué temáticas se desarrollan, desde qué perspectivas se abordan, cómo se concibe el carácter normativo de las teorías didáctica y curricular, etc.

\section{VII - 1 - Caracterización de las obras.}

Comenzamos este apartado con el análisis del trabajo “ ¿Antididáctica o nueva didáctica?" escrito por Barco. Se trata de un texto que originalmente fue publicado como artículo en 1973 en la Revista de Ciencias de la Educación, dirigida por Juan Carlos Tedesco, y luego, en 1975, formó parte del libro Crisis en la 
didáctica. En esta misma Revista se publicó en 1974 el trabajo de Edelstein y Rodríguez ${ }^{174}$.

La autora comienza el artículo sistematizando algunas definiciones de didáctica que aparecen en textos de Nérici, Stöcker, Larroyo e Ibarra Pérez, y concluye que se trata de una didáctica instrumental, despojada del tratamiento de los fines -los cuales se reservan para ser definidos en el marco de la filosofía de la educación-175, y concentrada en el aprendizaje de los estudiantes -y no en la enseñanza.

Así entendida, la didáctica se convierte en una teoría de carácter instrumental que brinda al docente los medios necesarios para manejar, con distintos grados de directividad, el aprendizaje de los alumnos. La relación entre la enseñanza y el aprendizaje y la relación entre el docente y el alumno son caracterizadas como "[...] verticalista[s] y autoritaria $[\mathrm{s}][\ldots]$ ". (p.96).

Según Barco, estas connotaciones verticalistas y autoritarias de la relación docente-alumno se mantienen a pesar de la introducción de algunos cambios en el ámbito educativo, que generan algunas modificaciones superficiales pero no logran modificar sustancialmente aquella relación.

El diagnóstico del estado de la educación la lleva a Barco a decir que es necesario "[...] un cuestionamiento de la totalidad de formas vigentes [...]" (p.98) en la institución escolar, del que debe participar activamente toda la comunidad educativa. Los cambios que se requieren no se realizarán, según expresa la autora, por imposición burocrática pero tampoco desde la improvisación. Los

\footnotetext{
${ }^{174}$ Además de la relevancia que le asignan los encuestados a los trabajos de Barco y de Edelstein y Rodríguez, como vimos en el capítulo IV, Furlán (en Furlán y Avolio, 2011) destaca ambas publicaciones aparecidas originalmente en la Revista de Ciencias de la Educación como indicativas de los temas relevantes que estructuraban los debates del campo pedagógico a principios de los años '70 en la Argentina y significativas, por tanto, para su propia formación.

Específicamente con respecto a la Revista de Ciencias de la Educación, Furlán dice que la misma se distribuía en todo el país "[...] donde hubiera pedagogos sedientos de aires polémicos [...]" (p.59).

${ }^{175}$ Esta característica de la época es también resaltada por Barco (2008).

Asimismo, podemos afirmar que es un tema abordado por diferentes autores al analizar críticamente las características de la influencia del tecnicismo en la educación en general, y en la didáctica y el curriculum en particular. Podemos pensar aquí que el análisis que realiza la autora la lleva a acercar una didáctica instrumental a una didáctica tecnicista.

Principalmente nos apoyamos en los siguientes autores: Barco (1989); Becker Soares (1985); Martínez Bonafé (2004); Davini (1996); Feldman (2008), para el caso de la didáctica. Para el curriculum, Stenhouse (1991); Grundy (1994); Salinas Fernández (1997). Para las características más generales de la teoría educativa positivista, nos basamos en Carr y Kemmis (1988).
} 
cambios demandan el compromiso de los docentes, alumnos, directivos y padres, movilizados y cuestionando los roles y formas de relación consuetudinariamente asignados.

La institución escolar, el sistema educativo y la sociedad se encuentran en relación y al servicio de la concreción de un proyecto de país. Desde la perspectiva crítica en la que la autora se posiciona, sostiene que la escuela en un país capitalista dependiente como el nuestro ha servido a los intereses de la burguesía. Es así que la relación docente-alumno, así como también diferentes aspectos que configuran la misma, se hallan teñidos por el verticalismo, el autoritarismo y la dominación. "[...] Depende del proyecto del país que el pueblo elija y que decida realizar, y al cual se subordina lógicamente, ya que el sistema educativo colabora en la concreción de un tipo de hombre determinado [...]" (p.101).

Con respecto a los contenidos, Barco plantea que la crítica más frecuente es la que apunta al enciclopedismo ${ }^{176}$, pero que también se puede analizar la carga ideológica que los mismos portan. Por otra parte, la autora realiza una fuerte crítica de la evaluación en la escuela en tanto práctica en la que se evidencia el ejercicio del poder; comienza analizando la relación docentealumno en la evaluación, la relación entre el saber y el poder, las connotaciones familiares y sociales de las calificaciones, etc. En el análisis de estos aspectos, como en los anteriores del trabajo de la autora, también se realiza una articulación de lo micro con lo macro, buscando contextualizar social y políticamente lo que acontece en el aula de clases y en la escuela.

Teniendo en cuenta el contexto de dependencia de nuestro país con respecto a aquellos más desarrollados, Barco plantea que la didáctica como disciplina también ha caído presa de la dependencia: la didáctica no ha tenido un desarrollo local profuso y las obras publicadas son extranjeras. Esta situación le lleva a preguntarse por la validez de estas publicaciones para

\footnotetext{
${ }^{176}$ Suponemos que Barco comparte las críticas al sistema educativo que expusimos en el capítulo II a partir del trabajo de Zoppi y Aguerrondo (1991). Recordamos que las autoras mencionan que hasta los años '60 la escuela en nuestro país presentaba un carácter formalista, memorístico, verbalista y enciclopedista. En ambos trabajos se menciona que a pesar de las renovaciones pedagógicas que se proponen a fines de los '60, algunas características centrales de la escolaridad no se modifican. Parece que la lógica escolar o "la forma de lo escolar" (remitimos especialmente a Baquero, Diker y Frigerio, 2007) se presenta con una fuerza que no es fácil modificar.
} 
resolver los problemas locales de la educación y dar respuesta a las reales necesidades educativas del país.

A su vez, Barco postula que estas obras de didáctica extranjeras responden a las necesidades de sus propios contextos de producción, países que ella califica como "imperialistas centrales" (p.113). En este sentido, la producción académica y cultural en general constituye el brazo ideológico de la dominación económica y contribuye a generar pseudonecesidades que se estiman adecuadas para los consumidores de los países colonizados. Esto no hacen más que permitir el mantenimiento de la dominación económica de los países centrales.

“[...] ¿Cómo se propagandiza un texto de didáctica en el medio? [...] Se lo hace a través de personas o entes educacionales que gozan de "prestigio", que son quienes lo recomiendan o los que se encargan de promocionar su lectura a través de la implementación de determinadas técnicas, métodos o ideas, en el sistema educativo [...]" (p.113).

En este sentido, la autora critica la instrucción programada, las pruebas objetivas y las taxonomías de objetivos (especialmente la de Bloom), como líneas de penetración ideológica promovidas por los países centrales, especialmente por Estados Unidos.

Todos los casos están en vinculación con lo que hemos denominado perspectiva tecnicista en educación, que supone, entre otras cuestiones, que es posible predecir los resultados del aprendizaje de los alumnos, que conocerlos y establecerlos con claridad desde el principio garantiza el éxito del proceso y que a su vez su cumplimiento se convierte en indicador de la calidad de la educación, por mencionar algunos de los aspectos centrales criticados por Barco como elementos de penetración ideológica. A su vez, cabe aclarar que estos elementos brindan información sobre el sistema educativo y el nivel de aprobación y acatamiento de los lineamientos difundidos por la bibliografía y propuestas internacionales.

Frente a esta particular construcción de la disciplina, Barco elabora una propuesta que considera superadora de las críticas y limitaciones tratadas. Esta 
propuesta sería una "antididáctica"177, si por didáctica se entiende la anteriormente criticada, o una nueva didáctica -disyuntiva que ya aparece desde el título del trabajo.

“[...] Poniendo en práctica una didáctica contestataria, concientizadora, estimuladora del espíritu crítico y creador, una antididáctica respecto de la anterior. En este sentido puede aceptarse la propuesta de la investigación como antididáctica, fundamentalmente por todo lo que de cambio de actitudes implica. Recién cuando el nuevo orden socioeconómico se concrete, podrá hablarse de una didáctica auténticamente nueva, cuyas modalidades y características no es posible dar hoy, salvo en rasgos generales que hacen más a los fines de la educación en una sociedad socialista que apuntan a la concepción de un hombre nuevo. La práctica educativa misma, la investigación sobre ella, irán delineando el modo de operar de la didáctica, que lo hará o no en un ámbito escolar (de estar con los que afirman que la escuela ha muerto) [...]" (p.121. La negrita figura en la edición consultada).

En la cita precedente se pone en evidencia que la construcción de una didáctica nueva, opuesta a la didáctica criticada líneas más arriba, conlleva la construcción de un nuevo orden sociopolítico, idea que se reitera en diferentes fragmentos apelando a algunas nociones apoyadas en la concepción marxista del cambio social.

Por otra parte, en aspectos estrictamente didácticos, la nueva didáctica debe revisar profundamente el carácter de la relación docente-alumno. La autora propone una relación más recíproca, de trabajo conjunto, de aprendizaje mutuo. Se apunta a que el alumno tenga una participación activa en el diseño, desarrollo y evaluación de las prácticas de enseñanza y de aprendizaje.

\footnotetext{
${ }^{177}$ Cuando Barco habla de "antididáctica" cita en una nota al pie de página la siguiente obra, como si retomara de este autor italiano algunas ideas: Bartolomeis, Francesco. La ricerca come antipedagogia. Feltrinelli, 1972. Al parecer, Bartolomeis realiza una serie de propuestas renovadoras de la escuela, asentado en los principios de la escuela activa, proponiendo entre otras cuestiones la investigación y las prácticas de laboratorios en todas las áreas o disciplinas que se enseñan y se aprenden en la escuela. Podemos suponer que se abre en esta perspectiva una oposición a la escuela enciclopedista, tradicional, también cuestionada por Barco en su trabajo. En este sentido, la "antididáctica" y la "antipedagogía" pueden interpretarse como movimientos en oposición a una disciplina hegemónica.

Queda por indagar si la denominación que utiliza Barco -“antididáctica"- puede tener algún vínculo con la "antipsiquiatría" como movimiento heterogéneo liderado por David Cooper e iniciado en 1967 (Vainer, 2000), o con la "antinovela" expresión atribuida a Sartre y equiparada con la antipsiquiatría por Mannoni (2000). Puede analizarse si estas expresiones no son parte de un clima de época que recupera el estado de crisis mundial que se genera desde fines de 1960. Llama la atención el hecho de que en todos los casos con el prefijo "anti" se está enfatizando la oposición a la forma hegemónica que ha adquirido la disciplina, el género literario o las prácticas sociales frente a las que se explicita la oposición.
} 
Para Barco el docente también tiene que adoptar un lugar activo y crítico con respecto a las prescripciones curriculares. En este sentido propone que junto a los estudiantes genere condiciones para convertir el aula en un espacio de experimentación pedagógico-didáctica.

En la presentación y defensa de una nueva propuesta para la didáctica, Barco destina también un apartado al tratamiento del contenido escolar y a las características que debe poseer en coherencia con el planteo disciplinar. Parte de la definición de los contenidos como aquellos conocimientos de la realidad que los estudiantes deben adquirir en la escuela. No obstante, se cuestiona, seguidamente, la "[...] extraña manera de "conocer" algo de lo cual, la escuela, está prolijamente aislada tras sus muros [...]" (p.105). Los contenidos que circulan en la escuela se presentan de manera recortada, aislada del contexto de producción científico o del contexto social en el cual adquieren sentido con el resto de los saberes que hacen a la comprensión y actuación en la vida cotidiana.

Para la autora, los contenidos reciben diversas críticas. Las más frecuentes los tildan de enciclopédicos; para el caso de las ciencias sociales se puede mencionar, además, que poseen una fuerte carga ideológica, impiden una lectura crítica del mundo, están descontextualizados y faltos de los procesos de investigación que les dieron origen. Para el caso de las ciencias exactas y naturales, la autora plantea que en algunas instituciones se realizan experimentos aislados, sobre un modelo dado, en los que los estudiantes aprenden a utilizar El método científico y adquieren una concepción de Ciencia pura, objetiva y que se realiza en los laboratorios.

En este contexto, Barco destaca que no está permitido interrogarse por el valor, uso y aplicación social de los conocimientos científicos, y que el alumno queda en una posición de recepción y repetición absoluta y acrítica de lo que aprende en la escuela, fragmentándose él mismo tanto como lo están los contenidos que aprende.

La propuesta superadora se delinea por el lado de la apertura de la escuela al contexto. Parafraseando a la autora, la escuela debería romper su aislamiento e integrarse al medio socio-cultural de una manera efectiva. 
En el artículo analizado aparece, junto a la exploración de los contenidos, un tratamiento particular de la evaluación y de los fines de la educación. Para el caso de estos últimos, Barco expone que en el planteo tecnicista la didáctica no se ocupa de la definición de los fines y objetivos de la educación.

Además, al hablar de los contenidos escolares, Barco aborda implícitamente otros componentes de los procesos de enseñanza y de aprendizaje. Por ejemplo, al criticar el tratamiento que los contenidos reciben en la didáctica tecnicista cuestiona las formas de enseñar y aprender dichos contenidos. Pero no aparecen explícitamente criterios sobre la selección y secuenciación de los contenidos en el curriculum.

No obstante, cuando Barco postula que la escuela debe integrarse al contexto sociocultural, romper las barreras que la separan de la sociedad en la que se inserta, lo con el fin de superar las críticas que previamente elabora sobre cómo aparecen los contenidos escolares en la didáctica tecnicista. Esta propuesta, a ser efectivizada por la nueva didáctica, busca mayor vinculación entre el afuera y el adentro de la institución educativa. Asimismo, se puede pensar que esta apertura permite priorizar determinados contenidos escolares y nuevas modalidades de enseñanza, como vemos más profundamente en el próximo apartado.

El trabajo de Edelstein y Rodríguez denominado "El método: factor definitorio y unificador de la instrumentación didáctica", reubica como una preocupación central de la didáctica la cuestión de lo metodológico.

Inicialmente, las autoras plantean que en su artículo se van a dedicar “[...] al problema del método178 y sus implicancias en el aprendizaje escolar, tema

\footnotetext{
178 "Lo metodológico" así como también la tensión "forma-contenido" es una preocupación constante en los trabajos de Edelstein. En un trabajo con Litwin, las autoras ponen de manifiesto la tendencia a olvidar la cuestión de las estrategias metodológicas al estudiar el curriculum universitario. "....La justificada preocupación por los contenidos, marca definitoria de las propuestas curriculares, lleva en muchos casos a olvidar que la forma es también contenido y que las vías o modos propuestos para la circulación o construcción de conocimientos permiten ciertos desarrollos y no otros. Las estrategias metodológicas operando como uno de los factores decisivos en el pasaje del curriculum prescripto al curriculum real se constituyen en general, en el caso de la currícula universitaria, en zonas de incertidumbre que abren intersticios a las propuestas innovadoras, razón por la que entendemos que se debieran plantear como una necesaria dimensión de análisis" (Edelstein y Litwin, 1993, p.80).
} 
fundamental para la Didáctica [...]" (p.21). A pesar de ser un tema del que se ocupa la didáctica desde su surgimiento, para las autoras, en el momento de la publicación del trabajo, el método se encuentra confinado al olvido o recibiendo un tratamiento parcial.

Edelstein y Rodríguez conciben la didáctica como una disciplina que implica tres niveles: 1- teórico; 2- técnico; 3- instrumental. A su vez, debe poseer una etapa crítica pero sin quedarse en ella, sino que en la

“[...] elaboración-producción [...] es fundamental que las alternativas que ofrezca la Didáctica para la transformación de la tarea educativa, tengan en cuenta las posibilidades de aplicación a una situación concreta, determinando cómo se puede pautar el proceso o definir etapas, previendo formas de transición [...]" (p.22).

Para Edelstein y Rodríguez el olvido en el tratamiento del método en la literatura didáctica tiene sus causas en dos líneas que vienen abordando el tema de manera deficitaria: la formal y la instrumental.

Como ejemplo del tratamiento formal del método, las autoras citan el trabajo de Schmieder, Didáctica General. Plantean que se realiza un abordaje confuso del método y que no permite obtener orientaciones para la práctica, tornándose inoperante para resolver situaciones concretas. Este tratamiento formal se asienta, por un lado, en la lógica y, por el otro, evidencia una faz psicológica, en tanto Schmieder plantea que debe apoyarse en el conocimiento del espíritu infantil.

La vertiente que realiza un tratamiento instrumental179 del método pretende, según exponen Edelstein y Rodríguez, “[...] encontrar formas metódicas, técnicas y procedimientos didácticos que resuelvan de manera eficiente y económica la conducción de determinadas fases del proceso de aprendizaje [...]" (p.24). Las autoras toman como exponentes de esta vertiente a Alves de Mattos, Nérici y Stöcker; a los fines de esta tesis, repararemos especialmente en el análisis que realizan de la concepción de Nérici.

\footnotetext{
${ }^{179}$ En un trabajo más reciente, Edelstein (1996) incluye la irrupción de la Tecnología Educativa como una corriente instrumentalista que obstaculizó la reflexión en torno al método y a la metodología, enfatizando casi exclusivamente la utilización de técnicas en la resolución de los problemas de enseñanza y de aprendizaje.

Se puede consultar también: Díaz Barriga (1991).
} 
Expresan Edelstein y Rodríguez que la concepción instrumental sólo repara en aspectos parciales del método, desgajados de los procesos de aprendizaje y de pensamiento. Hay una relación explícita entre los procedimientos, las técnicas y los recursos, y los objetivos que se desean alcanzar.

"[...] Si bien Nérici formula observaciones correctas al concebir el método como elemento unificador de otras formas más específicas a través de las cuales se concretiza, la dicotomía entre pensamiento real y quehacer metódico subsiste. El método es, asimismo, la disciplina "impuesta al pensamiento y a las acciones" para obtener mayor eficiencia en lo que se desea realizar $[\ldots]^{\prime \prime}$ (p.25).

Según analizan las autoras, para Nérici la cuestión metódica aparece como una respuesta al "cómo enseñar", que se formulan los docentes, al tener que poner en contacto a los alumnos con el contenido. El método no aparece como una articulación previa a la clase, en el momento de la planificación de la misma, organizando la búsqueda de contenidos y bibliografía dentro de la disciplina de referencia. Hay una separación entre la planificación y la acción en la clase. "[...] En consecuencia, en la clase se dan respuestas metódicas parciales derivadas de los emergentes situacionales del grupo, sin contextualizarse en la consideración global del proceso de aprendizaje [...]" (p.26).

Desde esta crítica, las autoras emprenden la construcción de un marco conceptual-referencial que compense o fortalezca las debilidades que presenta el enfoque instrumental del método. Así, desde la explicitación de su posicionamiento en el materialismo dialéctico, asientan la importancia de construir un método en articulación con el objeto de estudio.

El método general, para las autoras, debe ser el método dialéctico, que esté en consonancia con el desarrollo continuo de la realidad. Los métodos particulares mantienen una relación con la lógica general pero se van conformando en articulación con las particularidades de los procesos indagados.

Por su parte, la construcción de una metodología es conceptualizada como una instancia previa a la instrumentación de los métodos generales y/o 
específicos. En este sentido, “[...] implica una traducción de los principios generales, leyes y categorías aportados por el método en respuestas integradas a una situación dada y para ciertos y precisos objetivos [...]" (p.27).

El método dialéctico constituye ese conjunto de principios y fundamentos que da sustento al método general. Sus movimientos fundamentales son análisis y síntesis, que aparecen en un proceso de investigación pero también en la enseñanza.

A continuación, Edelstein y Rodríguez aluden a un problema que cobra actualidad tanto para la enseñanza como para el curriculum. Adoptando el método dialéctico y concibiendo que el punto de partida para el conocimiento es “[...] una práctica concreta sobre la realidad objetiva [...]" (p.29), el aprendizaje que se realiza en la escuela debe ser real, debe partir de una situación aparentemente problemática cuya resolución lleve al aprendizaje de los contenidos.

Esta afirmación para caracterizar cómo debe ser el aprendizaje escolar presenta algunas dificultades. En primer lugar, los contenidos se prescriben primero y luego se generan las situaciones problemáticas para que los estudiantes se pongan en relación con ellos. En este sentido, las situaciones problemáticas portan una cuota de situaciones inventadas. En segundo lugar, las auténticas situaciones problemáticas son posibles de diseñar teniendo en cuenta la interacción del sujeto con su contexto histórico y social. Cuestión que aún hoy sigue siendo difícil de resolver en la escuela considerando que desde sus inicios se trata de una institución que transmite un saber descontextualizado de sus contextos de producción y que demanda posteriormente un proceso de recontextualización para ser utilizado en la sociedad 180 .

“[Los procedimientos, técnicas y recursos son los] componentes operacionales del método; y al reconocer que éste no es observable sólo puede inferirse a través de la utilización que de dichos componentes se hace [...]" (p.29). La

\footnotetext{
180 Diferentes autores dan sustento a esta afirmación, entre ellos: Lundgren (1992); Basabe, Cols y Feeney (2004); Basabe y Cols (2007).
} 
metodología así entendida permite articular los principios y fundamentos en los que se sustenta, una forma particular de poner a los estudiantes en contacto con los contenidos seleccionados curricularmente, considerando ciertas intencionalidades, y habilitando al mismo tiempo, formas particulares de relación entre docente y alumno.

Edelstein y Rodríguez plantean que la planificación es un "proyecto de acción", y que su concreción o efectivización queda sujeta a la coherencia que el mismo guarde con la relación docente-alumno que se establezca. Esta relación tiñe todos los componentes que integran el plan. El alumno tiene un rol activo en la construcción del conocimiento, su relación sujeto-objeto de conocimiento es dialéctica y debe tener una participación compartida con el docente en la planificación de la enseñanza.

Por último, la evaluación aparece como un elemento fundamental, asignándole al plan un carácter dinámico, en evaluación y revisión permanente, permitiendo mejorar el proceso. A su vez, la evaluación permite que los criterios para la elaboración del plan surjan de las situaciones concretas, no apriorísticamente.

Por su parte, el trabajo de Avolio que analizamos (La tarea docente, publicado en 1975 en Buenos Aires por Ediciones Marymar) puede considerarse -según se desprende de lo planteado en el capítulo II de esta tesis-como uno de los primeros textos sobre curriculum que se produjeron en nuestro país.

La autora plantea en la introducción que en el texto se abordan las actividades y los aspectos teóricos y de fundamentos implicados en dicha tarea. Asimismo, adelanta que la obra sirve de base para estudiar posteriormente el planeamiento, la conducción y la evaluación del aprendizaje, que se convirtieron luego en ejes de otras publicaciones ${ }^{181}$.

\footnotetext{
${ }^{181}$ Las publicaciones posteriores a las que se refiere son: 1- Conducción del aprendizaje publicada en 1977; 2- Planeamiento del proceso de enseñanza-aprendizaje de 1985; y 3- Evaluación del proceso enseñanza-aprendizaje de 1987. Los tres trabajos fueron escritos por la autora y publicados por Ediciones Marymar.

En una comunicación personal el 16 de mayo de 2013, Susana Avolio me informó que los títulos de los libros de la colección "El maestro en su acción cotidiana", responden a una perspectiva tecnológico-
} 
“[... ] En el desarrollo del libro se enfocará la tarea docente desde el punto de vista de la tarea en el aula, en la relación docente-alumno, centrándose en la función de enseñar más que en la de orientar. Se desarrollarán aspectos técnicos que guiarán al docente en su tarea concreta y al mismo tiempo se analizarán los conceptos y principios que le sirven de fundamento" (p.10).

El libro está integrado por un prólogo, una introducción, el desarrollo de cinco (5) capítulos, el índice, y abarca un total de ciento cuarenta y seis (146) páginas. Cada capítulo presenta: 1- una breve introducción y 2- los objetivos que "los docentes serán capaces de" manejar, dominar, conocer, al final de la lectura del mismo; 3- el desarrollo de los núcleos temáticos seleccionados; 4- las conclusiones; 5- las actividades; 6- la encuesta para la autoevaluación; y 7- la bibliografía general.

Avolio comienza su trabajo abordando conceptualmente la educación, como forma de contextualizar la tarea docente. Esta perspectiva de abordaje de se define desde la introducción, en la que la autora plantea que las finalidades de la tarea docente no son sólo la enseñanza sino también y principalmente la educación de los hombres. La tarea docente se realiza en un contexto áulico, institucional y social.

Recuperando la etimología del vocablo "educación", la autora recuerda que deriva de dos verbos latinos, a saber: "educare" y "ex ducere". Esta referencia le permite explicar un complejo movimiento que se da entre la sociedad y la educación, involucrando los procesos de socialización e individuación. Menciona la necesaria cuota de reproducción social que porta la educación, cuando transfiere a las jóvenes generaciones los elementos culturales disponibles, pero también destaca la transformación de la sociedad a partir del aporte que pueden los hombres realizar a ella.

conductista que había invadido el área en aquellos años. No obstante, sus esfuerzos se concentraron en la construcción de un marco conceptual-referencial sólido (con autores como Freire y Lafourcade) que le permitiera fundamentar las orientaciones hacia la práctica. Asimismo, reconoce que este ejercicio de fundamentación teórica tiene en parte sus antecedentes en la formación realizada como ayudante en las cátedras de "Didáctica" primero y "Pedagogía” después, ésta última a cargo de Ethel Manganiello, en la Facultad de Filosofía y Letras de la Universidad de Buenos Aires.

Algunos de estos datos aparecen también desarrollados en Furlán y Avolio (2011). 
Avolio presenta la concepción de educación permanente, como educación durante toda la vida y que, por tanto, va más allá de la escuela. Asimismo, para la autora la educación parte de un estado actual, de un ser en particular, y tiende a alcanzar un deber ser, un estado de situación al cual se espera llegar.

Con respecto a los fines de la educación, Avolio plantea que éstos responden a una determinada concepción de hombre que se sostiene como valiosa en una sociedad, en un momento histórico particular. El ideal de hombre que se desea formar puede variar según el contexto social, histórico, político, cultural, etc.

Estos fines educativos, para la autora, son fijados por aquellos organismos oficiales que establecen la política educativa, que se integra a la política nacional en un proyecto de país y que no debería desconocer, para el caso particular de Argentina, su integración Latinoamericana. La filosofía y la investigación de la realidad son las fuentes a partir de las cuales estos fines se definen. Para la autora, la filosofía aporta elementos para formular la concepción de hombre que se desea formar y la investigación de la realidad brinda información sobre las características y necesidades de la sociedad actual.

Por otra parte, la autora plantea que a pesar del aumento de la matrícula o de la cobertura de los sistemas educativos latinoamericanos, no se ha logrado un aumento parejo de la calidad de la oferta. Afirma que el desafío de los países de la región pasa por lograr que los sistemas educativos respondan a sus características y necesidades.

Seguidamente confirma esta aserción cuando se separa de las teorías desescolarizantes, reiterando la apuesta a la escuela y la necesidad de producir un cambio cualitativo que mejore sustancialmente la educación.

Para Avolio, este cambio cualitativo comienza por el replanteo de los fines. "[...] Primero es necesario determinar el tipo de hombre que se desea formar, luego se seleccionarán los medios, que serán eficaces o no, en la medida que tiendan al logro del fin $[\ldots]^{\prime \prime}$ (p.26). Si bien el cambio debe ser promovido por el Estado y 
los organismos encargados de gestionar los sistemas educativos, el compromiso y la participación de los docentes es indispensable.

Por otro lado, y habiendo realizado esta contextualización, Avolio focaliza su atención en la acción docente.

“[...] Se realizará un enfoque tecnológico de la acción docente, entendiendo por tecnología educativa el estudio de la manera sistemática de enseñar, de acuerdo con objetivos específicos y basados en investigaciones, cuyos resultados se emplean para hacer más efectivo el proceso [...]" (p.34).

La autora alude a una serie de principios que guían la acción docente. Entendemos que estos principios pueden ser enunciados por los docentes, por los investigadores o por la propia didáctica, pero más allá de quién los formule, interesa destacar sus vinculaciones con la práctica educativa y con la teoría de la educación.

En este sentido, los principios que pretenden guiar la práctica educativa no pueden tener un carácter general sino que deben tener en cuenta ciertas condiciones y circunstancias particulares. La autora plantea que estos principios pueden ser adecuados a diferentes situaciones particulares.

Según Avolio, hay otra cuestión a tener en cuenta al hablar de principios que guían la acción docente y es la relativa a la ausencia de una teoría general de la educación que "[...] oriente la investigación y ayude a interpretar los resultados de la aplicación de muchos principios [...]" (p.34).

Por otra parte, define la enseñanza de la siguiente manera:

“La enseñanza es la serie de actos que realiza el docente con el propósito de crear condiciones que le den a los alumnos la posibilidad de aprender, es decir, de vivir experiencias que le permitan adquirir nuevas conductas o modificar las existentes [...]" (p.36).

Esta concepción de enseñanza, opuesta al directivismo, es coherente con las características que deben poseer los fines de la educación. Además, pone a la enseñanza en íntima relación con la acción educativa más amplia. Para la autora ambos procesos están en relación y articulación, variando uno respecto del otro en cuanto a la amplitud de las finalidades que persigue. En este sentido, mientras que la acción educativa busca el alcance de ese ideal de hombre antes 
definido y la formación integral de la persona, la enseñanza pretende alcanzar objetivos en coherencia con lo anterior, pero más acotados y parciales.

Por otro lado, con respecto a las relaciones entre enseñanza y aprendizaje, Avolio plantea:

“[...] Enseñar es estimular, conducir y evaluar permanentemente el proceso de aprendizaje que realizan los alumnos. Enseñanza y aprendizaje son interdependientes y en realidad integran un solo proceso, que sólo se puede separar en un análisis teórico.

En el proceso de enseñanza-aprendizaje, docentes y alumnos cumplen funciones diferenciadas e integradas [...]" (p.37).

Para la enseñanza es fundamental conocer las condiciones internas y externas que hacen posible el aprendizaje, para poder adecuarse a ellas en función de las finalidades a lograr.

“[...] Se entiende por situación de aprendizaje un conjunto estructurado de elementos que, en cierto momento y lugar, determinan el contexto en el que se desarrolla el proceso de enseñanza-aprendizaje [...]" (p.40).

La situación de enseñanza-aprendizaje, desde un punto de vista descriptivo, involucra una serie de elementos (contenidos, técnicas, actividades, recursos, etc.) que se conjugan con la intención de lograr los resultados de aprendizaje que se desea. Esta situación involucra tres procesos: el de aprendizaje que centraliza el alumno; el de enseñanza que conduce el docente; y el de comunicación didáctica que se da entre ambos.

El docente posee un lugar destacado, por un lado, en el diseño, implementación, conducción y evaluación de toda la situación de enseñanzaaprendizaje para lograr que los alumnos alcancen los objetivos previstos; y por el otro, en la selección y estructuración del contenido de la comunicación didáctica y en el llevar adelante dicha comunicación.

Asimismo, la planificación de las situaciones de aprendizaje requiere, en primera instancia, determinar los objetivos en términos de los resultados de aprendizaje que deben lograr los alumnos. En segundo lugar, es necesario “[...] determinar la estructura de aprendizaje estableciendo una secuencia en los resultados a lograr [...]" (p.43). Como tercer paso, en la planificación del aprendizaje hay que determinar las condiciones externas, a saber, los contenidos, actividades, 
recursos, etc., todos seleccionados y organizados en coherencia con aquellos aprendizajes que se desea alcanzar. Por último, es necesario distribuir en el tiempo todos estos elementos seleccionados. "[...] En sintesis, todo el plan responde a tres preguntas: ¿Qué se debe lograr? ¿Cómo se lo va a lograr? ¿Cuándo se lo va a lograr? [...]" (p.44).

$\mathrm{Al}$ tratarse de complejos procesos de toma de decisiones, en cada una de estas fases se sopesan alternativas posibles, se escoge aquella que se considera más apropiada en función de determinados criterios y también se evalúa permanentemente la puesta en práctica de dicha alternativa.

Con respecto al aprendizaje, Avolio expone que su conocimiento es fundamental para lograr una enseñanza eficaz. Todo aprendizaje implica un cambio relativamente permanente en el sujeto que aprende. El cambio puede ser de conducta, conocimientos, capacidad, potencialidad para las respuestas, etc. "[...] El aprendizaje es el proceso por el cual el alumno, sobre la base de su propia actividad y con el estímulo de agentes externos, logra modificaciones en su conducta [...]" (p.65). La enseñanza se produce de manera sistemática para producir un cambio en el alumno.

Por otra parte, Avolio alude a los resultados del aprendizaje. Sostiene que éstos pueden ser clasificados en tres dominios: cognoscitivo, psicomotriz y volitivo-afectivo.

A su vez, más allá de las diferencias involucradas en los distintos tipos de aprendizaje, la autora plantea que hay una serie de elementos comunes a todas las situaciones de aprendizaje. En todos los casos, el alumno se involucra en la situación de aprendizaje con motivaciones y capacidades previas, se le presentan condiciones externas o estímulos y están presentes también los resultados de aprendizaje que se espera que alcance, sean de cualquiera de los tres dominios antes mencionados.

Por último, Avolio destina un capítulo a estudiar "La tarea docente y el currículo". Este "nuevo término" se incluye como involucrado en la tarea del docente, y lo consideramos importante porque se trata de un texto nacional clásico sobre didáctica general que evidencia la inclusión de la teoría curricular 
en nuestro país por parte de esta disciplina, reconociendo que con anterioridad el término curriculum no se utilizaba y sí, en cambio, se usaban las expresiones "programas" y "planes de estudio".

La autora define al curriculum como "[...] el conjunto de experiencias de aprendizaje realizadas por los alumnos bajo la dirección de la escuela, y los recursos que ésta utiliza para promover dichas experiencias y alcanzar los objetivos derivados del fin de la educación" (p.117). Asimismo, el curriculum es conceptualizado como el medio que se despliega para transformar la educación y adaptarla a las demandas sociales.

El curriculum así entendido, según expone Avolio, abarca los diferentes niveles de especificación curricular. Desde el nivel más amplio o macro-político, donde se definen los Lineamientos o Bases Curriculares; hasta el nivel más concreto del aula donde el curriculum se corresponde con el programa de una asignatura y el docente lo emplea para guiar el aprendizaje de sus alumnos.

Para la "elaboración y desarrollo del currículo", Avolio propone la existencia de un Comité, a nivel nacional, que persiga el cambio del curriculum para el mejoramiento de la educación. Este Comité debe estar integrado por especialistas de la educación y de las diferentes disciplinas que se enseñan en las escuelas, y por docentes que se desempeñan en el sistema educativo maestros, directivos, inspectores, etc. Este Comité, a su vez, debe contar con escuelas experimentales que le permitan poner a prueba los cambios realizados. Además, la capacitación docente es un aspecto que la autora resalta como relevante para implementar los cambios en el curriculum.

En este planteo, aparece una instancia a nivel nacional que se encarga de la coordinación y de la planificación para todo el sistema educativo.

El planeamiento del curriculum se refiere a aquel "[...] proceso por el cual se establecen los objetivos que los alumnos deberán lograr y se elabora el diseño curricular, es decir, se seleccionan y organizan los contenidos y actividades de aprendizaje que se realizarán para lograr dichos objetivos [...]" (p.125). 
El planeamiento así entendido se basa en diferentes factores. Aludiendo a estudios de la época, Avolio destaca principalmente tres: las disciplinas que integran el curriculum, factores psicológicos y factores filosófico-políticos.

Como síntesis de esta instancia de planeamiento, la autora menciona una secuencia de acciones que se realizan. Éstas son:

1) Consideración de los factores filosóficos, políticos, psicológicos, sociales y relacionados con las disciplinas.

2) Formulación de objetivos de Sistema, Nivel, Ciclo, Modalidad.

3) Selección de las disciplinas en función de los objetivos.

4) Determinación de una estructura organizativa.

5) Determinación del alcance de cada disciplina, es decir cuáles serán los contenidos y procesos a incluir en cada grado o curso.

6) Determinación de la secuencia de contenidos dentro de cada grado, dentro del nivel y en relación con otros niveles.

7) Elaboración de criterios para la enseñanza y evaluación de cada disciplina.

8) Elaboración de guías para el maestro, explicando los fundamentos y las normas para aplicar el currículo. El objetivo de las guías es ayudar a interpretar, ejecutar, evaluar y mejorar el currículo, guiar a los docentes para organizar y desarrollar las experiencias de aprendizaje (pp.130-131).

A esta instancia de planeamiento, le sigue la puesta en marcha. Entran a jugar aquí aquellas escuelas experimentales ya mencionadas, en las que se implementará el curriculum diseñado y en función de sus resultados se procederá luego a la implementación generalizada en todo el sistema educativo.

Por último, en el proceso de elaboración y desarrollo del curriculum, Avolio menciona su evaluación. Ésta comprende la valoración permanente de todos los componentes, los sujetos, la institución, etc., involucrados en el curriculum, y su mejoramiento es la finalidad principal. 


\section{VII - 2 - Análisis de las obras: la aparición de algunos emergentes que permiten caracterizar el desarrollo local de la didáctica y el curriculum.}

VII - 2 - a-Carácter de la norma en una teoría normativa.

Con respecto al trabajo de Barco, “¿Antididáctica o nueva didáctica?”, podemos decir que la perspectiva crítica de análisis que adopta la autora la lleva a mirar el aula inserta en su contexto institucional y social amplio. Se trata de una perspectiva de carácter macro que permanentemente mira lo contextual. En este sentido, la crítica de la autora apunta a las características autoritarias, de dominación y dependencia que caracterizan tanto la estructura de la sociedad como del sistema educativo ${ }^{182}$.

Aún pudiendo utilizar diferentes criterios en la instrumentalización del proceso de enseñanza y de aprendizaje, los docentes no lo hacen por quedar atrapados en un verticalismo que los trasciende. Esta condición sólo puede ser superada por una didáctica crítico-propositiva, asentada en una perspectiva que le permita tensionar lo micro y lo macro superando las auto-comprensiones locales sesgadas ideológicamente (Kemmis, 1993; Grundy, 1994).

En el diagnóstico estructural que realiza la autora, el docente se caracteriza por poseer un rol de técnico que busca una eficaz aplicación de los medios para alcanzar los objetivos de aprendizaje. Este lugar de actuación docente se condice en términos disciplinarios con el carácter de disciplina aplicada que se configura para la didáctica. Por un lado, Barco afirma que la didáctica adquiere de esta manera "[...] pretensiones de asepsia, de no compromiso o incontaminación [...]" (p.97. La negrita figura en la edición consultada); por otro lado, la didáctica es una disciplina aplicada cuando la

\footnotetext{
182 Orozco Fuentes (2009) reconoce que este texto de Barco marca un giro en la conformación del pensamiento didáctico de la época. Para esta autora y también para Díaz Barriga (1991), el texto de Barco se convirtió en el primer análisis que vinculaba lo didáctico con lo político. Con anterioridad a esta publicación, según estos referentes, en didáctica no se pensaba en las relaciones que las formas de enseñar o el trabajo en el aula tenían con un determinado proyecto político.

Si bien Orozco Fuentes reconoce que estos planteos están muy aceptados en la actualidad, en la época en la que Barco publicó su artículo, esto se convirtió en una novedad y en un inicio de una pedagogía latinoamericana que comenzaba a surgir con el impulso de la obra de Freire.
} 
autora alude a la recepción de categorías, teorías y problemáticas importadas de países centrales hegemónicos que trasladadas al nuestro no contribuyen a la real solución de los problemas.

Barco realiza una propuesta tanto para el cambio de las prácticas educativas como de la didáctica que se va construyendo en las antípodas de aquella realidad criticada. Para el primer caso plantea que los contenidos, la relación docente-alumno, la evaluación, etc., deben ser democráticos. Para el segundo caso, la nueva didáctica o la anti-didáctica debe configurarse como una disciplina portadora de características diferentes a las que posee la disciplina hegemónica. Como vemos en el próximo apartado, es básicamente su posicionamiento teórico crítico el que le aporta una mirada de análisis macro e informa su construcción normativa acerca de cómo debe ser la teoría didáctica. A diferencia de la perspectiva autoritaria, su propuesta democrática y democratizadora deja amplios márgenes para el trabajo por parte del docente.

En el artículo de Edelstein y Rodríguez, “El método: factor definitorio y unificador de la instrumentación didáctica", y en comparación con el trabajo de Barco, podemos decir que la construcción de una normatividad didáctica avanza un paso más en su concreción. En este trabajo, el método, la crítica a la visión instrumental y la propuesta de un método dialéctico para la enseñanza parecen delinear una normativa acerca de cómo debe ser tratada la cuestión metodológica en la enseñanza. No obstante, el método pierde su carácter prescriptivo y su diseño pone en tensión otros componentes de la enseñanza.

En la crítica a la visión instrumental y universalista del método de la enseñanza, se va delineando una nueva forma de pensar lo metodológico. Coherente con este planteo y con otros más actuales de las mismas autoras ${ }^{183}$, no se dice cómo enseñar tal o cual contenido, sino que la normativa se configura

\footnotetext{
183 Podemos enfatizar aquí que la categoría "construcción metodológica" (Edelstein, 1996; 2011) sintetiza por un lado el carácter mencionado para lo metodológico y, por el otro, el lugar del docente en esa construcción. Es el docente el que construye una metodología acorde para la enseñanza de determinados contenidos, para sujetos particulares, en un contexto específico y con ciertas intencionalidades.

Para complementar el rol fundamental del docente en la construcción de la enseñanza, se puede profundizar en la categoría "configuraciones didácticas" de Litwin (1997) y en los "estilos de enseñanza" de (Cols, 2011).
} 
en decir qué aspectos de la enseñanza debe tener en cuenta la configuración de lo metodológico, como por ejemplo, el contenido, el alumno, el contexto, etc.

A partir de este planteo queda un paso más de concreción por parte del docente, o en el diálogo entre el docente y el didacta, para formular métodos y técnicas específicos para determinadas situaciones de enseñanza.

Por último, en el libro La tarea docente de Avolio hay algunos elementos que permiten también analizar el carácter de la normatividad didáctica. En vinculación con lo expuesto por Gimeno Sacristán (1998) a propósito de que el ser y el deber ser forman parte de la educación, podemos decir que en Avolio también aparece la cuestión de la normatividad como parte integrante de la educación. Según la autora, la educación parte de un estado actual, de un ser en particular, y tiende a alcanzar un deber ser, un estado de situación al cual se espera llegar. En ese estado futuro hay una combinación de elementos normativos y utópicos, en términos del análisis de Gimeno Sacristán (1978). Se presenta una interrelación permanente entre la escuela y la sociedad, y entre la enseñanza y la educación.

Por otra parte, si bien para Avolio el cambio debe ser promovido por el Estado y los organismos encargados de gestionar los sistemas educativos, el compromiso y la participación de los docentes es indispensable, tanto en las instancias macro, como por ejemplo, en el "Comité de curriculum", como en las instancias micro. La autora va configurando en torno a "la tarea docente" un espacio de realización o de autonomía.

Recordamos que en el capítulo II de esta tesis citamos el trabajo de Palamidessi y Feldman (2003), quienes sostienen que las primeras obras nacionales sobre curriculum se caracterizaron, entre otras cuestiones, por fomentar una división del trabajo pedagógico entre los diseñadores del curriculum y los docentes que debían llevarlo a la práctica. El análisis que estamos desarrollando del texto de Avolio nos lleva a poner en tensión dicha afirmación teniendo en cuenta, como expusimos, el lugar que la autora conceptualiza para el docente. Consideramos que no se evidencia dicha separación sino que por el contrario el docente está incluido en el diseño 
curricular. A su vez, su lugar en la concreción curricular demanda un accionar profesional.

Asimismo, Avolio propone la existencia de escuelas experimentales para ir poniendo a prueba los cambios producidos en el curriculum. Aquí aparece una concepción del cambio que demanda un diseño, una puesta a prueba, un ajuste, etc. Es decir, el cambio no se planifica desde las instancias centrales y se implementa sin previo ajuste a la práctica. En el próximo capítulo, al analizar el trabajo de Stenhouse (1991), encontramos algunos puntos de contacto con esta propuesta.

Con respecto al lugar que consideramos que Avolio le asigna al docente en la puesta en marcha del curriculum, podemos agregar que éste es el responsable de concretarlo en las aulas y darle más especificación a los lineamientos curriculares recibidos de las instancias centrales de diseño. Asimismo, la autora contempla la generación de adecuados canales de comunicación para que la opinión de los docentes llegue a quienes se ocupan del diseño, provocando así un mejoramiento continuo. "[...] es importante que el docente conozca y comprenda los conceptos relacionados con currículo y al mismo tiempo tome conciencia del papel fundamental que le cabe en el análisis crítico y mejoramiento del mismo" (p.143).

Asimismo, dicho espacio de realización se configura al diseñar y llevar adelante la enseñanza. Avolio le asigna al docente un lugar relevante en conocer las condiciones internas del aprendizaje, conocer cómo el mismo se lleva a cabo y diseñar qué se debe hacer desde la enseñanza para alcanzar los resultados previstos. Todas estas actividades implican procesos complejos de toma de decisiones permanentes.

Por otro lado, la autora reconoce que en la elaboración del curriculum se le asigna importancia a los especialistas en las diferentes disciplinas que se enseñan en la escuela, a las necesidades e intereses del niño con los aportes que se reciben de la psicología evolutiva y a los factores filosófico-políticos que entienden el curriculum en sus vinculaciones con la política educativa de un país. 
Se puede decir que las dos primeras consideraciones son similares al planteo que realiza Tyler. En cuanto al tercer aspecto, mientras Avolio alude a factores filosófico-políticos, Tyler es más genérico y habla de las necesidades de la sociedad contemporánea. Esta cuestión no está ausente en Avolio, pero su trabajo es más contextual y agrega elementos de la política educativa y nacional del país para conformar el curriculum.

Se puede decir que aparece aquello que Palamidessi y Feldman (2003) caracterizan como un intento de resignificar los aportes de las obras curriculares norteamericanas a la realidad de nuestro sistema educativo argentino, buscando una posibilidad de mejoramiento.

VII - 2 - b-Aspectos que constituyen la norma.

En las obras analizadas de Barco y de Edelstein y Rodríguez se visualiza la incorporación de teorías críticas para la fundamentación del planteo teórico. En el caso de Barco éstas se recuperan para analizar la tensión entre el aula, la escuela y la sociedad ${ }^{184}$; y en el caso de Edelstein y Rodríguez se retoma el método dialéctico y se lo adecua a la enseñanza.

Además de estas categorías teóricas que las autoras resignifican de campos no estrictamente didácticos, es de destacar que en los dos trabajos se destaca la importancia del contenido a enseñar. Se empieza a reconocer el “contenido" como categoría didáctica ya en los años '70, que estaba olvidado o descuidado, previo a lo que se conoce como "Pedagogía de los contenidos", que en nuestro país aparece con más fuerza en la década del '80, y al desarrollo de las didácticas especiales por contenido que son las que lo reponen en el triángulo didáctico (Poggi, 1997; Feldman, 2008).

\footnotetext{
${ }^{184}$ El trabajo que estamos tomando de Barco acentúa el carácter analítico de la didáctica, reforzado con el acervo conceptual crítico, aunque no deja de lado la normatividad, como planteamos. No obstante, en textos posteriores, la misma autora avanza en una perspectiva más intervencionista. Por ejemplo, Barco (1989) plantea que la didáctica debe intervenir en la enseñanza, debe generar un espacio de diálogo permanente con el docente, como sujeto protagonista de la enseñanza, para construir un conocimiento didáctico que se corra de las prescripciones tecnicistas y proponga mejoras concretas. Barco (1996), por su parte, da cuenta de una propuesta concreta de intervención no tecnicista, sino claramente participativa en la modificación de un curriculum universitario.
} 
Para Barco, el contenido y la forma de enseñarlo y aprenderlo se encuentran condicionadas por factores políticos y sociales. Por su parte, Edelstein y Rodríguez plantean la importancia que tiene la especificidad del contenido en la construcción del método. Es decir, en términos de lo que estamos aquí planteando, podemos decir que entra otro aspecto a considerar en la construcción de la normatividad y que tampoco proviene estrictamente de la didáctica, dada la diversidad de contenidos que se comunican en la enseñanza.

A su vez, podemos mencionar que para la construcción de la norma aparecen en ambos trabajos factores vinculados al momento interactivo de la enseñanza o, lo que sería lo mismo, a la puesta en marcha de la enseñanza en el aula.

En el caso del trabajo de Edelstein y Rodríguez, a esta consideración se suman las indicaciones acerca de cómo se debe construir el método, el momento preactivo. En la crítica que las autoras realizan al tratamiento instrumental del método aparece precisamente la idea de que esta perspectiva no toma la construcción de lo metodológico desde la planificación de la enseñanza.

Por su parte, en el trabajo de Avolio se destacan las relaciones que el aula y la escuela mantienen con la sociedad en la que está inserta. Al igual que en otros textos de didáctica de la época, como en el de Nérici que analizamos en el capítulo V, se explicita la conciencia de las articulaciones que la educación escolar mantiene con el contexto social y cultural más amplio.

Además, en vinculación con lo planteado en el capítulo I de esta tesis, consideramos que los fines de la educación o este ideal de hombre que se espera alcanzar, se configura como un aspecto que conforma la norma didáctica.

A su vez, Avolio explicita que los fines de la educación están definidos por la política educativa que se integra, al mismo tiempo, a la política nacional en un proyecto de país. Además del proceso de contextualización de la enseñanza escolar que ya mencionamos, aparece aquí un aspecto propio de la política curricular. La definición de curriculum que plantea de Alba (1995), que tanto ha enriquecido el campo, al menos en el contexto Latinoamericano, explica que el curriculum forma parte de una propuesta político-educativa; no 
de política partidaria sino vinculada a la direccionalidad que se le desea dar al rumbo de un país.

Por otra parte, en el trabajo de Avolio aparece una suerte de diagnóstico de la educación de la época. Un diagnóstico crítico de la educación también está presente en Barco, como vimos precedentemente ( $\mathrm{y}$ en Chadwick, que analizamos en el capítulo VI de esta tesis). El análisis crítico del estado de la educación es el que permite fundamentar la necesidad de realizar un cambio que se condiga con las características de la sociedad de la época.

Según el trabajo de Avolio este cambio está acompañado por los cambios que pueden llegarse a producir en el curriculum. La teoría curricular norteamericana lleva en sus orígenes esta marca de la crítica al sistema educativo vigente y la necesidad de un cambio (Camilloni, 2001).

La definición de los fines de la educación, así como también de los objetivos de la enseñanza y del aprendizaje, ocupa un lugar importante en este plano más general y en el momento de planificar la enseñanza. La autora expone que la pregunta “iqué se debe lograr?” representa el primer paso en el establecimiento de la propuesta de enseñanza y del planeamiento del curriculum.

Por otra parte, entre los aspectos que constituyen la norma didáctica, podemos mencionar aquéllos de carácter ideológico y teórico que integran su marco conceptual-referencial. A su vez, aparece una consideración interesante en torno a factores generales y otros particulares que deben formar parte de la normatividad. En la conformación del marco conceptual-referencial, además de los aspectos mencionados, ocupan un lugar relevante las teorías del aprendizaje. Al igual que en otros textos de didáctica, en el trabajo de Avolio se presenta una caracterización del aprendizaje como un proceso que se produce en el alumno y que es necesario conocer para luego poder pensar, diseñar y llevar a cabo las acciones de enseñanza. En este punto, la autora utiliza los aportes de Gagné para identificar “ocho tipos de aprendizaje"185, y a su vez

\footnotetext{
185 Recordamos que estos tipos son: 1- aprendizaje por reacción ante una señal; 2- por estímulorespuesta; 3- por encadenamiento motor; 4- por asociación verbal; 5- por discriminación múltiple; 6- de
} 
alude a una serie de principios que caracterizan el aprendizaje y que son materia de acuerdo entre diferentes teorías.

A pesar de las diferencias que han podido establecer las diferentes teorías psicológicas acerca del aprendizaje, sus tipos, procesos, características, etc., existe un conjunto de principios que generan acuerdo entre las diferentes escuelas y que pueden ser considerados como una base para el trabajo del docente ${ }^{186}$.

Por otra parte, ya pensando en la "tarea docente" más específicamente, junto con el saber didáctico se encuentra un análisis de la acción docente, para dar cuenta de sus procesos, conceptos y principios que la orientan. Aparece aquí una suerte de indagación empírica o al menos análisis de la experiencia, que aporta elementos para la construcción del saber didáctico.

A su vez, en este trabajo se visualiza la influencia de la tecnología educativa, en auge en Estados Unidos, y que también llega a nuestro país en estos años, como ya mencionamos en el capítulo anterior. Para Avolio, el enfoque tecnológico permite realizar un estudio de las formas de enseñar. Agrega la autora que la investigación ocupa un lugar importante al aportar resultados en los que basar los objetivos de la enseñanza y con los que también es posible otorgar efectividad al proceso.

Pero como vemos en el último cruce, la autora demanda la existencia de una teoría de la educación amplia que contribuya con el análisis de los resultados que arroja la investigación. Cuestión teórica más amplia que también consideramos se integra en la constitución de la norma didáctica.

Por otra parte, podemos recuperar para el análisis la definición de enseñanza que postula la autora. Como expusimos anteriormente, la enseñanza se define en la consecución del aprendizaje, o más aún, “[...] Enseñanza y

conceptos; 7- de principios y 8- de resolución de problemas. Estos tipos de aprendizaje están ordenados jerárquicamente de manera tal que el aprendizaje de los tipos superiores implica los de tipos inferiores.

${ }^{186}$ A modo de ejemplo se pueden citar dos (2) principios mencionados por la autora: "[...] La conducta es el resultado de la interrelación de dos factores: un organismo y la situación estimulante. El individuo interviene en la situación con sus necesidades, motivos, actitudes, aptitudes, intereses, aspiraciones, fines, valores, experiencias previas. Elige de la situación las cosas que tienen sentido y significado para él, y luego responde [...] La práctica de las respuestas es necesaria para adquirir nuevas conductas, la repetición de la conducta adquirida es necesaria para su fijación y para evitar el olvido [...]” (p.82). 
aprendizaje son interdependientes y en realidad integran un solo proceso, que sólo se puede separar en un análisis teórico [...]" (p.37). Definido el aprendizaje como la producción de cambios en el alumno, la enseñanza se diseña y se pone en marcha para la consecución de estos cambios.

Como hemos visto en capítulos precedentes, siguiendo a autores como Fenstermacher (1989), podemos decir que entre la enseñanza y el aprendizaje hay una relación ontológica y no causal. De esta manera, la definición de enseñanza adquiere sentido y mantiene una ligazón con el aprendizaje, pero se conceptualizan como procesos separados aunque interdependientes. Parece que esta idea no encuentra contradicciones en la obra de Avolio, no obstante, todavía en ella la ligazón entre la enseñanza y el aprendizaje es mayor o más cercana que lo que la didáctica conceptualiza en la actualidad. Se puede decir que el uso de la expresión "proceso de enseñanza-aprendizaje" por parte de la autora es indicativo de esta situación.

VII - $2-c-$ Presencia de aspectos normativos e interpretativos.

En el texto de Barco interpretamos que se configura una didáctica con un amplio caudal explicativo. Teniendo en cuenta lo que plantea Bolívar Botia (1999) para estudiar la corriente crítica en el campo del curriculum, consideramos que el trabajo de Barco es más bien en una "plataforma de análisis" de la realidad escolar del momento que en una propuesta concreta de intervención de la didáctica para el mejoramiento de la enseñanza.

En este sentido, su propuesta se ubica más en un momento descriptivo/interpretativo. Como vimos precedentemente, la autora realiza una lectura crítica de la sociedad y de la educación a principio de los años '70, evidenciando categorías propias de las teorías críticas que comenzaban a aflorar en otras partes del mundo. Si bien en esa época predominaba un momento más prescriptivo en la constitución de la didáctica en Argentina, consideramos que el trabajo de Barco puede interpretarse como en el inicio de un esfuerzo explicativo que se expande posteriormente en la década ' 80 . 
Asimismo, el trabajo de Barco evidencia un desdibujamiento del componente normativo en la didáctica, tal como lo plantea Davini (1996), propio de un momento explicativo influido por lenguajes interpretativos y comprensivos provenientes de otras teorías educativas y sociales. Como dijimos, consideramos que aparecen elementos normativos, pero generales y más afines a una teorización pedagógica, si aceptamos como ya dijimos al principio de esta tesis, que la didáctica posee un mayor acercamiento a la enseñanza.

La propuesta superadora que construye Barco se ubica en las antípodas de la didáctica tecnicista. En algunos pasajes del texto se pone de manifiesto que la autora adhiere a una concepción marxista del cambio social, que demanda un cambio radical de la estructura económica para que luego se produzca la conformación de una nueva superestructura, en la que se ubica la educación y la "didáctica auténticamente nueva" (p.121).

A diferencia de otros trabajos que están posicionados también en la didáctica, pero con la mirada más puesta en el aula y en la enseñanza, como puede ser el caso de las otras obras cuyo análisis integra este capítulo, el texto de Barco evidencia la prioridad asignada a la mirada analítica y contextual, antes que a la veta instrumental (aunque no en el sentido criticado por Edelstein y Rodríguez). Consideramos que cuando la autora enuncia la antididáctica o la nueva didáctica aparecen líneas propositivas acerca de qué características deben tener las prácticas de enseñanza, el vínculo docente-alumno o los contenidos de la educación, pero estas propuestas quedan enunciadas con cierto nivel de generalidad, restando avanzar en aspectos más concretos acerca de cómo pueden sustanciarse en el aula y con los docentes.

Por otro lado, podemos decir que el desarrollo del artículo es coherente con una didáctica crítico-propositiva, cuyas características centrales son: 1análisis crítico y elaboración de propuestas superadoras de acción; 2reconocimiento de la dimensión político-ideológica que atraviesa necesariamente la totalidad de las acciones humanas; 3 - un proyecto educativo indefectiblemente unido al proyecto de país que el pueblo elija; 4- una 
disciplina y textos que respondan a las necesidades reales de la situación de nuestro país; 5- "[...] una didáctica contestataria, concientizadora, estimuladora del espíritu crítico y creador [...]" (p.121) que contribuya desde el aula a la concreción de un proceso revolucionario.

Por su parte, las obras de Edelstein y Rodríguez y de Avolio representan trabajos más cercanos a un momento normativo/prescriptivo, teniendo en cuenta que avanzan en propuestas normativas cercanas a las prácticas de enseñanza. Como fundamentamos, al posicionarse en un punto más cercano a la enseñanza para construir sus planteos teóricos, encuentran más posibilidades de concretizar sus propuestas, sin desconocer que es el docente el que finalmente tiene que tomar decisiones para llevarlas a cabo.

Podemos arriesgar que Edelstein y Rodríguez se ubican "más cerca del aula", en un punto que analizan diferentes formas de tratar el cómo enseñar, lo que parece contribuir a la emergencia de la cuestión normativa. No dejan de lado estas autoras cuestiones más teóricas, como por ejemplo las referidas a la dialéctica que da sustento a la propuesta metodológica que enuncian, pero tampoco descuidan el avance normativo sobre cómo debe ser el método de la enseñanza desde el posicionamiento que explicitan.

Finalmente, con respecto al texto de Avolio, también se produce una articulación de aspectos normativo/prescriptivos y descriptivo/interpretativos, sobre todo en el recorrido que traza al buscar explicaciones a los aspectos complejos comprendidos en la tarea docente, y luego delineando orientaciones acerca de cómo debe llevarse a cabo la misma.

VII - 2 - d - Disponibilidad de saberes interdisciplinarios para la conformación de una teoría didáctica.

En el artículo de Barco y en el de Edelstein y Rodríguez consideramos que se pone en evidencia la utilización de saberes interdisciplinarios para la reflexión sobre la propia disciplina. 
Como mencionamos previamente, Barco se posiciona en la teoría crítica de raíz frankfurtiana para concebir la nueva didáctica; mientras que Edelstein y Rodríguez asientan su concepción de lo metodológico en el método dialéctico. En ambos casos, parece que se realiza el "rulo reflexivo" que ya hemos caracterizado, partiendo de la didáctica como disciplina de base, atravesando otros saberes disciplinarios y retomando a la didáctica con una mirada enriquecida. La presencia de saberes interdisciplinarios se visualiza en la conformación de una nueva matriz disciplinar y no tanto en la elaboración de normas para las prácticas de enseñanza.

Por otro lado, consideramos que la referencia a saberes interdisciplinarios para realizar una reflexión -en este caso- sobre la cuestión metodológica, se visualiza en el texto de Edelstein y Rodríguez cuando critican el tratamiento instrumental del método que realizan algunos autores, entre ellos, Nérici.

En este sentido, y tomando los aportes de Díaz Barriga (1991), podemos decir que la crítica al tratamiento instrumental del método sostiene que los autores que entran en este grupo no realizan una profundización conceptual de las cuestiones metodológicas.

Si bien estas críticas, en las que coinciden tanto Díaz Barriga como Edelstein y Rodríguez, engloban a Nérici y a Stöcker (1964), por mencionar algunos autores de la didáctica, el instrumentalismo es más exacerbado en autores como aquéllos incluidos en la tecnología educativa, como puede ser el caso de Chadwick.

Otra característica de la visión instrumental del método, según plantea específicamente Díaz Barriga (1991) y que se evidencia con más claridad en la tecnología educativa, se refiere a la consideración de la enseñanza como un problema técnico que se resuelve con un conjunto de técnicas didácticas que van normando la tarea del docente en el aula.

Según expresa Díaz Barriga, la tecnología educativa se presenta como parte del proyecto ideológico-político que tiene Estados Unidos para América Latina. 
“[...] Esta visión instrumental de la cuestión metodológica se caracteriza por reproducir tres tipos de problemáticas: a) La negación de una discusión sobre los problemas del conocimiento (o en ocasiones la deformación de este aspecto); b) La formulación de una propuesta técnica, que se abstrae de las condiciones específicas en las que se realiza el proceso de aprendizaje ("abstracción" que se hace tanto de la realidad objetiva de docentes y alumnos, como de los elementos internos de una disciplina en particular, o de su constitución epistemológica), lo cual lleva a realizar la propuesta técnica como una propuesta universal (todo es factible de ser enseñado y aprendido a través de ella); y c) La manera simplista y reduccionista de percibir el aspecto didáctico desde posiciones conceptuales muy diversas, lo cual constituye una manifestación del conocimiento específico del debate didáctico (en este caso del conocimiento didáctico, como un conocimiento disciplinar específico) [...]" (Díaz Barriga, 1991, p.83).

A su vez, Díaz Barriga y Barco coinciden en que la visión instrumental en la didáctica condujo a un estado anquilosado de la disciplina. Según los autores, el tratamiento etimológico que estos textos de didáctica realizan del método, su estudio desde la lógica o la consideración psicológica del estudiante, no hacen más que desviarse del tratamiento sustantivo.

En la crítica a la visión instrumental del método, surge como un aspecto fuerte la tensión forma-contenido. Según el análisis que realiza Díaz Barriga, las visiones instrumentalistas "[...] niegan que la resolución de la metodología parta del estudio de la estructura interna de la disciplina [...]" (1991, p.87).

No obstante, este reconocimiento de la consideración indispensable del contenido en el momento de pensar el cómo enseñar, ha producido algunas posturas que niegan, paralelamente, la posibilidad de pensar en el método como categoría de la didáctica general. Como dijimos, puede ampliarse esta tensión entre la didáctica general y las didácticas especializadas en campos de conocimientos con autores como Davini (1996) o Feldman (2008).

Por su parte, en el trabajo de Avolio, si bien no aparecen explícitamente desarrollados saberes epistemológicos que contribuyan a la realización de una reflexión de segundo orden en la didáctica, sí se expone una definición de esta disciplina, sus límites, su objeto de estudio, sus preocupaciones centrales, sus relaciones con otras disciplinas, etc. $\mathrm{Y}$ estas cuestiones tienen un carácter epistemológico en tanto tienden a dar cuenta de la constitución disciplinar de la didáctica. 
VII - 2 - e - Teorías de alcance intermedio o teorías cercanas a la práctica.

En los trabajos de Barco y de Edelstein y Rodríguez la cercanía a la práctica está presente pero de manera diferente. En el primero hay una mirada más amplia que en el segundo y esto contribuye, como dijimos, a un mayor acercamiento del segundo a lo normativo. No obstante, no podemos desconocer la referencialidad explícita de las dos producciones a las prácticas de enseñanza.

Ambos trabajos, pensados desde el campo de la didáctica y construidos en la reflexión de una nueva mirada sobre la disciplina, en oposición al tecnicismo reinante en la época, aluden permanentemente a las prácticas de enseñanza, a cómo son y a cómo deben ser desde un posicionamiento teóricoepistemológico alternativo.

Por otro lado, en el libro de Avolio también visualizamos la conformación de una teoría cercana a la práctica; parafraseando a la autora podemos decir que la didáctica es una teoría próxima a la tarea docente. Podemos suponer que es en esta cercanía en la que se construye el valor instrumental que el libro aporta para que el docente lleve a cabo la enseñanza.

Además, es de destacar -como sucede con otros textos de didáctica que mencionamos en el capítulo II- que Avolio destina un capítulo de su libro a contextualizar la tarea docente en los procesos educativos más amplios y la didáctica en la pedagogía como disciplina abarcadora. Se reclama también la existencia de una teoría general de la educación que oriente las investigaciones y que ayude a interpretar los resultados de la misma y de la aplicación de los principios didácticos.

En lo que respecta a este cruce, podemos decir que en La tarea docente aparece la formulación de un saber didáctico que se intenta articular entre las prácticas de enseñanza -cómo son, qué conceptos y principios las orientan, etc.y las teorías educativas más amplias que contribuyen a la interpretación de esa misma realidad. 
En este sentido, podemos arriesgar que la consideración de la tecnología educativa para el estudio de la práctica de enseñanza, una perspectiva más eficientista, que impacta en nuestro país a fines de los años '60, como vimos en el capítulo II, contrasta con la construcción de un saber didáctico que integra la enseñanza a la educación, la escuela a la sociedad, la didáctica a la pedagogía como teoría educativa más abarcadora. Posiblemente podamos interpretar, entonces, este trabajo de Avolio como un ejemplo de la manera en la que se van resignificando los aportes teóricos que ingresan al país en el marco de la producción didáctica local ya existente. 


\section{CAPÍTULO VIII:}

\section{LA EMERGENCIA DE LA PERSPECTIVA PRÁCTICA EN EL CURRICULUM Y SU IMPACTO EN LA DIDÁCTICA}

Estudiamos a continuación las siguientes obras (por orden cronológico):

- SCHWAB, Joseph J. (1974). Un enfoque práctico para la planificación del currículo. Buenos Aires: El ateneo.

- STENHOUSE, Lawrence. (1991). Investigación y desarrollo del curriculum (3a. ed.). Madrid: Morata. 1984.

Como expusimos en el capítulo IV nos dedicamos al análisis de estos dos trabajos como representantes de la perspectiva práctica que se desarrolla en el curriculum y que tiene impacto en la didáctica.

Los aportes teóricos y prácticos de Schwab se convirtieron, desde finales de los años '50, en centrales para esta disciplina y como referentes de la oposición de la racionalidad tecnicista. Stenhouse, por su parte, profundizó esta línea de corte filosófico en la reflexión curricular y concretó un diseño curricular asentado en supuestos contrarios a los del modelo de objetivos.

Ambos autores se difundieron e impactaron en Argentina con posterioridad al regreso de la democracia en la década del '80. Abrieron perspectivas de análisis novedosas tanto en la didáctica como en el curriculum.

Cabe recordar que el trabajo de Schwab se conoció en nuestro país a principio de los años '70. Su publicación en español es de 1974, un año después que la obra de Tyler. No obstante, el clima de la época y los años posteriores, con la dictadura y sus reformas educativas, no fueron propicios para su reconocimiento. 


\section{VIII - 1 - Caracterización de las obras seleccionadas.}

El trabajo de Schwab, Un enfoque práctico para la planificación del currículo, cuyo título original es The Practical: a Language for Curriculum, fue publicado en Washington en 1970. La exposición de la tesis central del autor se realizó en febrero de 1969 en la convención anual de la American Educational Research Association (AERA). Luego se le pidió que la amplíe para una publicación, que es la que conocemos.

Es aquí interesante destacar que este trabajo de Schwab forma parte de un informe más amplio denominado Schools for the 70's - and Beyond, llevado a cabo por la National Education Association's Center for the Study of Instruction (CSI). Según da a conocer Lois Edinger, el Presidente de la Comisión Asesora del CSI, quien escribe el prefacio del trabajo de Schwab que analizamos, este informe amplio pretende promover formas alternativas de resolver los problemas de la enseñanza y del aprendizaje.

"Schools for the 70's tiene tres partes: un informe y un programa de acción comprensivos; [...] una serie preliminar de publicaciones de autores renombrados que tratan los temas más importantes, y una serie auxiliar de tres volúmenes, dirigida principalmente a los especialistas en currículos e investigadores de todos los niveles de la enseñanza" (p.V).

El trabajo de Schwab que analizamos se corresponde con un volumen de esta serie auxiliar.

Por su parte, Camilloni agrega:

“...Schwab trabajó varios años en la elaboración de cinco trabajos sobre el currículo de los que "Lo práctico..." fue el primero. En el segundo artículo demuestra la necesidad de combinar de manera ecléctica las diferentes teorías en un curso de psicología de la educación. En el tercero se propone presentar la mejor constitución y las funciones que debe desarrollar el grupo de diseño curricular. En el cuarto artículo presta especial atención al rol institucional del especialista en curriculum como coordinador del grupo encargado del diseño curricular y en el quinto, muestra cómo enseñar los ejes y puntos centrales de la disciplina a través de enfoques alternativos de narrativa literaria" (2006, p.15).

Un enfoque práctico... se trata de un trabajo relativamente breve (37 páginas) y en el que, como se adelanta en el prefacio, priman las afirmaciones 
polémicas. Tal es así que es considerada una obra clave para pensar la teoría curricular tanto como la conformación de la metateoría del curriculum, como vemos más adelante, especialmente a partir del análisis que realiza Kemmis (1990; 1993).

“La aportación particular de Schwab en The Practical, fue distinguir entre el modo práctico de razonar requerido para resolver cuestiones de currículo, y el modo técnico de razonar utilizado en la aplicación de los conocimientos teóricos derivados de las disciplinas «fundamentales» a las que la educación, con excesiva presteza, pedía consejo sobre cuestiones de currículo con las que se enfrentan los educadores todos los días [...]" (Kemmis, 1990, p.25. La cursiva figura en la edición consultada).

El trabajo de Schwab se divide principalmente en dos partes, una denominada "Tesis y sinopsis" y otra llamada "Argumento y corolarios".

Entre las aserciones polémicas que caracterizan el trabajo, en la primera oración del libro el autor dice "[...] el campo del currículo está moribundo [...]" (p.1). Expone que partirá de tres afirmaciones, la mencionada se constituye en la primera y aclara que responde a que el campo del curriculum es incapaz de contribuir al progreso de la educación con sus principios y métodos actuales. Se necesitan nuevos principios para poseer una nueva visión de la educación; y nuevos métodos para estudiar los nuevos problemas.

La segunda afirmación establece que se ha llegado a esta situación porque se posee una confianza no cuestionada en la teoría. Esta afirmación se sustenta en la adopción por parte del campo del curriculum de teorías ajenas a la educación y su utilización como principios teóricos de los cuales deducir objetivos y procedimientos para las escuelas y las aulas.

La tercera afirmación postula que es posible lograr un renacimiento del campo del curriculum siempre y cuando las energías que hasta el momento se depositaron en la modalidad teórica se reorienten hacia tres nuevos modos de acción: práctico, cuasi-práctico y ecléctico.

La modalidad teórica que predominaba en el curriculum, criticada por Schwab, se dedicaba a la construcción de modelos comprensivos, explicaciones 
generales, principios globales, etc. Esta modalidad es la que puede ser denominada también como perspectiva técnica o de ciencia aplicada ${ }^{187}$.

En contraposición, la modalidad práctica de acción que el autor propone busca actuar en diferentes situaciones prácticas y decidir rumbos de acción posibles en ellas. Los problemas, visualizados en la diferencia entre lo real y lo deseable, y sus soluciones, son construcciones que llevan a cabo los sujetos involucrados en las situaciones. El método que propone Schwab para la realización de este trabajo es la deliberación.

La segunda de las modalidades de acción mencionadas por el autor se denomina cuasi-práctica y es muy similar a la práctica. La diferencia radica, principalmente, en "[...] una extensión de los métodos y propósitos prácticos a asuntos de creciente variedad interna. Esta variedad creciente hace cada vez más difícil ser eficazmente prácticos [...]" (p.5. El subrayado figura en cursiva en la edición consultada). Al aumentar la variedad de casos involucrados, se enfrentan mayores dificultades, entre ellas, el ejercicio correcto de la prudencia.

En educación nos encontramos con casos de gran heterogeneidad, pero también de dependencia mutua u orgánica, lo que impide adoptar una decisión en un aula o en una escuela sin que afecte también a otra aula o a otra escuela. En este sentido, las decisiones y las acciones propias de la modalidad cuasipráctica deben contemplar una serie de consideraciones a ser tenidas en cuenta por cada uno de los miembros del conjunto heterogéneo, como una especie de lineamientos generales (Schwab se encarga de remarcar que no se trata de directrices), que puedan ser usados en los casos particulares, adaptándose a las circunstancias específicas.

Por último, la modalidad ecléctica recupera la importancia de la teoría para interpretar y actuar frente a los problemas prácticos. Si bien las distintas teorías poseen un carácter fragmentario y parcial cuando enfocan sus respectivos objetos de estudio, la complementariedad de las diferentes perspectivas enriquece el análisis y la acción.

\footnotetext{
187 "[...] Schwab etiquetaba como "teórico" -lo que nosotros manteniendo el uso de Aristóteles, [sic] hemos denominado como "técnico" [...]" (Kemmis, 1993, p.63).
} 
La segunda parte del libro de Schwab se denomina "Argumento y corolarios" y está dedicada a argumentar a favor de las ideas expuestas previamente de manera sintética.

Schwab sostiene que la crisis por la que está atravesando el campo del curriculum no es independiente de lo que les sucede a otros campos de la actividad científica. Todos ellos, dice, atraviesan por cierta cantidad de crisis. Analiza seis procesos que denomina "huidas del campo" en las ciencias en general para luego ver y analizar cómo esas huidas se dan también en el campo curricular. Abordamos a continuación sólo aquellas "huidas" que tienen presencia en el curriculum.

La primera, que considera la más importante, es la huida del campo mismo, depositando en personajes que se encuentran fuera de éste los problemas y la búsqueda de soluciones. Esta huida se ve reflejada en la importante contribución de los especialistas de las disciplinas en la elaboración de curricula, dejando a los expertos de educación y de curriculum en un lugar de menor relevancia.

La segunda tiene un carácter ascendente, según el cual, Schwab entiende que se pasa "[...] del uso de principios y métodos, a las conversaciones acerca de ellos [...]" (p.16. El subrayado figura en cursiva en la edición consultada). En lugar de una concentración en el campo del curriculum y en sus problemas, esta huida representa aquel ejercicio de buscar explicaciones teóricas y metateóricas que siempre vayan un paso más allá. Esta huida frecuente lleva a los especialistas a buscar otros expertos que puedan solucionar los problemas propios. "[...] la única labor de los expertos en currículos es observar el trabajo de los otros expertos con la esperanza de encontrar las reglas o leyes de sus operaciones" (p.19) ${ }^{188}$.

Otra huida que tiene una presencia notable en el campo del curriculum, como expresa el autor, representa aquella forma de actividad por la cual los

\footnotetext{
${ }^{188}$ Recuperando las primeras dos huidas que Schwab destaca para el campo del curriculum, Davini analiza la evolución de la didáctica y sostiene que se produce una fuga hacia: "[...] la construcción de lo que daremos en llamar "megateorías" en el campo de la didáctica general, comprometidas con un discurso interpretativo que pretende reunir el abanico de producciones científicas en un marco global comprensivo, con la consecuente pérdida de producción de "reglas de acción" [...]" (1996, p.54).
} 
especialistas se convierten en comentaristas, analistas, estudiosos, de las contribuciones que otros realizaron a la disciplina.

Por su parte, "la perseverancia" es otra de las huidas que tiene una presencia importante en el curriculum. En este caso, Schwab dice que hay una revisión permanente de los trabajos ya familiares de la disciplina, que no aporta cuestiones sustancialmente novedosas, sino que reitera conceptos conocidos o introduce nuevos conceptos para designar procesos habituales.

La última huida se evidencia en el aumento de discusiones y debates que no contribuyen directamente al avance de las ideas sino que en la mayoría de los casos se dirigen contra las personas.

Según expone Schwab, estas huidas del campo mismo dan cuenta de una crisis de principios que el autor intenta superar con su posicionamiento en la modalidad práctica alternativa. La misma resulta pertinente, según defiende el autor, para actuar y construir teoría curricular sobre principios diferentes a los aportados por la modalidad teórica.

En este sentido, Schwab avanza en cuatro facetas de la modalidad práctica, a saber:

1- Cambio progresivo del curriculum: siempre hay que algo que cambia y algo que permanece. El estudio empírico de lo que pasa en las instituciones educativas es fundamental y permite evaluar los cambios necesarios, las posibilidades y su viabilidad manteniendo la coherencia de la estructura educativa.

2- Planificación y puesta en marcha de un cambio en el curriculum: se parte de un diagnóstico y de una planificación asentadas en los problemas construidos en la realidad educativa, y busca la manera de remediarlas, evaluando posibles soluciones y posibles consecuencias tanto favorables como desfavorables.

3- Creación anticipada de alternativas: la construcción del problema debe anidar una semilla de su posible solución y la creación anticipada de soluciones aporta elementos para vislumbrar una potencial solución real 
4- Deliberación: tiene como finalidad tomar "[...] una decisión sobre cómo actuar en una situación concreta [...]" (p.34).

“[...] La deliberación es compleja y ardua. Trata tanto los fines como los medios, y debe encararlos como si se determinaran mutuamente. Ha de intentar identificar, con respecto a ambos, qué hechos pueden ser importantes. Debe descubrir los hechos significativos en el caso concreto, tratar de hallar los desiderata del caso y crear soluciones alternativas. Tiene que esforzarse por rastrear las consecuencias de cada alternativa en todas sus ramificaciones si tales consecuencias afectan los desiderata. Tendrá, entonces, que sopesar las alternativas y sus costos y consecuencias, y elegir, no la alternativa correcta, pues no existe tal cosa, sino la mejor [...]" (p.34. La cursiva figura en la edición consultada).

Este método de deliberación demanda la participación de diferentes sujetos involucrados en la educación, incluyendo a los maestros y a los administradores, así como también a especialistas de diferentes disciplinas. Debe producirse una integración enriquecedora de puntos de vista diversos, por lo que no valen las jerarquías, sino más bien que se postula una deliberación entre pares. Schwab, a su vez, propone las publicaciones periódicas por parte de los maestros y la realización de foros para el intercambio de problemas y la creación de alternativas anticipadas a los mismos ${ }^{189}$.

Asimismo, reconoce que la implantación del método de la deliberación no será tarea sencilla, pero se puede ir haciendo, educando a los jóvenes que se están por graduar para que comiencen a trabajar con él en la construcción de problemas prácticos, en la creación de alternativas $\mathrm{y}$, en definitiva, en el mejoramiento de la educación. También, la investigación educacional irá aportando sus descubrimientos para que contribuyan al mejoramiento de las prácticas.

\footnotetext{
189 “[...] Schwab habla de la necesidad de nuevas formas de investigación, nuevos periódicos y nuevos foros para la investigación práctica. Pero Stenhouse adapta la noción de Schwab y la hace avanzar un paso más presentando con algún detalle, y en referencia a ejemplos de los tipos de trabajo requeridos, qué hará para establecer esta nueva tradición investigadora [...]" (Kemmis, 1993, p.76).
} 
Para finalizar con esta presentación, es interesante realizar algunos comentarios sobre una nota al pie de página ${ }^{190}$ en la que Schwab realiza una comparación de su propuesta con la de Tyler. En primer lugar afirma que su planteo es inherente a aquél postulado por Tyler en tanto ambos recuperan el tratamiento práctico y ecléctico de una variedad de factores. No obstante, según Schwab, el trabajo de Tyler se ve debilitado en la práctica porque el acento puesto en los objetivos es ambiguo, da lugar a equívocos y aporta muy poco material para la deliberación. Además, quienes utilizan la propuesta tyleriana no poseen la capacitación suficiente para llevar a cabo la deliberación.

La obra de Stenhouse, Investigación y desarrollo del curriculum, se titula originalmente An Introduction to Curriculum: Research and Development $\mathrm{y}$ fu publicada en Londres en 1981. En español es publicado en 1984 por la editorial Morata (de Madrid) y el prólogo lo escribe José Gimeno Sacristán ${ }^{191}$. Para el análisis contamos con la tercera edición, de 1991.

El libro se desarrolla en un total de trescientes diecinueve (319) páginas. Contiene: el índice (denominado "contenido"), el prefacio, el prólogo a la edición española, catorce (14) capítulos, la bibliografía, el índice de materias y el índice de autores.

Stenhouse comienza su trabajo repasando algunas definiciones de curriculum y concluye que ellas se refieren, por un lado, a las intenciones y prescripciones, como lo deseable y, por el otro, a aquello que efectivamente ocurre en las instituciones educativas. Aquí se expone una de las ideas principales de su pensamiento, a cuyo desarrollo dedica gran parte del libro, a saber, que el curriculum implica tanto lo prescripto como lo real, la teoría como la práctica, y que justamente el gran problema del curriculum radica en las

\footnotetext{
${ }^{190}$ Esta misma nota al pie de página está transcripta en Kemmis (1993, pp.65-66). Cabe mencionar que entre la edición que nosotros poseemos de Un enfoque práctico para la planificación del currículo, y la cita de Kemmis, hay algunas diferencias de traducción.

${ }^{191}$ Cabe mencionar que Gimeno Sacristán destaca que el cambio de la práctica educativa, el desarrollo del curriculum y el perfeccionamiento del profesorado, son los tres aspectos centrales abordados por Stenhouse en su libro. Desde la perspectiva del autor prologuista, estos aspectos cobran relevancia en España que, a mediados de los años '80, se caracterizaba por el predominio de una mentalidad curricular "oficial centralizada" y por la desprofesionalización del docente relegado a mero ejecutante.
} 
complejas relaciones ${ }^{192}$ que existen entre nuestras intenciones y los esfuerzos por llevarlas a la práctica.

Estas cuestiones nodales se reflejan en su propia definición de curriculum: "Un C. es una tentativa para comunicar los principios y rasgos esenciales de un propósito educativo, de forma tal que permanezca abierto a discusión crítica y pueda ser trasladado efectivamente a la práctica" (p.29).

Esta definición de curriculum, como Stenhouse lo expresa, lo separa críticamente del modelo de objetivos en el diseño y desarrollo curricular, y lo ubica en el "modelo de proceso". Si bien reconoce la importancia que Tyler ha tenido para la consolidación del campo y lo importante que son las intenciones para la práctica educativa, prefiere prestarle atención a cómo se concretan esas intenciones, cómo se llevan a la práctica, cómo hacen los docentes para implementarlas. En lugar de postular intenciones educativas al comienzo del proceso y ver luego si se cumplen o no, lo que representa en líneas generales la racionalidad medios-fines que subyace al modelo tyleriano, el foco está puesto en analizar las tensiones que se generan entre esas intenciones y los modos de hacerlas efectivas.

Por otro lado, para Stenhouse la escuela, como institución social, tiene la responsabilidad de poner a disposición de las jóvenes generaciones una selección de los conocimientos, valores, hábitos, herramientas, etc., que produce y posee la sociedad. Este capital es denominado "tradiciones públicas", que puede ser sinónimo, según expresa, de lo que los antropólogos y sociólogos denominan cultura.

A su vez, el curriculum implica un problema de conocimiento y, por tanto, su investigación e intervención demanda visualizarlo como una cuestión

\footnotetext{
192 “[...] Según Stenhouse, la problemática permanente del estudio del curriculum se fundamenta en la relación existente entre nuestras ideas (teorías) y la practica curricular. [Téngase en cuenta que se trata de una reformulación de la descripción de Stenhouse sobre el problema del estudio del curriculum en donde el término "vacio" ("gap"), empleado por él, ha sido reemplazada por "relación" ("relationship"): no existe un "vacio" entre la teoría y la práctica, como si ambas pertenecieran a dominio separados o de desarrollo diferente; por el contrario, la práctica educativa, entendiéndola como educativa, siempre está enmarcada en una teoría, y la teoría educativa siempre nace de la lucha para entender la educación como actividad práctica; así, teoría y práctica no son dominios distintos, sino partes constitutivas de lo que significa "educación" [...]" (Kemmis, 1993, p.29. El subrayado figura en cursiva en la edición consultada).
} 
que involucra saberes de la epistemología, la filosofía y la sociología del conocimiento.

Por su parte, la enseñanza se define como “[...] la promoción sistemática del aprendizaje mediante diversos medios [...]" (p.53). El autor prefiere hablar de estrategias de enseñanza y no de métodos de enseñanza, en tanto las primeras apuntan a la planificación de la enseñanza en base a principios y concediendo vital importancia al juicio profesional del docente.

El autor divide las estrategias de enseñanza en dos grandes grupos: directas e indirectas. Las primeras incluyen prácticas en las que el docente transmite a los estudiantes aquellos conocimientos o destrezas que domina. Por su parte, las estrategias de enseñanza indirecta, son aquéllas en las que el peso de la planificación recae en la situación de aprendizaje o en las condiciones que tienden a generar un ambiente propicio para que los alumnos descubran los principios de conocimiento que se desean enseñar.

Stenhouse retoma explícitamente a Schwab en este punto para plantear que a estas estrategias de enseñanza se le suma la consideración de la estructura sintáctica de cada disciplina, es decir, la forma particular en la que cada campo investiga sobre su objeto de estudio.

En lo que respecta específicamente al campo curricular, podemos decir que el aporte sustancial de Stenhouse en este trabajo se refiere a explicar y fundamentar la posibilidad de diseño, desarrollo, evaluación e investigación del curriculum asentado sobre el "modelo de proceso", sobre bases alternativas al "modelo de objetivos", hegemónico en el momento de la publicación de la obra.

El autor plantea que la referencia al modelo de objetivos es necesaria para estudiar el diseño del curriculum, considerando la gran influencia que el mismo ha ejercido. Si bien reconoce que los antecedentes más importantes del modelo de objetivos se encuentran en los libros de Bobbitt titulados The Curriculum (1918) y How to Make a Curriculum (1924), es justo señalar que el modelo adquiere su punto más álgido de la mano de Tyler en 1949 con su obra Principios básicos del curriculum y la instrucción ${ }^{193}$.

${ }^{193}$ El título aparece así citado en la edición del libro de Stenhouse que contamos para el análisis. 
A pesar de las ventajas que Stenhouse visualiza de este modelo de objetivos -relativas, básicamente al poder para organizar las tareas de diseño y desarrollo del curriculum y para ofrecer una teoría sistemática sobre dichas tareas-, se concentra en la realización de una serie de críticas que le permiten, paralelamente, detectar las fortalezas de su propio modelo de proceso. Es importante destacar, además, que en este punto el autor se enfrenta principalmente con Popham, considerado -como ya adelantamos- un autor radical en la utilización del modelo de objetivos.

Stenhouse ataca un supuesto central de este modelo al plantear que es una alternativa entre otras, no la única válida para todos los casos. " [...] la estructura de los objetivos es un esquema conceptual y no una cosa. Debemos evitar «reificarlo». No es que tengamos objetivos, sino que elegimos conceptuar o no nuestro comportamiento según objetivos [...]" (p.111. El subrayado figura en cursiva en la edición consultada).

En este sentido, el autor realiza dos objeciones fuertes al modelo de objetivos: la primera es que confunde la naturaleza del conocimiento y la segunda es que confunde la naturaleza del proceso por el que se mejora la práctica educativa.

Con respecto a la primera de las objeciones, Stenhouse plantea que el modelo de objetivos se ajusta razonablemente a ser utilizado en la instrucción y en el entrenamiento, como dos de los cuatro procesos educativos que distingue el autor. En estos procesos, al estar claramente planteados cuáles son los corpus de conocimientos y habilidades, respectivamente, que deben ser aprendidos, el planteo de objetivos puede ser útil y adecuado.

El tercer proceso educativo que diferencia Stenhouse se refiere a la iniciación, y en él no es apropiado el modelo de objetivos ya que la iniciación a los valores y pautas de comportamiento sociales se realiza en la interacción y en la convivencia con el grupo social.

Por último, Stenhouse ve serias dificultades para aplicar el modelo de objetivos en la inducción.

“[...] La inducción supone la introducción en los sistemas de pensamiento (el conocimiento) de la cultura y una inducción lograda da lugar a 
comprensión, tal como se pone de manifiesto en la capacidad para captar relaciones y juicios y para establecerlos por uno mismo $[\ldots]^{\prime \prime}$ (p.122).

En la inducción los objetivos no son necesarios como estados terminales conductuales; se valora, por el contrario, la comprensión, el análisis, la formulación de juicios, etc., que orientan la práctica pero no preestablecen estados a los que arribar.

En segundo lugar, Stenhouse plantea que el modelo de objetivos confunde la naturaleza del proceso por el que se mejora la práctica educativa:

“[...] No enseñaremos a nuestros alumnos a saltar más alto elevando el listón, sino permitiéndoles criticar su actual rendimiento. Son los criterios acerca del proceso los que ayudan al profesor a mejorar su enseñanza.

[...] No puede haber desarrollo educativo sin el del profesor y el mejor medio para esto no se obtiene clarificando los fines, sino criticando la práctica $[\ldots]^{\prime \prime}$ (p.126).

Sobre la base de estas críticas se edifica el modelo de proceso, que recupera dos posibilidades de diseño curricular desechadas por Tyler, como ya adelantamos en el capítulo VI. Recordamos que este último opta por la especificación de los objetivos al comienzo del diseño descartando la entrada por las actividades que debe desarrollar el profesor así como también por el contenido que tienen que aprender los estudiantes. Ambos casos, para Tyler, adolecen de clarificar qué es lo que los estudiantes deben lograr con el contenido, perdiendo eficacia para la orientación del proceso de aprendizaje.

Justamente Stenhouse retoma estas dos alternativas dándoles mayor sustento en vinculación con el establecimiento de principios de procedimiento. Recuperando la concepción de principios de selección de actividades de Raths ${ }^{194}$ y de principios también utilizados en el Man: a Course of Study, dirigido por Bruner ${ }^{195}$, avanza en la formulación de principios de procedimientos en

\footnotetext{
${ }^{194}$ Raths, James D. (1971). Teaching without Specific Objectives. Educational Leadership. Abril, 714-720.

${ }^{195}$ Bruner, Jerome S. (1966). Towards a Theory of Instruction. Cambridge, Mass.: The Belknap Press of Harvard University Press.

"[...] Las semejanzas entre los principios de procedimiento de Stenhouse y de Bruner son notables. Ambos curricula representan lo que Stenhouse llamaba modelo de diseño de proceso, en contraste con el diseño por objetivos. [...] ofrece una visión coherente del conjunto del curriculum a través de una especificación de las metas y principios educativos que deben regir el manejo de la información en las clases. Es más,
} 
tanto orientaciones para la acción asentados en criterios. "[...] podemos establecer razonablemente un diseño de C. intentando definir el proceso producido en la clase, con arreglo a la tarea del profesor de acuerdo con los principios y con cuál sea el contenido $[\ldots]^{\prime \prime}(\mathrm{p} .134)$.

El diseño experimental dirigido por Stenhouse se denomina Humanities Curriculum Project, que se propone explorar desde principios democráticos ciertas cuestiones controvertidas; es decir, cuestiones que en su misma definición no encuentran una postura consensuada en la sociedad. La finalidad está puesta más bien en el aprendizaje de la discusión, la búsqueda de información, la generación de opiniones fundamentadas, el respeto a las opiniones del otro, etc., que en el aprendizaje de la verdad o de la opinión del profesor.

Por otra parte, en todo el trabajo de Stenhouse el lugar del docente es fundamental. La calidad del profesor es precisamente para este modelo el punto más débil y el punto más fuerte al mismo tiempo en todas las instancias involucradas en el curriculum, a saber, diseño, desarrollo, evaluación e investigación.

El docente es conceptualizado como un profesional, con capacidad de decisión y acción, al que se le ofrecen una serie de principios de procedimiento para orientar y fundamentar su actuación en los momentos preactivo, interactivo y posactivo (Jackson, 1968) de la enseñanza. Más específicamente, se apuesta al "profesor como investigador" de su propia práctica y como el que realmente puede aportar datos para el mejoramiento de la misma.

En este modelo de proceso, además, se piensa la evaluación del curriculum, de la enseñanza y de los aprendizajes como un proceso complejo. La evaluación se basa en criterios y busca avanzar en contra de un proceso evaluativo puramente subjetivo aun cuando no logra ni persigue la objetividad de las pruebas estandarizadas o los tests psicométricos, más afines al modelo de objetivos. Stenhouse, así como también podemos decir de Schwab y de otros

deja mucho espacio para el juicio profesional y las decisiones de los profesores [...]" (Elliott, 1995, p.267. El subrayado figura en cursiva en la edición consultada). 
autores que comparten estos supuestos, no esquivan los problemas que se abren en torno a la centralidad del juicio del profesor en la evaluación.

El autor se opone a la evaluación con criterios estandarizados y a la presencia de evaluadores externos guiados por objetivos previamente estipulados.

“[...] En resumen, para evaluar hay que comprender. Cabe afirmar que las evaluaciones convencionales de tipo objetivo no van destinadas a comprender el proceso educativo. Lo tratan en términos de éxito o de fracaso. Pero un programa es siempre una mezcla de ambos que varía de un marco a otro $[\ldots]^{\prime \prime}($ p.156).

Stenhouse informa que McDonald conformó su enfoque holístico como respuesta a los problemas de evaluación con los que se encontró en la implementación del Humanities. El trabajo evaluativo de McDonald, comentado por el autor que estamos analizando, tuvo lugar entre los años 1968 y 1970, antes de que el Humanities tomara estado público, y pretendía conformar un proyecto de evaluación que lo acompañara.

En este marco, el enfoque holístico para la evaluación implicaba que se consideraran en principio todos los datos del proceso educativo relevados como válidos para su comprensión, que posteriormente se seleccionaban en base a criterios problemáticos (entre ellos: sentido, potencial, interés, condicionalidad y elucidación) que se iban conformando en contacto con la realidad empírica.

La evaluación se convirtió así en un proceso que buscaba recabar información para comprender el desarrollo del curriculum. En la generación de información intervenía el evaluador pero también tenían un lugar destacado los propios docentes que llevaban a cabo ese curriculum, en este caso, aquéllos que participaron del Humanities.

Por último, Stenhouse presenta un modelo de investigación del curriculum que abarca tanto el desarrollo como la evaluación del mismo y tiende a ser una superación tanto del modelo de objetivos como del modelo de proceso. Entender el desarrollo del curriculum desde un modelo de investigación significa para el autor pensarlo como un proceso permanente de exploración y comprobación de hipótesis. Todo curriculum presenta defectos y 
es susceptible de ser mejorado. En este sentido, siempre es posible mejorar un curriculum así como el avance en el conocimiento al que el mismo da lugar, adoptando una línea normativa que habilite un proceso prolongado y sistemático de perfeccionamiento.

Sostenemos que en este proceso de investigación permanente del curriculum hay algunos puntos de contacto con Schwab. En primer lugar, aparece una consideración de la complejidad de las situaciones particulares y de las dificultades o imposibilidades de que su diversidad sea abarcada por principios generales. Así, lo singular demanda análisis y comprensión. El curriculum es un aspecto más de los procesos educativos complejos.

En segundo lugar, aparece la importancia de encontrar soluciones también contextualizadas al curriculum. Al igual que en Schwab, está presente la posibilidad de que las soluciones construidas puedan contribuir a la mejora de problemas en distintos contextos, pero para esto se deben realizar las adecuaciones convenientes para que esas soluciones respondan con algunas características a lo general y con otras a lo particular.

VIII - 2 - Análisis de las obras: la aparición de algunos emergentes que permiten caracterizar la perspectiva práctica en el curriculum y su impacto en la didáctica.

VIII - 2 - a - Carácter de la norma en una teoría normativa.

A propósito de este primer cruce es pertinente focalizar la atención en la relación compleja que se construye en la perspectiva metaeórica práctica entre la norma curricular o, más específicamente, entre la forma de entender el curriculum que se expone en las obras de Schwab y Stenhouse, y el lugar que le reservan al sujeto docente en su diseño, desarrollo y evaluación. 
Un supuesto básico de esta perspectiva, que aparece resignificado en la obra de Schwab, se refiere a que el curriculum es un problema práctico, por lo que demanda un razonamiento adecuado para la resolución de sus problemas.

El razonamiento práctico, tal como es caracterizado por diferentes autores -prioritariamente Schwab (1974) y Kemmis (1990)- es un tipo de razonamiento de raíz aristotélica que resulta apropiado para las situaciones sociales en las que los sujetos se encuentran frente a la necesidad de tomar decisiones, sopesar alternativas y evaluar valores en conflicto.

Como expone Kemmis, en estas situaciones no hay medios ni fines conocidos o predeterminados, sino que ambos se vuelven problemáticos. Se sopesan las alternativas y se buscan las maneras más correctas de proceder. Estas formas de actuar son compatibles con aquéllas que Schwab defiende para el caso del curriculum, en abierta oposición a la modalidad teórica que él describe y que en esta tesis entendemos como perspectiva tecnicista.

Asimismo, este tipo de situaciones, como dice Kemmis, deben ser vividas. Es decir, deben ser experimentadas por los sujetos responsables de tomar las decisiones, en nuestro caso, curriculares. El conocimiento experiencial aporta elementos relevantes para la toma de decisiones. Además, por estas mismas condiciones, las decisiones situacionales que se toman pueden ser juzgadas retrospectivamente, una vez que se pusieron en marcha, y es posible evaluar sus resultados. Tomando esta caracterización, no hay posibilidades de valorar a priori los fines y los medios para alcanzarlos.

Estos supuestos se ven plasmados claramente en la descripción de la obra de Schwab que realizamos precedentemente. El autor parte del supuesto de que el curriculum es un problema práctico y desde allí edifica toda su postura, dando elementos acerca de cómo se debe proceder en materia curricular. En el texto aparecen orientaciones acerca de cómo diseñar un curriculum, cómo desarrollarlo, qué lugar debe desempeñar el docente en esos procesos, de qué cuestiones se tiene que ocupar y cómo se pueden resolver, etc.

En coherencia con el planteo de Schwab, esas orientaciones tienen un carácter abierto. Se trata más bien de orientaciones que indican cómo se puede 
proceder, de acuerdo a ciertos fines y supuestos epistemológicos, reservando márgenes importantes para el ejercicio de la deliberación.

A diferencia de aquella amplitud que destacamos para el caso de las prescripciones que presentaba Tyler, consideramos que Schwab, y posiblemente más aún Stenhouse, brindan orientaciones para que los docentes desarrollen y potencien los procesos de deliberación en la construcción del curriculum. Podemos decir que la estructura de estas orientaciones normativas está conformada por: elementos orientativos acerca de cómo proceder, una finalidad que se debe alcanzar y un alerta acerca del tipo de condicionantes de la práctica que se deben tener en cuenta.

Consideramos que estas consideraciones permiten revisar al menos tres cuestiones sobre la obra de Tyler. En primer lugar, lo planteado por Schwab da mayores créditos a la opinión de Kemmis (1990) acerca de que la obra de Tyler, en manos de lectores poco dados a discernir, se convierte en aquel "manual" que el propio Tyler rechaza en las primeras líneas de la introducción de sus Principios básicos del currículo. El método de la deliberación requiere capacitación y habilidades para ponerlo en práctica. Podemos suponer que sin la adecuada capacitación el método en cuestión no alcanza sus finalidades.

En segundo lugar, la ambigüedad que Schwab le asigna a los objetivos tylerianos puede ser otro de los aspectos que conduce a interpretaciones tan disímiles entre los teóricos que su obra. Específicamente, Hlebowitsh (1998) defiende, como ya expusimos, que Tyler deja mucho margen de decisión para los docentes en cuestiones curriculares. Pero como no aporta elementos concretos para la deliberación, nos encontramos con que los docentes y los diseñadores del curriculum terminan, por un lado, no tomando decisiones sobre ciertas cuestiones porque posiblemente no cuentan con los elementos para hacerlo y, por el otro, adoptando las antiguas formas, lo consuetudinario. Por lo tanto, lo que queda ambigua o vagamente planteado no orienta la acción.

Por otro lado, la forma de entender el diseño, el desarrollo y la evaluación del curriculum que presentan Schwab y Stenhouse lleva a Contreras Domingo (1990) a ubicarlos en una perspectiva alternativa a la tecnicista. La 
caracterización de esta perspectiva alternativa anticipa que la tensión entre la norma, el accionar del sujeto y el caso particular se va a resolver situacionalmente. No hay posibilidades de prescribir al detalle la acción del sujeto sin traicionar el supuesto de la racionalidad práctica que brega por la consideración del mismo con capacidad de decisión y acción.

Por su parte, Stenhouse conceptualiza explícitamente el curriculum como una ciencia normativa. Como tal, la teoría acerca del curriculum sirve para comprender y explicar los hechos a los que se refiere, por un lado, y por el otro sirve como base para la actuación. "[...] la teoría tiene que tener una vertiente normativa, así como una vertiente reflexiva [...]" (p.110).

Esta forma de conceptualizar la teoría curricular nos posibilita visualizar las funciones de la teoría, como Stenhouse las denomina. Pero también habilita una forma particular de entender la normatividad curricular. La norma se entiende como base para la actuación, es decir, como una orientación que encuentra concreción cuando en base a ella el docente elige cursos de acción.

$\mathrm{Si}$ a esto le sumamos la conceptualización del docente como profesional reflexivo e investigador de su propia práctica nos encontramos con una normatividad de "textura abierta", como plantea Frigerio (1991, p.27). La definición de esta autora se adecua aquí en tanto es coherente con el pensamiento de Stenhouse, al plantear que ninguna normativa puede clausurar la totalidad de sentidos que habilita su interpretación.

A su vez, entre el curriculum prescripto -entendido como una norma que busca su concreción en la práctica- y el curriculum real media una diversidad de factores. El autor menciona los siguientes: el curriculum oculto (categoría que retoma explícitamente de Jackson), la cultura institucional, la autonomía de los profesores, etc.

Stenhouse afirma en todo momento la centralidad del profesor, de su capacidad de inventiva y de mejoramiento de la enseñanza. El trabajo conjunto de los profesores para "[...] informarse e investigar [...]" (p.54) es importante, como otros profesionales también tienen la necesidad de colaborar entre sí. 
Para el autor, el profesional docente debe poseer las siguientes características para poder llevar adelante el modelo de investigación en el curriculum: "[...] una capacidad para un autodesarrollo profesional autónomo mediante un sistemático autoanálisis, el estudio de la labor de otros profesores y la comprobación de ideas mediante procedimientos de investigación en el aula [...]" (p.197).

Los espacios de realización profesional del docente también se pueden apreciar cuando Stenhouse habla de "estrategias de enseñanza". Diseñadas para la concreción de las intencionalidades que se propone la enseñanza, se conceptualizan como una forma de planificación en base a principios y en base a las particulares condiciones de enseñanza y de aprendizaje.

Parece que está presente esta idea explicitada también por Schwab y común a la perspectiva práctica, acerca de que no existen principios generales que puedan abarcar las condiciones singulares de la práctica. Los principios se transforman en orientaciones para diseñar y fundamentar las prácticas de enseñanza y requieren una resignificación, adecuación, adaptación, por parte del docente, a las condiciones de trabajo en el aula y en la institución.

En este sentido, Elliott (1995) ${ }^{196}$ revela que en los primeros pasos del Humanities Curriculum Project, los cambios educativos encontraban trabas en su puesta en marcha por parte de los profesores. El autor plantea que Stenhouse había visualizado dificultades por parte de los docentes para criticar las restricciones impuestas desde el sistema escolar, y que MacDonald había realizado un trabajo interesante de evaluación poniendo en evidencia diferencias entre las instituciones educativas y las aspiraciones de los sujetos externos a ellas pero con incidencia en las decisiones educativas.

“[...] La perspectiva de la construcción teórica del curriculum basada en la práctica supone un mundo en el que los profesores deben participar activamente en la toma de decisiones educativas y aceptar la responsabilidad derivada de hacerlo [...]"

\footnotetext{
${ }^{196}$ Elliott $(1994 ; 1995)$ participó de la experiencia del Huminities Curriculum Project entre 1967 y 1972, y previamente intervino con diferentes profesores en reformas educativas que confluyeron en la experiencia de Stenhouse. A su vez, plantea que fue Stenhouse quien articuló el movimiento de reforma curricular que tuvo lugar en Inglaterra en las décadas del ' 60 y '70, aunque éste ya se había iniciado, y fue uno de los primeros en darse cuenta que el mejoramiento de la práctica requería de la investigación por parte del profesor.
} 
(Kemmis, 1993, p.71. El subrayado figura en cursiva en la edición consultada). Estas cuestiones aparecen tanto en Schwab como en Stenhouse y podemos decir que extienden la profesionalidad del docente más allá del aula.

“[...] Para Stenhouse, los curricula [...] prestan su apoyo a la práctica reflexiva, en vez de constituir una "camisa de fuerza" a la que haya que ajustar la práctica. Las expresiones "planificación curricular" e "implementación curricular" sugieren que el papel del profesor consiste en adaptar su práctica a una serie de requisitos o planes curriculares externos. Por su parte, "desarrollo curricular" indica la continua reestructuración de las formas de representar los profesores el saber en las aulas en colaboración con sus alumnos, cuando reflexionan sobre su enseñanza. Aquí, el aula constituye más un laboratorio de experimentación pedagógica que un lugar para la implementación de normas externas [...]" (Elliott, 1995, p.252. La cursiva figura en la edición consultada).

VIII - $2-b-$ Aspectos que constituyen la norma.

La propuesta de Schwab, como vimos, muy informada filosóficamente, se asienta sobre bases radicalmente diferentes a la forma teórica o técnica predominante en el campo del curriculum, así como también en la forma de construir teoría curricular. Es en este doble plano en el que permanentemente se juega lo práctico.

La publicación de la obra de Schwab marcó un giro sustancial desde el punto de vista teórico y metateórico en lo que al curriculum se refiere (Kemmis, 1993). Según Carr y Kemmis (1988), cuando Schwab inició su trabajo criticando a la perspectiva teórica en el campo curricular, se estaba oponiendo principalmente al planteo fundamentalista en auge en las teorizaciones educativas de la época.

Sintéticamente, este planteo se orientaba a la recuperación de las disciplinas y su proyección hacia la educación. Disciplinas como filosofía, sociología, política, psicología, etc., desarrollaban una serie de investigaciones sobre la educación. Así surgieron la filosofía de la educación, la sociología de la educación, la política de la educación, la psicología de la educación, etc. Estas nuevas disciplinas, que fueron adquiriendo cierta autonomía respecto de las 
disciplinas madres, fueron produciendo una fragmentación en el curriculum, especializando cada vez más su mirada sobre la educación.

En conjunción con este planteo, autores como Hirst y O'Connor, con sus desarrollos de la teoría educacional principalmente en Inglaterra, postulaban que la educación era una teoría práctica, de menor status que otras teorías científicas, y que su corpus de saberes fundamentaba la práctica y brindaba principios de acción para su conducción.

Con estos elementos vemos que la inversión que propone Schwab es sustancial. Si podemos hablar de la construcción de una normatividad curricular en la perspectiva de este autor, es la práctica educativa la que ocupa un lugar central en su conformación.

Resulta clarificador para entender esta inversión aquella expresión de Grundy (1994) cuando dice que al curriculum no hay que buscarlo en la biblioteca del profesor, sino en la práctica del aula, en las interacciones entre docentes y estudiantes.

En efecto, si por normatividad entendemos el conjunto de orientaciones que brinda Schwab acerca de las modalidades prácticas, cuasi-prácticas y eclécticas que caracterizan las formas de pensar y actuar en el curriculum, entonces esta normatividad encuentra en la práctica su referente principal.

Por su parte, en el planteo de Stenhouse también encontramos diversos afluentes teóricos que desembocan en la construcción de la normativa curricular. Por un lado, cuando el autor plantea que el curriculum es una disciplina normativa que se refiere a una práctica compleja, se puede pensar que aparece un espacio para la inclusión de distintos saberes disciplinarios que aporten elementos para comprender la práctica curricular.

Por otro lado, el reconocimiento del autor hacia otros planteos teóricos es explícito cuando evalúa críticamente el modelo de objetivos, destacando sus puntos fuertes y aquellos otros débiles para explicar e intervenir en la educación. La ponderación que realiza Stenhouse del modelo de objetivos y la apertura de la posibilidad de que puede ser un modelo útil para pensar algunas 
modalidades educativas, reconoce diferentes referentes teóricos $\mathrm{y}$ consideraciones prácticas.

De la misma manera que Stenhouse valora positivamente algunos aportes de Tyler para el diseño del curriculum, siguiendo a Elliott (1995) podemos decir que igual consideración tiene para con los aportes de Taba. En este sentido, Stenhouse reconoce la defensa que realiza esta autora del aprendizaje por descubrimiento. No obstante, sostiene que el sustrato del modelo de objetivos, que la autora también sustenta, deforma el espíritu de lo innovador: "[...] Esta visión del aprendizaje por descubrimiento, reforzada por el modelo de objetivos, subordina, en último término, el objetivo de desarrollar las capacidades de comprensión al de adquirir conocimientos ciertos e indudables [...]" (Elliott, 1995, p.259).

Por otra parte, consideramos pertinente aludir aquí a las relaciones que Stenhouse plantea entre la enseñanza y el aprendizaje. Para el autor, como ya señalamos, la enseñanza es "[...] la promoción sistemática del aprendizaje mediante diversos medios [...]" (p.53). La enseñanza persigue el logro del aprendizaje y se define como proceso en torno a su consecución. El docente tiene la responsabilidad de llevar a cabo la enseñanza y se le adjudica la autonomía necesaria para lograrlo. Podemos recuperar complementariamente la conceptualización de "estrategias de enseñanza" que realiza Stenhouse para visualizar desde otro ángulo cómo se insiste sobre la capacidad profesional del docente para la realización de su trabajo.

En este sentido, sostenemos que el planteo más normativo que se dibuja en esta perspectiva práctica del curriculum se fundamenta, principalmente, en criterios que orientan la acción docente hacia determinadas intencionalidades. La concreción de esa normatividad sólo se produce en la interacción entre el sujeto docente y la práctica real en la que tiene que interactuar con los estudiantes en torno a un contenido. Es entonces una normativa que deja, por un lado, claros márgenes de interpretación al docente al que se dirige; y por otro, en su concreción necesita de los aportes de las prácticas reales de enseñanza. 
VIII - 2 - c - Presencia de aspectos normativos e interpretativos.

A partir del análisis realizado consideramos que los planteos de Schwab y Stenhouse evidencian una articulación entre aspectos normativos e interpretativos. Por lo dicho hasta aquí podemos ver que se da una conjunción de aspectos, por un lado, tendientes a orientar la práctica del docente en el curriculum y en el aula, cuestión que en este último caso es más explícita en Stenhouse, y, por otro lado, de aspectos relativos a aportarle inteligibilidad a una práctica compleja.

El trabajo de Schwab y su propuesta de acción práctica -incluyendo sus tres modalidades señaladas más arriba- también constituyen un ejemplo de articulación de estos aspectos. En todo momento se pretende la articulación entre aquellos saberes que apuntan a profundizar la comprensión de los problemas educativos y el diseño de las alternativas de solución de los mismos por parte de los docentes.

Cuando planteamos la inversión sustancial que realiza Schwab del par teoría-práctica propio de la perspectiva técnica o teórica, como él la define, nos referíamos en parte a esta situación. Hablar de las relaciones entre "prácticateoría" implica configurar el esquema teórico y de intervención en función de los problemas de la práctica. No se trata de un hacer un "premoldeado" de la práctica desde la disponibilidad de saberes teóricos. Se trata, por el contrario y como ya se dijo, de una intervención para el mejoramiento de las prácticas de enseñanza y curriculares, con una profunda comprensión de sus problemas a partir de los saberes disponibles y valorados como más adecuados en función de las aristas que ellos evidencian.

Por su parte, consideramos que la definición de curriculum como ciencia normativa que realiza Stenhouse es un ejemplo claro de cómo se articulan los aspectos comprensivos y aquellos otros orientativos sobre las prácticas educativas. El curriculum busca ayudar a los docentes a comprender su práctica 
a partir de distintos saberes, pero también pretende orientar y fundamentar sus intervenciones en las prácticas de enseñanza.

Asimismo, el curriculum como una ciencia normativa obliga a Stenhouse a reconocer la necesidad de un sólido conocimiento de lo que sucede en las escuelas y en las aulas: “[...] Las teorías a gran escala son muy útiles como andamiaje para el avance del conocimiento, pero cuanto más satisfactorias las encontremos desde el punto de vista lógico, tanto menos probable es que sean adecuadas [...]" (p.110).

VIII - $2-d$ - Disponibilidad de saberes interdisciplinarios para constitución de la teoría y del desarrollo del curriculum.

Kemmis (1993) sostiene que el trabajo de Schwab es uno de los filosóficamente mejor informados para analizar las cuestiones vinculadas a la teoría y la metateoría del curriculum. En este sentido, podemos decir que Schwab no sólo configura una nueva teoría para el curriculum en su crítica a la modalidad teórica de diseño curricular, sino que, básicamente, construye una nueva forma de construir la teoría del curriculum. Su aporte, primeramente, es epistemológico y luego teórico.

El análisis que realiza requiere de saberes epistemológicos, metodológicos y filosóficos ${ }^{197}$ que permiten dar cuenta del estado de situación del campo curricular en su época.

Posteriormente, la necesidad que visualiza y fundamenta de construir una perspectiva práctica que revitalice el curriculum también requiere de saberes provenientes de campos externos al mismo. Pero vale aquí la aclaración de que no cae en contradicción con sus propios postulados, ya que esa recuperación de saberes de otras disciplinas se realiza en base a juicios que indican la pertinencia de aportes externos al campo curricular.

\footnotetext{
197 “[...] Schwab llevó el debate sobre el pensamiento y sobre la elaboración teórica acerca del curriculum a un nuevo nivel, situando las perspectivas alternativas en el terreno filosófico, en los términos de la distinción aristotélica entre la razón técnica y la razón práctica [...]" (Kemmis, 1993, p.27. El subrayado figura en cursiva en la edición consultada).
} 
Con respecto al trabajo de Stenhouse consideramos que vale en este punto una reflexión en torno a la forma en la que el autor presenta las relaciones entre el curriculum y la sociedad en lo que se refiere específicamente a la selección de contenidos.

En este sentido, el tratamiento que el autor realiza de estas cuestiones debe descentrarse de lo estrictamente curricular, posicionarse en una mirada más general que abarca a la sociedad, para luego volver la mirada sobre problemas centrales del curriculum.

En primer lugar, retomamos en este comentario el trabajo de Kemmis (1993) y acordamos con el autor cuando expone que al curriculum lo atraviesan dos problemas centrales: uno relativo a la relación entre la teoría y la práctica; y otro referido a la tensión educación-sociedad.

Para explicar la primera de las relaciones mencionadas, Kemmis recupera justamente la definición de curriculum que brinda Stenhouse, equiparando la teoría a las intenciones y la práctica a las modalidades implementadas para hacerlas realidad. La inclusión de lo prescripto y lo real, de las intenciones y su concreción práctica es, para Kemmis, la expresión clara de esta relación problemática -entre la teoría y la práctica- que atraviesa y configura el campo.

Al aludir a las relaciones entre la educación y la sociedad, Kemmis se refiere a Lundgren y su conceptualización de que el curriculum es un texto que vendría a resolver el problema de la representación entre el contexto de producción y el de reproducción en una sociedad preocupada por la transmisión de su acervo cultural a las jóvenes generaciones.

Además de lo que plantea Kemmis, consideramos que esta tensión entre educación y sociedad nos ayuda a entender a Stenhouse y el recorrido que realiza para explicar el origen de los contenidos escolares y su incorporación en el curriculum. Si bien acordamos con Kemmis en que no podemos afirmar que Stenhouse es un autor fundamentado en la perspectiva metateórica crítica, consideramos que mira al curriculum y a la escuela en relación con el contexto, y posiblemente por este ejercicio analítico, es que puede comprender la 
complejidad de la selección cultural que realiza el curriculum. Pero al no ser un autor posicionado en la perspectiva metateórica crítica no incorpora algunas categorías como relaciones de poder, ideología, dominación social, hegemonía, etc., ni tampoco defiende, como dice Kemmis, la conformación de un colectivo docente con capacidad de decidir en materia de política educativa pública.

Podemos decir que la construcción consensuada de líneas de acción colectiva llega hasta el nivel institucional, explícitamente reconocido por Stenhouse y considerado como una mediación relevante entre el curriculum prescripto y el real.

A su vez, consideramos que la disponibilidad de saberes interdisciplinarios se pone en juego también en el estudio del contenido escolar, y esto actúa como una suerte de delimitación del campo curricular. Es decir, la selección del contenido de la escolarización y su clasificación pone en el centro del debate el tema de que el curriculum es un problema de conocimiento. Al mismo tiempo, el tratamiento del mismo demanda perspectivas de epistemología, de filosofía y de sociología del conocimiento. Podemos hipotetizar que la recuperación de estas perspectivas disciplinarias contribuye a la delimitación del campo en tanto la alusión a su contemplación puede oficiar como una prescripción acerca de cómo debe investigarse y desarrollarse el curriculum.

También se puede tomar como una delimitación del campo la definición de enseñanza que propone Stenhouse, a la que se refiere como la promoción de los aprendizajes en los estudiantes, siendo el docente el que diseña diversas estrategias de enseñanza para alcanzar sus finalidades. La propia definición de curriculum que propone el autor, a diferencia de la de programa, intenta dar cuenta de la definición de contenidos y de la forma de presentación que realiza el docente de esos contenidos a los estudiantes.

En nuestro país, en cambio, y tal como expusimos en el capítulo II, la enseñanza y las estrategias de enseñanza son una preocupación claramente didáctica, disciplina que ya tenía una tradición importante en la década del '80, 
cuando se conoció la obra de Stenhouse ${ }^{198}$. En Inglaterra, por su parte, sabemos que fue el curriculum el que se desarrolló principalmente para atender estas cuestiones sobre la enseñanza.

Por otra parte, entendemos que la disponibilidad de saberes interdisciplinarios también se pone en juego en Stenhouse cuando explica su concepción de curriculum y el lugar que desempeñan los docentes en su investigación y desarrollo. Para que las intenciones educativas puedan ser "trasladadas efectivamente a la práctica" se requiere de la participación comprometida de los docentes. Tal como se concreta en el Humanities Curriculum Project, ese curriculum prescripto se enriquece a partir de la investigación del curriculum real.

“[...] Hay que presentar, sin embargo, como punto de partida para experimentar, una especificación provisional del C., con su estrategia docente, aunque pueda estar sometido a modificaciones, a la luz de la experiencia [...]" (p.54).

Para Stenhouse, esta especificación provisional del curriculum se asienta en una serie de fuentes, como la psicología del aprendizaje, el estudio del desarrollo infantil, la psicología social, la sociología del aprendizaje, la lógica de la materia y la experiencia acumulada.

No obstante, en consonancia con la línea abierta por Schwab, aunque no expresado explícitamente, Stenhouse enfatiza la importancia de la práctica en el momento de considerar los aportes de estas disciplinas. "[...] Los investigadores del C. necesitan participar de la curiosidad del psicólogo acerca del proceso de aprendizaje, en vez de dejarse dominar por sus conclusiones [...]" (p.56).

Además, estas disciplinas elaboran normas sobre el comportamiento infantil desde la producción de conocimientos disponibles y, precisamente, la educación tiene la misión de superar esas normas, tal como lo expresa el autor, enriqueciéndolas con el aporte de las prácticas educativas. Aparece aquí una conceptualización de la normatividad emanada del conocimiento disponible y que, por tanto, expresa aquello consuetudinariamente estipulado, como plantea

\footnotetext{
${ }^{198}$ Por ejemplo: Cols (2003a) y Orienti (2012) describen dos grandes grupos de estrategias de enseñanza basándose principalmente en Stenhouse (1991), a saber: aquéllas directas o basadas en la instrucción y aquéllas indirectas o tendientes al descubrimiento.
} 
Silber (1997). Conceptualización que justamente es criticada por Stenhouse y que se busca ampliar pensando en "su traslado efectivo a la práctica".

VIII - 2 - e - Teorías de alcance intermedio o teorías cercanas a la práctica.

A partir del análisis precedente podemos afirmar que Schwab y Stenhouse construyen una teoría curricular cercana a la práctica. En ambos casos, se trabaja en la problematización de un espacio intermedio entre la "gran teoría" y la "práctica artesanal".

Schwab, por su parte, analiza detenidamente y enfatiza la imperiosa necesidad de asentar el campo del curriculum y la teoría curricular en los problemas de la práctica. Según expone, “[...] todo caso concreto poseerá ciertas características significativas no abarcadas por principio alguno [...]" (p.34). Los sujetos docentes y alumnos, el aula en la que se lleva a cabo la enseñanza y el aprendizaje, las interacciones, la institución, etc., son procesos particulares que no pueden caracterizarse ni explicarse sólo en base a una teoría, sino que demandan un conocimiento empírico y adecuaciones teóricas específicas.

Asimismo, cuando critica la modalidad teórica que a su juicio ha conducido a la crisis del curriculum, expone las "ineptitudes de las teorías". Las diferentes teorías - por sus perspectivas particulares para enfocar determinados aspectos de sus objetos de estudio, por sus abstracciones, por sus rivalidades con otras construcciones teóricas, etc.- no logran resolver individualmente un problema práctico. Entonces, Schwab no piensa en la construcción de una teoría abarcadora y unificada, sino que, contrariamente, apuesta a complementar las teorías, trabajar sobre sus ineptitudes y utilizar sus beneficios para el mejoramiento de la práctica educativa ${ }^{199}$.

Desde esta perspectiva, el autor propone tener en cuenta diferentes teorías que aborden varios de los sub-asuntos que atañen al hombre y al curriculum. Esto sería coherente con la postura planteada en la modalidad

\footnotetext{
${ }^{199}$ Un argumento similar utiliza Prego (1992) cuando defiende la importancia de las teorías de alcance intermedio para la sociología, tal como vimos en el capítulo III de esta tesis.
} 
ecléctica de acción. La misma demanda la articulación provisoria e inestable de diferentes teorías, por ejemplo de las ciencias sociales, que aporten toda su especificidad para el estudio y la intervención en los asuntos en cuestión.

El método de la deliberación, en este sentido, busca la construcción de problemas y la elaboración de estrategias de solución a partir del trabajo conjunto de los sujetos involucrados en el curriculum.

Cabe agregar que Schwab retoma la diferenciación de Aristóteles entre discurso técnico y discurso práctico 200 :

“[...] La aportación particular de Schwab en The Practical, fue distinguir entre el modo práctico de razonar requerido para resolver cuestiones de currículo, y el modo técnico de razonar utilizado en la aplicación de los conocimientos teóricos derivados de las disciplinas «fundamentales» a las que la educación, con excesiva presteza, pedía consejo sobre cuestiones de currículo con las que se enfrentan los educadores todos los días [...]" (Kemmis, 1990, p.25).

Por otro lado, la afirmación de Stenhouse acerca de que el curriculum es una ciencia normativa nos posibilita encontrar elementos para pensar que podría caracterizarse como una teoría de alcance intermedio o como una teoría cercana a la práctica. Dijimos que el curriculum, desde la perspectiva del autor, tiene una vertiente que brinda elementos para la comprensión de los problemas educativos y otra que aporta orientaciones para la intervención. La relación teoría-práctica, o la enunciación de intenciones formativas que buscan su concreción en la práctica como cuestión sustancial del curriculum, también es una forma de pensarlo que lo posiciona como un campo cercano a la práctica educativa.

Como hemos ya planteado en otras oportunidades, desde la perspectiva de los autores ningún curriculum se enuncia para quedar archivado en una estantería; todo curriculum se formula para ser llevado a la práctica. Se puede decir entonces que la teoría curricular que se va construyendo busca, en parte, explicar los problemas que se generan en su puesta en práctica; y en parte persigue orientar esa concreción.

${ }^{200}$ Entre otros autores se puede aludir a: Kemmis (1990; 1993); Edelstein (2011). 


\section{CAPÍTULO IX: CONCLUSIONES}

Pensar la normatividad en la didáctica nos introduce en una tarea compleja de análisis de perspectivas teóricas, epistemológicas, metodológicas e históricas. Consideramos que el recorrido realizado fundamenta la necesidad de contar con una didáctica normativa que construya un marco conceptualreferencial, desde un determinado posicionamiento ético-político, que le posibilite explicar y comprender la enseñanza, así como elaborar normas u orientaciones para que se lleven a cabo "buenas prácticas", hacia la concreción de un proyecto político-social.

En la actualidad, puede decirse que la didáctica se encuentra atravesando un momento de reconceptualización de su propio campo. Particularmente, se incluye aquí la revisión epistemológica de sus finalidades, proceso que enmarca aquel otro que encaramos en esta tesis, a saber: volver a pensar su base normativa.

En este sentido, consideramos que la revisión histórica realizada de las obras de didáctica y de curriculum aporta elementos sustantivos para la configuración actual de la base normativa en la didáctica.

En primer lugar, del momento normativo de la constitución histórica de la didáctica, podemos rescatar los siguientes componentes:

1- La vinculación de la enseñanza con la educación y de la escuela con la sociedad. La didáctica es una teoría que se ocupa de la enseñanza y sus preocupaciones deben abarcar las interrelaciones que la misma mantiene con otros procesos educativos y sociales más amplios. La enseñanza como práctica social se realiza en un contexto áulico, institucional y social, cuestiones que la didáctica debe tener presentes en el alcance de sus finalidades como disciplina 
(específicamente, estos aspectos se destacan en Nérici, 1973; Edelstein y Rodríguez, 1974; Avolio, 1975; y Barco, 1975).

Asimismo, consideramos como propio de una didáctica normativa, la intervención social (Camilloni, 1996). Esto significa que el diseño y puesta en marcha de mejores prácticas de enseñanza tiene como horizonte la concreción de un proyecto político-educativo más amplio y con mayor justicia para todos.

Estos últimos rasgos, como vimos, aparecen claramente planteados en los autores clásicos del campo, como por ejemplo en Comenio. Consideramos que la vinculación entre el método de enseñanza y el contexto político, social y cultural debe ser recuperada para fortalecer la justificación racional que el docente debería encontrar en la norma didáctica para sus acciones.

2- En relación con lo anterior, pero en un plano más teórico, aparece también la vinculación de la didáctica con otras disciplinas. Por un lado, se presenta como una disciplina enmarcada en la pedagogía o en una teoría de la educación más abarcadora (Nérici, 1973; Avolio, 1975), recuperando de alguna manera aquella alusión que realizamos al comienzo de esta tesis relativa a que la didáctica y la pedagogía diferían por el mayor acercamiento a la enseñanza de la primera.

Por otro lado, la didáctica recupera saberes de otras ciencias sociales para explicar y orientar su objeto de estudio, cuestión que se evidencia en todos los autores cuyas obras analizamos, aún cuando puedan ubicarse en un momento histórico en la constitución de la disciplina diferente al normativo. En este sentido, es posible conceptualizar la norma didáctica como aquella que se enmarca en un corpus de conocimientos propio de la didáctica e interdisciplinario.

Como explica Camilloni, la didáctica está atravesando por una crisis que la lleva a analizarse epistemológicamente y, en este sentido, a:

“[...] determinar qué es este campo de la disciplina didáctica, ya que por sus múltiples e imprescindibles relaciones con las otras disciplinas, "nada de lo humano parece serle ajeno", incluido en ello el producto de la actividad del hombre ya sea en la forma de conocimiento científico o en la de las otras modalidades de saber [...]" (1996, p.38). 
A su vez, esta vinculación permanente y necesaria con otras ciencias sociales complejiza su constitución teórica y epistemológica al hacerla heredera de problemas y esquemas de interpretación ajenos (Camilloni, 1996). En este sentido, enfatizamos la constitución de un corpus propiamente didáctico de conocimientos que, además, integre y resignifique los aportes de otras ciencias sociales en vistas a la enseñanza.

3- La configuración de una norma de textura abierta, como plantea Frigerio (1991). Consideramos que no es posible orientar la enseñanza sin reservar un espacio para el diálogo con el docente. La didáctica debe construir conjuntamente con el docente alternativas de acción para el mejoramiento de la enseñanza. La mayoría de los autores analizados, aunque no exclusivamente comprendidos en este período histórico de conformación disciplinar, enfatizan la importancia de la profesionalidad docente, de su creatividad, de su capacidad para llevar a cabo buenas prácticas de enseñanza (Nérici, 1973; Tyler, 1973; Taba, 1977; Edelstein y Rodríguez, 1974; Schwab, 1974; Avolio, 1975; Barco, 1975; Stenhouse, 1991; cada uno con sus especificidades). Entonces, la didáctica debe reconocer el lugar y los distintos saberes del docente para iniciar y sostener un trabajo compartido.

Investigaciones contemporáneas en el campo de la didáctica (como por ejemplo las de Cols, 2011; Edelstein, 2011; y Coscarelli et al, 2013) recuperan y analizan sistemáticamente la diversidad de saberes que poseen los docentes y que ponen en juego en las distintas instancias (preactiva, interactiva y posactiva, siguiendo a Jackson, 1968) del complejo proceso de "programación de la enseñanza" (Cols, 2004).

En segundo lugar, consideramos que el momento prescriptivo en la constitución histórica de la didáctica también nos aporta elementos para pensar la normatividad en esta disciplina. Si bien establecimos desde el comienzo una diferencia entre norma y prescripción (von Wright, 1970; Camilloni, 2007d), sostenemos que algunas prescripciones son útiles para mejorar la enseñanza en los siguientes sentidos: 
4- Algunas orientaciones claras, precisas, acerca de qué hacer y cómo hacerlo, avaladas por la amplia experiencia pedagógica de la que hoy disponemos, son necesarias para iniciar una buena práctica de enseñanza. Puede suceder -y es esperable que así sea- que estas "recetas iniciales" se flexibilicen y el docente con su experiencia las vaya enriqueciendo, pero ellas fueron el primer paso firme y brindaron confianza y eficiencia en el alcance de los resultados esperados.

5- Las prescripciones contienen en su formulación la contemplación de las condiciones en las que se van a aplicar. Esto también es importante porque vimos que la cercanía de la norma a los valores y a la enunciación general (Gallino, 1995), puede abstraerla de las condiciones particulares de implementación, haciéndole perder riqueza, cercenándole a los docentes los márgenes de actuación que quiere preservar, convirtiéndola en una "prescripción cerrada" (retomamos específicamente los análisis de Schwab, 1974; y Hlebowitsh, 1998; a propósito del trabajo de Tyler, 1973).

6- Las prescripciones se asientan sobre la base de los conocimientos científicos disponibles. Si bien la exclusiva fundamentación de las prescripciones en el corpus científico es un aspecto criticado de la racionalidad tecnológica (como lo hace Angulo Rasco, 1994a; Gimeno Sacristán, 1978; y Silber, 1997), sostenemos que la recuperación de los conocimientos acumulados por la ciencia, es un aspecto a considerar en la formulación de una didáctica normativa.

En tercer lugar, del momento interpretativo en la constitución de la didáctica como disciplina rescatamos, centralmente, los siguientes aspectos:

7- La importancia de recuperar categorías de análisis provenientes de otras disciplinas para explicar comprensiva y profundamente la enseñanza como práctica social (según los sentidos vistos de Kemmis, 1990; y Gimeno Sacristán, 1997). Orientar la enseñanza demanda conocer la práctica, no al estilo de la perspectiva tecnicista o teórica, sino partiendo de los problemas de la 
práctica para buscar luego aquellos marcos conceptual-referenciales que nos aporten comprensión (particularmente Schwab, 1974; y Stenhouse, 1991).

Por un lado, sostenemos que estos aportes de la perspectiva práctica en el curriculum enriquecen la construcción de una didáctica normativa y complementan lo ya expuesto en torno a la relevancia de los saberes docentes.

Por otro lado, retomar positivamente el enriquecimiento del caudal interpretativo de la didáctica en este período no debe hacernos perder de vista su especificidad como disciplina y sus intencionalidades hacia la enseñanza (Davini, 1996; Camilloni, 1996). Son pertinentes en este sentido, las consideraciones realizadas a propósito de la importancia de conformar un corpus de conocimientos propios, además de armonizar otros provenientes de las ciencias sociales en general.

Por último, habiendo construido este camino particular para estudiar la didáctica como disciplina, nos encontramos frente al desafío de enriquecer este momento actual de reconceptualización en vistas a la construcción de una didáctica normativa.

Queda pendiente aquí una indagación de la constitución de la base normativa de la didáctica en el contexto de florecimiento de teorías posmodernas y poscríticas en el campo de las ciencias sociales (Da Silva, 2001). La construcción de la imagen-guía de la norma didáctica ancla sus raíces en una concepción moderna de la educación y de la teorización educativa orientadas por una determinada racionalidad y hacia el logro de un cambio o el alcance de mayor progreso (Gimeno Sacristán, 1998). Por lo que queda abierta la pregunta acerca de si es posible pensar la "normatividad", al menos en el sentido antes enunciado, en la posmodernidad, orientando qué sujetos y qué prácticas, para qué finalidades, y desde qué marco conceptual-referencial. 


\section{BIBLIOGRAFÍA CONSULTADA}

ACHILLI, Elena Libia. (1996). Práctica docente y diversidad sociocultural. Los desafíos de la igualdad educativa frente a la desigualdad social. Rosario: Homo Sapiens.

ACHILLI, Elena Libia. (2000). Investigación y formación docente (Colección Universitaria, Serie Formación Docente). Rosario, Argentina: Laborde.

ACHILLI, Elena Libia. (s/f). La práctica docente: una interpretación desde los saberes del maestro. s/l: s/e.

AEBLI, Hans. (1958). Una didáctica fundada en la psicología de Jean Piaget. Buenos Aires: Kapelusz.

ALI JAFELLA, Sara. (1999). Perspectivas filosóficas en las teorías de la educación de Argentina en el siglo XX. Un enfoque desde la formación de profesores. Ponencia presentada en el I Congreso Nacional de Investigación Educativa Cipolletti, Río Negro.

ALI JAFELLA, Sara. (2001). Período fundacional de la Universidad Nacional de La Plata (1905-1920): Influencias filosóficas, científicas y educacionales. Ponencia presentada en el II Congreso de Investigación Educacional, Universidad Nacional del Comahue. Cipolletti, Río Negro.

ALI JAFELLA, Sara. (2002). Oposiciones epistemológicas en el ámbito universitario de Argentina y Estados Unidos a partir de la declinación del pensamiento positivista: 1920-1950. Una aproximación desde la formación de profesores en filosofía y ciencias de la educación. Ponencia presentada en el Tercer Encuentro "La Universidad como Objeto de Investigación", Departamento de Sociología, Facultad de Humanidades y Ciencias de la Educación, Universidad Nacional de La Plata.

ALI JAFELLA, Sara. (2006). Travesías filosóficas y sociales de la "escuela nueva" en Europa y Estados Unidos (1a. ed.). (Colección Universitaria). La Plata: Al Margen.

ALTAMIRANO, Carlos. (2006). Intelectuales. Notas de investigación (Enciclopedia Latinoamericana de Sociocultura y Comunicación). Colombia: Norma.

ÁLVAREZ MÉNDEZ, Juan Manuel. (2001). Entender la Didáctica, entender el Curriculum. Buenos Aires: Miño y Dávila. Capítulo 5: “Didáctica y Curriculum: dos tradiciones, dos culturas, un campo común de estudio y de trabajo". (pp.171-184).

AMANTEA, Alejandra, CAPPELLETTI, Graciela, COLS, Estela, y FEENEY, Silvina. (2004). "Concepciones sobre curriculum, el contenido escolar y el profesor en los procesos de elaboración de textos curriculares en Argentina". Archivos Analíticos de Política Educativa, 12(40).

ANDRÉU ABELA, Jaime. (2001). Las técnicas de análisis de contenido: una revisión actualizada. Documento de trabajo CENTRA 2001/03. http://public.centrodeestudiosandaluces.es/pdfs/S200103.pdf, consultado 17/09/2009.

ANGULO RASCO, José Félix. (1994a). “Enfoque tecnológico del curriculum (capítulo 5)". Angulo Rasco, José Félix, y Blanco, Nieves (Coords.), Teoría y desarrollo del curriculum (pp.79-109). Málaga: Aljibe.

ANGULO RASCO, José Félix. (1994b). “Enfoque práctico del curriculum (capítulo 6)”. Angulo Rasco, José Félix, y Blanco García, Nieves. Op.cit. (pp.111-132). 
ARAUJO, Sonia. (2006). Docencia y enseñanza. Una introducción a la didáctica (1a. ed.). (Cuadernos Universitarios) No. 13. Bernal, Buenos Aires: Universidad Nacional de Quilmes.

ARCHENTI, Nélida, y PIOVANI, Juan Ignacio. (2007). “Los debates metodológicos contemporáneos (capítulo 2)". Marradi, Alberto, Archenti, Nélida, y Piovani, Juan Ignacio. Metodología de las ciencias sociales (1a. ed., pp.29-46). Buenos Aires: Emecé.

ARCHENTI, Nélida. (2007). “El sondeo (capítulo 11)”. Marradi, Alberto, Archenti, Nélida, y Piovani, Juan Ignacio. Op.Cit. (1a. ed., pp. 203-214).

ARDOINO, Jacques. (2005). Complejidad y formación. Pensar la educación desde una mirada epistemológica (1a. ed.). (Colección formación de formadores) No. 13. Buenos Aires: Novedades Educativas; Facultad de Filosofía y Letras, Universidad de Buenos Aires.

AROSKIND, Ricardo. (2003). “El país del desarrollo posible (capítulo II)”. James, Daniel (Director del tomo), Nueva Historia Argentina - Tomo 9: Violencia, proscripción y autoritarismo (1955-1976) (1a. ed., pp. 63-116). Buenos Aires: Sudamericana.

ASSAEL, Jenny, EDWARDS, Verónica, y LÓPEZ, Graciela. (1992). Apuntes sobre el proceso de construcción etnográfica en la investigación educativa. Apuntes etnográficos del Programa Interdisciplinario de Investigaciones en Educación Chile: Mimeo.

ASTOLFI, Jean Pierre. (1993). Trois paradigmes pour les recherches en didactique. Revue Francaise de Pedagogie. (Traducción a cargo de la Residencia de Traducción I.E.S. en Lenguas Vivas-UBA), (N 103), 5-18.

AVOLIO DE COLS, Susana. (1975). La tarea docente. Buenos Aires: Marymar.

BAQUERO, Ricardo, DIKER, Gabriela, y FRIGERIO, Graciela. (2007). Las formas de lo escolar (1a. ed.). (Serie Educación). Buenos Aires: del Estante Editorial.

BARBOSA MOREIRA, Antonio Flavio. (1999). “Didáctica y curriculum: cuestionando fronteras". Propuesta Educativa. Novedades Educativas, FLACSO, (Año 10, N²0), 2430 .

BARCO DE SURGHI, Susana. (1975). “¿Antididáctica o nueva didáctica? (capítulo VII)". Illich, Ivan; Barreiro, Telma; Barbosa Faría, Regina; et al. Crisis en la didáctica (1a. ed., Vol. $2^{\circ}$ parte, pp.93-125). Argentina: Axis, Revista de Ciencias de la Educación.

BARCO DE SURGHI, Susana. (1989). "Estado actual de la pedagogía y la didáctica". Revista Argentina de Educación. Asociación de Graduados en Ciencias de la Educación, (Año VII, N 12), 7-23.

BARCO DE SURGHI, Susana. (1996). "Formulación participativa del currículo universitario: ¿quién dijo que no se puede?". Congreso Internacional de Educación, Universidad Nacional de Buenos Aires, Facultad de Filosofía y Letras.

BARCO DE SURGHI, Susana. (2008). “Prácticas participativas en la elaboración de documentos curriculares", conferencia dictada en la Facultad de Humanidades y Ciencias de la Educación, Universidad Nacional de La Plata, 28/10/2008.

BASABE, Laura, COLS, Estela B., y FEENEY, Silvina. (2004). "Los componentes del contenido escolar". Ficha de la cátedra de "Didáctica I", Facultad de Filosofía y Letras, Universidad de Buenos Aires Oficina de Publicaciones de la Facultad de Filosofía y Letras.

BASABE, Laura, y COLS, Estela. (2007). “La enseñanza (capítulo 6)”. Camilloni, Alicia (2007a) (Comp.), El saber didáctico (1a. ed., pp.125-161). Buenos Aires: Paidós. 
BASABE, Laura. (2007). "Acerca de los usos de la teoría didáctica (capítulo 8)". Camilloni, Alicia. Op.cit. (pp.201-231).

BATALLÁN, Graciela, y GARCÍA, Fernando. (1992). “La especificidad del trabajo docente y la transformación escolar". Alliaud, Andrea, y Duschatzky, Laura (Comps.), Maestros. Formación, práctica y transformación escolar (pp.217-233). Buenos Aires: Miño y Dávila.

BATALLÁN, Graciela. (2007). Docentes de infancia. Antropología del trabajo en la escuela primaria (1a. ed.). Buenos Aires: Paidós.

BECKER SOARES, Magda. (1985). “Didáctica, una disciplina en busca de su identidad". Revista A.N.D.E. Universidad Federal de Mina Gerais, (Año 5, No 9), 1-9.

BERNSTEIN, Basil. (1990). Poder, educación y conciencia. Sociología de la transmisión cultural (1a. ed.). Barcelona: El Roure.

BERNSTEIN, Basil. (1993). La estructura del discurso pedagógico. Madrid: Morata.

BERNSTEIN, Richard. (1982). La reestructuración de la teoría social y política. México: Fondo de Cultura Económica.

BLOOR, David. (1998). Conocimiento e imaginario social (1a. ed.). (CLA-DE-MA sociología). Barcelona: Gedisa. 1971.

BOLÍVAR BOTIA, Antonio. (1999). “Modelos de diseño curricular de corte crítico y postmoderno: descripción y balance (capítulo 6)". Escudero Muñoz, José María (Editor), Diseño, desarrollo e innovación del curriculum (pp. 145-162). Madrid: Síntesis.

BOLIVAR BOTIA, Antonio. (2008). Didáctica y curriculum: de la modernidad a la posmodernidad. Málaga: Aljibe.

BOURDIEU, Pierre, y GROS, François. (1997). “Principios para una reflexión sobre los contenidos de la enseñanza (capítulo 9)". Bourdieu, Pierre Capital cultural, escuela y espacio social (pp. 129-144). México: Siglo XXI.

BRASLAVSKY, Cecilia, y RIQUELME, Graciela G. (1984). Propuestas para el debate educativo en 1984 (Biblioteca Política Argentina) No. 63. Buenos Aires: Centro Editor de América Latina.

BRUNER, Jerome S. (1969). Hacia una teoría de la instrucción (1a. ed.). México: UTHEA.

BRUNER, Jerome S. (1988). Realidad mental y mundos posibles. Los actos de la imaginación que dan sentido a la experiencia. España: Gedisa. Capítulo X: "La teoría del desarrollo como cultura" (pp.138-152).

CAMILLONI, Alicia (2001). "Modalidades y proyectos de cambio curricular". Aportes para el Cambio Curricular en Argentina 2001 (pp.23-52). Universidad de Buenos Aires, Facultad de Medicina, OPS/OMS. Disponible en http://www.cbc.uba.ar/noti/jornada_iep/PC_Camilloni.pdf Consultado 28/04/2010.

CAMILLONI, Alicia. (1993). “Epistemología de la didáctica de las ciencias sociales (capítulo 1)". Aisenberg, Beatriz, y Alderoqui, Silvia (Comps.), Didáctica de las ciencias sociales. Aportes y reflexiones (1a. ed., pp.25-41). Buenos Aires: Paidós.

CAMILLONI, Alicia. (1996). “De herencias, deudas y legados. Una introducción a las corrientes actuales de la didáctica (capítulo 1)". Camilloni, Alicia, Davini, María Cristina, Edelstein, Gloria, Litwin, Edith, Souto, Marta, y Barco, Susana Corrientes didácticas contemporáneas (pp. 17-39). Buenos Aires: Paidós. 
CAMILLONI, Alicia (2001). "Modalidades y proyectos de cambio curricular". Aportes para un cambio curricular en Argentina 2001 (pp.23-52). Universidad de Buenos Aires, Facultad de Medicina, OPS/OMS. Disponible en http://www.cbc.uba.ar/noti/jornada_iep/PC_Camilloni.pdf Consultado 28/04/2010.

CAMILLONI, Alicia. (2006). Notas para una historia de la Teoría del Currículo. Ficha de la cátedra "Didáctica I", Facultad de Filosofía y Letras, Universidad de Buenos Aires. Buenos Aires: Facultad de Filosofía y Letras, Universidad de Buenos Aires.

CAMILLONI, Alicia. (2007b). "Justificación de la didáctica (capítulo 1)". Camilloni, Alicia (2007a). (Comp.). Op.cit. (pp.19-22).

CAMILLONI, Alicia. (2007c). “Didáctica general y didácticas específicas (capítulo 2)”. Camilloni, Alicia (2007a). (Comp.). Op.cit. (pp.23-39).

CAMILLONI, Alicia. (2007d). “Los profesores y el saber didáctico (capítulo 3)”. Camilloni, Alicia. (2007a). (Comp.). Op.cit. (pp.41-60).

CAMILLONI, Alicia. (2007e). “El sujeto del discurso didáctico (capítulo 4)”. Camilloni, Alicia. (2007a). (Comp.). Op.cit. (pp.61-70).

CAMILLONI, Alicia. (2013). “Las metáforas conceptuales en el discurso pedagógico". Conferencia de apertura de las VII Jornadas Nacionales sobre la Formación del Profesorado: "Narrativa(s), Práctica(s) e Investigación(es)". Mar del Plata. 12, 13 y 14 de septiembre.

CANDAU, Vera Maria. (1996). “A revisăo da Didática (capítulo I)”. Candau, Vera Maria (Org.), Rumo a uma nova didática (8a. ed., pp.13-18). Petrópolis: Vozes.

CAPPELLETTI, Graciela, y FEENEY, Silvina. (2000). El curriculum en la Argentina: la búsqueda de un lugar. Trabajo presentado en el grupo de trabajo $N^{o} 12$ "curriculum" de la $23^{a}$ reunião anual Associação Nacional de Pós-Graduação e Pesquisa em Educação. http://168.96.200.17/ar/libros/anped/1220T.PDF, consultado 13/06/2010.

CARLI, Sandra. (2002). Niñez, pedagogía y política. Transformaciones de los discursos acerca de la infancia en la historia de la educación argentina entre 1880 y 1955 (1a. ed.). Buenos Aires: Miño y Dávila.

CARLINO, Florencia Ruth. (1999). El evaluación educacional. Historia, problemas y propuestas (1a. ed.). Buenos Aires: Aique.

CARR, Wilfred, y KEMMIS, Stephen. (1988). Teoría crítica de la enseñanza. España: Martínez Roca.

CARR, Wilfred. (1996). Una teoría para la educación. Hacia una investigación educativa crítica. Madrid: Morata, Fundación Paideia.

CARUSO, Marcelo, y DUSSEL, Inés. (2009). “Dewey en Argentina (1916-1946): Tradición, intención y situación en la producción de una lectura selectiva". Encuentros Sobre Educación, 10, 23-41.

CASTIÑEIRAS, Julio R. (1985). Historia de la Universidad de La Plata (II). La Plata: Universidad Nacional de La Plata. Fascímile de la primera edición de 1940.

CASTRO, Edgardo. (2004). El vocabulario de Michel Foucault. Un recorrido alfabético por sus temas, conceptos y autores. Bernal: Universidad Nacional de Quilmes.

CHADWICK, Clifton B. (1992). Tecnología educacional para el docente (3a. revisada y ampliada ed.). (Paidós Educador) No. 75. Barcelona: Paidós. 1977. 
CIVAROLA, María Mercedes. (2005). "Una nueva lectura sobre la idea de didáctica". Revista Internacional Magisterio, (16). http:/ / revista.magisterio.com.co/index.php?option=com_content\&task=view\&id=76 \&Itemid=96, consultado 20/06/2007

COLS, Estela B. (2000a). “La enseñanza y los profesores: metáforas, modelos y formas de enseñar". Revista del Instituto de Investigaciones en Ciencias de la Educación (IICE), (Año IX, No 17), 8-22.

COLS, Estela B. (2003a). El campo de la didáctica: recorrido histórico y perspectivas actuales. Ficha de circulación interna de la cátedra "Didáctica", Facultad de Humanidades y Ciencias de la Educación, Universidad Nacional de La Plata.

COLS, Estela B. (2003b). “La enseñanza como acción del profesor: tradiciones de investigación y propuestas". III Jornadas de investigación en Educación, Educación y procesos sociales actuales: respuestas, compromisos y tensiones. Centro de Investigaciones de la Facultad de Filosofía y Humanidades, Universidad Nacional de Córdoba. Mimeo.

COLS, Estela B. (2004). "Programación de la enseñanza". Ficha de la cátedra de "Didáctica I", Facultad de Filosofía y Letras, Universidad de Buenos Aires Oficina de Publicaciones de la Facultad de Filosofía y Letras.

COLS, Estela B. (2007). "Problemas de la enseñanza y propuestas didácticas a través del tiempo (capítulo 5)”. Camilloni, Alicia. (2007a). (Comp.). Op.cit. (pp.71-124).

COLS, Estela B. (2011). Estilos de enseñanza. Sentidos personales y configuraciones de acción tras la semejanza de las palabras (1a. ed.). (Enfoques y perspectivas). Rosario, Argentina: Homo Sapiens.

COLS, Estela, AMANTEA, Alejandra, CAPPELLETTI, Graciela, y FEENEY, Silvina. (2002). Los procesos de diseño curricular en la Argentina: diversidad de tradiciones sobre el curriculum, el contenido y el profesor. Trabajo realizado en el marco del Proyecto UBACyT F015 "Tendencias en el diseño y desarrollo del currículum" (Período 2000-2002), directora Alicia Camilloni. Universidad de Buenos Aires, Facultad de Filosofía y Letras, IICE. Mimeo.

COLS, Estela. (2000b). Las intenciones educativas: objetivos y contenidos. Ficha de circulación interna de la cátedra "Didáctica General", Facultad de Humanidades y Ciencias de la Educación, Universidad Nacional de La Plata Mimeo.

COMENIO, Joan A. (2000). Didáctica Magna (11a. ed.). ("Sepan cuántos...") No. 167. México: Porrúa. 1922.

CONGRESO PEDAGÓGICO (1988). Informe final de la Asamblea Nacional. Buenos Aires: EUDEBA.

CONGRESO PEDAGÓGICO (1988). Informe sobre posibles reformas del sistema educativo. Buenos Aires: EUDEBA.

CONTRERAS DOMINGO, José. (1990). Enseñanza, curriculum y profesorado. Introducción crítica a la didáctica. Madrid: Akal.

CORDERO ARROYO, Graciela, y GARCÍA GARDUÑO, José María. (2004). “The Tylerian curriculum model and the reconceptualists. Interview with Ralph W. Tyler (1902-1994)". Revista Electrónica de Investigación Educativa, 6 (2). http://redie.uabc.mx/vol6no2/contents-cordero.html, consultado 30/06/2005

COSCARELLI, María Raquel; DUMRAUF, Ana; CORDERO, Silvina; TRAVERSO, Viviana; PICCO, Sofía; ORELLANO, Verónica; LÓPEZ, Aldana; VOLPE, Silvina; 
DONADI, Vanesa; MONTENEGRO, Jesica; ORIENTI, Noelia (2013). Informe final del proyecto de investigación "Programación de la enseñanza en la escuela primaria: discursos y prácticas", Facultad de Humanidades y Ciencias de la Educación, Universidad Nacional de La Plata, Programa de Incentivos a la Investigación, Ministerio de Ciencia, Tecnología e Innovación Productiva de la Nación. (H588).

COSCARELLI, María Raquel, y PICCO, Sofía. (2006). "Formación de formadores en los proyectos de extensión universitaria: aportes para la reflexión". Revista Escenarios/11 Relaciones entre Universidades y Sociedad: Algunas Reflexiones Teóricas y Experiencias Interdisciplinarias de Proyectos de Extensión, (Año 6, N 11), 35-44.

COSCARELLI, María Raquel, y PICCO, Sofía. (2009). “Protocurriculum: sentidos dispersos en un campo complejo (capítulo 2)". Coscarelli, María Raquel (Comp.), La extensión universitaria: sujetos, formación y saberes (pp.63-85). La Plata: Facultad de Periodismo y Comunicación Social, Universidad Nacional de La Plata.

DA SILVA, Tomaz Tadeu. (2001). Espacios de Identidad (1a. ed.). Barcelona: Octaedro.

DAVINI, María Cristina. (1995). La formación docente en cuestión: política y pedagogía (1a. ed.). Buenos Aires: Paidós.

DAVINI, María Cristina. (1996). "Conflictos en la evolución de la didáctica. La demarcación de la didáctica general y las didácticas especiales (capítulo 2)". Camilloni, Alicia; Davini, María Cristina; Edelstein, Gloria; et al. Op.cit. (pp.41-73).

DAVINI, María Cristina. (1998). El curriculum de formación de magisterio. Planes de estudio y programas de enseñanza (Investigaciones sobre formación docente) No. II. Buenos Aires: Miño y Dávila.

DAVINI, María Cristina. (2008). Métodos de enseñanza. Didáctica general para maestros y profesores (1a. ed.). Buenos Aires: Santillana.

DE ALBA, Alicia. (1991). Evaluación curricular. Conformación conceptual del campo. México: Universidad Nacional Autónoma de México. Capítulo tercero: "Evaluación curricular: corte y articulación conceptual, compromiso y direccionalidad" (pp. 116161).

DE ALBA, Alicia. (1995). Curriculum: Crisis, Mito y Perspectivas. Buenos Aires: Miño y Dávila.

DE LA MORA, Gabriel. (2000). “Prólogo". Comenio, Joan A. Didáctica Magna (11a. ed., p.IX-XXXVIII). México: Porrúa.

DE VITA, Graciela y equipo técnico. (2009). “La planificación desde un curriculum prescripto". Subsecretaría de Educación, Dirección Provincial de Planeamiento, Dirección General de Cultura y Educación, Provincia de Buenos Aires. Disponible en http://abc.gov.ar/lainstitucion/organismos/direccionprovincialplaneamiento/defaul t.cfm, consultado 11/07/2011.

DELAMONT, Sara. (1984). La interacción didáctica. Madrid: Cincel, Kapelusz.

DÍAZ BARRIGA, Ángel. (1991). Didáctica y curriculum. Convergencias en los programas de estudio (12a. ed.). México: Ediciones Nuevomar S.A. de C.V. 1984.

DÍAZ BARRIGA, Ángel. (1994). El currículo escolar. Surgimiento y perspectivas (2a. ed.). Buenos Aires: Rei Argentina; Instituto de Estudio y Acción Social; Aique. 1992.

DÍAZ BARRIGA, Ángel. (1998). “La investigación en el campo de la didáctica. Modelos históricos". Revista Perfiles. CESU-UNAM, (79-80). 
DÍAZ, Esther. (1997). “Conocimiento, ciencia y epistemología”. Díaz, Esther (Editora), Metodología de las ciencias sociales (1a. ed., pp. 13-28). Buenos Aires: Biblos.

Diccionario de la Lengua Española de la Real Academia Española. (2001). 22a edición. Disponible en http://www.rae.es/rae.html

Diccionario de las Ciencias de la Educación. (1995). $1^{\text {a }}$ edición. México: Aula Santillana.

Dirección General de Cultura y Educación (2007). Marco General de Política Curricular. Niveles y modalidades del sistema educativo. Provincia de Buenos Aires.

DUSSEL, Inés, y CARUSO, Marcelo. (1999). La invención del aula. Una genealogía de las formas de enseñar (1a. ed.). Buenos Aires: Santillana.

DUSSEL, Inés. (2004). "Inclusión y exclusión en la escuela moderna argentina: una perspectiva postestructuralista". Cuadernos de Pesquisa, 34 (122), 305-335.

DUSSEL, Inés. (2010). “El curriculum”. Explora. Las ciencias en el mundo contemporáneo. Programa de Capacitación Multimedial, Ministerio de Educación de la Nación. Disponible en http://explora.educ.ar/wp-content/uploads/2010/04/PEDAG07-Elcurriculum.pdf, consultado 03/05/2012.

EDELSTEIN, Gloria, y LITWIN, Edith. (1993). “Nuevos debates en las estrategias metodológicas del curriculum universitario". Revista Argentina de Educación. Asociación de Graduados en Ciencias de la Educación, (Año XI, No19), 79-86.

EDELSTEIN, Gloria, y RODRÍGUEZ OUSSET, Azucena. (1974). “El método: factor definitorio y unificador de la instrumentación didáctica". Revista de Ciencias de la Educación, (Año IV, Nº12), 21-33.

EDELSTEIN, Gloria. (1996). "Un capítulo pendiente: el método en el debate didáctico (capítulo 3)". Camilloni, Alicia, et al. Op.cit. (pp.75-89).

EDELSTEIN, Gloria. (2011). Formar y formarse en la enseñanza (1a. ed.). Buenos Aires: Paidós.

EGAN, Kieran. (2000): Mentes educadas. Barcelona, Editorial Paidós.

EGGEN, P., y KAUCHAK, D. (1999). Estrategias docentes. México: Fondo de Cultura Económica.

EISNER, Elliot W. (1989). “Los objetivos educativos ¿ayuda o estorbo?”. Gimeno Sacristán, José, y Pérez Gómez, Ángel I. (Compiladores), La enseñanza: su teoría y su práctica (3a. ed., pp. 257-264). Madrid: Akal.

ELLIOTT, John. (1994). "Un curriculum para el estudio de los asuntos humanos: la contribución de Lawrence Stenhouse (capítulo XIII)". Elliott, John La investigaciónacción en educación (2a. ed., pp. 263-282). Madrid: Morata.

ELLIOTT, John. (1995). “El papel del profesorado en el desarrollo curricular: una cuestión irresuelta en los intentos ingleses de reforma curricular". AA.VV. Volver a pensar la educación. Prácticas y discursos educativos. (Congreso Internacional de Didáctica) (1a. ed., Vol. II, pp.245-272). España: Fundación Paideia; Morata.

ELMORE, Richard, y SYKES, Gary. (1992). "Curriculum policy". Jackson, Philip (Editor), Handbook of Research on Curriculum (pp. 185-215). Nueva York: Macmillan. Versión en español de Cols, Estela y Feeney, Silvina. Mimeo.

ERICKSON, Frederick. (1990). "Métodos cualitativos de investigación sobre la enseñanza (capítulo IV)". Wittrock, Merlin C. La investigación de la enseñanza, II. Métodos 
cualitativos y de observación (1a. ed., pp.195-247). Madrid: Centro de Publicaciones Ministerio de Educación y Cultura y Paidós Ibérica.

ESCOLANO, Agustín, SÁNCHEZ DE ZAVALA, Víctor, FERNÁNDEZ PÉREZ, Miguel, QUINTANILLA, Miguel A., CASTRO SANTAMARÍA, Ramiro, CARRASCO, Joaquín G., ORTEGA, José, PÉREZ GÓMEZ, Ángel, y GIMENO SACRISTÁN, José. (1978). Epistemología y educación (Pedagogía y Sociedad) No. 8. Salamanca: Sígueme.

FATTORE, Natalia. (2007). “Apuntes sobre la forma escolar «tradicional» y sus desplazamientos". Baquero, Ricardo; Diker, Gabriela; y Frigerio, Graciela (Comps.), Las formas de lo escolar (1a. ed., pp.13-32). Buenos Aires: Del Estante.

FEENEY, Silvina. (2007). "La emergencia de los estudios sobre el currículo en la Argentina (capítulo 7)”. Camilloni, Alicia. (2007a). (Comp.). Op.cit. (pp.163-199).

FELDMAN, Daniel, y PALAMIDESSI, Mariano. (1994). “Viejos y nuevos planes. El currículum como texto normativo". Propuesta Educativa, Año 5 (11), 69-73.

FELDMAN, Daniel, y PALAMIDESSI, Mariano. (2001). “Programación de la enseñanza en la universidad. Problemas y enfoques". Colección Universidad y Educación: Serie Formación Docente $N^{o} 1$ Universidad Nacional de General Sarmiento.

FELDMAN, Daniel. (2002). "Reconceptualizaciones en el campo de la didáctica". Didática e Práticas De Ensino: Interfaces Com Diferentes Saberes e Lugares Formativos. Río De Janeiro, XI ENDIPE DPEA Editora Ltda, 69-84.

FELDMAN, Daniel. (2008). Ayudar a enseñar. Relaciones entre didáctica y enseñanza (1a. edición, 2a. reimpresión ed.). Buenos Aires: Aique. 1999.

FELDMAN, Daniel. (2010a). Didáctica general. Aportes para el desarrollo curricular: Instituto Nacional de Formación Docente (INFod) Argentina: Ministerio de Educación. http://www.me.gov.ar/infod/documentos/didactica_general.pdf, consultado 26/06/2010.

FELDMAN, Daniel. (2010b). Enseñanza y escuela (1a. ed.). Buenos Aires: Paidós.

FENSTERMACHER, Gary D. (1989). “Tres aspectos de la filosofía de la investigación sobre la enseñanza". Wittrock, Merlin C. La investigación de la enseñanza, I. Enfoques, teorías y métodos (1a. ed., Vol. I, pp. 149-179). Madrid: Centro de Publicaciones Ministerio de Educación y Cultura y Paidós Ibérica.

FERRATER MORA, José. (1994). Diccionario de Filosofía (1a. edición revisada, aumentada y actualizada ed.). Barcelona: Ariel S.A.

FINOCCHIO, Silvia (2007). "Del quiosco al aula. Lecturas docentes”. Tesis de Doctorado. Doctorado en Ciencias Sociales, Facultad Latinoamericana de Ciencias Sociales (FLACSO), Sede Académica Argentina.

FLICK, Uwe. (2007). Introducción a la investigación cualitativa (2a. ed.). Madrid: Morata. 2004.

FOLLARI, Roberto. (2000). Epistemología y sociedad. Acerca del debate contemporáneo. Rosario: Homo Sapiens.

FRIGERIO, Graciela. (1991). “Curriculum: norma, intersticios, transposición y textos (capítulo 1)". Frigerio, Graciela (Comp.), Curriculum presente ciencia ausente. Normas, teorías y críticas (1a. ed., Vol. I, pp.17-45). Buenos Aires: Miño y Dávila; FLACSO.

FUMAGALLI, Laura (2008). "El curriculum como norma pública". Diplomatura en Curriculum y Prácticas Escolares en Contexto. Buenos Aires: FLACSO Virtual. 
FURLÁN, Alfredo, y GVIRTZ, Silvina. (1999). “Didáctica y curriculum: nuevas tendencias (presentación del dossier)". Propuesta Educativa, (Año 10, № 20), 4-5.

FURLÁN, Alfredo, y PASILLAS, Miguel Ángel. (1993). “Investigación y campo pedagógico". Revista Argentina de Educación, Asociación de Graduados en Ciencias de la Educación, (Año XI, N²0), 7-26.

FURLÁN, Alfredo. (1997). La ideología del discurso curricular (1a. ed.). México: Universidad Autónoma de Sinaloa y Universidad Nacional Autónoma de México.

FURLÁN, Alfredo, y AVOLIO DE COLS, Susana. (2011). “El campo de las ciencias de la educación en la trayectoria de los actores: entrevistas a Alfredo Furlán y Susana Avolio de Cols". Revista Archivos de Ciencias de la Educación, Año 5, Nro. 5, 57-72. http://www.memoria.fahce.unlo.edu.ar/art_revistas/pr.5428/pr.5428.pdf

GAGNÉ, Robert M. (1979). Las condiciones del aprendizaje (3a. ed.). México: Nueva Editorial Interamericana. 1966.

GALLINO, Luciano. (1995). Diccionario de sociología. México: Siglo XXI Editores.

GARATTE, María Luciana. (2008). “Grupos académicos y cambios curriculares durante la normalización universitaria en Argentina 1983-1986". Tesis de Maestría. Maestría en Ciencias Sociales, Facultad Latinoamericana de Ciencias Sociales (FLACSO), Sede Académica Argentina.http://www.flacsoandes.org/dspace/bitstream/10469/1969/1/Tesis_Maria _Luciana_Garatte.pdf, consultado 15/09/2010.

GARRIDO PIMENTA, Selma. (1998). “Cap a una resignificació de la Didŕctica Cičncies de l' Educació, Pedagogía i Didŕctica-: una revisió conceptual i una síntesi provisional”. Temps d' Educació, Revista de la Divisió de Cičncies de l' Educació, Universitat de Barcelona, (19), 221-251.

GIMENO SACRISTÁN, José. (1978). “Explicación, norma y utopía en las ciencias de la educación". Escolano, Agustín Benito Epistemología y educación (pp.158-167). Salamanca: Sígueme.

GIMENO SACRISTÁN, José. (1997). “Sentido y utilidad del conocimiento y de la investigación en la práctica pedagógica (capítulo 1)". Gimeno Sacristán, José Docencia y cultura escolar. Reformas y modelo educativo (pp. 7-23). Buenos Aires: Lugar/Instituto de Estudios y Acción Social (IDEAS).

GIMENO SACRISTÁN, José. (1998). Poderes inestables en educación (Pedagogía). Madrid: Morata.

GIMENO SACRISTÁN, José. (2012). “¿Qué significa el curriculum? (capítulo II)”. Gimeno Sacristán, José, Feito Alonso, Rafael, Perremoud, Philippe, y Clemente Linuesa, María Diseño, desarrollo e innovación del curriculum (2a. ed., Vol. 1, pp. 25-47). Madrid: Morata.

GORDILLO, Mónica B. (2003). “Protesta, rebelión y movilización: de la resistencia a la lucha armada, 1955-1973 (capítulo VIII)". James, Daniel (Director del tomo), Nueva Historia Argentina - Tomo 9: Violencia, proscripción y autoritarismo (1955-1976) (1a. ed., pp. 329-380). Buenos Aires: Sudamericana.

GOODSON, Ivor F. (1995). Historia del curriculum. La construcción social de las disciplinas escolares. Barcelona: Pomares-Corredor.

GOODSON, Ivor F. (2000). El cambio en el curriculum (1a. ed.). Barcelona: Octaedro.

GRUNDY, Shirley. (1994). Producto y praxis del curriculum. Madrid: Morata. 
GUBER, Rosana. (2001). La etnografía. Método, campo y reflexividad (1a. ed.). Argentina: Grupo Editorial Norma.

HABERMAS, Jürgen. (1982). Conocimiento e interés (1a. ed.). Madrid: Taurus.

HABERMAS, Jürgen. (1992). “Conocimiento e interés”. Habermas, Jürgen Ciencia y técnica como "ideología" (2a. ed., pp.159-181). Madrid: Tecnos.

HAMILTON, David. (1993). “Orígenes de los términos educativos 'clase' y 'curriculum'". Revista Iberoamericana de Educación "Estado y Educación", (1). www.campus-oei/revista/index.html

HAMILTON, David. (1996). La transformación de la educación en el tiempo. Estudio de la educación y la enseñanza formal. México: Trillas.

HAMILTON, David. (1999). “La paradoja pedagógica (O: ¿por qué no hay una didáctica en Inglaterra?)". Revista Propuesta Educativa, (Año 10, Nº 20), 6-13.

HAMMERSLEY, Martyn, y ATKINSON, Paul. (1994). Etnografía. Métodos de investigación (1a. ed.). Barcelona: Paidós. 1983.

HLEBOWITSH, Peter S. (1998). “Reevaluación de las valoraciones del «Rationale de Tyler»". Revista de Estudios del Curriculum. Teoría del Curriculum, 1 (1), 170-189.

JACKSON, Philip. (1992). La vida en las aulas (2a. ed.). Madrid: Morata. 1968.

JOYCE, B., y WEIL, M. (2002). Modelos de enseñanza. Barcelona: Gedisa.

KEMMIS, Stephen. (1990). "Introducción". Carr, Wilfred Hacia una ciencia crítica de la educación (pp.7-38). Barcelona: Laertes.

KEMMIS, Stephen. (1993). El curriculum: más allá de la teoría de la reproducción. Madrid: Morata. 1988.

KLIEBARD, Herbert M. (1998). "Revisión del «Rationale de Tyler»". Revista de Estudios del Curriculum. Política Educativa y Reforma del Curriculum, I (2), 165-175.

KLIMOVSKY, Gregorio. (1994). Las desventuras del conocimiento científico. Una introducción a la epistemología. Buenos Aires: A-Z Editora.

KLIMOVSKY, Gregorio, e HIDALGO, Cecilia. (1998). La inexplicable sociedad. Cuestiones de epistemología de las ciencias sociales. Buenos Aires: A-Z Editora.

KREIMER, Pablo. (2005). “Estudio preliminar: El conocimiento se fabrica. ¿Cuándo? ¿Dónde? ¿Cómo?". Knorr Cetina, Karin La fabricación del conocimiento. Un ensayo sobre el carácter constructivista y contextual de la ciencia (pp.11-44). Buenos Aires: Universidad Nacional de Quilmes.

KRIPPENDORFF, Klaus. (1990). Metodología de análisis de contenido. Teoría y práctica. Barcelona: Paidós. 1980.

KRULL, Edgar. (2003). “Hilda Taba (1902-1967)". Perspectivas: revista trimestral de educación comparada. Paris: UNESCO, Oficina Internacional de Educación. Vol.XXXIII, $\mathrm{N}^{\mathrm{o}} 4$, diciembre.

LATOUR, Bruno. (1992a). "Introducción. Abrir la caja negra de Pandora". Latour, Bruno Ciencia en acción. Cómo seguir a los científicos e ingenieros a través de la sociedad (1a. ed., pp.1-17). Barcelona: Labor.

LATOUR, Bruno. (1992b). "Post scriptum. Un giro más después del giro social". Latour, Bruno Op.cit. (pp.245-261). 
LITWIN, Edith. (1997). Las configuraciones didácticas. Una nueva agenda para la enseñanza superior. Buenos Aires: Paidós.

LORES ARNAIZ, María del Rosario. (1986). Hacia una epistemología de las ciencias humanas. Buenos Aires: Belgrano.

LUNDGREN, Ulf P. (1992). Teoría del Curriculum y Escolarización. Madrid: Morata.

LUZURIAGA, Lorenzo. (1958). Pedagogía (4a. ed.). Buenos Aires: Losada.

MAGER, Robert F. (1973). Análisis de metas (1a. ed.). México: Trillas.

MANCOVSKY, Viviana. (2000). "Hacia una mirada reveladora de los procesos valorativos que recubren la interacción pedagógica (capítulo 6)". Guariglia, Osvaldo, Ferry, Gilles, Filloux, Jean-Claude, Nathanson, Jacques, Cullen, Carlos A., Mancovsky, Viviana et al. Reflexión ética en educación y formación (pp. 85-113). Buenos Aires: Novedades Educativas.

MANGANIELLO, Ethel M. (1968). Didáctica general. Desarrollo del programa de la asignatura correspondiente al 1er. año del ciclo del Magisterio (15a. ed.). Buenos Aires: Librerías del Colegio.

MANNONI, Maud. (2000). La educación imposible. México DF: Siglo XXI. 1973.

MARDONES, José María. (1991). Filosofía de las ciencias humanas y sociales. Materiales para una fundamentación científica (1a. ed.). Barcelona: Anthropos. 1982.

MARRADI, Alberto. (2007a). “Tres aproximaciones a la ciencia (capítulo 1)”. Marradi, Alberto, Archenti, Nélida, y Piovani, Juan Ignacio Op.cit. (pp.17-27).

MARRADI, Alberto. (2007b). “Método, metodología, técnicas (capítulo 3)”. Marradi, Alberto, Archenti, Nélida, y Piovani, Juan Ignacio Op.cit. (pp.47-60).

MARTÍNEZ BONAFÉ, Jaume. (2004). Esfera pública, conocimiento escolar y didáctica crítica. X Congreso Fedicaria, Valencia. http://www.fmrppv.org/eets/fedi.doc, consultado 15/06/2007.

MARTÍNEZ, Sergio F., y OLIVÉ, León. (1997). “Introducción”. Martínez, Sergio F., y Olivé, León (Comps.), Epistemología evolucionista (1a. ed., pp.11-23). México: Paidós.

MARTINS, Maria do Carmo. (2012). “Circulación de autores, teorías y métodos de investigación en Historia del Currículum". Conferencia organizada por la cátedra "Historia de la educación general", Departamento de Ciencias de la Educación, Facultad de Humanidades y Ciencias de la Educación, Universidad Nacional de La Plata. 21/11/2012.

MATTOS, Luiz Alves de. (1974). Compendio de didáctica general (2a. ed.). Buenos Aires: Kapelusz. 1973.

MEIRIEU, Philippe. (2010). Una llamada de atención. Carta a los mayores sobre los niños de hoy (1a. ed.). Madrid: Ariel. 2009.

MERTON, Robert K. (1970). Teoría y estructura sociales. México: Fondo de Cultura Económica. 1949.

MOLINER, María. (2007). Diccionario. $3^{\mathrm{a}}$. ed. Disponible en http:// www.diclib.com/cgi-bin/d1.cgi?l=en\&base=moliner\&page=showindex, consultado 25/05/2012.

NARODOWSKI, Mariano. (1994). Infancia y poder. Buenos Aires: Aique. 
NASSIF, Ricardo. (1958). Pedagogía General (1a. ed.). Buenos Aires: Kapelusz.

NASSIF, Ricardo. (1980). Teoría de la educación. Problemática pedagógica contemporánea. Buenos Aires: Cincel.

NÉRICI, Imídeo Giuseppe. (1973). Hacia una didáctica general dinámica (2a.ed.). Buenos Aires: Kapelusz. 1966.

NOVARO, Marcos y PALERMO, Vicente. (2003). La dictadura militar (1976-1983). Del golpe de estado a la restauración democrática. Buenos Aires: Paidós. Caps. 1 y 2.

OLIVÉ, León. (1985). La explicación social del conocimiento (1a. ed.). México: Universidad Nacional Autónoma de México.

OLIVÉ, León. (1995). Racionalidad epistémica. Madrid: Trotta.

OLIVÉ, León. (2004). “De la estructura normativa de la ciencia a las prácticas científicas. Normas y valores en la ciencia: La concepción mertoniana y el enfoque "practicista»". Valero Matas, Jesús A. (Coord.), Sociología de la ciencia (pp.57-80). Madrid: EDAF.

OLMEDO, Mariana. (2006). Pedagogía y Ciencias de la Educación: estudio comparativo. Tesina de la Licenciatura en Ciencias de la Educación, Facultad de Humanidades y Ciencias de la Educación, Universidad Nacional de La Plata.

ORIENTI, Noelia A. (2012). Estrategias de enseñanza. Ficha de circulación interna de la cátedra "Didáctica y curriculum", Facultad de Humanidades y Ciencias de la Educación, Universidad Nacional de La Plata Mimeo.

OROZCO FUENTES, Bertha. (2009). “Competencias y curriculum: una relación tensa y compleja".http://www.riseu.unam.mx/documentos/acervo_documental/txtid0057.p df, consultado $23 / 01 / 2012$.

PALAMIDESSI, Mariano, y FELDMAN, Daniel. (2003). "The development of curriculum thinking in Argentina (chapter 6)". Pinar, William (Editor), International Handbook of Curriculum Research (pp. 109-122). New Jersey: Lawrence Erlbaum.

PARDO, Rubén H. (1997). “La problemática del método en ciencias naturales y sociales". Díaz, Esther (Editora), Metodología de las ciencias sociales (1a. ed., pp. 67-95). Buenos Aires: Biblos.

PARRA, Gustavo, y PASILLAS MIGUEL ÁNGEL. (1991). “Lo sustancial y lo accesorio en el curriculum". Revista Argentina de Educación, (Año IX, N 16), 29-50.

PÉREZ GÓMEZ, Ángel I. (1993a). “Comprender la enseñanza en la escuela. Modelos metodológicos de investigación educativa (capítulo V)". Gimeno Sacristán, José, y Pérez Gómez, Ángel I. Comprender y transformar la enseñanza. (2a. ed., pp.115-136). Madrid: Morata.

PÉREZ GÓMEZ, Ángel I. (1993b). “La función y formación del profesor/a en la enseñanza para la comprensión. Diferentes perspectivas (capítulo XI)". Gimeno Sacristán, José, y Pérez Gómez, Ángel I. Op.cit. (pp.398-429).

PÉREZ SERRANO, Gloria. (1994). Investigación cualitativa. Retos e interrogantes. II Técnicas y análisis de datos (Colección Aula Abierta). Madrid: La Muralla.

PERRENOUD, Philippe. (2004). Diez nuevas competencias para enseñar (1a. ed.). Barcelona: Graó. 1999. 
PICCO, Sofía. (2007): “Metodología de la enseñanza y formación del profesorado: el caso de la Sección Pedagógica y la Facultad de Ciencias de la Educción en la Universidad Nacional de La Plata entre 1906 y 1920". (En línea). Tesina de la Licenciatura en Ciencias de la Educación publicada en el repositorio institucional "Memoria Académica", Facultad de Humanidades y Ciencias de la Educación, Universidad Nacional de La Plata Disponible en: http://www.fuentesmemoria.fahce.unlp.edu.ar/tesis/te.273/te.273.pdf

PICCO, Sofía. (2010): “La normatividad en discusión: El caso de la didáctica a partir de debates epistemológicos y metodológicos contemporáneos". (En línea). Tesis de la Maestría en Ciencias Sociales, publicada en el repositorio institucional "Memoria Académica", Facultad de Humanidades y Ciencias de la Educación, Universidad Nacional de La Plata. Disponible en: http://www.memoria.fahce.unlp.edu.ar/tesis/te.390/te.390.pdf

PINEAU, Pablo, DUSSEL, Inés, y CARUSO, Marcelo. (2001). La escuela como máquina de educar. Tres escrito sobre un proyecto de la modernidad. Buenos Aires: Paidós.

PINEAU, Pablo. (1996). "La escuela en el paisaje moderno. Consideraciones sobre el proceso de escolarización”. Cucuza, Rubén (Comp.), Historia de la educación en debate. Buenos Aires: Miño y Dávila.

PIOVANI, Juan Ignacio coordinador, ADRIANI, Luis, ALZUGARAY, Lucas, EGUÍA, Amalia, GÓMEZ ROJAS, Valeria, IULIANO, Rodolfo et. al. (2008). "Producción y reproducción de sentidos en torno a lo cualitativo y lo cuantitativo en la sociología". Cohen, Néstor, y Piovani, Juan Ignacio (Comps.), La metodología de la investigación en debate (1a. ed., pp.121-196). Buenos Aires: EDULP; EUDEBA.

PIOVANI, Juan Ignacio. (2006). "Relativismo y representación de la diversidad cultural: hacia una integración de la reflexión filosófica y la investigación empírica". Di Gregori, María Cristina, y Di Berardino, A. (Eds.), Conocimiento, realidad y relativismo (pp.193-207). México: UNAM.

PIOVANI, Juan Ignacio. (2007). “La entrevista en profundidad (capítulo 12)”. Marradi, Alberto, Archenti, Nélida, y Piovani, Juan Ignacio. Op.Cit. (1a. ed., pp. 215-225).

PIOVANI, Juan Ignacion. (2014). “Teoría”. En: Carballo, Carlos. (Director). Primer Diccionario Crítico de la Educación Física Académica Argentina. En preparación.

POGGI, Margarita. (1997). "Sobre continentes y contenidos: el aprendizaje escolar". Poggi, Margarita (Comp.), Apuntes y aportes para la gestión curricular (pp.79-100). Buenos Aires: Kapelusz.

POPKEWITZ, Thomas S. (1988). Paradigmas e ideología en investigación educativa. Las funciones sociales del intelectual. Madrid: Mondadori.

PREGO, Carlos A. (1992). Las bases sociales del conocimiento científico. La revolución cognitiva en sociología de la ciencia. Buenos Aires: Centro Editor de América Latina.

PRUZZO, Vilma. (2006). "La didáctica: su reconstrucción desde la historia". Praxis Educativa. Facultad de Ciencias Humanas, Universidad Nacional de La Pampa. ( $\left.{ }^{\circ} 10\right)$, 39-49.

Disponible

en http://www.biblioteca.unlpam.edu.ar/pubpdf/praxis/n10a07pruzzo.pdf, consultado 12/06/2013. 
PUIGGRÓS, Adriana. (1990). Sujetos, Disciplina y Curriculum en los orígenes del sistema educativo argentino (Historia de la educación argentina) No. I. Buenos Aires: Galerna.

PUIGGRÓS, Adriana. (1998). Qué pasó en la educación argentina. Desde la conquista al menemismo. Buenos Aires: Kapelusz.

RAVECQ, María Magdalena. (1957). “Comenius, apóstol de la educación. El precursor de la educación moderna". El correo de la UNESCO. (Año X, Noviembre), 4-15. Disponible en http://unesdoc.unesco.org/images/0006/000679/067956so.pdf, consultado 12/6/2013

REAL ACADEMIA ESPAÑOLA (2001). Diccionario de la Lengua Española. 22a.ed. Disponible en http://www.rae.es/rae.html

SALINAS FERNÁNDEZ, Bernardino. (1995). "Límites del discurso didáctico actual". AA.VV. Volver a pensar la educación. Prácticas y discursos educativos. (Congreso Internacional de Didáctica) (1a. ed., Vol. II, pp.45-60). España: Fundación Paideia; Morata.

SALINAS FERNÁNDEZ, Dino. (1997). “Curriculum, racionalidad y discurso didáctico". Poggi, Margarita (Compiladora), Apuntes y aportes para la gestión curricular (pp. 21-59). Buenos Aires: Kapelusz.

SÁNCHEZ VÁZQUEZ, Adolfo. (2005). De la estética de la recepción a una estética de la participación. (Ciclo de conferencias pronunciadas en septiembre de 2004). México: Facultad de Filosofía y Letras, Universidad Nacional Autónoma de México.

SANCHO, Juana María, HERNÁNDEZ, Fernando, CARBONELL, Jaume, TORT, Antoni, SÁNCHEZ-CORTÉS, Emilia, y SIMÓ, Nuria. (1998). Aprendiendo de las innovaciones en los centros. La perspectiva interpretativa de investigación aplicada a tres estudios de caso. Barcelona: Octaedro.

SCHUSTER, Federico L. (2001). "Exposición". Schuster, Federico L., Giarraca, N., Aparicio, S., et al. El oficio de investigador (pp.11-51). Buenos Aires: Homo Sapiens; Instituto de Investigaciones en Ciencias de la Educación, Facultad de Filosofía y Letras, Universidad de Buenos Aires.

SCHUSTER, Federico L. (2007). Presentación del libro: MARRADI, Alberto, ARCHENTI, Nélida, y PIOVANI, Juan Ignacio. (2007). Metodología de las ciencias sociales (1a. ed.). Buenos Aires: Emecé.

SCHWAB, Joseph. (1974). Un enfoque práctico para la planificación del currículo. Buenos Aires: El ateneo. 1973.

SCHWARTZ, Gladys. (2000). “Crisis en el saber didáctico: motivos y posibilidades de superación". Revista Contextos de Educación, (III). Disponible en http://www.unrc.edu.ar/publicar/cde/art10.htm, consultado 27/03/2011

SHAPIRO, Svy. (1990). “Educación y democracia: estructuración de un discurso contrahegemónico del cambio educativo". Revista de Educación, (291), 33-54.

SHULMAN, Lee S. (1989). “Paradigmas y programas de investigación en el estudio de la enseñanza: una perspectiva contemporánea". Wittrock, Merlin C. Op.cit. (pp.9-91).

SILBER, Julia. (1996). “Intervención pedagógica”. Ficha de circulación interna de la cátedra Pedagogía Sistemática, Facultad de Humanidades y Ciencias de la Educación, Universidad Nacional de La Plata. 
SILBER, Julia. (1997). "Otra vez pedagogía". Ficha de circulación interna de la cátedra Pedagogía Sistemática, Facultad de Humanidades y Ciencias de la Educación, Universidad Nacional de La Plata.

SILBER, Julia. (2000). “Acerca de la construcción del campo pedagógico desde el paradigma crítico". AA.VV. Análisis político y propuestas pedagógicas. Congreso Internacional de Educación. Buenos Aires: UBA-Aique.

SILBER, Julia. (2007). "Algunas cuestiones relativas a la especificidad del saber pedagógico". Vogliotti, A., Barrera, S., y Benegas, A. (Comps.), Aportes a la pedagogía y a su enseñanza. Debaten y escriben pedagogos. Córdoba, Argentina: Universidad Nacional de Córdoba.

SILBER, Julia. (s/d). El campo pedagógico. Disquisiciones epistemológicas y categorías básicas. Ficha de circulación interna de la cátedra Pedagogía II, Facultad de Humanidades y Ciencias de la Educación, Universidad Nacional de La Plata.

SOUTHWELL, Myriam. (1995). “Historia y formación docente”. Revista del Instituto de Investigaciones en Ciencias de la Educación (I.I.C.E.). Buenos Aires, Miño y Dávila, Facultad de Filosofía y Letras, Universidad de Buenos Aires, (Año IV, N 7), 10-15.

SOUTHWELL, Myriam. (2003). Psicología Experimental y Ciencias de la Educación. Notas de historias y fundaciones (1a. ed.). La Plata: Universidad Nacional de La Plata.

SOUTO, Marta. (1996). “La clase escolar. Una mirada desde la didáctica de lo grupal (capítulo 5)". Camilloni, Alicia, Davini, María Cristina, Edelstein, et al. Op.cit. (pp.117155).

SOUTO, Marta, y MAZZA, Diana. (2001). Encuadre metodológico. Ficha de cátedra $N^{\circ} 1$, "Didáctica II", Facultad de Filosofía y Letras, Universidad de Buenos Aires.

STENHOUSE, Lawrence. (1991). Investigación y desarrollo del curriculum (3a. ed.). Madrid: Morata. 1981.

STÖCKER, Karl. (1964). Principios de didáctica moderna (1a. ed.). (Biblioteca de Cultura Pedagógica). Buenos Aires: Kapelusz. 1954.

SUASNÁBAR, Claudio. (2004). Universidad e intelectuales. Educación y politica en la Argentina (1955-1976) (1a. ed.). Buenos Aires: FLACSO-Manantial.

SUASNÁBAR, Claudio y PALAMIDESSI, Mariano. (2007). “Notas para una historia del campo de producción de conocimientos sobre educación en la Argentina (capítulo 2)". Palamidessi, Mariano; Suasnábar, Claudio; Galarza, Daniel (Comps.). Educación, conocimiento y politica. Buenos Aires: FLACSO-Manantial.

SVAMPA, Maristella. (2003). “El populismo imposible y su actores, 1973-1976 (capítulo IX)". James, Daniel (Director del tomo), Nueva Historia Argentina - Tomo 9: Violencia, proscripción y autoritarismo (1955-1976) (1a. ed., pp. 381-438). Buenos Aires: Sudamericana.

SZTULWARK, Diego. (2007). "Prólogo". Duschatzky, Silvia. Maestros errantes. Experimentaciones sociales en la intemperie (pp. 13-19). Buenos Aires: Paidós.

TABA, Hilda. (1977). Elaboración del currículo. Teoría y práctica (3a. ed.). Buenos Aires: Troquel. 1962.

TARDIF, Maurice, y GAUTHIER, Clermont. (2008). "El maestro como "actor racional": racionalidad, conocimiento, juicio (capítulo X)". Paquay, Leopold, Altet, Marguerite, 
Charlier, Evelyne, y Perremoud, Philippe (Coords.), La formación profesional del maestro: estrategias y competencias (pp.309-351). México: Fondo de Cultura Económica.

TAYLOR, S. J., y BOGDAN, R. (1986). Introducción a los métodos cualitativos de investigación. La búsqueda de significados. Barcelona: Paidós.

TEDESCO, Juan Carlos. (1983). “Elementos para una sociología del curriculum escolar en Argentina". Tedesco, Juan Carlos, Braslavsky, Cecilia, y Carciofi, Ricardo El proyecto educativo autoritario. Argentina 1976-1982 (pp. 17-73). Buenos Aires: FLACSO.

TERIGI, Flavia. (1999). Curriculum. Itinerarios para aprehender un territorio. Buenos Aires: Santillana.

THIRIÓN DE VERÓN, Esther. (1965). Curso de didáctica general. De acuerdo con el programa oficial de la asignatura correspondiente al primer año del ciclo de magisterio (4to. año normal) (5a. ed.). Buenos Aires: Troquel. 1963.

TIRAMONTI, Guillermina. (2010). “Mutaciones y permanencias en la estructura de gobierno de la educación". Propuesta Educativa. Novedades Educativas, FLACSO, (Año 19, No33), 43-52.

TYLER, Ralph W. (1973). Principios básicos del currículo. Buenos Aires: Troquel. 1949.

VAINER, Alejandro. (2000). "El padre de la antipsiquiatría vivió en la Argentina”. En: http://www.topia.com.ar/articulos/el-padre-de-la-antipsiquiatr\%C3\%ADvivi\%C3\%B3-en-la-argentina, consultado 22/10/2012.

VALERO MATAS, Jesús A. (2004). “Sociología de la ciencia: un análisis posmertoniano". Valero Matas, Jesús A. Op.cit. (pp.81-138).

VALLES, Miguel S. (2000). Técnicas cualitativas de investigación social. Reflexión metodológica y práctica profesional. Madrid: Síntesis.

VASILACHIS DE GIALDINO, Irene. (2008). “Los fundamentos epistemológicos de la Investigación Cualitativa”. Cohen, Néstor, y Piovani, Juan Ignacio Op.cit. (pp.197-218).

VEZZETTI, Hugo. (2002). Pasado y presente. Guerra, dictadura y sociedad en la Argentina. Buenos Aires: Siglo XXI. Prólogo y cap. 2.

VILTE, Laura, CALVÓ, Margarita, PORTAL, Hilario, y GONZÁLEZ, Ana María. (1998). "Una experiencia de intercambio entre escuela y comunidad (en capítulo IV)". Birgin, Alejandra, Dussel, Inés, Duschatzky, Silvia, y Tiramonti, Guillermina (Compiladoras), La formación docente. Cultura, escuela y política. Debates y experiencias (pp. 153-158). Buenos Aires: Troquel.

VON WRIGHT, Georg Henrik. (1970). Norma y acción. Una investigación lógica. Madrid: Tecnos.

VON WRIGHT, Georg Henrik. (1979). Explicación y comprensión. Madrid: Alianza.

WOODS, Peter. (1995). La escuela por dentro. Barcelona: Paidós.

ZEMELMAN, Hugo. (1989): De la historia a la política. México: Siglo XXI.

ZOPPI DE CERRUTI, Ana María, y AGUERRONDO, Inés. (1991). “Curriculum y planificación educativa". Aguerrondo, Inés. El planeamiento educativo como instrumento de cambio (2a. ed., pp. 69-87). Buenos Aires: Troquel. 


\section{ANEXO I:}

\section{Encuesta a informantes clave para la conformación del corpus empírico para analizar en la tesis doctoral.}

\section{Presentación:}

Esta encuesta se construye y administra como parte de las actividades previstas para la realización de la tesis doctoral denominada "La normatividad en discusión: el caso de la didáctica y el curriculum a partir de debates epistemológicos y metodológicos contemporáneos", dirigida por el Dr. Juan Ignacio Piovani ${ }^{201}$. La misma corresponde al Doctorado en Ciencias de la Educación, Facultad de Humanidades y Ciencias de la Educación, Universidad Nacional de La Plata.

Para cumplir con los objetivos propuestos pretendemos analizar algunas obras didácticas y curriculares que involucren posiciones contrastantes en torno a la normatividad. Sintéticamente podríamos decir que hemos utilizado dos criterios principales en la conformación de un corpus amplio a partir del cual, y con su valiosa colaboración, esperamos ajustarlo a una cantidad manejable de textos para el análisis en el contexto y en los plazos de la tesis.

Un primer criterio está conformado por un eje que define tres momentos generados en el desarrollo histórico de las disciplinas, a saber, normativo, prescriptivo y descriptivo ${ }^{202}$. En líneas generales, en el primer momento, la constitución de la norma -inseparable del surgimiento de la didáctica como disciplina- se presenta en articulación con un proyecto político-educativo y con una axiología explícita que postula qué se debe enseñar porque es bueno ${ }^{203}$. Aquí es posible analizar obras didácticas que evidencien en los años '60 aún marcas del origen. Por su lado, en el momento prescriptivo, se exalta la elaboración de técnicas cuya utilización posibilite el alcance eficiente de los resultados ${ }^{204}$, al margen

\footnotetext{
${ }^{201}$ Esta tesis ha sido co-dirigida hasta Marzo de 2010 por la Dra. Estela B. Cols cuya muerte he sentido muy profundamente y a quien le estaré siempre muy agradecida por sus valiosísimas enseñanzas en la didáctica y del curriculum.

${ }^{202}$ Cabe aclarar que estos momentos se pueden identificar con claridad en la didáctica. Para el caso del curriculum específicamente, conceptualizamos un primer momento prescriptivo y otro descriptivo. A pesar de las diferencias disciplinarias, mantenemos el eje mencionado con sus tres momentos por considerarlo más abarcador y pertinente a la perspectiva teórica adoptada en nuestro trabajo.

203 Camilloni, Alicia (1997). "Sobre los aportes de la psicología del aprendizaje a la didáctica". Revista Novedades Educativas, 84, 4-7; citado en COLS, Estela B. (2003). El campo de la didáctica: recorrido histórico y perspectivas actuales. Ficha de circulación interna de la cátedra "Didáctica", Facultad de Humanidades y Ciencias de la Educación, Universidad Nacional de La Plata.

También: CAMILLONI, Alicia. (2007). "Los profesores y el saber didáctico (capítulo 3)". Camilloni, Alicia (Comp.), El saber didáctico (1a. ed., pp.41-60). Buenos Aires: Paidós.

En una línea similar, Barco reserva para lo normativo la vinculación con los fines de la educación, con un proyecto educativo global y con los fundamentos de las acciones (BARCO, Susana. (1989). "Estado actual de la pedagogía y la didáctica". Revista Argentina de Educación. Asociación de Graduados en Ciencias de la Educación, (Año VII, N¹2), 7-23).

${ }^{204}$ Camilloni, 2007, op.cit.
} 
de la discusión utópico-política que estas modalidades acarrean ${ }^{205}$. Encontramos algunas obras teóricas de una didáctica tecnicista y de producciones curriculares locales posteriores al impacto de la teoría curricular norteamericana en la didáctica general en nuestro país. Por último, en el momento descriptivo visualizamos un desdibujamiento de la normatividad y los planteos a ella asociados a partir de la confluencia de diferentes factores que se ponen en juego en la didáctica y en el curriculum. Visualizamos aquí quiebres entre una didáctica tecnicista y la emergencia de tendencias descriptivas, y entre el planeamiento del curriculum y la descripción de las prácticas curriculares.

En segundo plano, utilizamos como criterios para la conformación del corpus empírico que las obras teóricas didácticas y curriculares hayan sido publicadas entre 1960 y 1990, y que sean de autores nacionales o extranjeros con impacto en la producción local.

\section{Encuesta:}

En el marco de lo antes mencionado, le solicitamos que por favor indique del listado que aparece a continuación aquellas cinco (5) obras que a su juicio resultan ser las que más se adecuan a los criterios antes descriptos.

Los recordamos: a)- representan posturas contrastantes en el eje normativo/prescriptivo/descriptivo, siendo cada una de ellas representativa de un posicionamiento particular con respecto a la normatividad; b)- están comprendidas entre los años 1960-1990; c)- han sido escritas por autores nacionales o extranjeros pero con impacto en la producción local.

Al final del listado, encontrará espacios en blanco en los que puede agregar alguna obra que considere relevante y que no haya sido incluida.

\begin{tabular}{|l|l|}
\hline \multicolumn{2}{|l|}{ LISTADO DE OBRAS } \\
\hline & $\begin{array}{l}\text { TYLER, Ralph W. (1973). Principios básicos del currículo. Buenos Aires: Troquel. } 1949 . \\
\text { STÖCKER, Karl. (1964). Principios de didáctica moderna (Biblioteca de Cultura Pedagógica). } \\
\text { Buenos Aires: Kapelusz. 1954. }\end{array}$ \\
\hline $\begin{array}{l}\text { AEBLI, Hans. (1958). Una didáctica fundada en la psicología de Jean Piaget. Buenos Aires: } \\
\text { Kapelusz. }\end{array}$ \\
\hline $\begin{array}{l}\text { TABA, Hilda. (1977). Elaboración del currículo (3a. ed.). Buenos Aires: Troquel. 1962. } \\
\text { Kapelusz. }\end{array}$ \\
\hline \begin{tabular}{l} 
BRUNER, Jerome S. (1969). Hacia una teoría de la instrucción (1a. ed.). México: UTHEA. (1969). Hacia una didáctica general dinámica (1 ${ }^{\text {a } . ~ e d .) . ~ B u e n o s ~ A i r e s: ~}$ \\
\hline
\end{tabular} \\
\hline
\end{tabular}

205 DAVINI, María Cristina (1996). "Conflictos en la evolución de la didáctica. La demarcación de la didáctica general y las didácticas especiales". Camilloni, Alicia, y otros. Corrientes didácticas contemporáneas (1a. ed., pp. 41-73). Buenos Aires: Paidós.

Araujo caracteriza de manera similar este momento para el caso del curriculum (ARAUJO, Sonia (2006). Docencia y enseñanza. Una introducción a la didáctica (1a. ed.). (Cuadernos Universitarios) No. 13. Bernal, Buenos Aires: Universidad Nacional de Quilmes). 


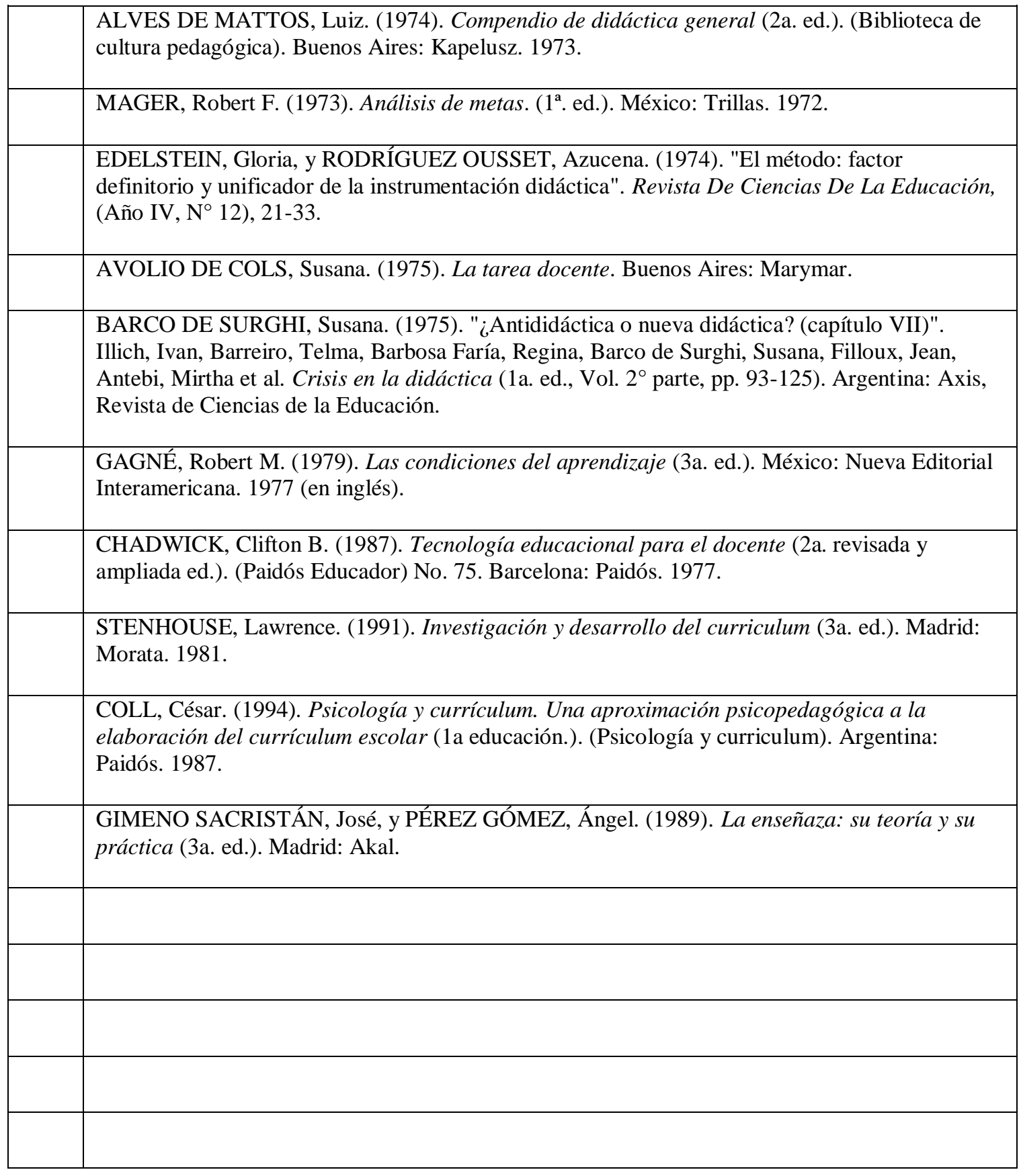

\section{Desde ya muchísimas gracias.}

